Subcontractor Report

\title{
Research on the Pyrolysis of Hardwood in an Entrained Bed Process Development Unit
}

August 1991

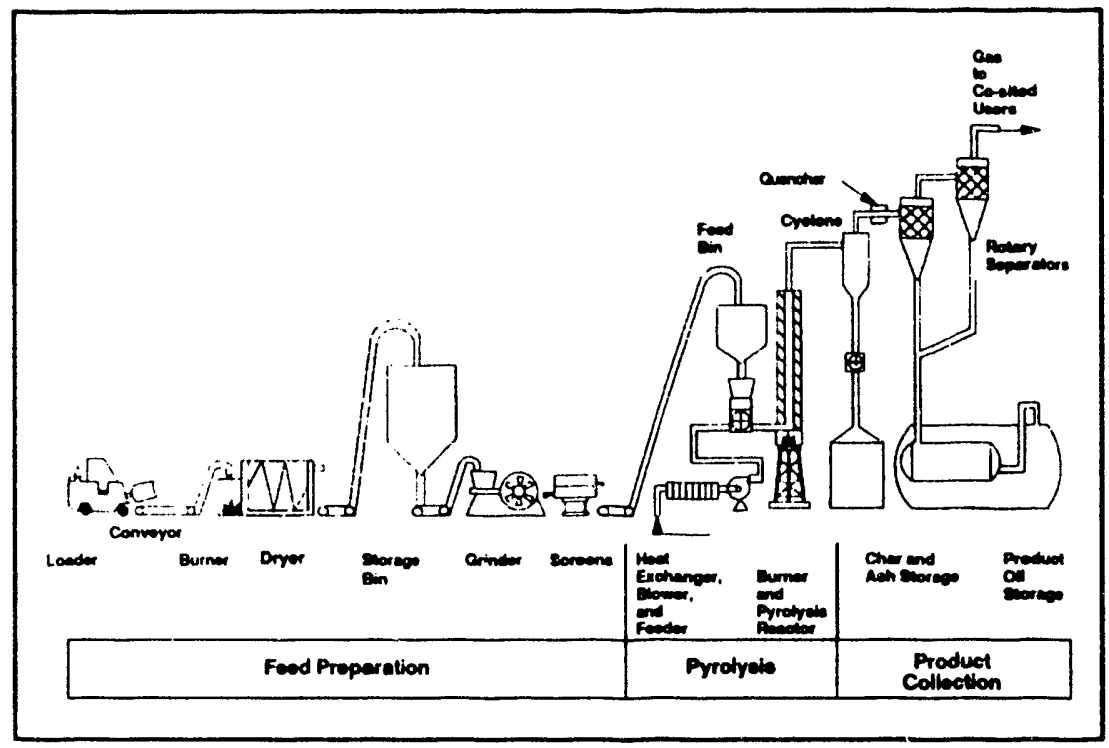

Prepared for the U.S. Department of Energy under Contract DE-AC06-76RLO 1830

Pacific Northwest Laboratory Operated for the U.S. Department of Energy by Battelle Memorial Institute 


\title{
DISCLAIMER
}

This report was prepared as an account of work sponsored by an agency of the United States Government. Neither the United States Government nor any agency thereof, nor Battelle Memorial Institute, nor any of their employees, makes any warranty, expressed or implied, or assumes any legal liability or responsibility for the accuracy, completeness, or usefulness of any information, apparatus, product, or process disclosed, or represents that its use would not infringe privately owned rights. Reference herein to any specific commercial product, process, or service by trade name, trademark, manufaclurer, or otherwise does not necessarily constitute or imply its endorsement, recommendation, or favoring by the United States Government or any agency thereof, or Battelle Memorial Institute. The views and opinions of authors expressed herein do not necessarily state or reflect those of the United States Government or any agency thereof.

\author{
PACIFIC NORTHWEST LABORATORY \\ operated by \\ BATTELLE MEMORIAL INSTITUTE \\ for the \\ UNITED STATES DEPARTMENT OF ENERGY \\ under Contract DE-AC06-76RLO 1830
}

Printed in the United States of America

Available to DOE and DOE contractors from the

Office of Scientific and Technical Information, P.O. Box 62, Oak Ridge, TN 37831;

prices available from (615) 576-8401. FTS 626-8401.

Available to the public from the National Technical Information Service,

U.S. Department of Commerce, 5285 Port Royal Rd., Springfield, VA 22161. 
R. J. Kovac, C. W. Gorton, J. A. Knight, C. J. Newman and D. J. O'Neil

Georgia Tech Research Institute Georgia Institute of Technoloyy Atlanta, Georgia

G. F. Schiefelbein, PNL Project Manager

August 1991

Prepared by Georgia Tech Research Institute for Pacific Northwest Laboratory under Contract DE-AC06-76RLO 1830 with the U.S. Department of Energy under Agreement 005863-A-Q

Contract Period: May 1, 1982 - May 31, 1989

Pacific Northwest Laboratory Richland, Washington 99352

\section{MASTER}


RESEARCH ON THE PYROLYSIS OF HARDWOOD IN

AN ENTRAINED BED PROCESS DEVELOPMENT UNIT

\section{EXECUTIVE SUMMARY}

An atmospheric flash pyrolysis process, the Georgia Tech Entrained Flow Pyrolysis Process, for the production of liquid biofuels from oak hardwood is described. The development of the process began with bench-scale studies and a conceptual design in the 1978-1981 timeframe. Its development and successful demonstration through research on the pyrolysis of hardwood in an entrained bed process development unit (PDU), in the period of 1982-1989, is presented. 0 il yields (dry basis) up to $60 \%$ were achieved in the 1.5 ton-perday PDU, far exceeding the initial target/forecast of $40 \%$ oil yields. Experimental data, based on over forty runs under steady-state conditions, supported by material and energy balances of near-100\% closures, have been used to establish a process model which indicates that oil yields well in excess of $60 \%$ (dry basis) can be achieved in a commercial reactor.

Experimental results demonstrate a gross product thermal efficiency of $94 \%$ and a net product thermal efficiency of $72 \%$ or more; the highest values yet achieved with a large-scale biomass liquefaction process.

A conceptual manufacturing process and an economic analysis for liquid biofuel production at $60 \%$ oil yield from a $200-$ TPD commercial plant is reported. The plant appears to be profitable at contemporary fuel costs of $\$ 21 /$ barrel oil-equivalent. Total capital investment is estimated at under $\$ 2.5$ million. A rate-of-return on investment of $39.4 \%$ and a pay-out period of 2.1 years has been estimated. The manufacturing cost of the combustible pyrolysis oil is $\$ 2.70$ per gigajoule. 


\section{ACKNOWLEDGEMENTS}

This work was conducted at the Georgia Tech Research Institute (GTRI) of the Georgia Institute of Technology as part of the Biomass Thermochemical Program of the United States Department of Energy and its Biofuels and Municipal Waste Technology Division (BMWTD), Office of Renewable Energy Technologies. The Pacific Northwest Laboratory (PNL) has been the Technical field Management Office for the Biomass Thermochemical Conversion Program. We are grateful for the support of Mr. Donald Walter, Mr. Simon Friedrich, and Dr. Beverly Berger of USDOE/BMWTD and to the sustained interest of Dr. Robert San Martin of USDOE/Conservation and Renewable Energy Technologies. The technical and programmatic assistance of the PNL staff is recognized, in particular, Mr. Gary Schiefelbein and Mr. Mark Gerber. At GTRI, the early work of Dr. Kenneth Purdy, Mr. David Hurst and the late L. W. ("Pete") Elston was invaluable. The contributions to reaction/reactor modeling of T. I. Nygaard, School of Chemical Engineering, Georgia Institute of Technology is recognized. The efforts of the Interim Director of GTRI's Materials Science and Technology Laboratory, Ms. K. V. Logan and the patience and support of Mr. Schiefelbein of PNL resulted in the final delivery of this report despite the loss of the participation of the principal investigator (R. J. Kovac) in the late stages of this program. 


\section{CONTENTS}

1.0 INTRODUCTION . . . . . . . . . . . . . . . . . . . 1

2.0 PRESENTATIONS AND REPORTS . . . . . . . . . . . . . . 5

3.0 TASK 1. DESIGN AND CONSTRUCTION OF THE ENTRAINED PYROLYSIS PDU . . . 9

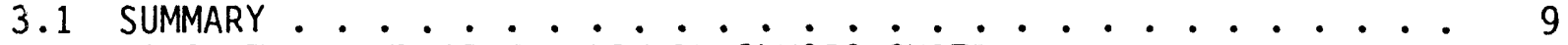

3.2 CONCEPTUAL ENTRAINED-FLOW PYROLYSIS SYSTEM . . . . . . . . . . 9

3.3 MAJOR EQUIPMENT COMPONENTS . . . . . . . . . . . . . . . . 12

3.4 PROCUREMENT AND ASSEMBLY . . . . . . . . . . . . . . . . . 21

4.0 TASK 2A - PYROLYSIS PDU OPERATION -- START-UP, STEADY-STATE

OPERATION, AND PRELIMINARY EXPERIMENTS - CONFIGURATION I . . . . . 25

4.1 SUMMARY . . . . . . . . . . . . . . . . . . . 25

4.2 MASS BALANCE CONSIDERATIONS ................ 26

4.3 ENERGY BALANCE CONSIDERATIONS . . . . . . . . . . . . . . 29

4.4 PRELIMINARY PYROLYSIS RUNS WITH PDU . . . . . . . . . . . . . . 30

4.5 OPERATING PROCEDURES FOR THE ENTRAINED-FLOW PROCESS

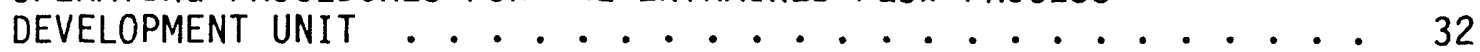

4.6 SUMMARY OF RUN NO. 12................... . . . . . 34

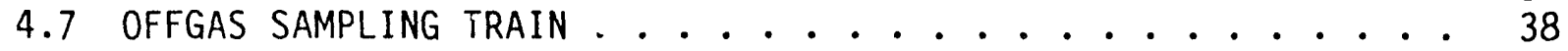

5.0 TASK 2B. EXPERIMENTAL PYROLYSIS PROGRAM PYROLYSIS PDU

CONFIGURATION I ........................ . . . 45

5.1 INTRODUCTION . . . . . . . . . . . . . . . . . . . 45

5.2 PYROLYSIS EXPERIMENTS - CONFIGURATION I . . . . . . . . . 45

5.3 MASS AND ENERGY BALANCES . . . . . . . . . . . . . . . . 45

5.4 PRELIMINARY REACTOR MODELING - CONFIGURATION I . . . . . . . 49

6.0 TASK 2C. MODIFICATION OF THE PDU . . . . . . . . . . . . . 61

6.1 INTRODUCTION . . . . . . . . . . . . . . . . . . 61

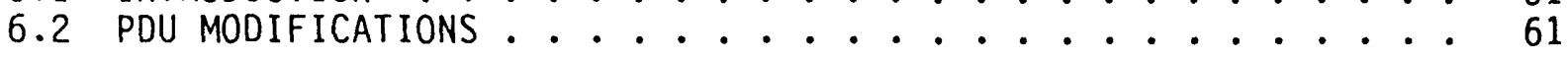

7.0 TASK 2D. PRELIMINARY EXPERIMENTS - PYROLYSIS PDU CONFIGURATION II . 67

7.1 INTRODUCTION . . . . . . . . . . . . . . . 67

7.2 PYROLYSIS RESEARCH UNIT (PRU)

CONFIGURATION II I-SYSTEM DESCRIPTION ............ 67

7.3 PRU OPERATION . . . . . . . . . . . . . . . . . . . . . . 69

7.4 QUALITY ASSURANCE SYSTEM - CONFIGURATION II . . . . . . . . 71

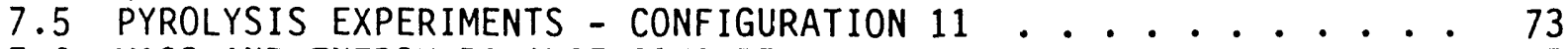

7.6 MASS AND ENERGY BALANCE CONSIDERATIONS - CONFIGURATION II . . . 77

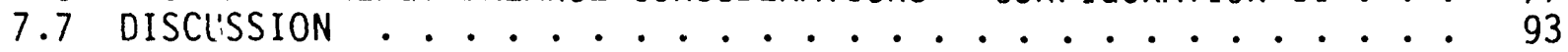

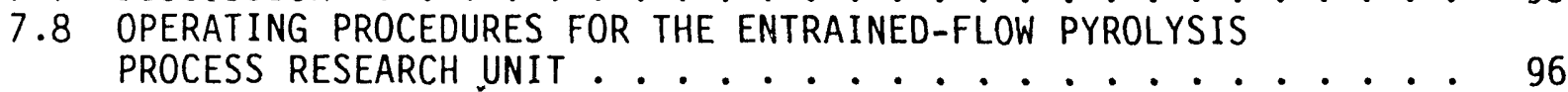

8.0 TASK 3A. EXPERIMENTAL PYROLYSIS PROGRAM PYROLYSIS PRU

CONFIGURATION III ......................... 111

8.1 INTRODUCTION . . . . . . . . . . . . . . . . . . . 111

8.2 PRU OPERATION - CONFIGURATION III . . . . . . . . . . . . . 112

8.3 DESCRIPTION OF SYSTEM ....................... . . . 116 
8.4 PYROLYSIS EXPERIMENTS - CONFIGURATION III . . . . . . . . . 118

8.5 MASS AND ENERGY BALANCES - CONFIGURATION III . . . . . . . . . 118

8.6 DISCUSSION ........................... 130

9.0 TASK 3B. COMPUTER MODELING OF PYROLYSIS REACTOR . . . . . . . . . 139

9.1 SUMMARY . . . . . . . . . . . . . . . . . . . 139

9.2 INTRODUCTION . . . . . . . . . . . . . . . . . . . 139

9.3 PHYSICAL/EXPERIMENTAL INPUT FOR REACTOR MODEL . . . . . . . . 139

9.4 REACTOR MODELING RESULTS . . . . . . . . . . . . . . 143

9.5 NOMENCLATURE . . . . . . . . . . . . . . . . . . 150

9.6 THEORETICAL DESCRIPTION OF COMPUTER MODEL . . . . . . . . . 151

9.7 COMPUTER PROGRAMS ................... . . . 155

10.0 TASK 4.CONCEPTUAL DESIGN AND ECONOMIC ANALYSIS FOR A COMMERCIAL

ENTRAINED-FLOW PYROLYSIS FACILITY . . . . . . . . . . . . 159

10.1 SUMMARY . . . . . . . . . . . . . . . . . 159

10.2 INTRODUCTION ...................... . . 159

10.3 PROCESS DESCRIPTION . . . . . . . . . . . . ... 161

10.4 DESIGN BASIS ... . . . . . . . . . . . . . . . . 163

10.5 ECONOMIC ANALYSIS .................... 164

10.6 SUMMARY ......................... . . . 171

11.0 TASK 5. CATALYTIC UPGRADING OF "BIOCRUDE" PYROLYSIS OIL . . . . . 177

APPENDIX A ENERGY AND MATERIAL BALANCES FOR THE EXPERIMENTAL PYROLYSIS

SYSTEM * COMPUTER PROGRAM - MODEL 1 * . . . . . . . . A-1

APPENDIX B ESTIMATION OF CYCLONE PARAMETERS . . . . . . . . . . . . B-1

APPENDIX C QUALITY ASSURANCE SYSTEM . . . . . . . . . . . . . . . C C i

APPENDIX D OPERATING PROCEDURES FOR THE ENTRAINED FLOW PROCESS RESEARCH

UNIT . . . . . . . . . . . . . . . . . . . D-1

APPENDIX E DATA SHEETS . . . . . . . . . . . . . . . . . E-1

APPENDIX F PRELIMINARY REACTOR MODELING - CONFIGURATION I . . . . . . . F-1

APPENDIX G CHEMICAL AND GAS ANALYSIS . . . . . . . . . . . . . . . G-1

APPENDIX H COMPUTER PROGRAM LISTING - "TSQMAX" — . . . . . . . . . . H-1

APPENDIX I COMPUTER PROGRAM LISTING - "PYRGRAF" • . . . . . . . . . . . I-1

APPENDIX J ECONOMIC ANALYSIS OIL PRODUCTION VIA ENTRAINED-FLOW

PYROLYSIS OF BIOMASS .................. J-1 


\section{FIGURES}

1 Georgia Tech Entrained-Bed Pyrolysis Process Development Unit . . . 10

2 Entrained Flow Pyrolysis System . . . . . . . . . . . . . 11

3 Entrained Bed Process Development Unit . . . . . . . . . . . 13

4 Mixing and Entrainment Section ............... . 18

5 Condenser . . . . . . . . . . . . . . . . . . 19

6 Demister ........................ 20

7 Entrained Bed Pyrolysis PDU Layout . . . . . . . . . . . . . 22

8 Wood Storage and Preparation System . . . . . . . . . . . 23

9 Entrained Flow Pyrolysis Process Development Unit -

10 Offgas Sampling Train - Schematic . . . . . . . . . . . 43

11 Flow Diagram of Process Research Unit - Configuration II . . . . 68

12 Typical Local $0 i l$ Yields . . . . . . . . . . . . . . . . 114

13 Flow Diagram -- Process Research Unit - Configuration III . . . . 117

14 Predicted $0 i l$ Yields . . . . . . . . . . . . . . . 149

15 Manufacturing Flow Diagram of the Georgia Tech Entrained Flow Pyrolysis Process . . . . . . . . . . . . 162

16 Process Flow Block Diagram of the Georgia Tech Entrained Flow Pyrolysis Process ....................... 162

A-1 Flow Diagram For MODEL1 Program . . . . . . . . . . . A-12

J-1 Entrained Flow Pyrolysis System . . . . . . . . . . . . . J-3

J-2 Wet Wood Storage Area - 250 TPD System . . . . . . . . . . J-8

J-3 Wet Wood Storage Area - 1000 TPD System . . . . . . . . . . J-23 
1 Size Reduction Equipment ................ 14

2 Feed System Equipment . . . . . . . . . . . 15

3 Inert Gas Generator . . . . . . . . . . . . 15

4 Pyrolysis Reactor -- Hot-Gas Burner.............. 16

5 Char Cyclone Separator ................ 16

6 Chemical Analysis .................. 29

7 Preliminary Pyrolysis Runs With PDU ............. 32

8 Comments on Preliminary Runs .............. 33

9 Mass Balance - Run No 12............. 35

10 Run No 12 - Mass Data . . . . . . . . . . . . 36

11 Energy Balance - Run No $12 \ldots 39$

12 Run No 12 - Energy Data . . . . . . . . . . . . . 40

13 PDU Operating Data - Configuration I . . . . . . . . 46

14 Percent 0 il and Char Yield Data - Configuration I . . . . . 47

15 Mass Balances - lb/hr - Configuration I . . . . . . . . 50

16 Energy Inputs and Outputs - Btu/hr ............ 51

17 Energy Balances - Configuration I, Btu/hr . . . . . . . 54

18 Percent 0il Yield Data - Configuration I ......... 55

19 Composite 0il Data - Configuration I . . . . . . . . . 56

20 Percent 0il Energy Yields - Configuration I . . . . . . . 57

21 Char Data - Configuration I . . . . . . . . . . 58

22 Typical Gas Analysis - Run No22 . . . . . . . . . . . 59

23 Chemical Analysis - PRU Configuration II . . . . . . . . 72

24 PRU Operating Data..................... 74

25 Percent $0 i l$ and Char Yield Data ............... 75 
26 Percent $0 i l$ Yield Data . . . . . . . . . . . . . 76

$270 i l$ Data . . . . . . . . . . . . . . . 78

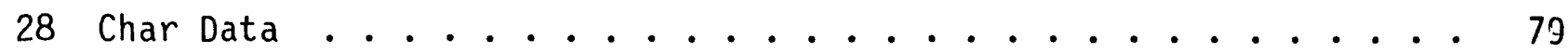

29 Pyrolysis Runs With PRU - Configuration II . . . . . . . . . 80

30 Comments on Experimental Runs - Configuration II . . . . . . . 81

31 Carbon Balance - lb carbon/hr .............. 83

32 Mass Balances - Entering Streams - lb/hr . . . . . . . . . 85

33 Mass Balances - Leaving Streams - 1b/hr . . . . . . . . . 86

34 Mass Balances - Summary . . . . . . . . . . . . . 87

35 Energy Inputs and Outputs - Entering Streams - Btu/hr . . . . . 89

36 Energy Inputs and Outputs - Leaving Streams - Btu/hr . . . . . . 90

37 Energy Inputs and Outputs - Btu/hr .............. 91

38 Energy Balances Btu/hr . . . . . . . . . . . . . . 92

39 Design of Experiments for Determining Conditions for Optimum

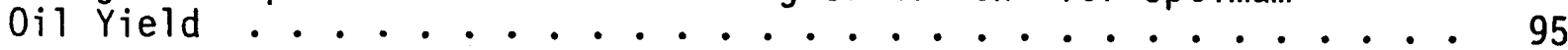

40 Predicted Reactor Profile . . . . . . . . . . . . . 113

41 PRU Operating Data Configuration III . . . . . . . . . . . 119

42 Percent $0 i 1$ ario Char Yield Data Configuration III . . . . . . . 120

430 il Data - Configuration III . . . . . . . . . . . . 121

44 Char Data - Configuration III . . . . . . . . . . . . 123

45 Pyrolysis Runs With PRU - Configuration III . . . . . . . . . 124

46 Comments on Experimental Runs - Configuration II . . . . . . . . 125

47 Mass Balances - Entering Streams lb/hr . . . . . . . . . . . 127

48 Mass Balances - Leaving Streams - 1b/hr . . . . . . . . . 128

49 Mass Balances, Configuration III, Summary . . . . . . . . . 129

50 Energy Inputs and Outputs - Entering Streams . . . . . . . . . 131

51 Energy Inputs and Outputs - Leaving Streams . . . . . . . . 132 
52 Energy Inputs and Outputs . . . . . . . . . . . . 133

53 Energy Balances - Configuration III - Btu/hr . . . . . . . . 134

54 Carbon Balances - Entering Streams - lb/hr . . . . . . . . . 135

55 Carbon Balances - Leaving Streams - lb/hr . . . . . . . . . 135

56 Carbon Balances - Configuration III - Summary . . . . . . . . 136

57 Entrained-Flow Pyrolysis Data - Configuration I . . . . . . . 141

58 Entrained-Flow Pyrolysis Data - Configuration II . . . . . . 142

59 Kinetic Parameters . . . . . . . . . . . . . . . . 146

60 Predicted Reactor Profiles . . . . . . . . . . . . . . 147

61 Predicted $0 i 1$ Yields . . . . . . . . . . . . . . . . 148

62 Design Basis - GT Entrained Flow Pyrolysis Plant . . . . . . . . 165

63 Equipment Costs, 200-dry TPD . . . . . . . . . . . . 166

64 Total Capital Investment, 200-dry TPD . . . . . . . . . . 167

65 Total Manufacturing (Product) Costs, 60\% 0 i1 Yield . . . . . . 169

66 Annual Sales Revenue, 60\% 0 il Yield, 200-dry TPD . . . . . . . 170

67 Annual Rate of Return on Investment, 200-dry TPD . . . . . . . 172

68 Payout Period and Discounted Cash Flow-Rate of Return on

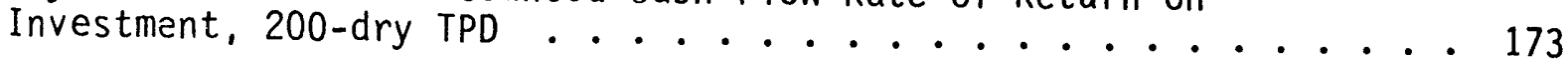

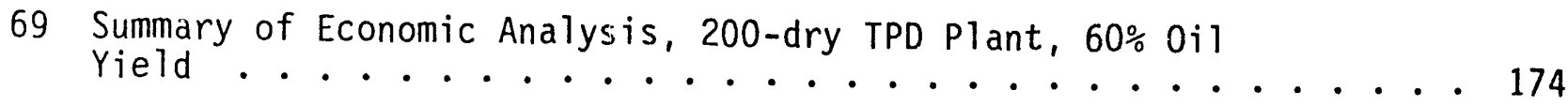

A-1 Pyrolyzer System flow Rates . . . . . . . . . . . . . . A-10

A-2 Pyrolysis Reactor Stream Profiles . . . . . . . . . . . A-11

F-1 Entrained-Flow nyrolys is Data - Preliminary Experiments . . . . . F-3

F-2 Nonlinear Least-Squares Results . . . . . . . . . . . . F-5

F-3 Comparison Between Experimental and Calculated $0 i 1$ Yield . . . . F-6

F-4 Model Predictions of $0 i l$ Yield . . . . . . . . . . . . . F-6

F-5 Model Predictions of Maximum 0il Yields . . . . . . . . . . F-8 


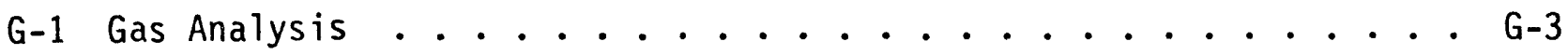

J-1 Design Basis - Entrained-Flow Pyrolysis System . . . . . J J-5

$\mathrm{J}-2$ Equipment Costs * $250 \mathrm{dt} / \mathrm{d}, 40 \% 0 i 1$ Yield ......... J-6

$\mathrm{J}-3$ Equipment Costs $* 1,000 \mathrm{dt} / \mathrm{d}, 40 \% 0 i 1$ Yield . . . . . . J-22

J-4 Total Capital Investment, $40 \% 0$ il Yield .......... J-31

J-5 Manufacturing Costs, $40 \% 0 i 1$ Yield ........... J-32

J-6 Sales Revenue, 40\% $0 i 1$ Yield .............. J-36

J-7 Rate of Return, $250 \mathrm{dt} / \mathrm{d}, 40 \% 0 \mathrm{il}$ Yield ........... J-37

J-8 Rate of Return, $1000 \mathrm{dt} / \mathrm{d}, 40 \% 0 \mathrm{i} 1$ Yield .......... J-39

J-9 Payout Period And Discounted Cash Flow Rate of Return . . . . . J-41

J-10 Equipment Costs, $1,000 \mathrm{dt} / \mathrm{d}, 40 \% 0 i 1$ Yield . . . . . . . J-42 


\subsection{INTRODUCTION}

The work presented under this project is a continuation of a project "Thermochemical Conversion of Biomass Via the Georgia Tech Entrained Pyrolysis/Gasification Process," originally funded by the Department of Energy under Contract No. DE-AS05-SOCS-83007.001.

This prior project had an effective starting date of July 1, 1980 and, due to a modification of the contract, a revised termination date of March 31, 1982. In the original contract the purpose of the multi-year project was to perform basic, exploratory pyrolysis and gasification studies, to perform the engineering design for a pyrolyzer/gasifier system, and to procure, build, and test a Process Development Unit (PDU) which combined both pyrolys is and gasification of biomass in separate (not coupled) entrained-bed reactors.

In FY 1981, the Biomass Thermochemical Conversion Program Office suspended procurement and construction on the pyrolysis section of the PDU (the gasification section of the PDU was scheduled to be buit after successful testing of the pyrolysis system) pending a review of pyrolysis and gasification processes. Basic resea, sh on pyrolysis was allowed to continue during this period. In early 1982, it was decided that the project would be restricted to pyrolysis research. At the direction of the Department of Energy, the scope and objectives of the contract were modified to concentrate on the development of a PDU for investigating the entrained-flow pyrolysis of biomass. The major goal was to maximize the yield of pyrolysis oil (i.e. dry, liquid, organic product) in the PDU. Permission was received to continue work on, and to comp'ete the detailed, engineering design of the modified process and to continue procurement and construction of the PDU.

In FY 1981 Paifific Northwest Laboratories (PNL) was designated as the Lead Laboratory for the Biomass Thermochemical Conversion Program, for the Biomass Energy Technology Division of DOE, and was responsible for the procurement of contracts for research in the area of bioniass thermochemical conversion. Pacific Northwest Laboratories continued as Lead Laboratory for the remainder of this project. 
The contract for this present project, "Research on the Pyrolysis of Hardwood in an Entrained-Bed Process Development Unit", (prime contract DE-AC06-76RL0-1830, subcontract no. B-C5863-A-Q), was signed on May 10, 1982 with an effective starting date of May 1, 1982 and a termination date of April 30, 1983. The contract was subsequently revised, undergoing more than 20 minor changes (supplements) and four major modifications. The work on this contract began on May 1, 1982 and this final report covers the work performed from that date through May 31, 1989.

The objectives of this project were to complete the design and construction of an entrained-bed pyrolysis reactor PDU, and conduct an experimental program with the PDU to obtain basic engineering data on the entrained-flow pyrolysis of hardwood to provide optimum yields of pyrolysis oil. An economic analysis of the process based on the results of the experimental program was to be performed. To complete these objectives three tasks were defined in the Statement of Work (May 1982), and are given belcw.

Task 1 - Completion of the design, procurement, and assembly of equipment components, and construction of the entrained bed pyrolysis PDU,

Task 2 - Conduct start-up and steady-state testing to determine the adequacy of the design, demonstrate the closure of the energy and material balances for the system, and provide a general procedure to be used to operate, maintain and verify steady-state in the PDU, including collection of data, during each experiment.

Task 3 - Conduct an experimental program to obtain the basic engineering data on the pyrolys is of hardwood in the PDU to provide optimum yields of pyrolysis oil, investigating the effects of reactor temperature, wood particle size, and gas and solid residence times on throughput, product yields, product composition, and process efficiency.

In August 1983, Task 3 was modified to include to development of a computer model of the pyrolysis reactor to interpret the experimental data, 
due to the complex nature of the two-phase flow phenomena in the pyrolysis reactor.

In June 1984, Task 2 was modified to require recommendations for design changes in the pyrolysis system, modification of the PDU, and operation of the PDU to verify the adequacy of the modified design. Task 3 was also modified to better define the matrix of experiments to be conducted using the PDU.

In July 1987, Task 3 was amended to include the modification of the PDU to improve pyrolysis oil collection and pyrolysis oil quality. Task 4, Identification and evaluation of upgrading catalysts, was added. 


\subsection{PRESENTATIONS AND REPORTS}

Presentations on the status of the project have been made, at the request of the Department of Energy, during the term of the contract and are detailed below:

"Thermochemical Conversion of Biomass to Syngas via tre Georgia Tech Entrained Pyrolysis/Gasification Process" at the Eleventh Biomass Thermochemical Conversion Contractors' Meeting in Richland, Washington, on September 23-24, 1980 ;

"Thermochemical Conversion of Biomass to Syngas via the Georgia Tech Entrained Pyrolysis/Gasification Process" at the Twelfth Biomass Thermochemical Conversion Contractors, Meeting in Washington, D. C., on March 18-19, 1981;

"0il Production via Entrained-Flow Pyrolysis of Biomass" at the Thirteenth Biomass Thermochemical Conversion Contractors' Meeting in Arlington, Virginia, on October 27-29, 198?;

"Entrained-Flow Pyrolysis of Biomass" at the Fourteenth Biomass Thermochemical Conversion Contractors' meeting in Arlington, Virginia, on June 23-24, 1982;

"Entrained-Flow Pyrolys is of Biomass" at the Fifteenth Biomass Thermochemical Conversion Contractors' meeting in Atlanta, Georgia, on March 16-17, 1983;

"Entrained-Flow Pyrolysis of Biomass" at the Sixteenth Biomass Thermochemical Conversicn Contractors' Meeting in Portland, Oregon, on May 8-9, 1984;

"Entrained-Flow Pyrolysis of Biomass" at the 1985 Biomass Thermochemical Conversion Contractors' meeting in Minneapolis, Minnesota, on October 15-16, 1985;

"Low Pressure Entrained-Flow Pyrolysis of Biomass to Produce Liquid Fuels' at the 1987 Biomass Thermochemical Conversion Contractors' Review Meeting in Atlanta, Georgia, on May 20-21, 1987;

"Production and Upgrading of Biomass Pyrolysis 0ils" at the Thermochemical Conversion Program Annual Review Meeting in Denver, Colorado, on June 21-22, 1988 . 
A number of technical presentations have been presented at various conferences and forums, as shown below:

A technical presentation, "0il Production by Entrained-Flow Pyrolysis of Biomass," was made at the Wood Industrial Energy Forum 83, September 19-21, 1983, in Nashville, Tennessee;

A technical presentation, "0il Production by Entrained-Flow Pyrolysis of Biomass," was made at the Southeastern Biomass Energy Research Conference, October 18-20, 1983, in Tuscaloosa, Alabama;

"Oil Production by Entrained-Flow Pyrolysis of Biomass" was presented at the Third Canadian Biomass Liquefaction Meeting, September 29-30, 1983, at the University of Sherbrooke, Sherbrooke, Quebec, Canada;

"Oil From Biomass by Entrained-Flow Pyrolysis," was presented at the Sixth Symposium on Biotechnology for Fuels and Chemicals, May 15-18, 1984, in Gat I inburg, Tennessee;

"0il Production by Entrained-Flow Pyrolysis of Biomass," was presented at the Bio-Energy ' 84 Conference, June 18-21, 1984, in Gothenburg, Sweden;

"0il Production via Entrained-Flow Pyrolysis of Biomass," was presented at the National Meeting on Biomass R \& D for Energy Applications, October 1-3, 1984, in Arlington, Virginia;

"Oil Production via Entrained-Flow Pyrolysis of Biomass," was presented at Energy From Biomass: Technical Review Meeting Southeast Industrial Biomass Energy EXPO, November 27-29, 1984, in Atlanta, Georgia;

"Modeling Pyrolysis 0il Production in an Entrained-Flow Reactor," was presented at the Seventh Symposium on Biotechnology for Fuels and Chemicals, May 14-17, 1985, in Gatlinburg Tennessee;

"0il Production in Entrained-Flow Pyrolysis: Pilot Plant Design and Process Economics,' was presented at the Confederation of Engineering Industry of India; the 9th World Energy Engineering Congress, October 22-24, 1986, in Atlanta, Georgia;

"Experimental Process Research Study and Techno-Economic Analys is of the GIT Entrained-Flow Pyrolysis Process," was presented at the 193rd National Meeting of the American Chemical Society, April 5-10, 1987, in Denver, Colorado. 
The following technical papers were published during the project:

"Oil Production by Entrained-Flow Pyrolysis of Biomass," Biomass $\underline{6}, \mathrm{pp}$. 69-76, (1984);

"0il from Biomass by Entrained-Flow Pyrolysis, "Biotechnology and Bioengineering Symposium", No. 14, pp. 15-20, (1984);

"0il Production via Entrained-Flow Pyrolys is of Biomass," Proceedings of the 20th Intersociety Energy Conversion Engineering Conference 1, p. 1569 (August 1985);

"Advanced Biomass Pyrolysis Technologies in the United States, "Proceedings of the International Workshop on Pyrolys is as a Basic Technology for Large

Agro-Energy Projects, Commission of the European Communities, Directorate-General for Science, Research and Development, pp. 77-89, (October 1987);

"Modeling Pyrolysis $0 i 1$ Production in an Entrained-Flow Reactor," Biomass, 19 pp. 1-10 (1989);

"Liquid Biofuels Production by an Entrained Pyrolysis Process," Proceedings of Energy from Biomass and Wastes XIII, Institute of Gas Technology, (February 1989) (in press);

"The Georgia Tech Entrained-Flow Pyrolysis Process" Proceedings of the International Conference on Pyrolysis and Gasification, Commission of the European Communit es, Directorate-General for Energy, (May 1989) (in press).

A topical refort on process economics, "0il Production Via Entrained-Flow Pyrolysis of Biomass - Economic Analysis," was submitted to the Biomass Program Office, Battelle-Pacific Northwest Laboratories, in December, 1981;

An interim report, "Research on the Pyrolysis of Hardwood in an Entrained Bed Process Development Unit," covering the period May, 1982 to September, 1983 describing a series of preliminary runs made with mixed hardwood feed, was submitted to Battelle-PNL on November 30, 1983.

Special Technical Report No. 1, "Entrained-Flow Pyrolysis Screening Runs," describing a total of 11 screening runs conducted during the period 
October 11, 1983 through March 26, 1984, was submitted to Battelle-PNL on June $28,1984$.

Special Technical Report No. 2, "Entrained-Flow Pyrolysis Screening Runs," describing modifications to the PDU and the results of a set of preliminary tests, covering the period April 1984 through March 1985, was submitted to Battelle-PNL on May 7, 1985.

An interim report, "Research on the Pyrolysis of Hardwood in an Entrained Bed Process Development Unit - Task 2, Interim Technical Report," describing Configuration 2 of the process research unit (PRU) and the screening runs conducted during the period December 1984 through June 1985, was submitted to Battelle-PNL on September 30, 1985.

The report, "Addendum - Task 2 Interim Technical Report," describing two additional preliminary runs conducted between July 1985 and September 1985 and including carbon balances, was submitted to Battelle-PNL on October 30, 1985. 


\subsection{TASK 1. DESIGN AND CONSTRUCTION OF THE ENTRAINED PYROLYSIS PDU}

\subsection{SUMMARY}

As of May 1982, this project had been in progress for 20 months under a previous contract with the Department of Energy. During that period the design of the entrained-flow pyrolysis portion of a larger, entrained pyrolysis/gasification system was completed. Procurement of the major equipment items for the pyrolysis system was initiated, and the laboratory experiments were completed. The laboratory experiments included: exploratory pyrolysis research using a six-inch tube reactor to provide yield and thermodynamic data; free-fall pyrolysis experiments and thermogravimetric analyses (TGA) to obtain pyrolysis kinetic data; and pyrolysis experiments using a rotating two-inch tube reactor equipped with a condensation train. These experiments have been reported in detail.

In early 1982, permission was granted to continue work on the pyrolysis segment of the program, while the scope of the project was reduced by excluding the gasification portion of the program. The detailed, engineering design of the pyrolysis system was to be completed. Procurement of equipment, materials and supplies was to continue, and construction and assembly of the PDU was to be completed. The following sections describe the conceptual entrained-flow pyrolysis system and the major equipment components of the system. Figure 1 is a photograph of the Entrained-Bed PDU.

\subsection{CONCEPTUAL ENTRAINED-FLOW PYROLYSIS SYSTEM}

The main components of the innovative, entrained-flow pyrolys is system are shown in Figure 2, Conceptual Process Flow Diagram - Entrained-Flow Pyrolysis System. In Figure 2, green (wet) wood chips with a moisture content (wet basis) of 50 percent are brought into the wood storage area. The wood chips are convoyed (1) to the dryer. Dryer flue gases are exhausted to the atmosphere (2). The dryer is fueled by pyrolysis gases (15) and char (13). Preheated air (18) as well as ambient air (19) are used to supply the air requirements for the dryer. The wood chips are dried to 10 percent moisture (wet basis) and are conveyed (3) to the hammermill. Some moisture is evaporated (4) in the hammermill and the wood particles leave at 6 percent 


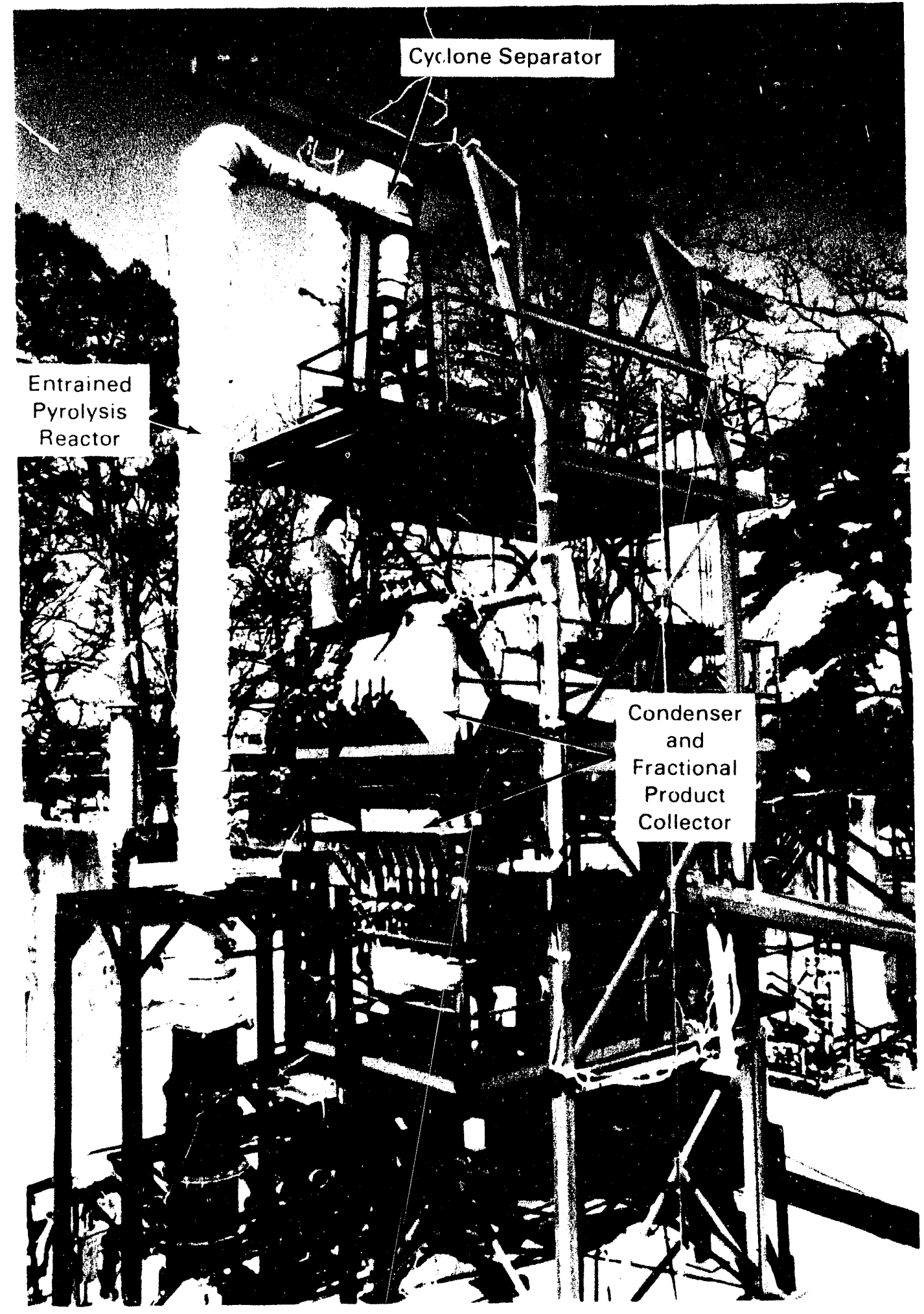

FIGURE 1. Georgia Tech Entrained-Bed Pyrolys is Process Development Unit 


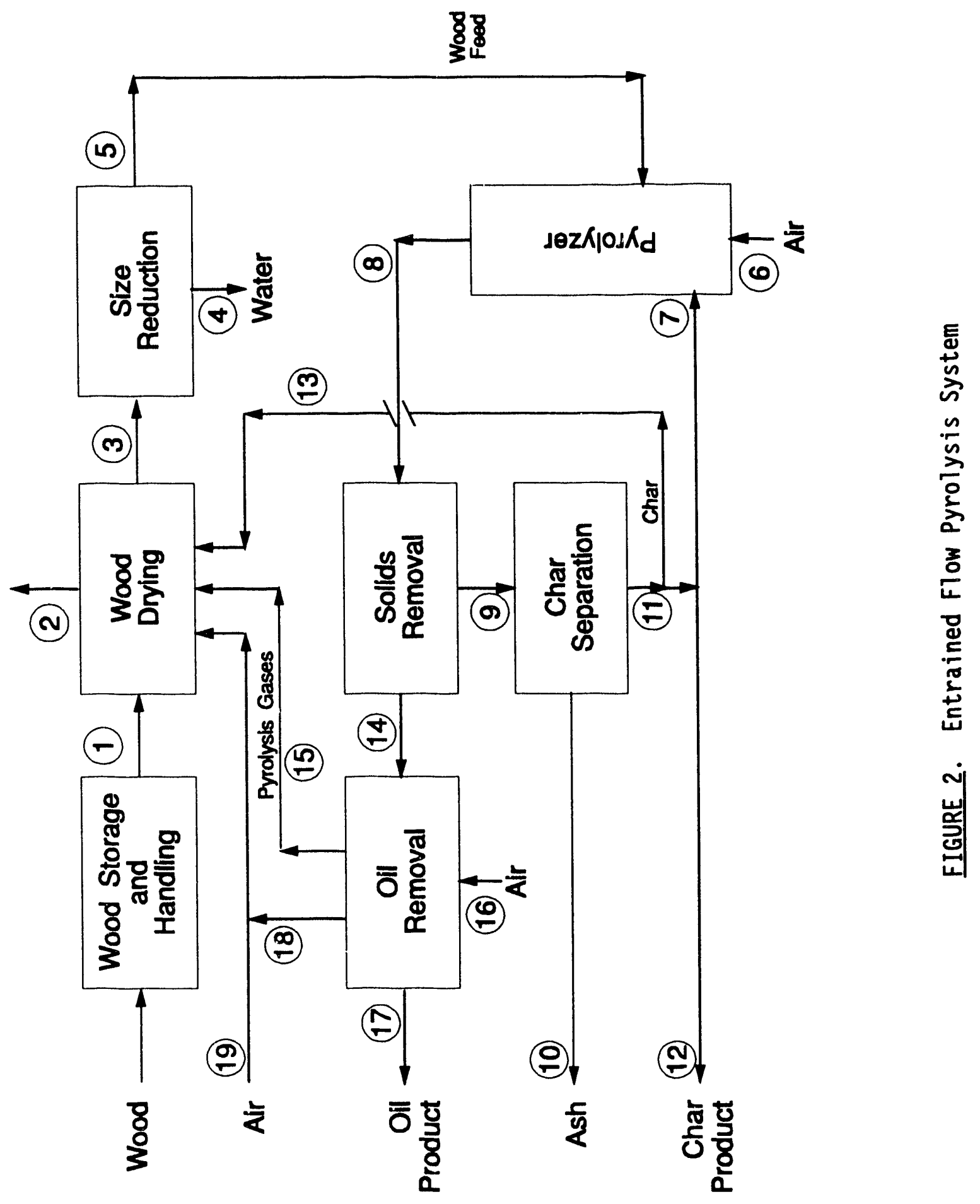


moisture (wet basis) (5), (the reduction in moisture is associated with the size reduction process). Some of the char (7) is burned with ambient air (6) to supply the energy needs for the pyrolyzer. The stream leaving the pyrolysis reactor (8) consists of newly formed char, pyrolysis gases, pyrolysis vapors, water vapor, nitrogen and ash from the char combustion. The char and ash (9) are removed by cyclone separators and are subsequently separated. The char stream (11) is split into two streams, one of them (7) provides the char for the pyrolysis reactor, the remainder (12) is char product. The ash (10) will be sold as an agricultural additive or landfilled. The pyrolysis vapors are removed from the mixture of pyrolysis gases, pyrolysis vapors, water vapor and nitrogen (14) by means of an air-cooled condenser and a demister. The entering ambient air (16) is heated in the condenser and supplies part of the air needed in the dryer. The product oil (17) contains about 10 percent moisture (this increases the fluidity of the oil, a desirable result).

The experimental system, as constructed to investigate the entrained pyrolysis of wood under steady-state conditions. A drawing of this pyrolysis system is given in Figure 3, Experimental Pyrolysis System - Schematic. The experimental parameters included feed material, pyrolysis temperature, particle size and residence time. The experimental data was analyzed using mathematical models of the kinetic and transport processes taking place during pyrolysis. Data analysis and experimentation were scheduled to proceed simultaneously so that optimization of the experimental program would be realized. This permitted the production of optimal yields of oil in the most efficient manner.

\subsection{MAJOR EQUIPMENT COMPONENTS}

The major components of the entrained pyrolysis system are:

Dryer

Size-Reduction and Storage System

Feed System

Inert Gas Generator

Entrained Pyrolysis Reactor

Cyclone Separator

Heat Exchanger 


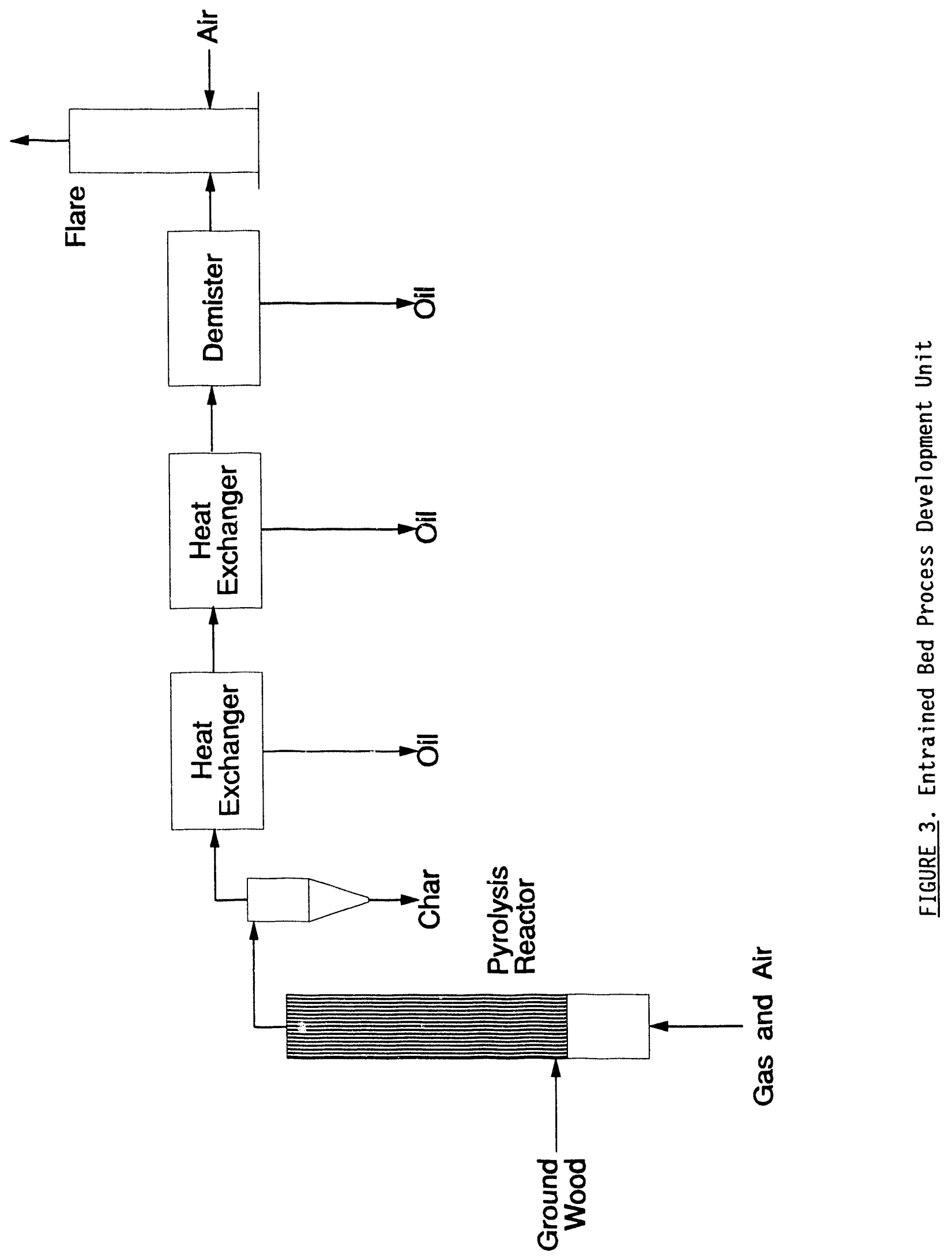




\section{Demister}

\section{Exhaust Gas Flare}

These components will be discussed in the following sections. The design of the experimental pyrolysis system was based on a computer code (program) using material and energy balances to determine the temperatures and flow rates of the various streams. The computer code used is given in Appendix A Energy and Material Balances for the Experimental Entrained Pyrolysis System -- Computer Program - "Model 1." A computer program was also developed for preliminary cyclone analysis. This program is shown in Aspendix B Estimation of Char Cyclone Parameters.

(1) Dryer

The purpose of the dryer is to dry wood chips from about fifty percent moisture (wet basis) to approximately ten percent moisture (wet basis). During the grirding operation, the moisture will be reduced to the desired design cundition of about six percent moisture (wet basis). This drying operation is a standard unit operation and a wide variety of dryers could be used. In this system a mobile, commercially available, agricultural dryer is used for drying the feed.

(2) Size Reduction and Storage System

The size reduction and storage system consists of a hammermill, a screen, and a feed storage bin. The detailed specifications of the size reduction system are given in Table 1 .

TABLE 1. Size Reduction Equipment

\begin{tabular}{|c|c|c|c|c|}
\hline Component & Manufacturer & Model No. & Description & \\
\hline $\begin{array}{l}\text { Hammermill } \\
\text { Crusher and } \\
20 \\
\text { chips }\end{array}$ & $\begin{array}{l}\text { Williams Patent } \\
\text { Series } \\
\text { dry lb/hr }\end{array}$ & $\begin{array}{l}\text { Torit } \\
900 \text { - } 1000 \\
\text { Co., Inc. }\end{array}$ & $\begin{array}{l}60 \mathrm{HP} \\
\text { Pulverizer }\end{array}$ & $\begin{array}{l}\text { No. } \\
\text { wood }\end{array}$ \\
\hline $\begin{array}{l}\text { Vibratory } \\
\text { separator } \\
\text { with screens }\end{array}$ & Sweco, Inc. & L524S4444 & $\begin{array}{l}24 \text { in. dia. } \\
3 \text { - deck } \\
\text { SS Separator }\end{array}$ & \\
\hline
\end{tabular}


(3) Feed System

The feed system consists of a surge hopper, loss-in-weight feeder, and an air lock. The loss-in-weight feeder and air lock are described in Table 2.

TABLE 2. Feed System Equipment

\begin{tabular}{llll}
\hline Component & Manufacturer & Model No. & Description \\
$\begin{array}{l}\text { Loss-in-weight } \\
\text { Feeder }\end{array}$ & $\begin{array}{l}\text { K-Tron } \\
\text { Corp. }\end{array}$ & LWF-3-35-500/45 & $\begin{array}{l}10-200 \\
1 \mathrm{bs} / \mathrm{hr}\end{array}$ \\
Air Lock & $\begin{array}{l}\text { Sprout Waldron } \\
\text { Division } \\
\text { Koppers } \\
\text { Co., Inc. }\end{array}$ & $\begin{array}{l}4 \times 3 \\
\text { Rotary } \\
\text { valve }\end{array}$ & 0.0119 \\
\hline
\end{tabular}

(4) Inert Gas Generator

The inert gas generator provides non-reactive, conveying gases for the feed and also serves to moderate the temperatures in the pyrolysis reactor. A description of the inert gas generator is given in Table 3 .

TABLE 3. Inert Gas Gerierator

Manufacturer

Industrial Gas

Systems. Inc.
Model No.

No. LE - 24
Description

$2400 \mathrm{SCFH}$

20 in. Water

Propane fueled

(5) Entrained Pyrolysis Reactor

The entrained pyrolysis reactor consists of three main parts. These are the burner, the mixing and entrainment section, and the reaction tube. The burner is described in Table 4.

The reaction tube is an eight inch, schedule forty, 304 stainless steel tube, twenty feet long. The tube was insulated externally throughout its length. The inlet region was insulated internally for a length of two feet. 
Manufacturer

North American

Manufacturing Co.
Model No.

No. $6425-3$
Description

$1-1 / 2$ in. Dual fuel

12 psi

9 in. tile

The mixing and entrainment section consisted of two metal shells with an internal castable refractory lining which provided a concentric cylindrical opening of five inches in inside diameter.

The mixing and entrainment section consisted of two metal shells with an internal castable refractory lining which provided a concentric cylindrical opening of five inches in inside diameter (this is the diameter of the burner outlet).

The design and construction of the mixing and entrainment section is shown in Figure 4, Mixing and Entrainment Section. The inert (nonreactive) moderating gas and the wood feed (with inert gas) enters through cylindrical holes in the castable refractory such that the streams enter tangentially to the five-inch cylindrical opening.

(6) Cyclone Separator

A single cyclone separator was used to collect the char particles at the exit of tine pyrolysis reactor. A description of the cyclone is given in Table 5 .

\section{TABLE 5. Char Cyclone Separator}

\section{Manufacturer}

Fisher-

Klosterman, Inc.
Model No. XQ340-5
Description

310 ACFM

Pressure drop - 2.3 in. water Cut diameter - 1.7 microns 
The mixture of noncondensable gases, water vapor, and oil vapors leaving the cyclone enter directly into the condenser. Most of the heat load in the condenser will be sensible heat related to the change in temperature of the noncondensable gases and water vapor. Some heat will have to be removed to condense the oil vapors. The condenser contains sixty, one-inch 14 BWG 304 stainless steel tubes, three feet long. The tubes are in line on a square pitch with a center to center distance of the tubes of 2.0 inches. The tubes are cooled by air forced past each tube by means of a fan. The condenser contains 60 tubes, five tubes deep and twelve tubes wide. The condensed oil from each consecutive tube pass is collected to provide six cuts or fractions. The air flow is directed by means of partitions so that an energy balance can be made related to each of the six cuts. A sketch of the condenser is given in Figure 5 , Air-Cooled Condenser - Schematic.

(8) Demister

The demister (impingement separator) was designed such that relatively large entrained liquid oil droplets in the gas mixture leaving the condenser would be removed. The design basis selected was that droplets larger than approximately 100 microns would be captured with only a small pressure drop. A sketch of the demister is given in Figure 6, Demister -- Impingement Separator - Schematic.

\section{(9) Flare}

The flare is a device for burning the combustible components of the mixture leaving the demister. The flare consists of a four-inch schedule forty steel pipe, six feet in length (thermally insulated), the end of which is surrounded by a cylindrical refractory shell. The refractory aids in maintaining the flame. A small natural gas pilot light will serve as an igniter. 


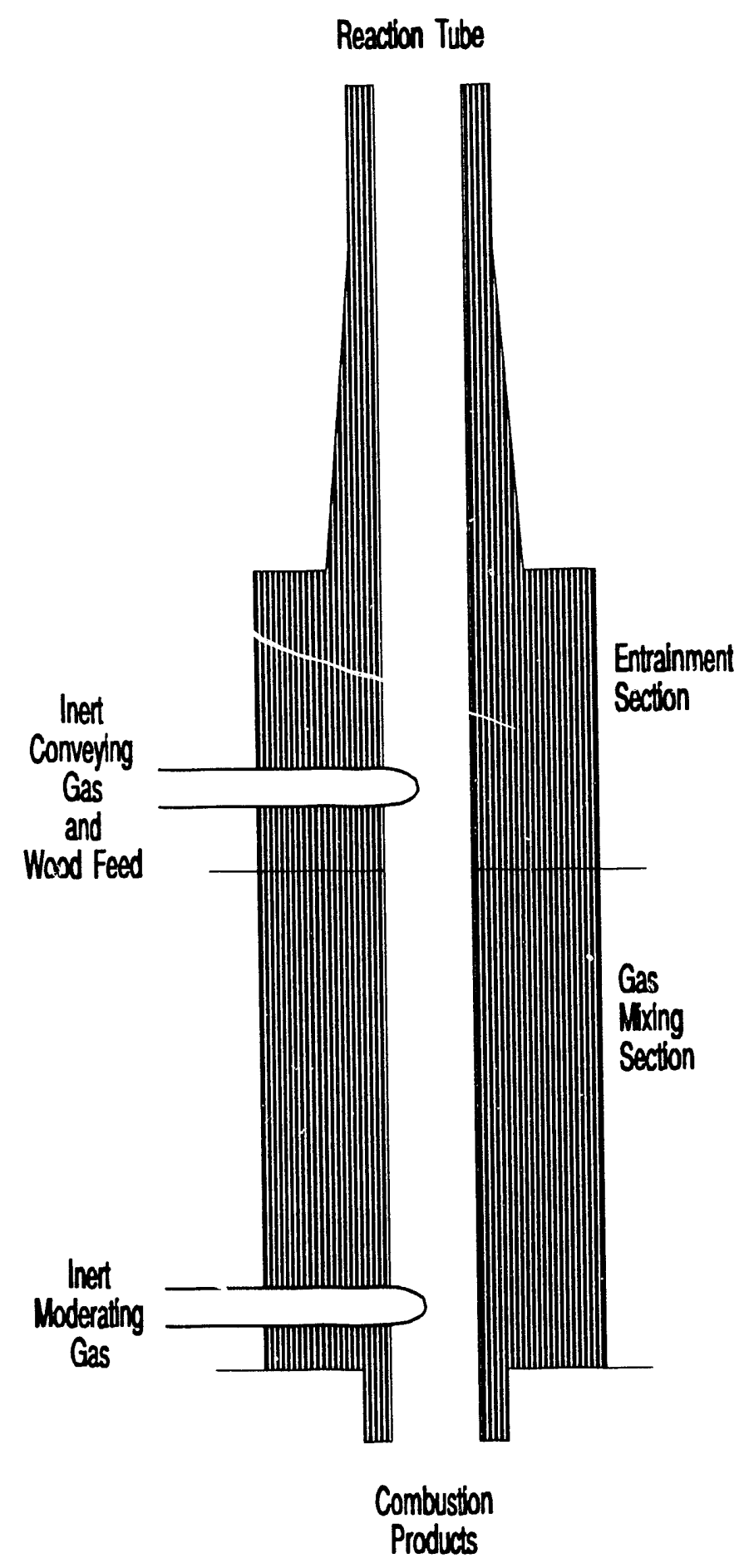

FIGURE 4. Mixing and Entrainment Section 


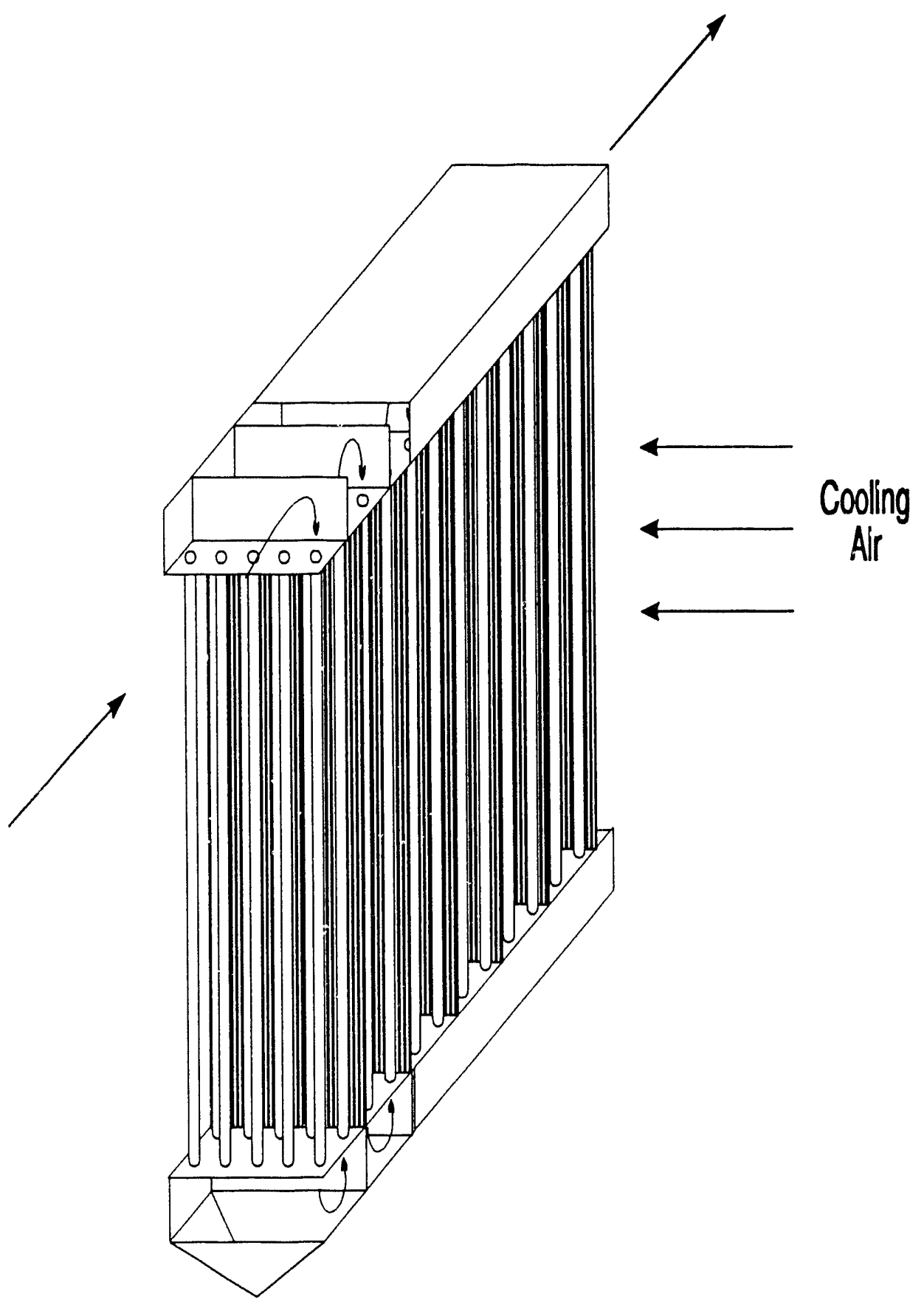

FIGURE 5. Condenser 


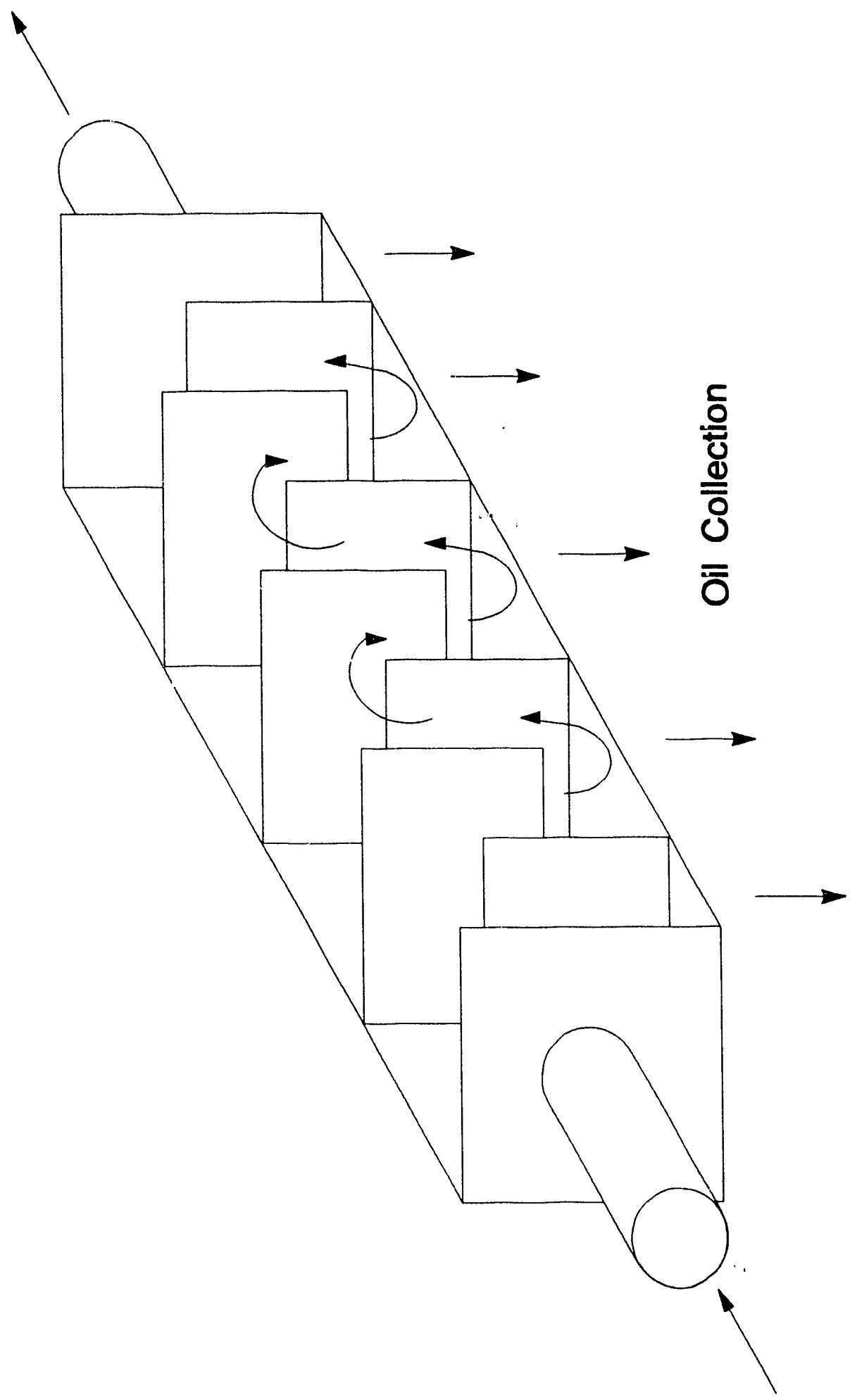

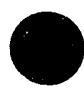

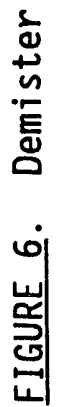

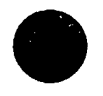

20 


\subsection{PROCUREMENT AND ASSEMBLY}

(1) Site Location of Entrained-Flow Pyrolyzer

The entrained-flow pyrolys is reactor is located in Research Area II on the Georgia Tech campus. Pilot plants and a large number of buildings which contain offices, laboratories, storage areas and large bench scale process equipment, are located in th is area.

The space in Research Area II which was assigned for this program is 92 feet by 122 feet, and includes a building 40 feet by 48 feet. This building is of sufficient size to house the control room with the necessary controls, monitoring equipment and instrument panels, and to provide adequate space for a small shop and work area, and storage. The necessary modifications and installation of adequate services to prepare this building for use on this program were completed by Georgia Tech personnel, and the cost for these improvements and renovations were borne by the Georgia Tech Research Institute.

The site layout of the entrained-flow pyrolyzer and feed preparation system is shown in Figure 7, Entrained-Flow Pyrolysis PDU Site Layout. The feed preparation includes the dryers (1), the hammermil1 (2), and the vibratory separator (3). The inert gas generator (4) and loss-in-weight feeder (5) was located in line near the support structure (6). The entrained-flow pyrolyzer (7) with cyclone, heat exchanger, demister and flare wius located on the support structure. The control building was located in the northeast corner of the plan view. It contains the control room (8) a work area for assembly of components, minor fabrication and space for the storage of mechanical and electrical supplies, spare parts, tools, prepared wood feed and supplies.

(2) Wood Feed Preparation

The schematic for the wood feed preparation is shown in Figure 8 , Wood Storage and Preparation System - Block Diagram. North Georgia hardwood chips, with a moisture content of about 50 percent, were stored in Building 78-H, in Research Area II, at Georgia Tech. The wet wood chips were dried in a forced-air, propane-fired batch dryer to a moisture content of 6 to 10 percent and stored in drums. Grinding was accomplished in a hammermill in two stages. 


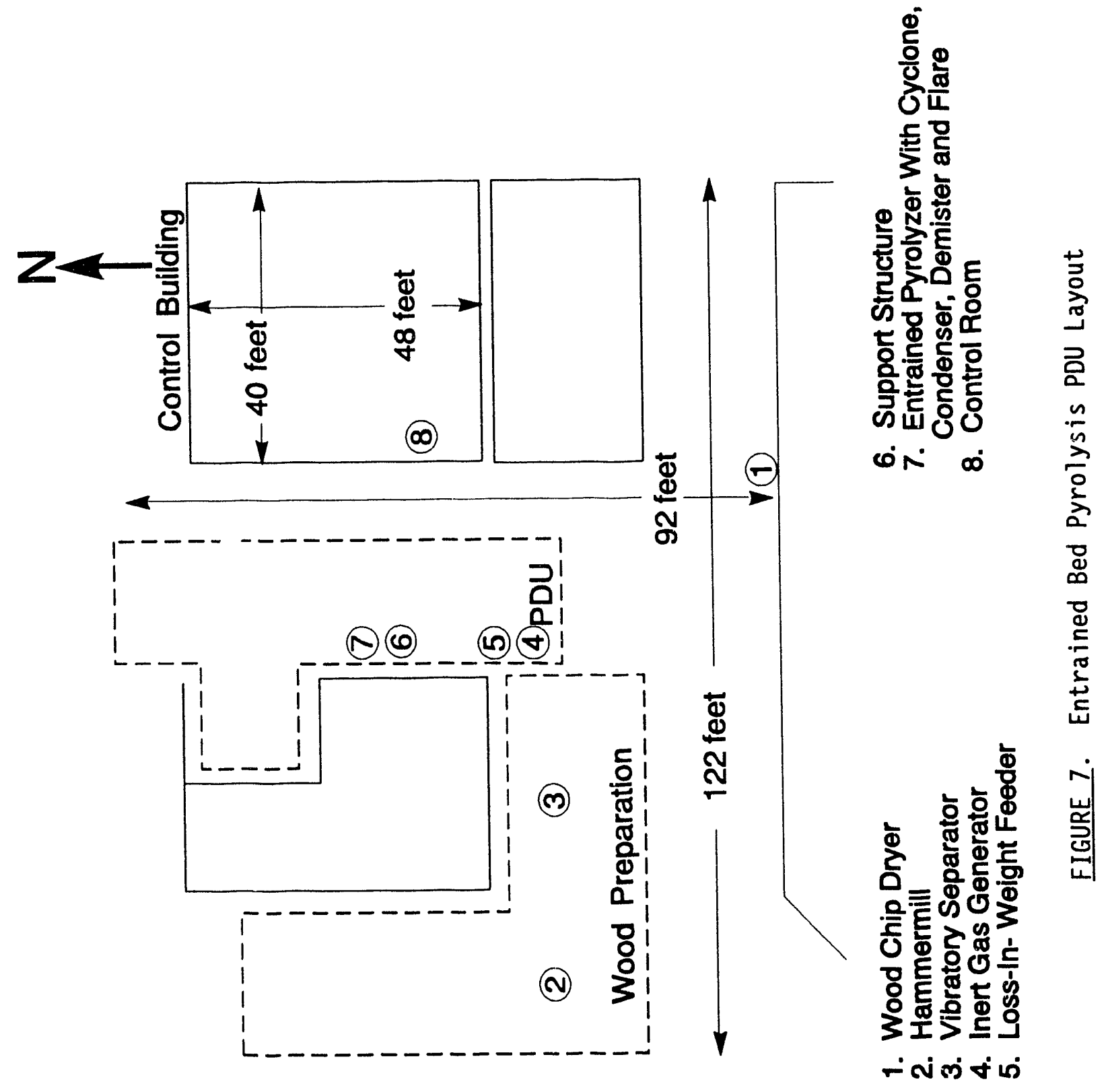




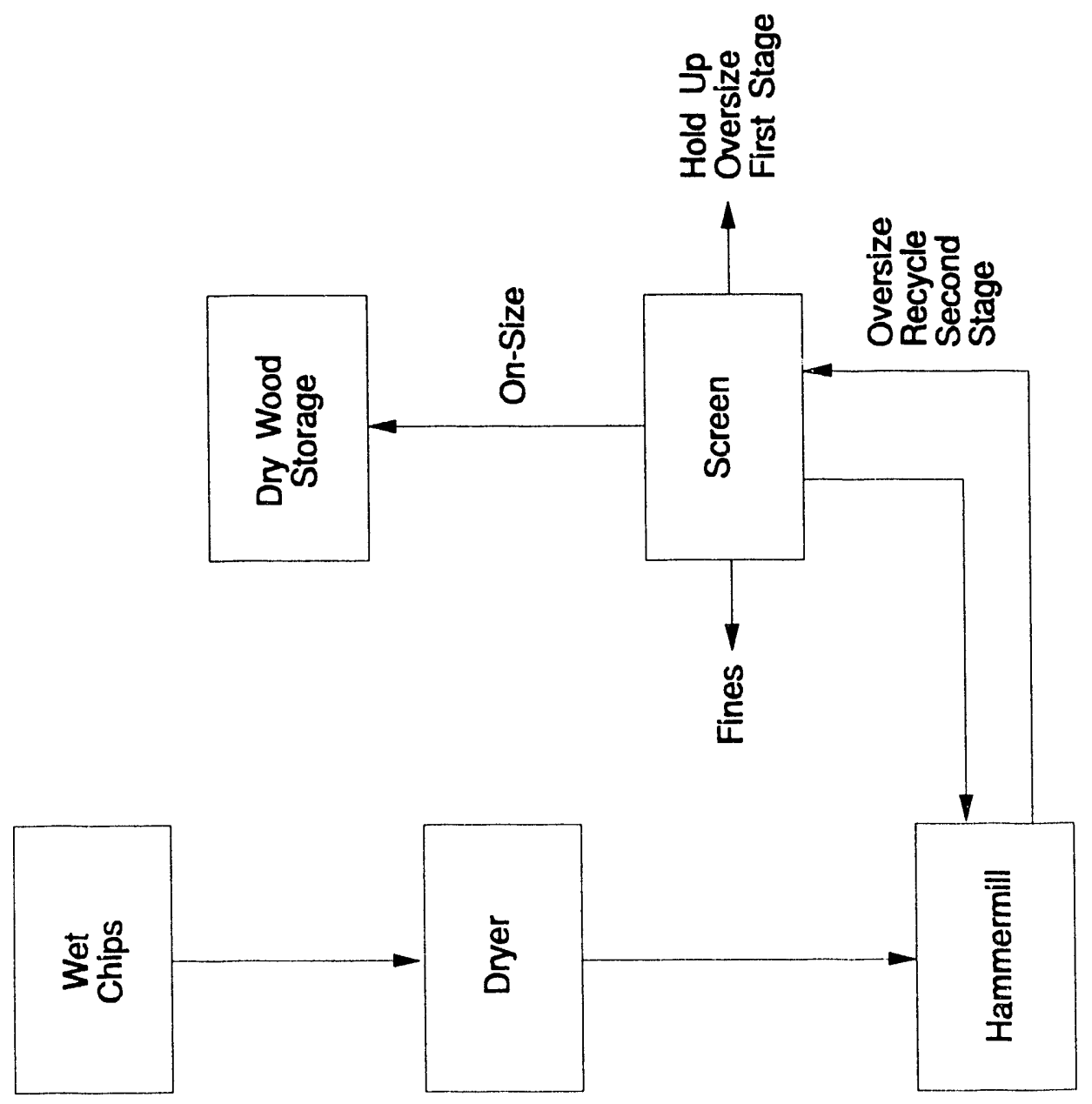

言

동

党

융

등

ัำ

京

웅

㐫 
In the first stage, a predetermined amount of laterial was processed and discharged onto a screen separator. The screen separated the ground wood into three fractions: oversize, on-size, and fines. When a quantity of wood chips had been processed, the screen in the middle was replaced by a finer screen to effect the second stage grinding.

All the material from the oversize fraction was processed through the hammermill a second time, and the ground wood was separated into appropriate sizes in the in the separator. The on-size material from the two stages was stored in drums. The fines fraction was saved for future use. The oversize fraction from the second stage grinding was recycled to the hammermill.

The propane-fired batch dryer is Georgia Tech equipment that is available for this program. The hammermill, including the magnetic separator as an integral part, was mounted on a concrete foundation. The hammermill cyclone, including the dust-collection bags, was mounted on a steel frame and located on the feed preparation site. The Sweco screening equipment, including a removable cover, was mounted on a steel frame. The required electrical motor starters, start-stop switches, forward-reverse switches, and overload switches were mounted in a weather protected enclosure attached to the south, outside wall of the building near the feed preparation area. 


\subsection{TASK 2A - PYROLYSIS PDU OPERATION -- START-UP, STEADY-STATE OPERATION, AND PRELIMINARY EXPERIMENTS - CONFIGURATION I}

\subsection{SUMMARY}

The construction and installation of the components and instrumentation of the process development unit (PDU) were completed in March, 1983. In runs without feed, the system operated well and no problems developed during the course of these runs. A series of preliminary runs were made with mixed hardwood feed during the next two months and are summarized below in Section 4.4, Praliminary Pyrolys is Runs with PDU. Based on the experience from these pyrolysis runs, Run No. 11 was conducted on June 10, 1983 with the objective of demonstrating mass and energy ba? ance closures for the PDU. The feed was 50 × 60 mesh mixed hardwood, and the feed rate was $103 \mathrm{lb} / \mathrm{hr}$. The mass balance indicated a substantial difference between the input and output flow rates. This led to a thorough experimental investigation of all of the flow meters in the system. As a result of this study, several changes were made followed by both cold and hot flow tests.

An orifice was installed in the conveying line to replace the waugh flowmeter. U-tube manometers (previously magnehelic gauges had been used) were installed on the PDU tower for measuring the static and differential pressures at the air orifice for the hot gas burner, the orifices for the moderating and conveying gas, and the orifice for the offgases downstream of the demister and upstream of the flare. With these modifications, cold flow tests were conducted with the PDU with air alone from the burner air blower and the air blower of the inert gas generator, and with propane as a tracer to check and calibrate the orifices. The results were satisfactory. Hot flow tests without feed were conducted to determine the steady-state operating temperatures. Thermocouples were installed on the outside of the reactor and their operation was chocked during the hot flow tests. These results were used in the energy balance calculations. The flowmeters for the cooling air in each of the six ducts for the condenser were calibrated using propane as a tracer.

The results of the cold and hot flow tests were satisfactory. Run No. 12 was conducted on September 23, 1983 with oak feed to demonstrate mass and 
energy balance closures. The results of this run were satisfactory and are discussed in Section 4.2, Mass Balance Considerations, in Section 4.3, Energy Balance Considerations, and in Section 4.5, Summary of Run No. 12.

A flow diagram of the PDU is given in Figure 9, Entrained Flow Pyrolysis Process Development Unit - Configuration I, and its operation is described in the following. Propane gas (1) and air (2) supplied by an air blower are burned stoichiometrically in an inert gas generator, and the combustion products are cooled with a water spray (3) so that the gases leave saturated with water vapor. The exit stream from the inert gas generator is split into two streams. One of these (4) provides moderating gas for the burner and the other (5) provides conveying gas for the feed particles (6). Propane (7) also fuels the burner, which also operates stoichiometrically with air (8) supplied by a blower.

The mixture consisting of moderating gas, conveying gas, burner combustion products, and wood particles moves vertically upwards through the reactor tube in which the entrained pyrolysis

takes place; the resulting mixture (9) consists of noncondensable gases, water vapor (entering moisture plus combustion and pyrulys is products), and pyrolysis oil vapors. In the cyclone, almost all of the char particles (10) are removed, and the stream (11) leaving the cyclone consists of noncondensable gases, water vapor, pyrolysis oil vapor, and some char fines. This mixture enters the condenser, and the pyrolysis vapor (and some water vapor) are condensed in the air-cooled condenser. The condensed phases (12) are removed via sumps and collection receivers, and the exiting mixture (13) consisting of noncondensable gases, water vapor, light oil vapors, aerosol, and possibly some fines enter the demister. In the demister most of the aerosol and fines are removed (14). The resulting mixture (15) consisting mainly of noncondensable gases and water vapor with some aerosol enters the flare where air is introduced, the mixture is burned, and the products of combustion (16) are exhausted to the atmosphere.

\subsection{MASS BALANCE CONSIDERATIONS}

Pyrolysis Run No. 12 was conducted September 23, 1983. The feed vas ground oak, $40 \times 60$ mesh (Sweco screen) with a moisture content of $5 \%$ on a wet 


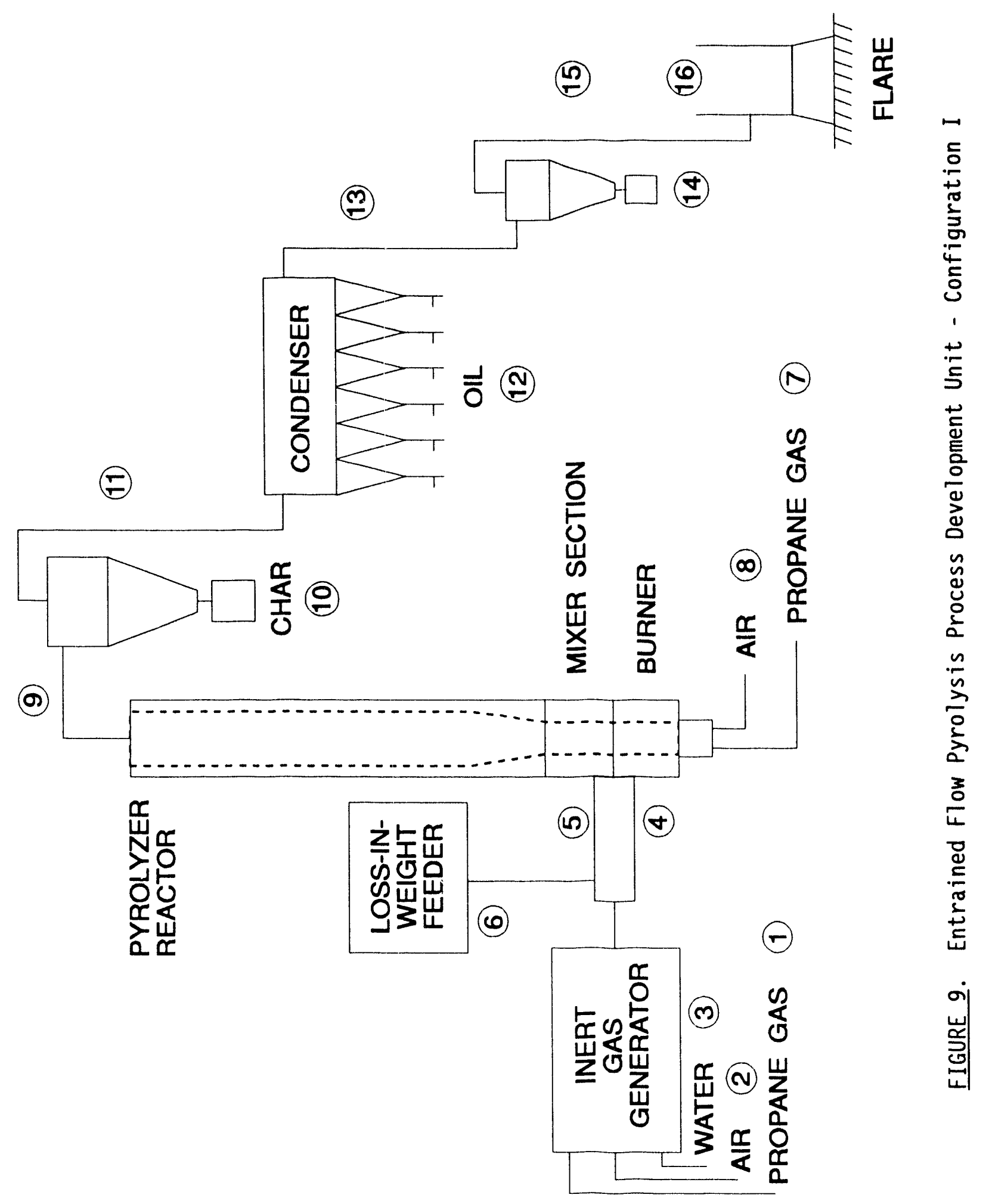


basis. The data test period vas 65 minutes at a feed rate of 111.6 lbs feed (wet basis) per hour.

(1) Orifice Meters

Orifice meters were used to determine the flow rates of the air, propane, conveying gas, and moderating gas. There is also an orifice meter in the pipe leading to the flare. The calculated flow rate through this orifice is not used in the mass balance due to the uncertainty in the physical state (vapor or liquid) of the pyrolysis products, the water formed by combustion, and water brought in with the air and inert gases.

The orifice meter for propane is an integral part of a control device which maintains essentially stoichiometric conditions. A calibration curve supplied with the device was used to determine the propane flow rate. All of the other orifice meters were purchased separately and are orifice plates fitted with flange pressure taps. The orifice pressure drops are determined with U-tube manometers which are physically located near each orifice so as to minimize measurement errors.

The flow rates through the orifices (with the exception of the propane orifice) were calculated using a computer program based on the information provided in "Fluid Meters; Their Theory and Application," ASME (1959). The viscosity was calculated as a function of temperature and composition. The density was calculated as a function of pressure, temperature and composition. Estimated errors in flows calculated in this manner will be discussed in a later section of the report.

(2) Chemical Analysis

The chemical analyses that are performed on the input gas streams and feed and output products and offgas stream are given in Table 6 .

PDU Inputs and Outputs

The inputs to the system are feed with moisture, inert gas from the inert gas generator, and propane (commercial) and air for the hot gas burner. The weight of the input feed is determined with the loss-in-weight feeder. The inert gas is used for both moderating gas and 
TABLE 6. Chemical Analysis

Material

Analytical Determinations

Feed

Moisture, ash, higher heating value.

Inert gas

Composition determined by gas chromatography.

Air

Composition determined by gas chromatography.

Propane

Composition determined by gas chromatography.

Char

$0 i 1$

Offgas

Moisture, ash, higher heating value.

Water (Karl-Fisher technique), higher heating value.

Composition determined by gas chromatography and data from condensation train. Higher heating value calculated from composition.

conveying gas and the mass flow rates of each of these streams are determined with orifice plates. The mass flow rates of the air and propane gas for the hot gas burner are determined with orifice plates. During a data test run, the inert gas, air and propane are sampled, and the composition of each gas is determined by analyzing the samples by gas chromatography.

The char and liquid products are weighed. The offgas stream is sampled continuously during the test period of a pyrolysis rua, downstream of the demister cyclone. The volume of the offgas stream sampled is measured with a dry test meter. The sample is passed through a condensation train for analysis of the condensable components and periodic sampling of the noncondensed gases, which are analyzed by gas chromatography $(\mathrm{GC})$. These data are used to calculate the mass flow of the offgas stream by a nitrogen balance. At the end of each run, any deposits in the condenser are recovered and weighed.

\subsection{ENERGY BALANCE CONSIDERATIONS}

The basis for the energy balance is the steady-flow energy equation. The approach taken was to determine the total rate of enthalpy entering and the 
trital rate of enthalpy leaving the PDU. The difference between these two quantities was compared to the calculated rate of heat loss and cooling in the condenser (with due regard to sign). This neglects any minor contributions related to changes in kinetic and potential energies. The enthalpies of gaseous argon, oxygen, nitrogen, and carbon dioxide were arbitrarily set equal to zero at $25{ }^{\circ} \mathrm{C}$. The enthalpy of liquid water at $25{ }^{\circ} \mathrm{C}$ was also taken to be zero. This is equivalent to assigning the enthalpy of a combustible material at $25^{\circ} \mathrm{C}$ a value equal to its higher heating value. A further implication is that the entliclpy of water vapor at $25{ }^{\circ} \mathrm{C}$ is equal to the latent heat of vaporization at that temperature.

Heat loss estimations were based on results obtained from running the PDU hot but without feed. Using temperature drops in the process fluid, heat losses in various sections of the system were determined. These losses were related to temperatures measured at selected locations in the PDU. Since external temperatures were not measured on the condenser (which was not insulated at ihat time), the heat loss was associated with the condenser cooling temperatures. The calculations resulted in a small negative loss for the condenser. As a result of these calculations, the condenser heat loss (not the heat removed by the cooling air) was neglected in these energy balance calculations. The energy balance will be discussed subsequently.

\subsection{PRELIMINARY PYROLYSIS RUNS WITH PDU}

Prior to the start-up of the PDU, a quality assurance system vas developed to check and maintain the calibration and performance of the equipment and instruments associated with the PDU. A description of the quality assurance system is given in Appendix C, Quality Assurance System. The instrumentation associated with the PD's provided temperature, flow, and pressure measurements during operation of the PDU Gas samples were taken at approximately 20 minute intervals, during operation, of the gaseous input streams and from the gaseous output stream just prior to its entering the flare, and were analyzed immediately. The instrumentation was checked and calibrated, as necessary, prior to operation of the PDU to ensure proper performance. Performance tests and recalibrations were conducted on a regular basis throughout the program. 
The operational performance and outputs of the loss-in-weight feeder and inert gas generator (conveying and moderating gas) were checked. The loss-in-weight feeder's data were verified by weighing the feed material discharged over a given time interval. The composition of the gas outputs from the inert gas generator and the pyrolyzer combustor (or hot-gas generator) were determined by gas chromatography. Checks, and adjustments when needed, were made on these system components prior to each test run.

Prior to start-up and hot operation of the PDU, cold-flow tests were conducted to verify the proper operation of the feedstock discharge and conveying system, the entrainment section, and the collection of the feedstock in the cyclones. Tests were also conducted to check the operation of the PDU with hot reactor gas and conveying gas, but without the addition of any feedstock. Temperature, pressure and flow data were taken during these tests to check the operational ranges of the various parameters, and to allow the calculation of mass balances and closure. Based on these tests, a prelimiiary procedure for the start-up and steady-state operation of the PDU was prepared. This operating procedure is discussed in the next section.

After the above testing and checking, the PDU was prepared for start-up and (hot) steady-state operation. Runs with feedstock at specific, predetermined conditions were made to show that the PDU was operating properly. The PDU was then operated to demonstrate the closure of the material and energy balances of the system. Based on the test results and operating experience, a general operating procedure was prepared for operating the PDU at steady-state and for the collection of data and feed and product samples for each experiment.

After the PDU system had performed well without feed, a series of preliminary tests were made with a mixed hardwood feed. The results of these tests are shown in Table 7, Preliminary Pyrolysis Runs with PDU. Table 7 shows the dry feedrate of the input wood, the dry yield of the char and pyrolytic oil products, the pyrolysis reactor reference temperature which was maintained for the test, and the elapsed time of the actual testing period (as opposed to online time). Pertinent comments regarding the preliminary runs are given in Table 8, Comments on Preliminary Runs. 
TABLE 7. Preliminary Pyrolysis Runs With PDU

\begin{tabular}{|c|c|c|c|c|c|c|}
\hline $\begin{array}{l}\text { Run } \\
\text { No. }\end{array}$ & Date & $\begin{array}{l}\text { Feed(dry) } \\
\text { lb/hr }\end{array}$ & $\underset{(\min )}{\operatorname{Run}}$ & $\%$ Char & $\% 0 i 1$ & $\begin{array}{c}\text { Temperatu } \\
{ }^{\circ} \mathrm{F} \text { * }\end{array}$ \\
\hline 1 & $3 / 21 / 83$ & & -- & & & \\
\hline 2 & $3 / 25 / 83$ & & -- & & & \\
\hline 3 & $3 / 29 / 83$ & 70.4 & 52 & 3.2 & 4.4 & 1,160 \\
\hline 4 & $4 / 11 / 83$ & 57.8 & 61 & 10.8 & 28.7 & 1,000 \\
\hline 5 & $4 / 15 / 83$ & 62.9 & 51 & 8.9 & 24.3 & 800 \\
\hline 6 & $4 / 20 / 83$ & 53.5 & 75 & 16.0 & 20.2 & 1,130 \\
\hline 7 & $4 / 26 / 83$ & 46.3 & 41 & 18.6 & 20.6 & 1,340 \\
\hline 8 & $5 / 12 / 83$ & 55.0 & 50 & 16.6 & 40.6 & 900 \\
\hline 9 & $6 / 01 / 83$ & & -- & & & \\
\hline 10 & $6 / 09 / 83$ & & -- & & & \\
\hline
\end{tabular}

* Temperature reading at entranced of reactor at start of data test run.

\subsection{OPERATING PROCEDURES FOR THE ENTRAINED-FLOW PROCESS DEVELOPMENT UNIT}

The procedures which are used for preparing and operating the Process Development Unit - Configuration I were documented and assembled in an operations manual. These procedures include instructions for preparing the PDU prior to a test, directions for bringing the pilot unit online and operating at steady-state, data collection, product recovery, sampling during a run, shutdown, and clean-up are presented in Appendix D, Operating Procedures for the Entrained Flow Pyrolysis Process Development Unit. Data sheets which were used during the pyrolysis tests to record instrument readings and feed and product measurements are shown in Appendix E, Data Sheets. 
TABLE 8. Comments on Preliminary Runs

Run 1

These two runs were shakedown runs to test the PDU as

Run 2

a unit and to gain experience in the operational characteristics of the PDU.

Run 3

Analys is of gas taken downstream of demister showed $7.14 \%$ oxygen, which indicated an excess of air. Based on this data and the low char and oil yields, this run did not represent a valid pyrolysis run. No plausible explanation could be found for the excess oxygen.

Run 4 Run was reasonably satisfactory. 0il yield vas lover than expected.

Run 5 Reactor was operated at a lower temperature than Run 4. Run was unsatisfactory as brown wood was present in char showing incomplete carbonization.

Run 6 Objective was to maintain reactor temperature as steady as feasible by varying the burner temperatures in an effort to reproduce temperatures of Run 4. Results were not satisfactory.

Run 7

Objective was to operate so that reactor outlet temperature was in the range $850-900^{\circ} \mathrm{F}$. The feed material for this run was - 30 mesh. For Runs $1-6,-50$ mesh feed was used. Difficulties were experienced in maintaining the burner flame. It was necessary to increase burner settings so as to maintain the flame, which resulted in higher reactor temperatures than planned. Results were not satisfactory.

Run 8 Reactor was operated at conditions very similar to Run 4. The oil yield was $40.6 \%$. The method for determining the water content of the oil samples was changed to the Karl-Fisher technique. Previously, the Dean-Stark technique was used. During the run, a smali leak developed at a gasket at the entrance to the reactor.

Run 9 Shortly after this run was started, a gasket blew out in the reducer section at the reactor exit. Prior to the failure of the gasket, the feed rate was $108 \mathrm{lb} / \mathrm{hr}$.

Run 10 At 18 minutes into the data test run, the pressure readings in the reactor increased greater than normally expected, indicating that plugging was occurring. The run was discontinued. Inspection of the PDU, after it had cooled, showed that plugging of some of the tubes in the first section of the condenser had taken place. 


\subsection{SUMMARY OF RUN NO. 12}

A summary of the mass flow rate data for the entering and leaving streams for pyrolysis Run No. 12 is given in Table 9, Mass Balance - Run No. 12. A more detailed presentation of the data is given in Table 10, Run No. 12 - Mass Data. Table 10 gives the mass flow rate of each component or compound entering and leaving the pyrolysis system. Data on pyrolysis oil collection is given for each individual sump or collection point. The composition of the oil product, that is the amount of dry (organic) $0 i 1$ and the amount of water combined in the oil product, is given.

A summary of the enthalpy rates for the entering and leaving streams for pyrolysis Run No. 12 is given in Table 11, Energy Balance, Run No. 12. Additional data is presented in Table 12, Run No. 12 - Energy Data. Table 12 gives the energy content, or higher heating value (in Btu per hour) of all of the entering and leaving streams of the entrained-flow pyrolysis system. All of the values given are measured values except those of the gases. The heating values of the gases were calculated from composition data, which were determined by gas chromatography.

As indicated in Table 9, the mass balance closure was 96.8 per cent. In addition to this result, an estimate of the maximum error was made by means of an error analysis. Initial estimates of errors in flow rates associated with direct measurements of weight indicated that this source of error was negligible.

The estimated error in input flow rate was based on the calculated flow rates for burner air, propane gas and inert gas. All of these flow rates were determined using orifice plates. The error in the air and propane orifice calculations was assumed to be caused by the measurement error of the pressure drop and the inherent error in the orifice coefficient itself (estimated to be one per cent). Similar assumptions were made for the determination of the inert gas flow rate, and in addition, the error associated with the inert gas density caused by errors in composition measurements was included. The resulting estimated maximum error in inlet flow rate was \pm 2.5 per cent.

The exit flow rate of the offgas stream (noncondensables, vapors and aerosols) was determined by a nitrogen balance. The estimated error in the 
TABLE 9. Mass Balance - Run No. 12

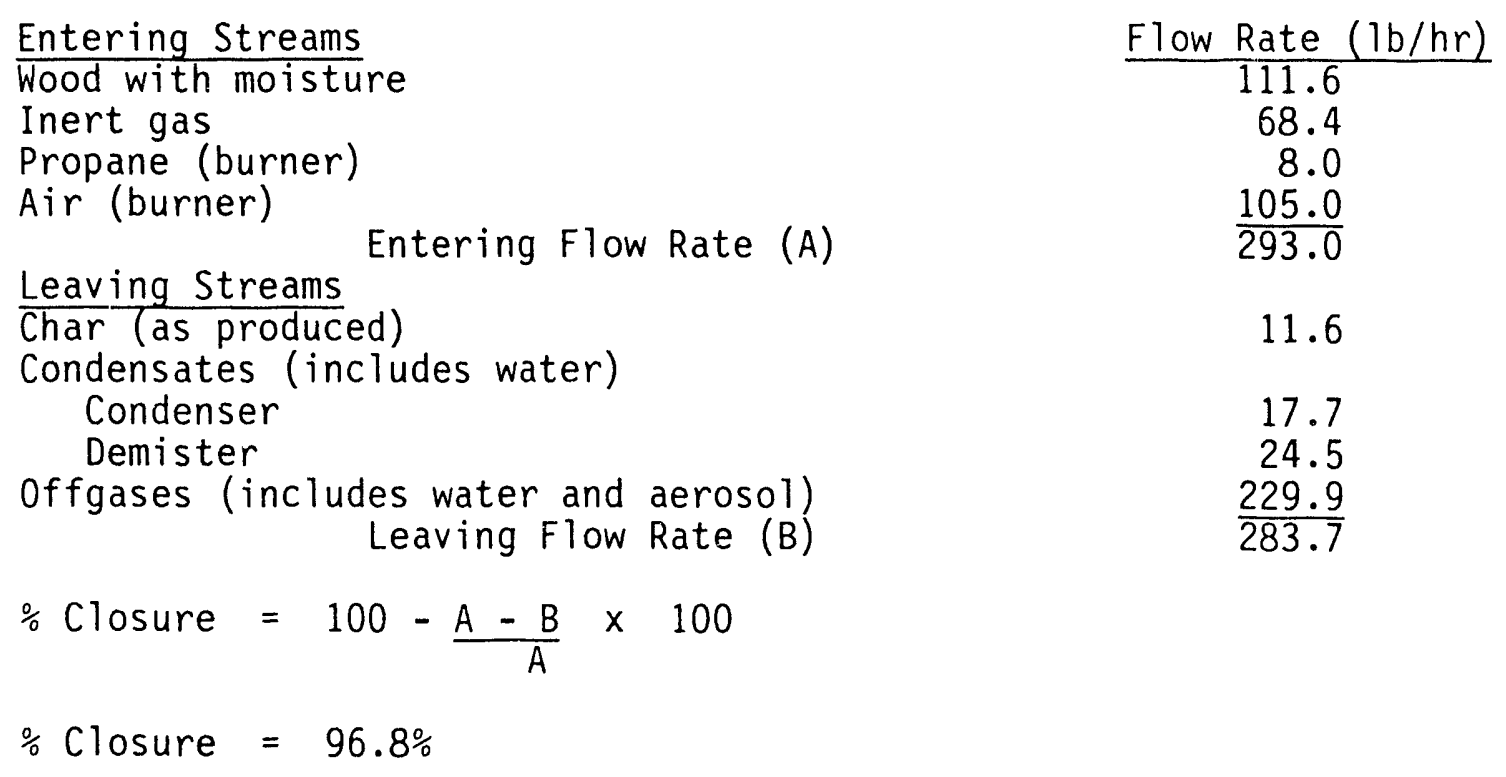

offgas noncondensable flow rate was based on the estimated accuracy of the total inlet nitrogen flow rate and the estimated accuracy of the measurement of gas compositions. The exit aerosol, light oil, and water vapor flow rates are also subject to composition measurement error, since they were obtained by ratioing sample measurements to the calculated offgas flow rate. Using this procedure, the estimated maximum error in total output flow rate was \pm 6 per cent. This was based on variations in the determination of the mass fraction of nitrogen determined by gas chromatography using 'identical" samples (samples obtained from a relatively large volume of gages collected in the offgas sampling train). It should be noted that the material balance closure given in Table 9 lies within the estimated maximum error bounds.

Table 11 presents the results of the energy balance calculations. A maximum error was estimated for the energy balance as was done for the mass balance. One of the assumptions made vas that the measured heating values of the feed, char, and oils (condenser, demister, or aerosol) had a maximum absolute error of $100 \mathrm{Btu}$ (based on experience with these determinations). The maximum heating value error estimate for the offgas was based on the maximum estimated errors in the offgas composition. Small errors in the measurement of 


\section{ENTERING STREAMS}

$$
\text { Feed }
$$

Wood (maf)

Moisture in wood

Ash in wood

Inert Gas

Argon

$\mathrm{N}_{2}^{2}$

$\mathrm{CO}_{2}$

$\mathrm{H}_{2}^{2} \mathrm{O}$

Propane Fuel (Burner)

Propane

Ethane

Propylene

Iso-Butane

Air (Burner)

$\mathrm{N}_{2}$

$\mathrm{H}_{2}^{2} \mathrm{O}$

Argon

$\mathrm{CO}_{2}$

\author{
$\underline{\mathrm{lb} / \mathrm{hr}} \quad \underline{\mathrm{lb} / \mathrm{hr}}$ \\ 105.33 \\ 5.58 \\ 0.69 \\ $11 \overline{1.60}$ \\ 111.60 \\ $\underline{l b / h r}$ \\ 0.90 \\ 0.28 \\ 52.96 \\ 0.06 \\ 12.91 \\ 0.01 \\ 1.29 \\ $6 \overline{8.41}$ \\ 68.41 \\ $\mathrm{lb} / \mathrm{hr}$ \\ 7.67 \\ 0.19 \\ 0.02 \\ 0.10 \\ 7.98 \\ 7.98 \\ $\underline{\mathrm{lb} / \mathrm{hr}}$ \\ 24.20 \\ 78.75 \\ 0.63 \\ 1.35 \\ 0.05 \\ $10 \overline{4.98} \quad 104.98$
}

Total Entering Streams 292.97

\section{LEAVING STREAMS}

Char

Char (maf)

Moisture in char

$\underline{\mathrm{lb} / \mathrm{hr}} \quad \underline{\mathrm{lb} / \mathrm{hr}}$

Ash in char
10.71

0.15

0.73

$1 \overline{1.59}$ 
TABLE 10. Run No. 12 - Mass Data (Cont.)

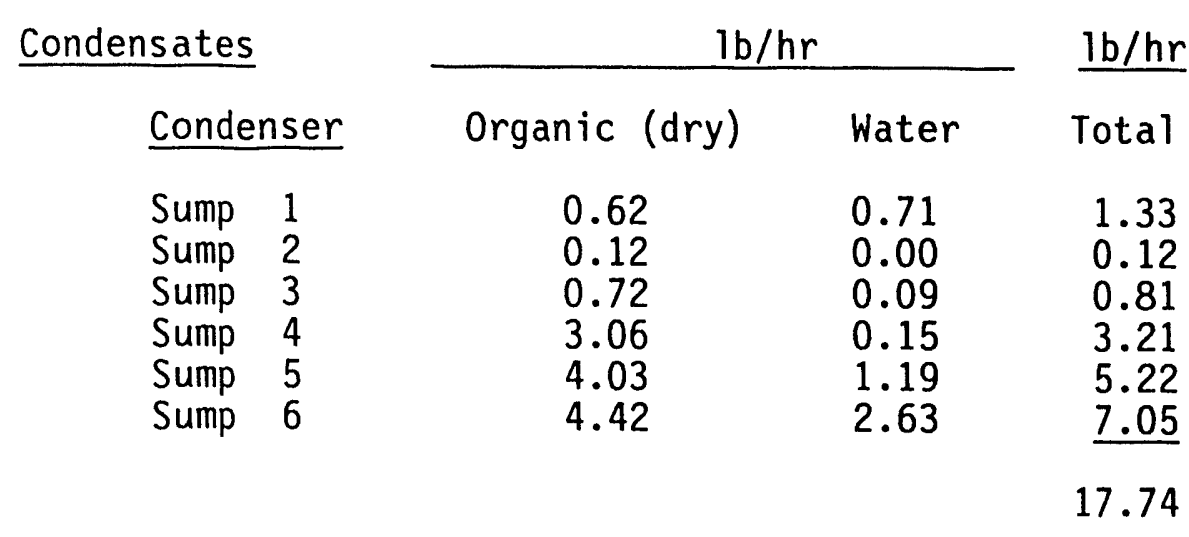

Demister

Organic (dry) 19.43

Water

$\underline{5.04}$

24.47

24.47

Offgases

$\underline{1 b / h r} \quad \underline{l b / h r}$

Condensates-Sampling Train

$\begin{array}{ll}\text { Organic (dry) } & 5.87\end{array}$

Water

\begin{tabular}{l}
$5.87 \quad 22.80$ \\
\hline
\end{tabular}

Light oil (dry-ice trap)

1.20

$29.87 \quad 29.87$

Offgas (Noncondensable)

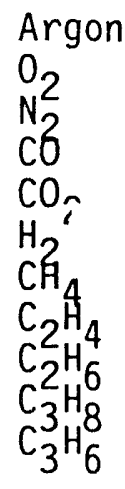

$\begin{array}{r}2.27 \\ 0.91 \\ 131.71 \\ 25.24 \\ 35.05 \\ 0.71 \\ 1.63 \\ 1.21 \\ 0.17 \\ 0.21 \\ 0.94 \\ \hline\end{array}$

200.05

200.05

Total Leaving Streams

283.72 
relatively high molecular weight species ( $\mathrm{CH} 4$ and higher) result in substantial changes in the heating value of the noncondensable offgases. Since the value for the offgases is the largest leaving energy stream (see Table 11), the measurement of the offgas composition plays a major role in determining the accuracy of the energy balance. Also, the mass balance calculations have a direct impact on the energy balance calculations. That is, an exit mass flow rate different from the inlet flow rate will automatically reflect adversely on the energy balance. The estimated maximum error in the energy balance based on these considerations was \pm eight per cent. As indicated in Table 11, the error was determined to be approximately 18 per cent (which includes estimated errors of the flow rates) which is outside the estimated maximum error. This is possibly due, in part, to the failure to properly determine the heat losses from the PDU. Although an 18 per cent error is relatively large, the energy balance closure was good enough to indicate substantial consistency of the data. That is, there was no direct indication of a major weakness in the methods of accumulating and analyzing the data.

\subsection{OFFGAS SAMPLING TRAIN}

(1) Apparatus

The pilot plant offgas sampling system consists of three modules, which are mounted in cases for transportation from the laboratory to the pilot plant units or to larger demonstration units in the field. The first (ambient) module, which is located below the sampling point, contains ice-cooled traps, condensers cooled by circulating ice water, a glass-wool-packed demister and a calcium sulfate drying tube.

The second (cold trap) module contains traps cooled by dry ice and acetone, condensers chilled by alcohol circulating through a heat exchanger immersed in a mixture of dry ice and ethylene glycol or dry ice and acetone, and a noncondensable gas purifier tube containing magnesium perchlorate.

The third (mechanical) moduie contains the stainless steel diaphragm pumps which drive the sampling train, stainless steel needle valves for regulating flow rates, gas meters, gas collection vessels and a gear pump for circulating the alcohol coolant. A diagram of the sampling train is shown in Figure 10, Offgas Sampling Train - Schematic. 


\section{TABLE 11. Energy Balance - Run No. 12}

\section{Entering Streams Enthalpy (Btu/hr)}

Wood

886,751

Inert Gas ( $\mathrm{CO}, \mathrm{H}_{2}, \mathrm{H}_{2} \mathrm{O}$ vapor)

2,093

Air $\left(\mathrm{H}_{2} \mathrm{O}\right.$ vapor)

661

Propane (burner)

172,854

Entering Enthalpy Rate (A)

$1,062,359$

Leaving Streams

Enthalpy (Btu/hr)

Char

129,933

Condensate

306,274

Offgases (includes aerosol)

343,532

Leaving Enthalpy Rate

(B)

779,739

Equipment

Calculated Heat Transfer Rate (Btu/hr)

Reactor

15,510

Cyclone

7,471

Condenser (includes cooling gain)

69,002

Demister

328

Piping

Heating Removed

(C)

92,441

130

$\%$ Closure $=100-\frac{A-(B+C)}{A} \times 100$

$\%$ Closure $=82.1 \%$ 
TABLE 12. Run No. 12 - Energy Data

ENTERING STREAMS

Wood (dry basis)

Propane (burner fuel)

(Calculated from composition)
HHV-Btu/Ib

8,364

21,673

\section{LEAVING STREAMS}

Char (dry basis)

11,213

Condenser condensates (dry basis)

Sump 1

Sump 2

8,750

9,413

Sump 3

Sump 4

Sump 5

Sump 6

Demister oil (dry basis)

Offgas sample (sampling train)

$0 i 1$ (ice trap; assumed same value as demister oil)

Light oil (dry ice trap; assumed HHV based on prior work)

Gases (noncondensable; calculated from composition)
10,565

9,105

8,501

8,463

9,783

9,783

18,000

1,229 
(2) Operation

The trap flasks, the glass-wool demister and the calcium sulfate drying tube are weighed to the nearest 0.1 gram, and the apparatus is assembled and tested for leaks. Sampling is accomplished through a metal probe inserted through a gas-tight bushing into the offgas stream at the point of interest. From the sampling probe, the offgas sample is drawn downward through a $9.5-\mathrm{mm}$ ID (3/8 inch) heavy walled "Tygon" tube into the sample inlet (1) through the ice-cooled traps (2) and condensers (3), the demister (4) and the calcium sulfate dryer (5). A 9.5-mm ID (3/8-inch) "Tygon" tube of sufficient length to remove the dry ice and mechanical modules from the congested area below the sampling point is used between the calcium sulfate dryer (5) and the dry ice module. The gas stream, stripped of most of the water and heavy organic material, is passed through the alcohol chilled condensers (6), the dry ice and acetone traps (7) and the purifier tube (8).

The stripped, noncondensable gases then pass through the main sampling pumps (9), the main sampling rate control valve (10) and a dry-gas test meter (11) into the $6.4-\mathrm{mm}$ ID (1/4-inch) exhaust tube to the exhaust (12). The main flow control valve (10) is adjusted so that a total of approximately 600 liters of noncondensable gas will be passed through the system during the test, e. g., 10 liters per minute for one hour or five liters per minute for two hours. This volume of noncondensable gas was chosen to provide sufficient condensates in the ambient module and the ice-trap module for laboratory analysis.

An integrated noncondensable gas sample is drawn from a tee in the exhaust line through the integrated-sample pump (13), a rate-control valve (14) and wet-test meter (15) into a 96-liter plastic collection bag. This gas flow rate is adjusted to collect a total of approximately 60 liters during the sample period. As the sample is collected at a constant rate during the entire test, its composition is representative of the average gas composition. The wet-test meter is filled with dilute acetic acid rather than water to prevent absorption of carbon dioxide.

A second tee in the exhaust line is used for instantaneous (grab) samples. Noncondensable gas is drawn through the grab sampling pump 
(16), a rate control valve (17) and a gas collection tube (18). Grab samples are taken at regular intervals to indicate any fluctuations in the noncondensable gas composition during normal operation, or at any time unusual behavior in the pilot plant is suspected.

At the end of the test the weights of the condensates are determined, and the noncondensable gas sample volumes are recorded. The condensates and noncondensable gas samples are transported to the laboratory for analysis. 
(9)

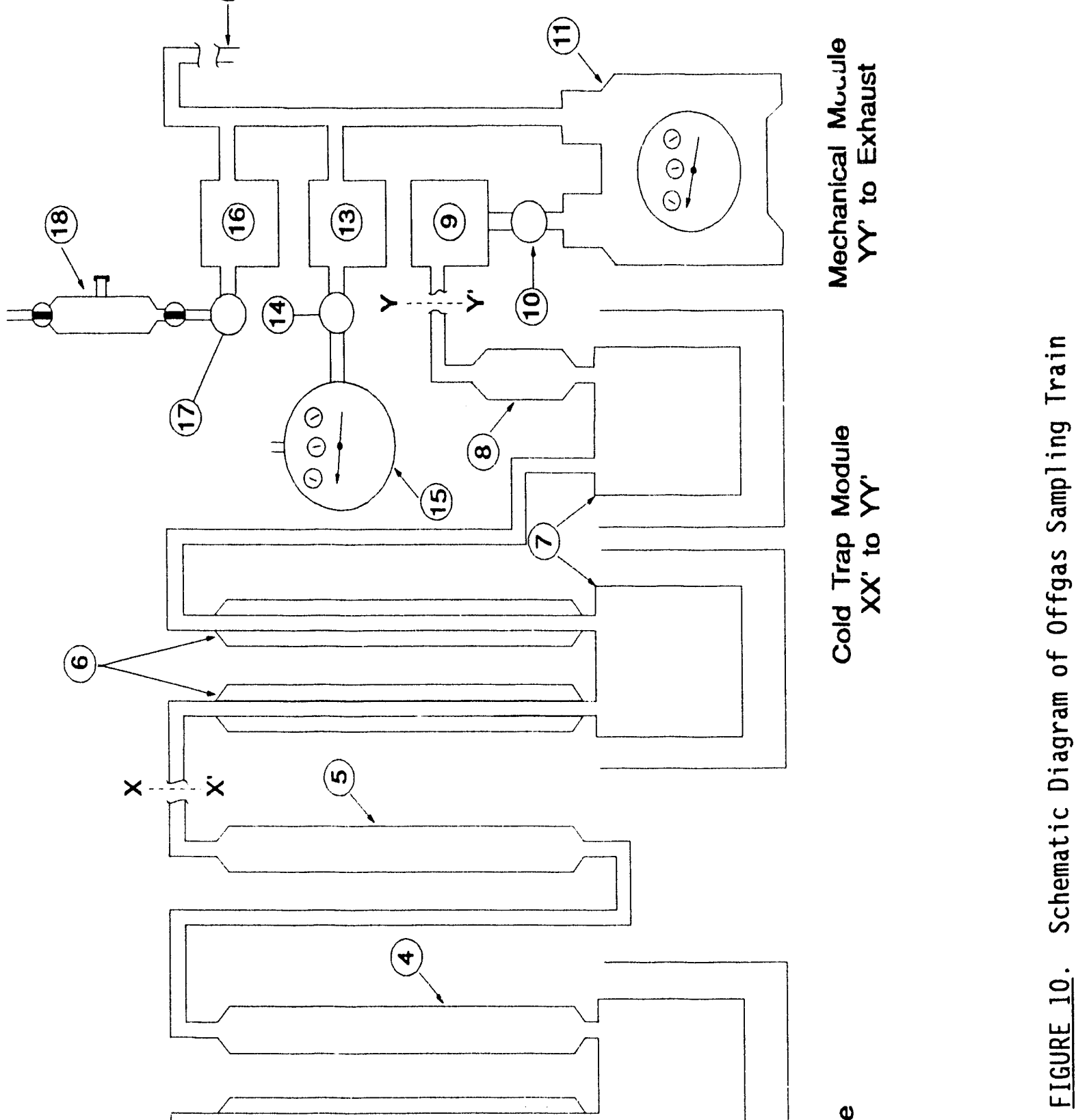

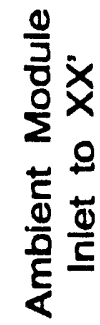




\subsection{TASK 2B. EXPERIMENTAL PYROLYSIS PROGRAM \\ PYROLYSIS PDU CONFIGURATION I}

\subsection{INTRODUCTION}

An interim technical report ${ }^{2}$ was submitted on November 30,1983 , which covered preliminary runs one through twelve that were made with the entrained-flow pyrolysis development unit (PDU) from March 21, 1983 through September 23, 1983 (see Section 4). The PDU operated satisfactorily overal1, and some minor modifications were made. The results of Run No. 8 were especially encouraging as an oil yield of 40.6 percent was obtained. From October 11, 1983 through March 26, 1984, a total of 11 pyrolysis experiments (Run No. 13 through Run No. 23) were made with the PDU, and the results are presented in this report.

\subsection{PYROLYSIS EXPERIMENTS - CONFIGURATION I}

The objective of these screening runs was to conduct pyrolysis experiments in the temperature range of $400{ }^{\circ} \mathrm{C}$ to $550{ }^{\circ} \mathrm{C}$ to determine the effect of temperature on the oil yield. For Runs 13 through 19, a nominal feed rate of $60 \mathrm{lb} / \mathrm{hr}$ was selected, and for Runs 20 through 23, higher feed rates were used. For Runs 13 through 18, and Runs 20 and 21, a $40 \times 50$ mesh size feed (Sweco screener) was used, and for Runs 19, 22, and 23, a $50 \times 60$ mesh size feed was used. The temperature, which was used as a reference temperature for the pyrolysis reactor in conducting these tests, was measured with a K-type thermocouple located at the entrance to the reactor. The PDU operating data are presented in Table 13. The percent mass oil and char yields are presented in Table 14. For these runs, the best oil yields were obtained at $475^{\circ} \mathrm{C}$ (reference temperature) and ranged from 41.8 percent to 51.3 percent on a moisture-ash-free feed basis.

\subsection{MASS AND ENERGY BALANCES}

The operating procedures for the PDU and data acquisition were discussed in the interim report (November $30,-1983)^{2}$ and in the report presented at the Sixteenth Biomass Thermochemical Conversion Contractors' Meeting ${ }^{3}$. The chemical analyses and the methods used concerning the mass and energy balance 


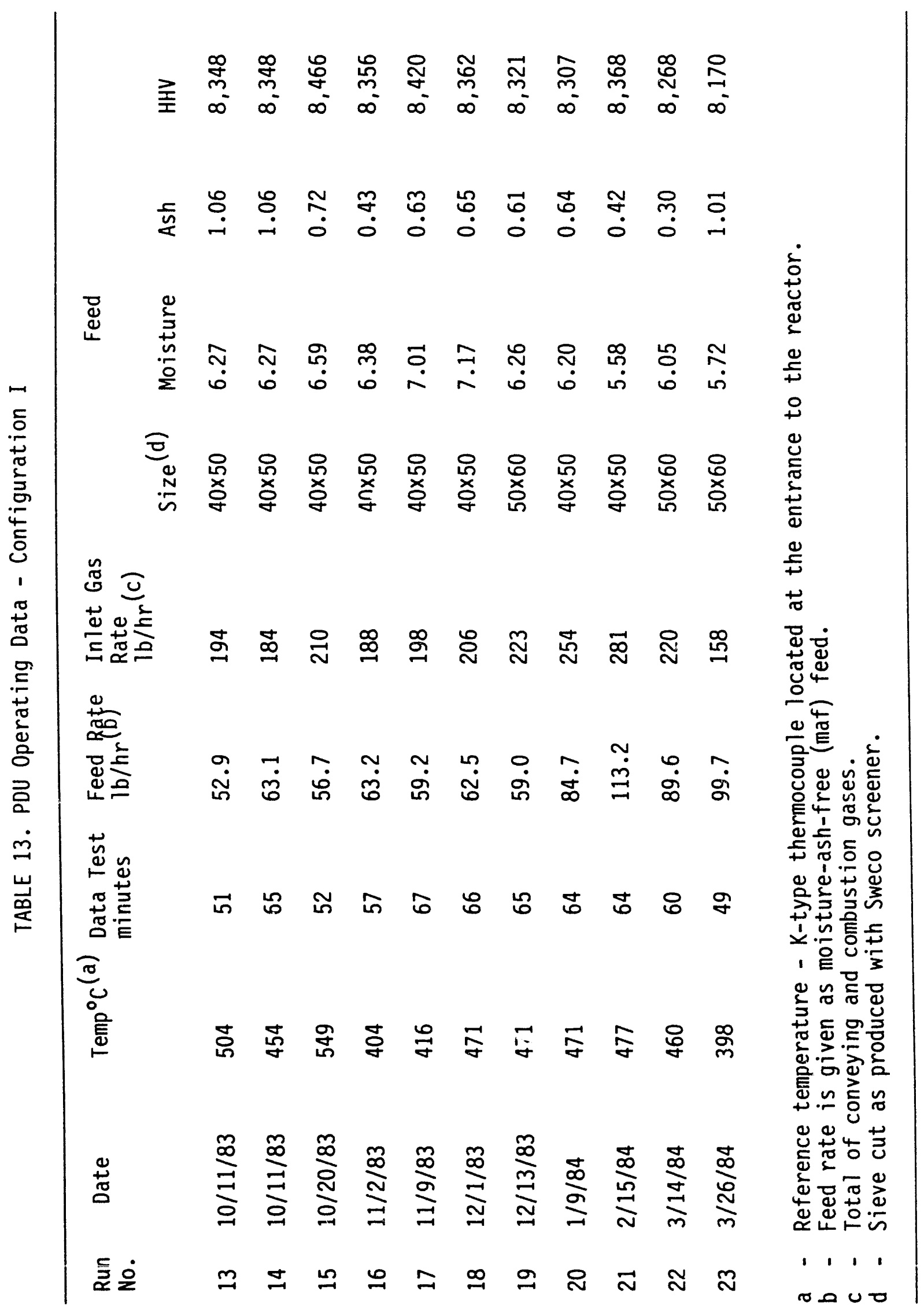


TABLE 14. Percent $0 i 1$ and Char Yield Data Configuration I

\begin{tabular}{cccc}
\hline Run No. & Temp ${ }^{\circ} \mathrm{C}(\mathrm{a})$ & $\begin{array}{c}\% \text { Oil Yield } \\
\text { (dry basis) }\end{array}$ & $\begin{array}{c}\% \text { Char Yield } \\
\text { (dry basis) }\end{array}$ \\
\hline 13 & 504 & 35.2 & 7.8 \\
14 & 454 & 41.8 & 13.1 \\
15 & 549 & 31.0 & 6.1 \\
16 & 404 & 33.7 & 20.0 \\
17 & 416 & 40.1 & 19.8 \\
18 & 471 & 49.4 & 12.0 \\
19 & 471 & 46.0 & 12.9 \\
20 & 471 & 51.3 & 10.7 \\
21 & 477 & 47.7 & 9.0 \\
22 & 460 & 46.0 & 16.5 \\
23 & 398 & 41.8 & \\
\hline
\end{tabular}


calculations were also described in those reports. The results of the mass balance calculations are presented in Table 15. The char and liquid products (condensates) were weighted and are reported as produced. The data obtained from continuous sampling of the offgas stream vas used to calculate the mass flow of the offgas stream by a nitrogen balance. The energy inputs and outputs are presented in Table 16 and energy balances, in Table 17.

The total oil yield, based on maf feed, represents on a dry basis the oil in the liquid condensates from the condenser and the demister, the tarry deposits that accumulated in the first section of the condenser during the run, and the oily material in the offgas stream downstream of the demister. During each run, the offgas stream was sampled continuously during the data test run period, and the sample was passed through a condensation train in which the condensable material was recovered. This condensed material was analyzed for organic content, and the total amount in the offgas stream was calculated using a nitrogen balance. It vas anticipated that a second demister in the modified PDU would remove the major fraction of this oily component. The tarry deposits were recovered from the condenser after each rai and verde included in the total oil yield. These deposits were thought to be the higher molecular weight organic components which condense in the first section of the condenser and are viscous at the condenser temperature, and therefore, do not flow freely into the sumps.

The total ash in the condenser deposits from Run 19 varied from $0.08 \%$ to $0.58 \%$, which indicates that the deposits contain very little char, as the ash in the char for Run 19 was $6.2 \%$.

The percent oil yield data is presented in Table 18. The percent water and higher heating value (dry basis) of composite liquid samples from the condenser and demister are given in Table 19. The percent energy yield, based on the energy in the feed, for liquids from the condenser and demister, condenser deposits and condensation train are reported in Table 20. Composite samples of the char from each run were analyzed for total ash, volatiles, moisture, and higher heating value, and these data are presented in Table 21. The char from each run was a free-flowing, powdery material.

During each data test run, a sample of the offgas stream was taken continuously at the demister outlet and passed through a condensation train for recovery of the condensable material. Gas samples verude taken 
periodically for analysis by gas chromatography (GC). An integrated sample of the exit streami from the condensation train was collected and analyzed by GC. The analytical results for Run No. 22, a typical run, are presented in Table 22.

\subsection{PRELIMINARY REACTOR MODELING - CONFIGURATION I}

A pyrolysis kinetic model was developed which can be used for the prediction of pyrolysis oil yields for oak in an entrained-flow reactor, and the data from the preliminary experiments, Run 13 through Run 23, were used in the modeling efforts. A more detailed discussion of the preliminary pyrolysis modeling effort is given in Appendix $F$. The maximum oil yield obtained experimentally was 51 percent, whereas, the model predicted a maximum oil yield of 61 percent in the temperature range for which data were available. Although the model used was highly idealized, the results were useful in the planning of future experiments. The results from this modeling effort served as a starting point for a more sophisticated model. The results of the preliminary modeling effort were presented at the Sixth Symposium on Biotechnology for Fuels and Chemicals, Gatlinburg, Tennessee, May 15-18, 1984. 


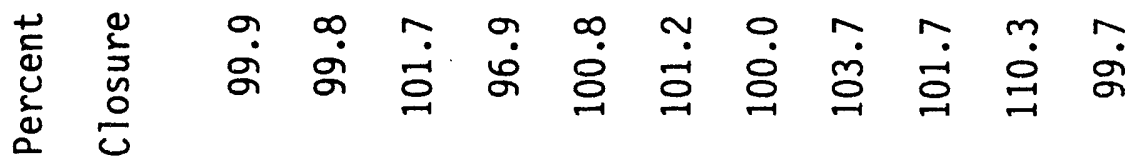

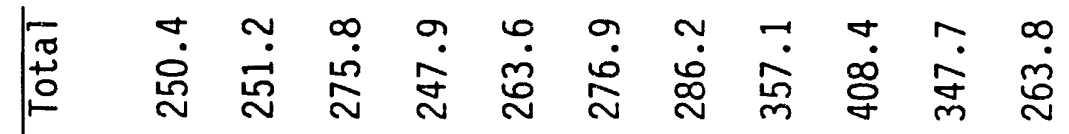

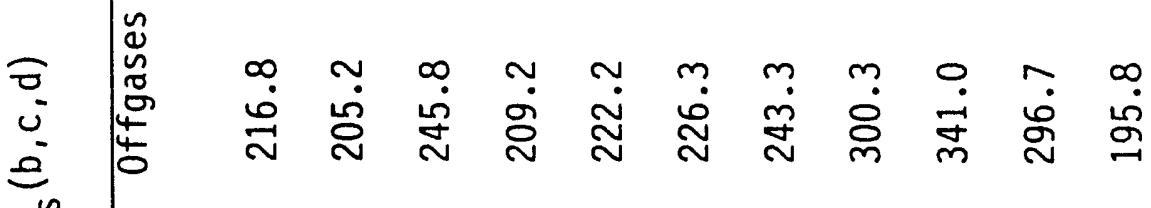

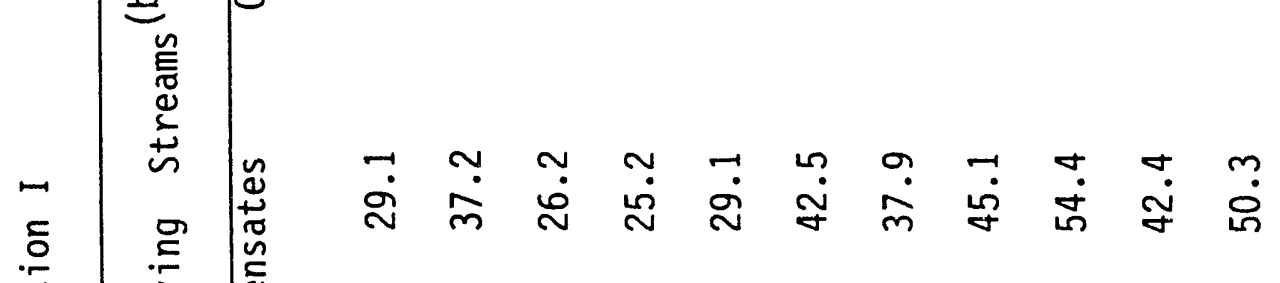

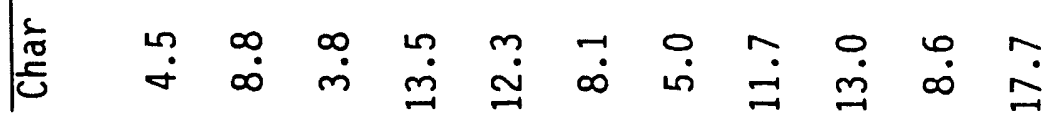

䓠

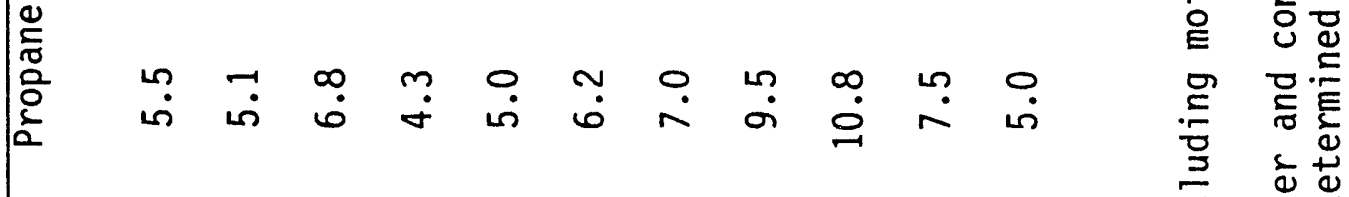

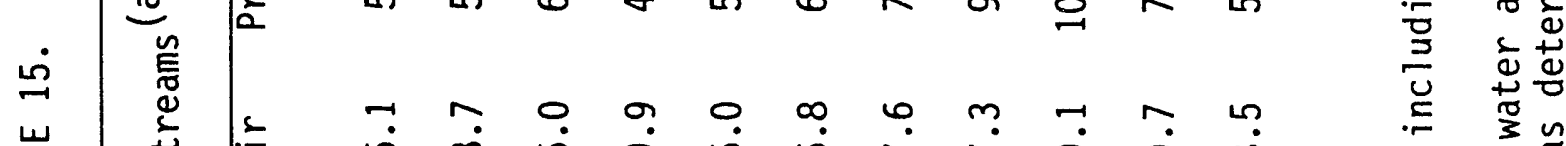

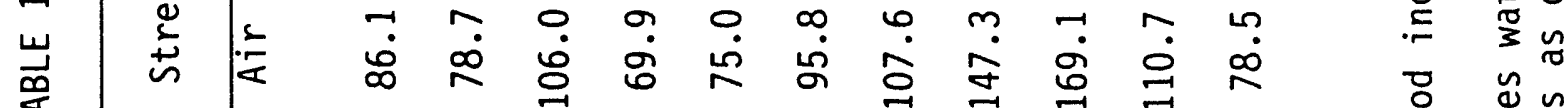
昰 品 旁 خ

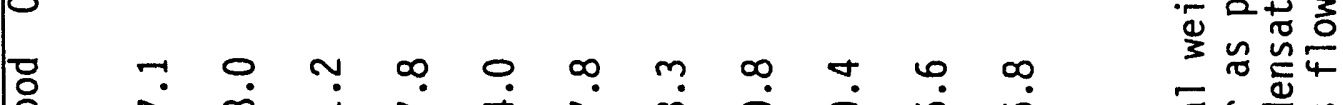

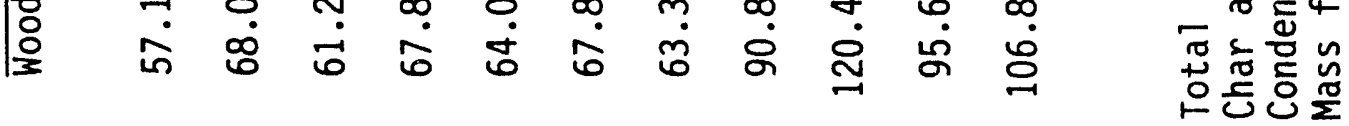

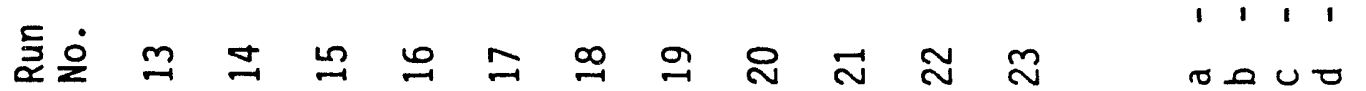


TABLE 16. Energy Inputs and Outputs - Btu/hr

Entering Streams - Configuration I

\begin{tabular}{|c|c|c|c|c|c|}
\hline Run & No. & Wood & $\begin{array}{c}\text { Conveyjug } \\
\text { Gas }\end{array}$ & Propane & Total \\
\hline 13 & & 441,800 & 16,800 & 118,800 & 577,400 \\
\hline 14 & & 526,700 & 2,900 & 110,400 & 640,000 \\
\hline 15 & & 480,100 & 0 & 147,500 & 627,600 \\
\hline 16 & & 528,000 & 0 & 92,800 & 620,800 \\
\hline 17 & & 498,200 & 0 & 107,400 & 605,600 \\
\hline 18 & & 523,100 & 0 & 133,900 & 657,000 \\
\hline 19 & & 490,900 & 0 & 151,500 & 642,400 \\
\hline 20 & & 703,300 & 29,200 & 205,200 & 934,700 \\
\hline 21 & & 947,100 & 1,100 & 234,300 & $1,182,500$ \\
\hline 22 & & 741,700 & 0 & 162,800 & 904,500 \\
\hline 23 & & 813,800 & 2,400 & 108,700 & 924,900 \\
\hline \multicolumn{6}{|c|}{$\begin{array}{l}\text { a - Conveying gas in some runs contained small amounts of carbon } \\
\text { monoxide and hydrogen. }\end{array}$} \\
\hline
\end{tabular}


TABLE 16. Energy Inputs and Outputs - Btu/hr (cont.) Leaving Streams - Configuration I

\begin{tabular}{crccc}
\hline Run No. & Char & 0il & Gases & Total \\
\hline 13 & 50,600 & 208,700 & 153,300 & 412,600 \\
14 & 96,200 & 246,800 & 121,900 & 464,900 \\
15 & 43,700 & 188,400 & 235,500 & 467,600 \\
16 & 150,300 & 227,600 & 111,800 & 489,700 \\
17 & 124,800 & 245,300 & 124,600 & 494,700 \\
18 & 87,200 & 294,700 & 159,100 & 541,000 \\
19 & 51,400 & 254,900 & 194,900 & 501,200 \\
20 & 122,500 & 442,600 & 294,500 & 859,600 \\
21 & 144,000 & 522,400 & 297,400 & 963,800 \\
22 & 93,200 & 403,200 & 265,200 & 761,600 \\
23 & 185,200 & 399,300 & 198,400 & 782,900 \\
\hline
\end{tabular}


TABLE 16. Energy Inputs and Outputs - Btu/hr (cont.) Heat Losses - Configuration I

\begin{tabular}{lccccc}
\hline Run No. & $\begin{array}{c}\text { Hot Gas } \\
\text { Generator }\end{array}$ & System & $\begin{array}{c}\text { Condenser } \\
\text { Cooling Air }\end{array}$ & $\begin{array}{c}\text { Net } \\
\text { Sensible } \\
\text { Heat }\end{array}$ & Total \\
\hline 13 & 26,100 & 25,100 & 36,400 & 4,300 & 91,900 \\
14 & 24,000 & 22,700 & 33,100 & 4,800 & 84,600 \\
15 & 27,200 & 26,500 & 39,600 & 4,700 & 98,000 \\
16 & 21,100 & 21,900 & 33,200 & 4,400 & 80,600 \\
17 & 22,100 & 22,000 & 28,700 & 5,000 & 77,800 \\
18 & 25,100 & 41,600 & 71,300 & 6,700 & 144,700 \\
19 & 25,300 & 42,300 & 37,900 & 6,900 & 112,400 \\
20 & 19,000 & 46,200 & 116,600 & 9,400 & 191,200 \\
21 & 24,900 & 46,500 & 64,100 & 12,800 & 148,300 \\
22 & 24,500 & 46,300 & 49,700 & 9,500 & 130,000 \\
23 & 20,200 & 48,800 & 48,700 & 10,600 & 128,300 \\
\hline
\end{tabular}




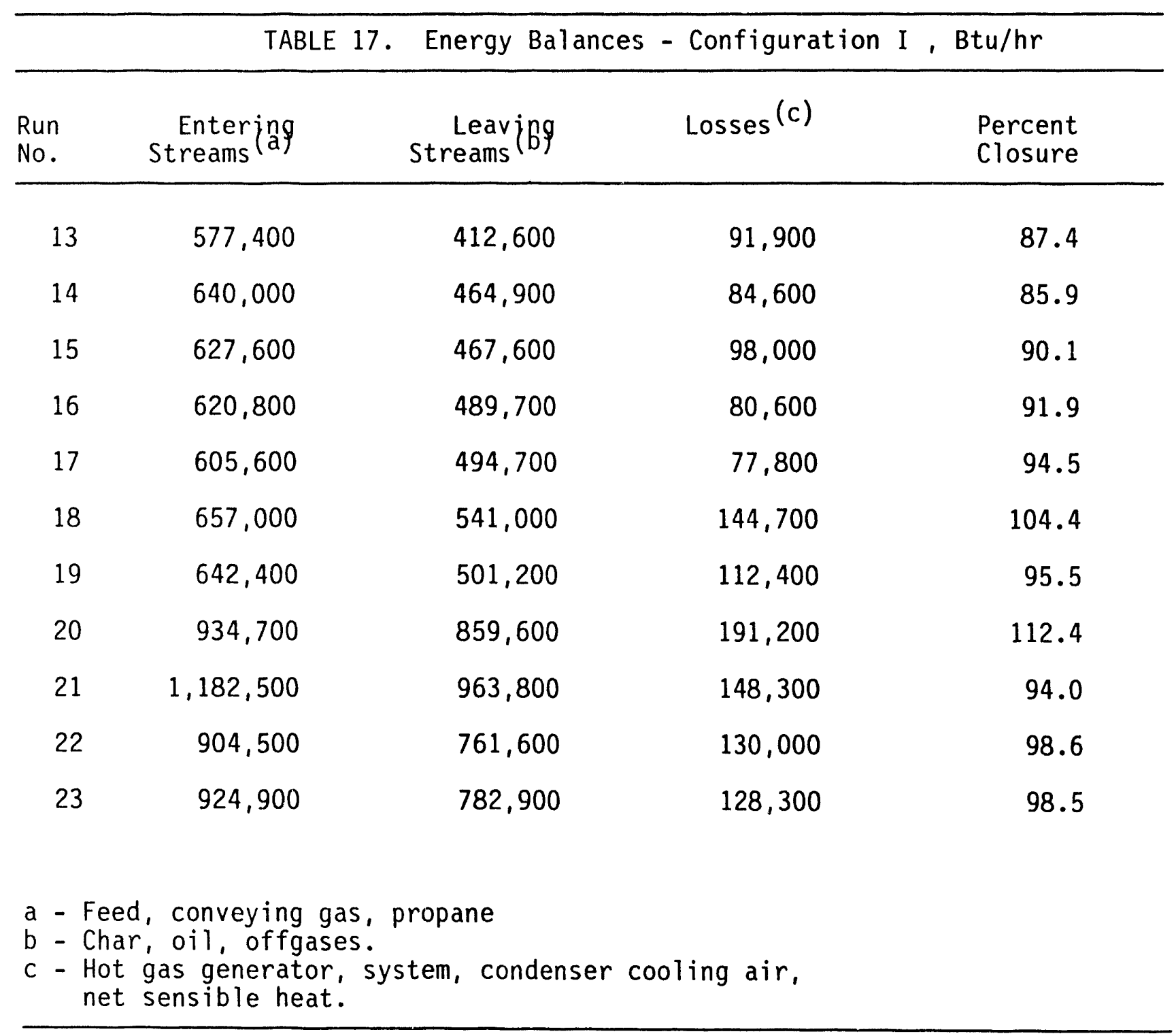


TABLE 18. Percent 0il Yield Data(a) - Configuration I

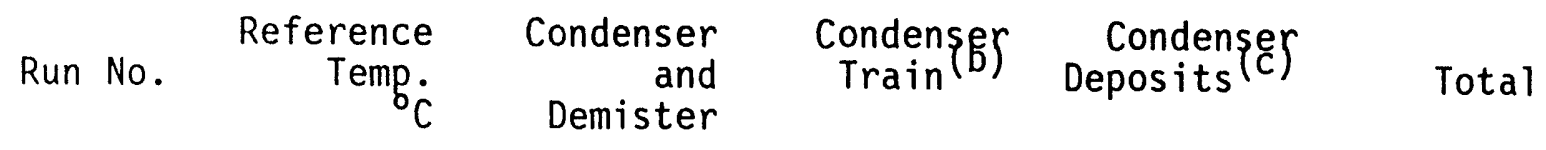

$\begin{array}{llllll}13 & 504 & 24.4 & 6.2 & 4.5 & 35.2 \\ 14 & 454 & 33.4 & 4.6 & 3.8 & 41.8 \\ 15 & 549 & 18.8 & 7.8 & 4.3 & 31.0 \\ 16 & 404 & 20.0 & 5.0 & 8.7 & 33.7 \\ 17 & 416 & 29.1 & 6.3 & 4.7 & 40.1 \\ 18 & 471 & 35.8 & 6.6 & 7.0 & 49.4 \\ 19 & 471 & 36.7 & 5.9 & 3.4 & 46.0 \\ 20 & 471 & 39.3 & 8.7 & 3.3 & 51.3 \\ 21 & 477 & 36.7 & 8.3 & 2.7 & 47.7 \\ 22 & 460 & 30.2 & 8.0 & 7.7 & 46.0 \\ 23 & 398 & 28.0 & 4.2 & 9.6 & 41.8\end{array}$

a - Calculated on dry basis of oit from maf feed.

b - Based on recovery of the oil condensate recovered from a representative sample taken continuously in a condensation train downstream of the demister cyclone.

c - Tarry deposits recovered from the condenser after each test run. 
TABLE 19. Composite 0il Data - Configuration I

\begin{tabular}{|c|c|c|c|c|}
\hline $\begin{array}{l}\text { Run } \\
\text { No. }\end{array}$ & $\%$ Water $(a)$ & $\begin{array}{l}\text { Condenser } \\
\quad \text { HHV-Btu/1b }\end{array}$ & $\%$ Water & $\begin{array}{l}\text { Demister } \\
\qquad \text { HHV-Btu/1b }\end{array}$ \\
\hline 13 & 58.6 & 10,330 & 40.2 & 11,406 \\
\hline 14 & 41.0 & 8,298 & 34.0 & 9,702 \\
\hline 15 & 58.3 & 8,494 & 47.3 & 10,683 \\
\hline 16 & 36.4 & 7,608 & 27.0 & 9,575 \\
\hline 17 & 44.7 & 8,181 & 25.7 & 9,668 \\
\hline 18 & 45.2 & 7,900 & 30.3 & 9,940 \\
\hline 19 & 45.7 & 8,216 & 25.8 & 8,916 \\
\hline 20 & 22.8 & 8,633 & 22.2 & 9,597 \\
\hline 21 & 24.7 & 9,183 & 17.9 & 9,532 \\
\hline 22 & 24.0 & 8,405 & 23.2 & 9,897 \\
\hline 23 & 32.6 & 8,657 & 30.4 & 9,701 \\
\hline \multicolumn{5}{|c|}{$\begin{array}{l}\text { a - Determined by Karl Fischer method } \\
\text { b - Dry Basis }\end{array}$} \\
\hline
\end{tabular}


TABLE 20. Percent 0 il Energy Yields - Configuration I

\begin{tabular}{lccccc}
\hline $\begin{array}{l}\text { Run } \\
\text { No. }\end{array}$ & Condenser & Demister & $\begin{array}{c}\text { Condensation } \\
\text { Train }\end{array}$ & $\begin{array}{c}\text { Condenser } \\
\text { Deposits }\end{array}$ & Total \\
\hline 13 & 12.7 & 19.4 & 9.3 & 5.8 & 47.2 \\
14 & 16.5 & 19.4 & 6.0 & 4.9 & 46.8 \\
15 & 9.4 & 11.9 & 12.3 & 5.7 & 39.3 \\
16 & 5.3 & 16.3 & 6.4 & 15.1 & 43.1 \\
17 & 10.5 & 20.9 & 8.0 & 5.6 & 45.0 \\
18 & 14.8 & 23.4 & 8.9 & 9.3 & 56.3 \\
19 & 16.6 & 21.2 & 7.3 & 6.8 & 51.9 \\
20 & 19.0 & 25.5 & 10.7 & 7.8 & 63.0 \\
21 & 20.5 & 21.2 & 10.2 & 3.3 & 55.2 \\
22 & 14.9 & 19.0 & 10.9 & 9.9 & 54.5 \\
23 & 20.4 & 10.5 & 5.8 & 12.3 & 49.0 \\
\hline
\end{tabular}




\begin{tabular}{lccccc}
\hline \multicolumn{1}{c}{ TABLE } & 21. & Char Data & Configuration & \\
\hline $\begin{array}{l}\text { Run } \\
\text { No. }\end{array}$ & $\begin{array}{c}\text { Percent } \\
\text { Yield(maf) }\end{array}$ & $\begin{array}{c}\text { HHV } \\
\text { (maf) }\end{array}$ & $\begin{array}{c}\text { Percent Ash } \\
\text { (dry basis) }\end{array}$ & $\begin{array}{c}\text { Percent } \\
\text { Volatiles } \\
\text { (dry basis) }\end{array}$ & $\begin{array}{c}\text { Percent } \\
\text { Moisture }\end{array}$ \\
\hline 13 & 7.8 & 12,236 & 6.75 & 30.5 & 1.75 \\
14 & 13.1 & 11,620 & 4.45 & 42.6 & 1.25 \\
15 & 6.1 & 12,677 & 9.25 & 26.9 & 0.14 \\
16 & 20.0 & 11,885 & 3.02 & 43.2 & 3.18 \\
17 & 19.8 & 10,624 & 3.49 & 54.6 & 1.09 \\
18 & 12.0 & 11,663 & 6.94 & 38.4 & 0.63 \\
19 & 7.9 & 11,075 & 6.22 & 39.0 & 1.05 \\
20 & 12.9 & 11,191 & 5.79 & 42.7 & 0.91 \\
21 & 10.7 & 11,908 & 5.88 & 36.8 & 0.78 \\
22 & 9.0 & 11,598 & 6.42 & 36.5 & 0.09 \\
23 & 16.5 & 11,294 & 5.06 & 37.1 & 2.17 \\
\hline & & & & & \\
\hline
\end{tabular}


TABLE 22. Typical Gas Analysis - Run No. 22

\begin{tabular}{|c|c|c|c|c|c|c|}
\hline \multirow[b]{2}{*}{$\begin{array}{c}\text { Gas } \\
\text { Component }\end{array}$} & \multicolumn{5}{|c|}{ Minutes Into Run } & \multirow[b]{2}{*}{$\begin{array}{r}\text { Integrated } \\
\text { Sample }\end{array}$} \\
\hline & 15 & 25 & 35 & 45 & 55 & \\
\hline Argon & 0.87 & 0.9 & 0.86 & 0.83 & 0.87 & 0.83 \\
\hline Oxygen & 1.43 & 0.1 & 0.01 & 0.32 & 0.26 & 0.94 \\
\hline Nitrogen & 69.87 & 71.99 & 69.54 & 66.73 & 69.87 & 66.92 \\
\hline $\begin{array}{l}\text { Carbon } \\
\text { Monoxide }\end{array}$ & 10.36 & 12.18 & 12.09 & 13.94 & 11.42 & 11.98 \\
\hline $\begin{array}{l}\text { Carbon } \\
\text { Dioxide }\end{array}$ & 9.67 & 11.39 & 11.06 & 10.64 & 11.12 & 10.59 \\
\hline Hydrogen & 3.23 & 4.21 & 4.5 & 5.16 & 4.25 & 3.98 \\
\hline Methane & 1.07 & 1.37 & 1.33 & 1.37 & 1.21 & 1.35 \\
\hline Ethane & 0.43 & 0.12 & 0.14 & 0.15 & 0.13 & 0.12 \\
\hline Ethylene & 0.99 & 0.57 & 0.58 & 0.75 & 0.52 & 0.57 \\
\hline Propane & 0.03 & 0.01 & 0.01 & 0.01 & 0.01 & 0.01 \\
\hline Propene & 0.27 & 0.06 & 0.07 & 0.08 & 0.06 & 0.07 \\
\hline Acetylene & $\underline{0.12}$ & $\underline{0.39}$ & $\underline{0.48}$ & $\underline{0.52}$ & $\underline{0.43}$ & $\underline{0.13}$ \\
\hline Totals & 98.34 & 103.29 & 100.4 & 100.5 & 100.15 & 97.79 \\
\hline
\end{tabular}




\section{REFERENCES}

1. J. A. Knight and C. W. Gorton, "Research on the Pyrolys is of Hardwood in an Entrained-Bed Process Development Unit", Interim Technical Report, submitted to Pacific Northwest Laboratories, November 30, 1983. Contract No. B-C5863-A-Q.

2. J. A. Knight, C. W. Gorton and R. J. Kovac, "Entrained-Flow Pyrolys is of Biomass", p. 287 In the Proceedings of the Sixteenth Biomass Thermochemical Conversion Contractors Meeting, Portland, Oregon. May 89, 1984. CONF-8405157/ PNL-SA-12403. AvailabTe from the National Technical Information Service, U.S. Department of Commerce, 5285 Port Royal Road, Springfield, VA 22161. 


\subsection{TASK 2C. MODIFICATION OF THE PDU}

\subsection{INTRODUCTION}

The entrained-flow pyrolysis PDU had been operational from March, 1983 to March, 1984. During that time more than 20 shakedown runs and pyrolysis experiments had been conducted. The results of those tests established that total yields of pyrolytic oil and tarry condensate (on a dry basis) of $50 \%$ could be achieved (based on moisture-ash-free wood). Based on operational experience and test results, a number of improvements for the PDU verde recommended. The design changes and modifications to implement these improvements are discussed below. The modifications were made to the entrained-flow pyrolysis unit during the period of April to November, 1984.

\subsection{PDU MODIFICATIONS}

In order to maximize the oil yield by the thermochemical conversion of biomass in the entrained-flow pyrolysis system, it is necessary to operate the reactor system so that the maximum yield of condensable organics are produced in the vapor phase in the reactor. This maximum yield of condensable organics must then exit the reactor without degradation or conversion to secondary products. The final step is to recover the maximum amount of the condensable organics in the condenser and demister units. The following modifications were made so that the maximization of the oil yield could be investigated. ... quench of the Gas and Vapor Stream from the Char Cyclone The gas and vapor stream entered the condenser at about $550{ }^{\circ} \mathrm{F}$. Tarry organics condensed in the inlet header and in the vertical tubes in the first section of the condenser and those organics were continuously exposed to temperatures of about $550^{\circ} \mathrm{F}$ or greater. A problem was experienced in operating the PDU in that tarry deposits collected in the inlet header and a constriction or partial plugging of the condenser tubes took place. This lead to a restriction of flow and an increase in the pressure drop required to mairitain steady conditions. In some cases, certain tubes were completely plugged, requiring the termination of the test. It was theorized that the pyrolysis oil and vapor undergo polymimerization and decomposition at temperatures of approximately $375^{\circ} \mathrm{F}$ 
and above, and that secondary products were formed which had higher viscosities. If so, some of the condensable oil and vapor could have been converted to other products (gas or char) resulting in a reduction in the final pyrolytic oil yield.

A water quench spray system was designed and installed so that the temperature of the gas and vapor stream could be quickly dropped to a preselected point less than $375^{\circ} \mathrm{F}$. The spray system was designed so that the liquid injection rate could be regulated and measured, and that intimate mixing of the liquid (water) spray and the gas and vapor stream occurred. Rapid cooling of the organic vapors and any condensate in the stream to a temperature $375^{\circ} \mathrm{F}$ was expected to reduce the polymerization and decomposition reactions, and would yield a less viscous product that would easily flow out of the condenser tubes into the sump. The cooling of this stream also reduced the temperature to which the condensate in the first condenser section was exposed to, and thereby greatly reduced the possibility of plugging of the condenser tubes.

\section{(2) Six-Inch Reactor}

The eight-inch (nominal diameter) reactor tube used in the Configuration I tests performed satisfactorily in the shakedown and preliminary pyrolysis experimental runs. The data from those tests indicated that the maximum throughput obtained was about $360 \mathrm{lb} / \mathrm{hr}^{\star} \mathrm{ft}^{2}$ while the largest feed size used for those tests vas a $40 \times 50$ mesh size (Sweco screener). In addition, a comparatively large amount of time was required to prepare a sufficient quantity of properly sized feed for an experiment. Those limitations represented disadvantages in investigating the entrained-flow pyrolys is process. The eight-inch (nom. dia.) reactor tube vas replaced with a six-inch (nom. dia.) reactor tube which would allow for a greater throughput (an increase by a factor of about 1.73 based on the cross-sectional area of the reactors) or higher gas velocities. The increased gas velocities made it possible to investigate the oil yields using much lower residence times, and allowed the possibility of investigating larger feed particles sizes, which are important factor for commercialization of the process. 
(3) Hot-Gas Burner

The hot-gas burner was previously located vertically in line with the feed mixing section and the reactor tube, and was mounted at the bottom of the assembly. This physical arrangement caused some operational difficulties. At times, in this position, some of the feed and partially pyrolyzed particies dropped down into the lower part of the burner section. Those hot particles continued to pyrolyze and generate smoke. The quartz window for the ultraviolet (UV) flame detector became cloudy causing attenuation of the signal received by the UV detector, in turn causing the burner to operate erratically or to shut down. At higher gas flow rates there was also the possibility that not all of the oxygen had been consumed in the burner combustion zone before the hot gases mixed with the incoming food, due to the proximity of the combustion zone to the feed inlet port.

The burner section was removed from the bottom of the reactor. A refractory-lined post-combustion chamber ( $4 \mathrm{ft} \times: \mathrm{ft} \times 3 \mathrm{ft}$ ) was fabricated and installed on the reactor and the "old" burner section was attached horizontally to one end of the postcombustion chamber. Combustion gases exited the burner and burner section, traveled horizontally across the length of the post-combustion chamber, and turned vertically upward, entering the vertical reactor assembly attached to the top of the postcombustion chamber. The post-combustion chamber was used to insure complete combustion of the air and propane before the hot gazes mixed with the entrained feed. The new arrangement eliminated the clouding problem associated with the UV detector quartz window since the detector was located away from any potential smoky conditions. An inspection and clean-out door was installed in the side of the post-combustion chamber to allow for easy removal of any ash, oversized feed and/or pyrolyzed particles that might drop down from the feed and mixing sections of the reactor.

\section{(4) Char Cyclone}

An additional char receiver and char knife gate valve vas added to the previous cyclone system to improve and facilitate the removal of char from the cyclone. With the additional char receiver and gate valve, char was collected in the lover receiver, and then removed by closing the 
upper gate valve and opening the lower gate valve to allow the char to drop into the char receiver. The lower gate valve was then closed and the upper gate valve opened, resuming normal operations. In the previous mode, pressure surges occurred at times when char was removed from the system. This change minimized the occurrence of pressure surges and helped maintain steady-state conditions in the PDU. In addition, the new arrangement eliminated the possibility of out-side oxygen entering the system during the cycling of the pressure surges. 0xygen which entered the system could react with the hot pyrolysis oil and vapors and cause a reduction in the oil yield.

Demister Cyclone

Based on the data from the condensation train and the mass and energy balances, the gas and vapor stream leaving the demister contained about five per cent of condensable organic material (by weight). Based on prior experience with pyrolysis offgas streams (in the PDU and other pyrolysis systems), and the fact that approximately $40 \%$ of the (dry) oil yield from the PDU was collected from the demister, most of the uncollected organic were expected to be in an aerosol state. In order to recover as much of the condensable organic product as possible, a second demister cyclone was designed and installed downstream of the current first demister. The second demister cyclone was designed to have the capability to remove smaller oil droplets that the previous cyclone (down to about one micron), thereby increasing the total recovery of pyrolysis oil.

\section{(6) Draft Fan}

In Configuration I, the PDU was operated without a draft fan. A variable speed draft fan was installed downstream of the second demister to increase the potential, maximum gas flow rate, and thus allow for an increased throughput or lower reactor residence time for the PDU system.

(7) Structural Support Addition to the PDU Tower

In order to complete the modifications to the PDU described above for the water quench system and the additional char receiver and gate valve, it was necessary to add additional support platforms to the west 
side of the PDU tower. The amount of space available was not sufficient to accommodate the modifications. The structural addition also allowed sufficient space for instrumentation, temporary storage of char product containers during a test, and space for personnel to safely move about and inspect the equipment and components of the PDU.

\section{(8) Minor PDU Modifications}

The installation of the six-inch reactor and the postcombustion chamber necessitated the installation of an additional feed mixing section. The new feed mixing section was fabricated with four additional feed inlet ports. These additional inlet ports provided another method of changing the reactor residence time (by changing the effective length of the reactor). The UV detector, a safety feature, in the hot-gas generator system was replaced with a flame rod, which is a more reliable detector for the PDU operation. A platform was fabricated and installed that raised the loss-in-weight feeder about five feet compared to the previous elevation. This increase in height reduced the pressure required to convey the feed to the inlet ports of the reactor.

The inert gas generator was also relocated closer to the PDU tower, next to the loss-in-weight feeder so that the inert gas discharge line was horizontally and vertically aligned with the loss-in-weight discharge chute. This rearrangement reduced the length of the pipe run and the number of fittings and therefore reduced the pressure drop of the system.

A natural gas burner was installed in the flare to assure complete combustion of the offgases entering the flare during start-up periods and test runs. After completion of the PDU modifications, the components of the PDU were insulated. These included the hot-gas burner, postcombustion chamber, feed-mixing section, pyrolysis reactor, char cyclone, quench vessel, condenser, demister cyclones, and connecting piping. Thermocouples were installed (or reinstalled) throughout the unit, including locations in the insulation, so that temperatures could be monitored adequately during operations. Nine pressure transducers verde used to monitor critical pressure measurements on a continuous basis. $U$-tube and inclined manometers and magnehelic gauges were installed and used to make other pressure measurements, which were recorded manually. 


\section{REFERENCES}

1. Knight, J.A. and C. W. Gorton, "Research on the Pyrolys is of Hardwood in an Entrained-Bed Process Development Unit", Interim Technical Report, submitted to Pacific Northwest Laboratories, November 30, 1983.

2. J. A. Knight, C. W. Gorton and R. J. Kovac, "Entrained-Flow Pyrolys is of Biomass", p. 287 In the Proceedings of the Sixteenth Biomass

Thermochemical Conversion Contractors Meeting, Portland, Oregon. May 89. 1984. CONF-8405157/ PNL-SA-12403. Available from the National

Technical Information Service, U.S. Department of Commerce, 5285 Port Royal Road, Springfield, VA 22161. 


\subsection{TASK 2D. PRELIMINARY EXPERIMENTS - PYROLYSIS PDU}

CONFIGURATION II

\subsection{INTRODUCTION}

The entrained-flow pyrolysis development unit (PDU), Configuration I, was completed in March, 1983. A series of 12 shakedown runs and preliminary tests were conducted, and the PDU operated satisfactorily. These tests were followed by a series of eleven pyrolysis experiments with hardwood oak feed, a reactor temperature range of $400{ }^{\circ} \mathrm{C}$ to $550{ }^{\circ} \mathrm{C}$, and feed rates of $53 \mathrm{lb} / \mathrm{hr}$ to $113 \mathrm{lb} / \mathrm{hr}$, based on moisture-ash-free feed. These results have been reported in detail, and are presented in Sections 4 and 5 . The results of the screening runs demonstrated that dry oil yields of up to $51 \%$ based on moisture-ash-free feed could be obtained. The highest oil yields for the operating conditions used were obtained at a reactor reference temperature of about $475{ }^{\circ} \mathrm{C}$. This temperature was measured at the entrance to the tubular reactor. Based on the experience gained in operating the PDU and the results of the previous experiments and initial modeling efforts, it was evident that some modifications of the PDU were needed so that the optimization of the oil yield could be thoroughly investigated. These modifications were made during the period of Apri1, 1984 to November, 1984. In December, 1984, cold flow and hot flow tests without feed were made. Those tests were followed with preliminary experiments using a mixed oak feed. The results of the preliminary experiments are described in the following section.

\subsection{PYROLYSIS RESEARCH UNIT (PRU) CONFIGURATION II - SYSTEM DESCRIPTION}

After the previously described series of major modifications was made to the entrained-flow pyrolysis system, it was referred to as the entrained-flow process research unit (PRU). A flow diagram of Configuration II, of the process research unit (PRU), is given in Figure 11, Flow Diagram of Process Research Unit Configuration II, and its operation is described in the following text.

Propane gas (1) and air (2) are burned stoichiometrically in an inert gas generator, and the combustion products are cooled with a water spray (3) so that the gases leave saturated with water vapor. The exit stream from the 


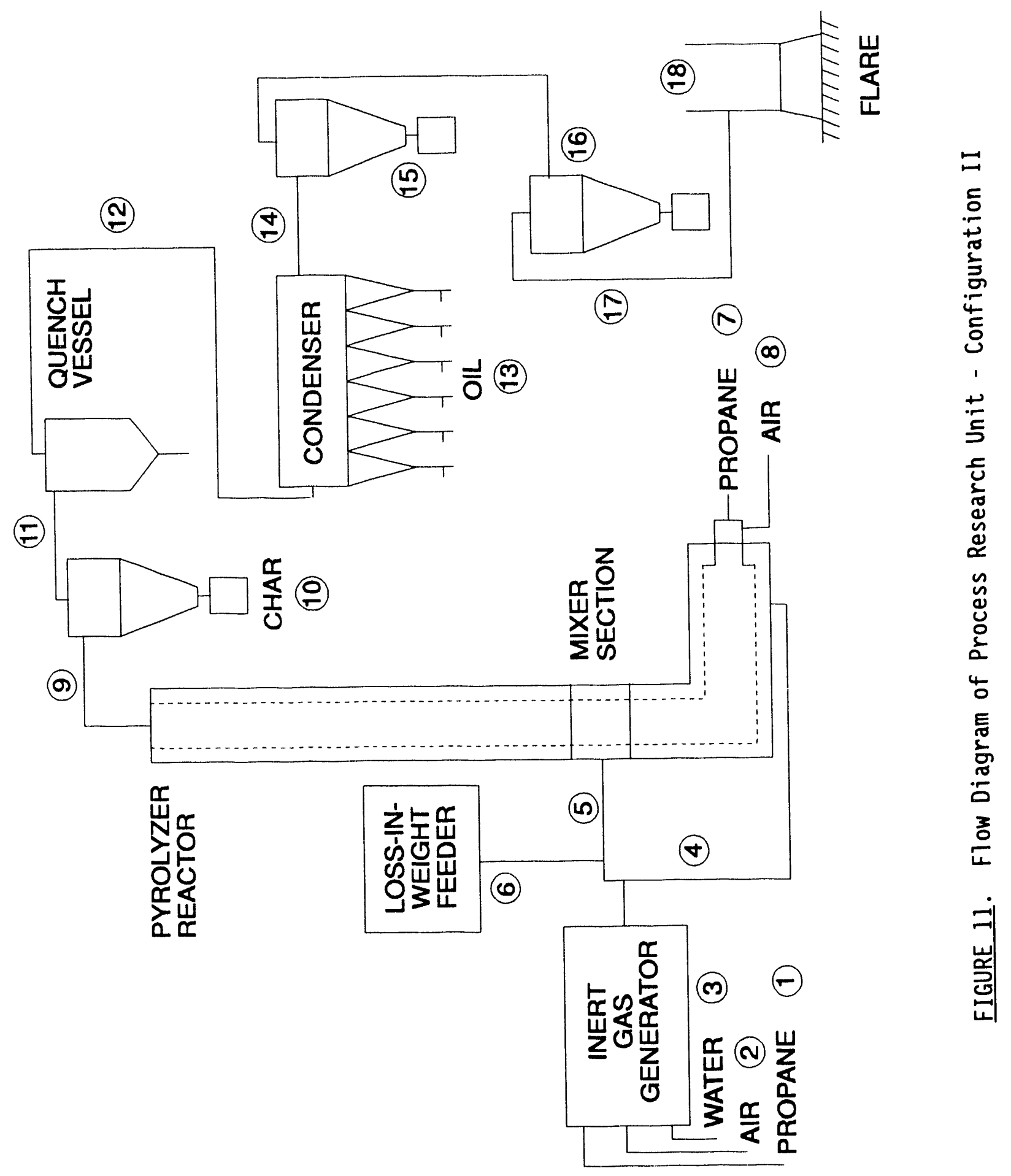


inert gas generator is split into two streams. One of these (4) provides moderating gas for the burner and the other (5) provides conveying gas for the feed particles (6). Propane (7) also fuels the burner which operates stoichiometrically with air (8) supplied by a blower. The mixture consisting of moderating gas, conveying gas, burner combustion products, and wood particles moves vertically upwards through the reactor tube in which the pyrolysis takes place; the resulting mixture (9) consists of noncondensable gases, water vapor (entering moisture plus combustion and pyrolysis products), pyrolysis oil vapors and char. In the cyclone, almost all of the char particles (10) are removed, and the stream (11) leaving the cyclone consists of noncondensable gases, water vapor, pyrolysis oil vapor, and some char fines. This mixture enters the quench vessel into which a liquid (e.g. water) is sprayed so that the mixture can be quenched rapidly. The mixture (12) then enters the condenser, and the pyrolysis vapors (and some water vapor) are condensed in the air-cooled condenser. The condensed phases (13) are removed via sumps and collection receivers, and the existing mixture (14) consisting of noncondensable gases, water vapor, light oil vapors, and an aerosol of oil passes through two demisters connected in series (15) and (16). Most of the aerosol is removed in the demisters. The resulting mixture (17) consisting mainly of noncondensable gases, water vapor, and remaining aerosol, enters the flare where air is introduced. The mixture is burned, and the products of combustion (18) are exhausted to the atmosphere. The revised operating procedures for the PRU Configuration II are discussed later in this section and the data sheets are shown in Appendix E. The Quality Assurance System is discussed in Appendix $C$.

\subsection{PRU OPERATION}

(1) Operation Without Feed

A series of cold flow tests were made on the modified PRU to test for leaks and to check pressure and temperature measurements. Smoke bombs were used for the leak tests. The necessary measures needed to eliminate leaks and correct any malfunctioning pressure and temperature measuring equipment were taken. Additional cold flow tests were then made, and the PRU operated satisfactorily. A series of hot flow tests 
without feed were conducted to obtain data required for heat loss calculations.

\section{(2) Operation With Feed}

Nine experimental runs were conducted with oak hardwood feed to obtain data on the operation of the modified PRU, (Configuration II). Each of the first seven runs was divided into two test periods. Tests eight and nine were each treated as single tests and each was conducted for a four hour period. A summary of these runs is given later in this section.

A summary of the experimental procedure and data acquisition for these runs is given below. A detailed operating procedure for Configuration II is given at the end of this section. On the day prior to a scheduled run, the components and instrumentation of the PRU were checked to determine proper operation. This included the hot-gas burner, loss-in-weight feeder and inert gas generator. The PRU was operated without feed for a check of the pressure and temperature measuring instrumentation. All gas sampling probes and equipment were made ready for use. Product containers were tared and labeled. Feed required for the run was weighed and placed in closed barrels.

On the day of the run, the PRU was started without feed, and the temperatures in the reactor were brought up to the selected values and allowed to reach steady-state conditions. Gas samples were taken of the combustion gas, the propane fuel, and the inert gas for gas chromatographic analysis. At this point, feed was added, starting at a relatively low feed rate, to the conveying gas stream. The feed rate was gradually increased to the selected feed rate over a period of 30 to 50 minutes. Adjustments were made to the hot-gas burner so as to control and maintain the reactor temperatures. It was also nece:sary, on occasion, to make fine adjustments in the hot-gas burner system to attain the desired, steady, operating conditions. When the PRU reached steady-state, the data test run was started. Data taken during the test run period included temperature and pressure measurements with strip chart recorders, additional pressure measurements with U-tube manometers and magnehelic gauges, and the feed rate using the loss-in-weight feeder. 
During the test run period, char was removed every six to ten minutes and pyrolytic oil was removed from the condenser sumps and demister receivers as needed.

At the start of the data test run, the gas and vapor stream downstream of the demister was sampled continuously. The sample was passed through a condensation train in which all condensable material was collected, and grab samples were taken about every five to ten minutes from the dried gas stream that left the sampling train. Those samples were analyzed after the test by gas chromatography to determine composition. The condensates were analyzed to determine the water and oil content of the offgas stream. The char and oil products were weighed.

Following the run, all of the data taken during the run was collected and organized for data analysis. Representative samples of the char and oil products were taken for chemical analysis. The condenser was checked, and any deposits were recovered and sampled for analysis. The chemical analyses that were performed on the feed, input gas streams, products and offgas streams are listed in Table 23, Chemical Analys is PRU Configuration II. The chemical and gas analyses are discussed in Appendix G, and the offgas sampling system is described in Section 4.6.

\subsection{QUALITY ASSURANCE SYSTEM - CONFIGURATION II}

The quality assurance system consisted of the calibration and performance checks of instruments and equipment, data collection, and recording of experimental data test results in a permanent traceable manner. The manner in which these tasks were accomplished on this program for the PRU Configuration I is given in Appendix C - Quality Assurance System. The quality assurance program for the PRU Configuration II followed the articles described in Appendix $C$, for the most part. The exceptions are described below.

(1) Performance Checks and Calibration

(a) PRU Components

i) Loss-in-Weight Feeder

The loss-in-weight feeder is a K-Tron Model T35 twin screw volumetric feeder with a maximum capacity of 200 


\section{TABLE 23. Chemical Analysis - PRU Configuration II}

\begin{tabular}{ll}
\hline Material/Stream & \multicolumn{1}{c}{ Analytical Determination } \\
Feed & Moisture, ash, higher heating value. \\
Inert Gas & Composition determined by gas chromatography. \\
Combustion Gas & Composition determined by gas chromatography. \\
Air & Composition determined by gas chromatography. \\
Propane & Composition determined by gas chromatography. \\
Char & $\begin{array}{l}\text { Moisture, volatiles, ash, } \\
\text { higher heating value. }\end{array}$ \\
0il & $\begin{array}{l}\text { Water (Karl-Fischer technique), } \\
\text { higher heating value. }\end{array}$ \\
Condenser Deposit & $\begin{array}{l}\text { Moisture, higher heating value. } \\
\text { Offgas }\end{array}$ \\
Composition determined by gas chromatography \\
and data from condensation train. Higher \\
heating value calculated from composition.
\end{tabular}


lbs/hr. This unit was checked by filling the feed hopper with wood particles of a specific size, e.g. $40 \times 50$, and operating at outputs of about 10 to $60 \mathrm{lbs} / \mathrm{hr}$. The output rates were verified by collecting a series of timed samples, which were weighed.

(b) Chemical-Analytical Instrumentation

(i) Integrators

The integrators used on this project were

Hewlett-Packard 3390A integrators and Perkin Elmer Laboratory Computing Integrator, LCI 100 Reporting Integrators. Calibration was accomplished by observing the integrator response to repeated injections of Matheson certified calibration gas mixtures in the gas chromatographs to which they were attached. Concentrations of the gases in the calibration mixtures were specified to resemble those in the gas stream which were analyzed. The calibration procedure was performed before each set of analyses and repeated throughout the analyses to check for detector drift. The HP 3390A identified peaks by Retention Time and reported concentration of unknowns after injection of calibration gas mixtures to determine response factors. The External Standard subroutine was used for this calculation. The LCI 100 was calibrated in a similar fashion with the major difference being the peak identification. The LCI 100 has alpha capability so that compounds could be given a name of up to 16 characters.

\subsection{PYROLYSIS EXPERIMENTS - CONFIGURATION 11}

The PRU operating data for these nine runs (16 test periods) are presented in Table 24, and the percent yield of oil and char, in Table 25. Data on the percent oil yield obtained at each collection point of the pou are given in Table 26. The oil yield given is determined on a dry basis of the organic material in the cunutensate, ariu is based on maf feed input. The percent water and the higher heating value of representative samples from the 


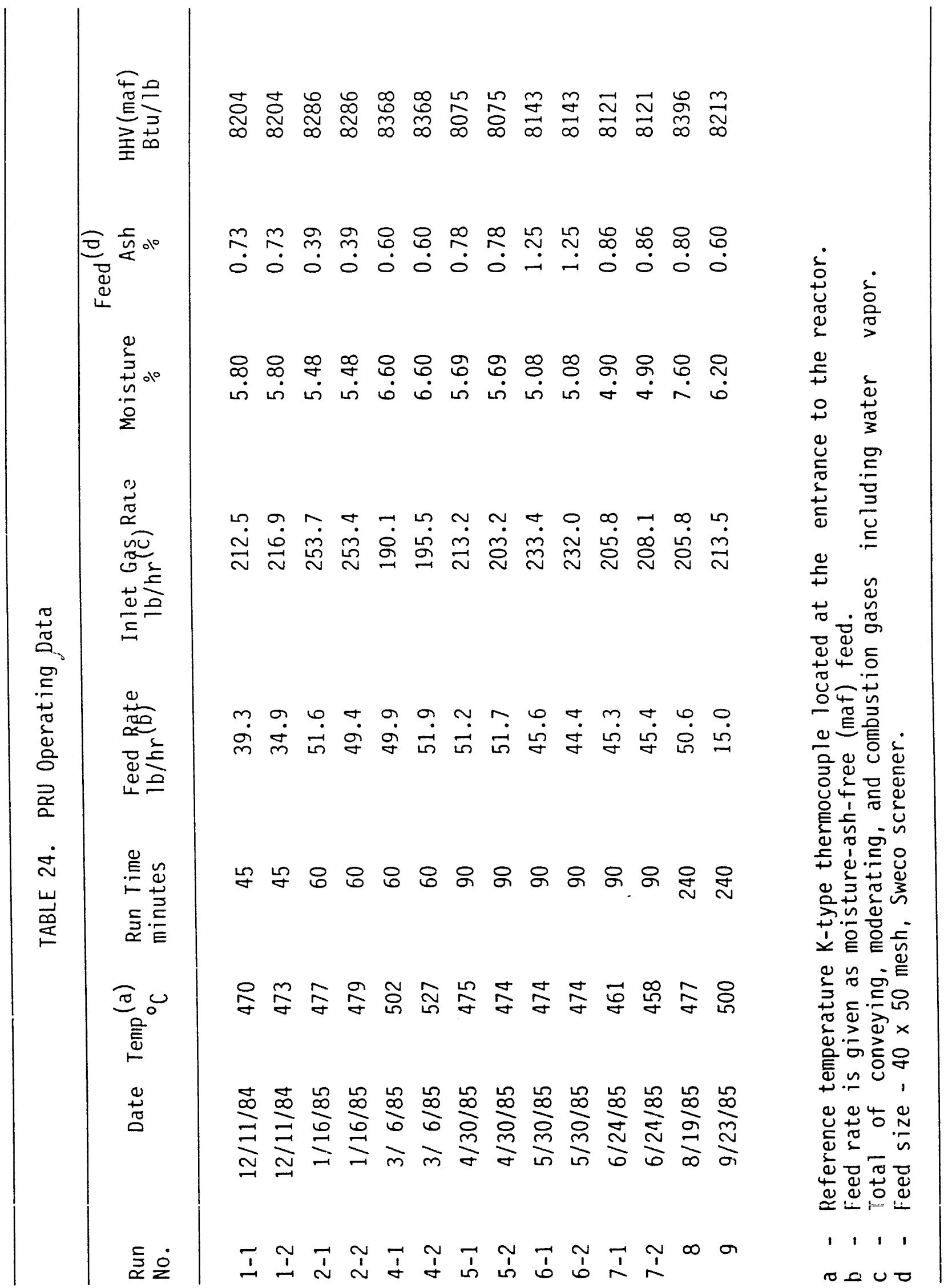


TABLE 25. Percent $0 i 1$ and Char Yield Data

\begin{tabular}{|c|c|}
\hline un No. & $\operatorname{Temp}_{\mathrm{C}}(\mathrm{a})$ \\
\hline
\end{tabular}

\begin{tabular}{|c|c|c|c|c|}
\hline & $1-1$ & 470 & 48.6 & 15.7 \\
\hline & $1-2$ & 473 & 44.0 & 17.6 \\
\hline & $2-1$ & 477 & 51.0 & 24.3 \\
\hline & $2-2$ & 479 & 44.2 & 27.6 \\
\hline & $4-1$ & 502 & 44.6 & 12.7 \\
\hline & $4-2$ & 527 & 41.4 & 9.2 \\
\hline & $5-1$ & 475 & 43.2 & 25.8 \\
\hline & $5-2$ & 474 & 43.8 & 25.3 \\
\hline & $6-1$ & 474 & 45.0 & 21.1 \\
\hline & $6-2$ & 474 & 44.5 & 19.0 \\
\hline & $7-1$ & 461 & 37.5 & 33.2 \\
\hline & $7-2$ & 458 & 38.7 & 34.4 \\
\hline & 8 & 477 & 50.3 & 26.6 \\
\hline & 9 & 500 & 42.5 & 11.7 \\
\hline a & \multicolumn{4}{|c|}{$\begin{array}{l}\text { - Reference temperature } \mathrm{K} \text {-type thermocouple located at the entrance to the } \\
\text { reactor. }\end{array}$} \\
\hline$b$ & \multicolumn{4}{|c|}{$\begin{array}{l}\text { - The oil yield represents on a dry basis the organic material of the } \\
\text { condensates from the condenser, demisters, the gas and vapor sampling } \\
\text { train (downstream of the demisters) and the deposits in the condenser an } \\
\text { quench tank. Yield is based on maf feed. }\end{array}$} \\
\hline
\end{tabular}




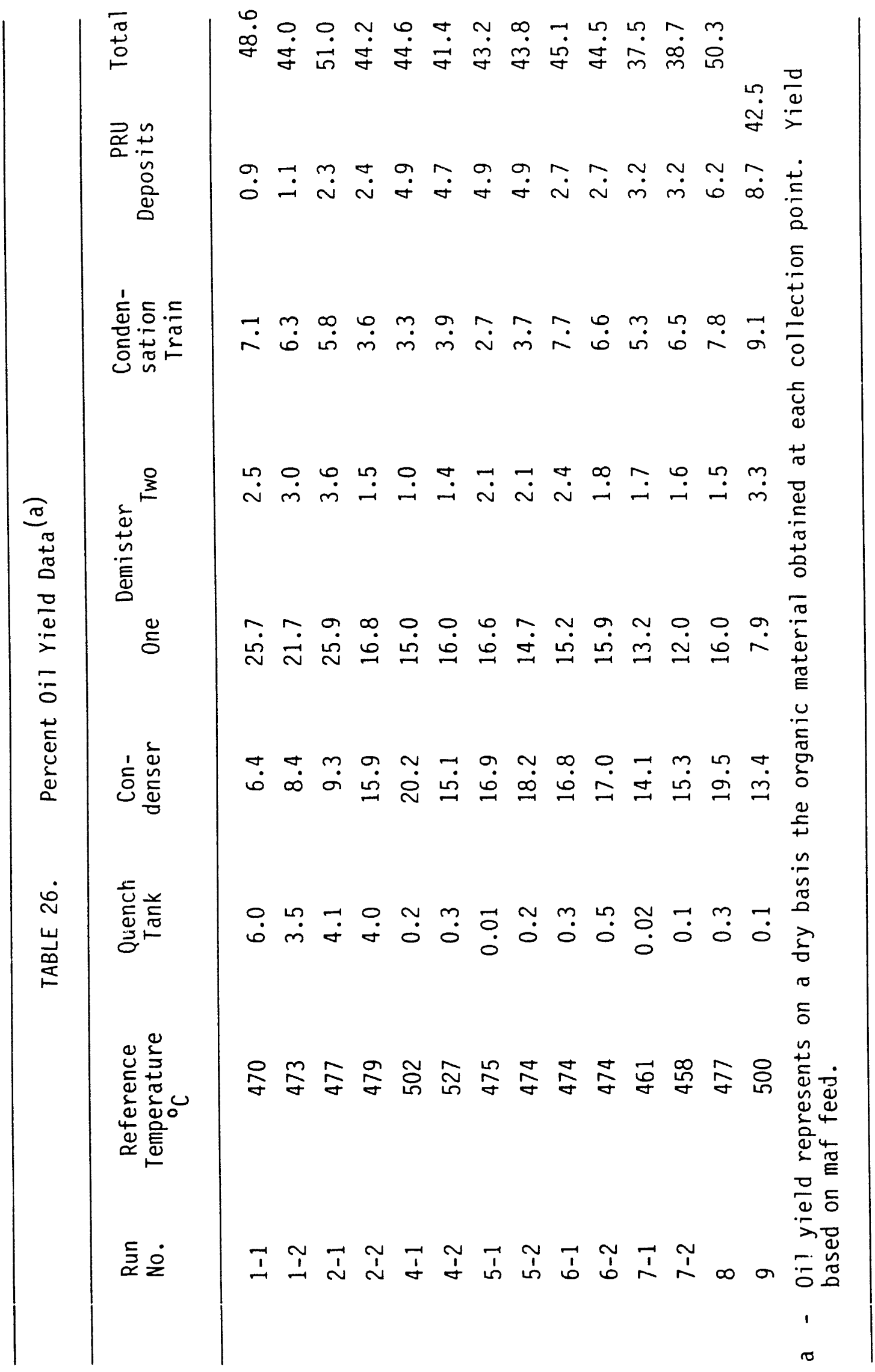


condensates of each of the sumps and the demisters are presented in Table 27 for runs $5,6,7,8$, and 9. Data on representative samples of the char from each of the test periods are given in Table 28. Table 29 shows the dry feed rate, the dry oil yield, the actual testing period, and the reactor reference temperature. Pertinent comments concerning the experimental runs are given in Table 30.

A carbon balance was determined for Run 8 and Run 9. The carbon content of representative samples of the feed, char, each of the condensates, and deposits was determined with a Perkin-Elmer CHN analyzer, Model 240C. The carbon content $r i$ the conveying and moderating gases, air, propane and offgases was calculated from the gas chromatographic analysis of each gas. The carbon recovery for Run 8 was $95.77 \%$ and for Run $9,100.8 \%$. The carbon balance data represented in Table 31 .

\subsection{MASS AND ENERGY BALANCE CONSIDERATIONS - CONFIGURATION II}

The inputs to the system were feed with moisture, inert gas from the inert gas generator, propane (commercial), air, and water for the quench tank. The weight of the input feed was determined by a loss-in-weight feeder. The inert gas was used for conveying gas and moderating gas, and the mass flow rate of each of these streams was determined with the aid of an orifice plate. The mass flow rates of the air and propane gas for the hot-gas burner were also determined with orifice plates. During a data test run, the inert gas, air and propane were sampled and the composition of each gas was determined by analyzing the samples by gas chromatography. The water flow rate for the quench tank was measured with a calibrated metering pump, and the total amount of water used was checked from the initial and final liquid level readings on the water reservoir tank.

The orifice meter for the propane was an integral part of a control device which maintains essentially stoichiometric conditions. A calibration curve supplied with the device was used to determine the propane flow rate. All of the other orifice meters were purchased separately and were fitted with flange pressure taps. The orifice pressure drops were determined with U-tube manometers which were physically located near each orifice so as to minimize measurement errors. 


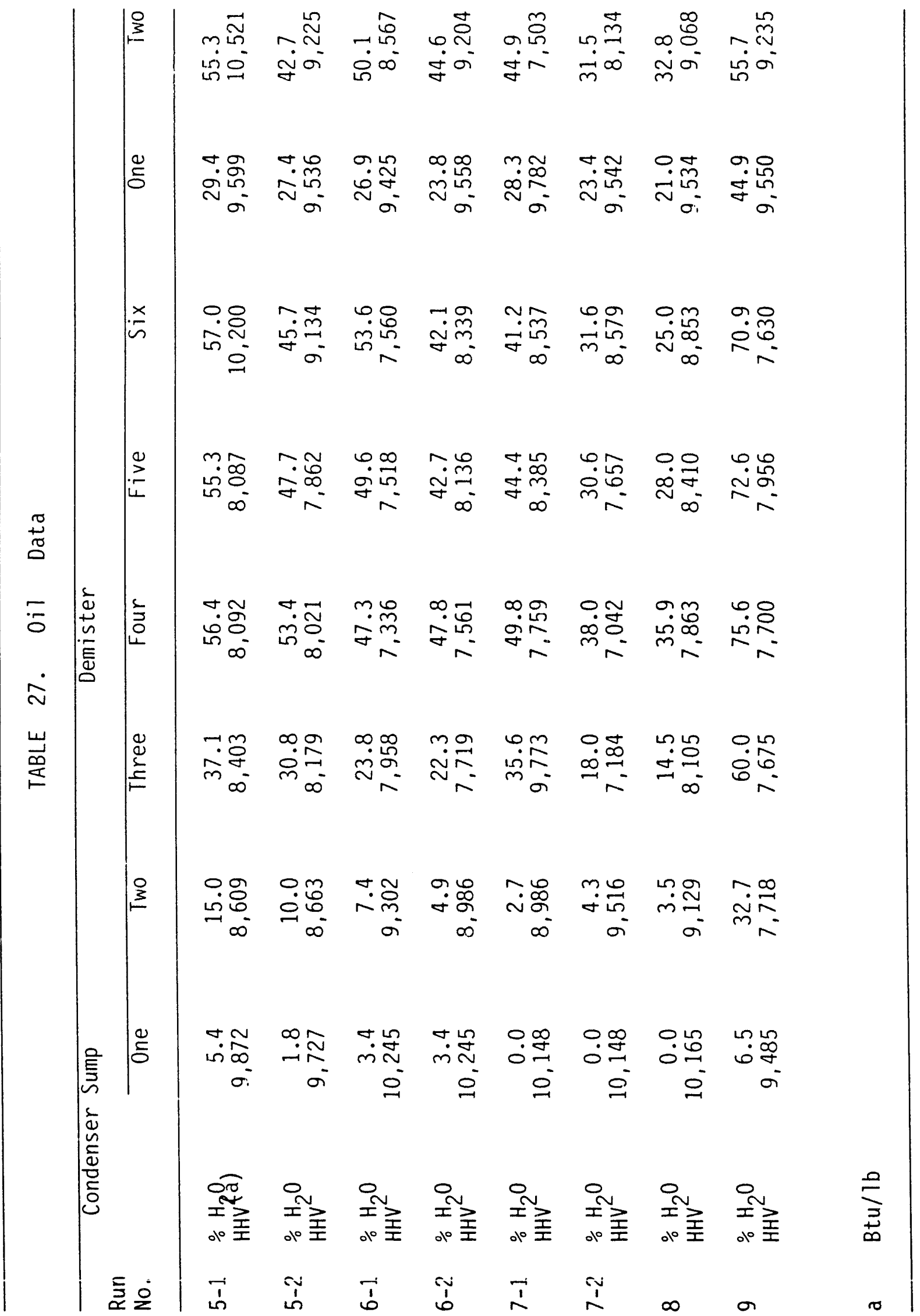


TABLE 28. Char Data

\begin{tabular}{|c|c|c|c|c|c|c|}
\hline & $\begin{array}{l}\text { Run } \\
\text { No. }\end{array}$ & $\begin{array}{l}\text { Percent } \\
\text { Yield }\end{array}$ & $\begin{array}{l}H H V(b) \\
B t u / I b\end{array}$ & $\begin{array}{l}\text { Percent } \\
\text { Ash (c) }\end{array}$ & $\begin{array}{r}\text { Percent } \\
\text { Volatiles }\end{array}$ & $\begin{array}{l}\text { Percent } \\
\text { Moisture }\end{array}$ \\
\hline & $1-1$ & 15.7 & 10,183 & 3.3 & 59.6 & 9.30 \\
\hline & $1-2$ & 17.6 & 9,861 & 2.8 & 61.4 & 6.55 \\
\hline & $2-1$ & 24.3 & 9,449 & 2.7 & 62.5 & 0.88 \\
\hline & $2-2$ & 27.6 & 9,395 & 2.2 & 64.1 & 1.17 \\
\hline & $4-1$ & 12.7 & 10,628 & 5.5 & 45.7 & 2.95 \\
\hline & $4-2$ & 9.2 & 10,975 & 6.9 & 37.4 & 1.89 \\
\hline & $5-1$ & 25.8 & 9,621 & 2.7 & 63.4 & 0.43 \\
\hline & $5-2$ & 25.3 & 9,510 & 2.2 & 65.6 & 0.23 \\
\hline & $6-1$ & 21.1 & 9,668 & 4.9 & 59.1 & 0.87 \\
\hline & $6-2$ & 19.0 & 10,003 & 4.7 & 56.1 & 0.68 \\
\hline & $7-1$ & 33.2 & 9,430 & 2.7 & 66.2 & 0.73 \\
\hline & $7-2$ & 34.4 & 9,283 & 2.5 & 71.2 & 0.16 \\
\hline & 8 & 26.6 & 9,810 & 3.4 & 62.5 & 2.20 \\
\hline & 9 & 11.7 & 11,401 & 7.3 & 37.6 & 5.60 \\
\hline $\begin{array}{l}a \\
b \\
c \\
d\end{array}$ & \multicolumn{2}{|c|}{$\begin{array}{l}\text { Dry char/maf feed } \\
\text { Maf char } \\
\text { Dry basis of char } \\
\text { As is basis }\end{array}$} & & & & \\
\hline
\end{tabular}




\begin{tabular}{|c|c|c|c|c|c|c|c|}
\hline & TABLE 29. & Pyrolysis & Runs & With & PRU & Configuration & II \\
\hline $\begin{array}{l}\text { Run } \\
\text { No. }\end{array}$ & Date & $\begin{array}{l}\text { Feed } \\
\text { (dry) } \\
1 \mathrm{~b} / \mathrm{hr}\end{array}$ & & $\underset{(\min )}{\operatorname{Run}}$ & $\begin{array}{c}\text { Total } \\
\text { Inlet Gas } \\
\text { Rate }\end{array}$ & $\% 0 \mathrm{i} 1$ & $\begin{array}{l}\text { Temp. } \\
{ }^{\circ} \mathrm{F} /{ }^{\circ} \mathrm{C}\end{array}$ \\
\hline $2 / 1-1$ & $12 / 11 / 84$ & 39.6 & & 45 & 212.6 & 48.6 & $878 / 470$ \\
\hline $2 / 1-2$ & $12 / 11 / 84$ & 35.2 & & 45 & 216.8 & 44.0 & $883 / 473$ \\
\hline $2 / 2-1$ & $1 / 16 / 85$ & 51.8 & & 60 & 253.7 & 51.0 & $891 / 477$ \\
\hline $2 / 2-2$ & $1 / 16 / 85$ & 49.6 & & 60 & 253.4 & 44.2 & $894 / 479$ \\
\hline $2 / 3-1$ & $2 / 26 / 85$ & 75 & & 20 & ---- & --- & $887 / 475$ \\
\hline $2 / 3-2$ & $2 / 27 / 85$ & 75 & & 50 & ---- & --- & $887 / 475$ \\
\hline $2 / 4-1$ & $3 / 6 / 85$ & 50.2 & & 60 & 190.1 & 44.6 & $936 / 502$ \\
\hline $2 / 4-2$ & $3 / 6 / 85$ & 52.2 & & 60 & 195.5 & 41.4 & $981 / 527$ \\
\hline $2 / 5-1$ & $4 / 30 / 85$ & 51.6 & & 90 & 213.1 & 43.2 & $887 / 475$ \\
\hline $2 / 5-2$ & $4 / 30 / 85$ & 52.1 & & 90 & 203.3 & 43.8 & $885 / 474$ \\
\hline $2 / 6-1$ & $5 / 30 / 85$ & 46.1 & & 90 & 233.4 & 45.0 & $885 / 474$ \\
\hline $2 / 6-2$ & $5 / 30 / 85$ & 45.0 & & 90 & 232.0 & 44.5 & $885 / 474$ \\
\hline $2 / 7-1$ & $6 / 24 / 85$ & 45.7 & & 90 & 205.8 & 37.5 & $862 / 461$ \\
\hline $2 / 7-2$ & $6 / 24 / 85$ & 45.8 & & 90 & 208.1 & 38.7 & $856 / 458$ \\
\hline 218 & $8 / 19 / 85$ & 51.0 & & 240 & 205.8 & 50.3 & $891 / 477$ \\
\hline $2 / \quad 9$ & $9 / 23 / 85$ & 15.1 & & 240 & 213.5 & 42.5 & $932 / 500$ \\
\hline
\end{tabular}


TABLE 30. Comments on Experimental Runs - Configuration II

Run $2 / 1-1$
$\&$
$2 / 1-2$

Run 2/2-1

$\&$

$2 / 2-2$

Run $2 / 3-1$

Run $2 / 3-2$

Run $2 / 4-1$

\&

$2 / 4-2$
Shake down run on new pyrolys is system. Draft fan not used. Moderating gas used. very little residue found in quench tank; no residue in condenser. One condenser fan used. Several small oil leaks, not evident in prior leak testing, developed during the run and were repaired. No major operational problems with components.

Draft fan in use. Moderating gas used. Some residue on quench tank wall and condenser inlet section. Higher rate used to test PRU operation.

Purpose of these tests was to determine maximum feed rate. Draft fan in use. Moderating gas in use. Feed rate $(3-1)$ was not steady, ranging from 66 to $80 \mathrm{lb} / \mathrm{hr}$. (Avg. feed rate over last 10 min. was 74.0 lb per hour, as is feed.) A buildup of material in the char cyclone occurred. However, the char cyclone did not plug. The PRU was shut down when it was observed that the char was not being discharged at an adequate rate. The char cyclone and receiver were cleaned. The rest of the PRU was cleaned and prepared for operation.

Operated at a feed rate of $74.1 \mathrm{lb}$ per hour for $20 \mathrm{~min}$, and $77.0 \mathrm{lb}$ per hour for $12 \mathrm{~min}$. Could not maintain temperature and feed rate due to constraint of maximum static pressure of system combined with the increased system pressure drop due to increased feed rate. At the end of the run the draft fan shut down when the circuit breaker kicked out. Inspection of the draft fan showed that the shut down was due to the collection /deposition of pyrolytic oil on the fan (internal) casing and impeller causing the motor to overload. Note: the feed rates and reference temperatures achieved for both runs were the target conditions planned for these test runs.

Moderating gas not used. Draft fan not used. Two condenser fans in use. Installed smaller nozzle in quench spray system to reduce water spray rate while maintaining atomization and spray pattern. Some residue on quench tank walls and condenser inlet. Acetone wash of condenser tubes initiated. Adjusted inert gas generator pressure. No problem maintaining feed rate and increased operating temperature. Feed very steady. 
TABLE 30. Comments on Experimental Runs - Configuration II, (cont.)

Run $2 / 5-1$
$\&$
$2 / 5-2$

Run 2/6-1

\&

$2 / 6-2$

Run 2/7-1

\&

$2 / 7-2$

Run 2/ 8

Run 2/ 9
Moderating gas in use. Draft fan not used. Two condenser fans in use. Lowest quench water spray rate used to date ( $6.5 \mathrm{lb}$ per hour). Evidence of oil condensing on and flowing down the wall of the quench tank. A small amount of residue was collected from the distributor plates of No. 1 and No. 2 condenser sumps. The material collected in sump No. 1 (both test periods) tarry in character.

No moderating gas. Draft fan not used. Two condenser fans in use. Prior to test, while feeding, adjusted inert gas generator parameters to get maximum inlet gas flow for a feed rate of $50 \mathrm{lb}$ per hour and $475{ }^{\circ} \mathrm{C}$ reference temperature. Discharge pipe of sump No. 1 plugged during each run and required the use of a heat gun (type of hot air blower) to cause material to flow. Sump No. 1 product tarry and very viscous. Sump No. 2 product tarry but flowed slightly at room temperature.

Run at lower temperature to expand data base. No moderating gas. Draft fan not used. Two condenser

fans in use. Feed very steady. Increased quench water spray rate to reduce tarry products in sumps No. 1 and No. 2. Sump No. 1 flowed during first part of each test run but solidified about halfway into each run. A hot air gun was used to heat the discharge pipe to allow the oil to flow into the product receiver.

Extended data test period to 4 hours. Moderating gas used. Two condenser fans used. Sump No. 1 valve left open during test to allow oil to flow into sealed container. Sump did not plug during test. Adjusted quench spray flow rate so that essentially no liquid was collected in quench tank--succeeded. Use of less quench water improved quality of $0 i l$ and aided in high oil yield of $50.3 \%$. Char yield still higher than desired at $26.6 \%$. Could not achieved desired inlet gas rate of $255 \mathrm{lb} / \mathrm{hr}$ at given feed rate and reference temperature. Projected that higher oil yield possible if residence time was reduced (i.e. if higher inlet gas rates were possible).

No moderating gas. Draft fan used-All 3 condenser fans used. Quench spray rate reduced. Too much water condensed with oil using 3 fans. Reference temperature increased to $500{ }^{\circ} \mathrm{C}$ and feed rate reduced to $15 \mathrm{lb} / \mathrm{hr}$ to examine effect of dilute reactor phase on oil collection and reduced char production. Char yield in desired range at $11-7 \%$, but $0 i 1$ yield lower than expected at 42-5\%. 


\section{TABLE 31. Carbon Balance - lb carbon/hr}

Run No.

8

9

INPUTS

Feed

Conveying Gas

24.61

7.02

Moderating Gas

3.58

6.11

Air

2.46

0.00

Propane

0.02

0.02

Total

5.26

$\underline{5.20}$

35.93

18.35

OUTPUTS

Char

7.20

Quench Tank (1)

1.10

0.11

Coridenser (2)

5.30

1.52

Demister One

4.37

1.21

Demister Two

0.50

0.29

Condensation Train $0 i 1$

1.01

0.45

Offgas

$\underline{14.93}$

$\underline{13.77}$

Total

34.41

18.50

Total Carbon Recovery (\%)

95.77

100.80

Carbon in condensates/

Carbon in feed $(\%)$

49.90

51.00

Carbon in charl

Carbon in feed (\%)

29.26

16.38

1 - Includes product collected during run and residue collected after run.

2 - Includes combined product of all sumps, residue collected after run, and material collected from acetone wash of condenser after run. 
The flow rates through the orifices (with the exception of the propane orifice) were calculated using a computer program based on the information provided in "Fluid Meters; Their Theory and Application," ASME (1959). The viscosity was calculated as a function of temperature and composition. The density was calculated as a function of pressure, temperature, and composition.

The leaving streams consisted of char, condensates and offgases. The char and liquid products were weighed. The liquid products also included deposits in the condenser which were recovered after the run. The offgas stream was sampled continuously during the test period of a pyrolysis run, downstream of the second demister cyclone. The sample was passed through a condensation train for: analysis of the condensable components, collection of an integrated gas sample, and periodic sampling of the noncondensed gases, which were analyzed by gas chromatography. The volume of the offgas stream sampled was measured with a dry test meter. These dat; were used to calculate the mass flow of the offgas stream by a nitrogen Dalance. Although there was an orifice meter located in the pipe leading to the flare, the "calculated" flow rate through this orifice was not used in the mass balance. The reason for this was the uncertainty of the physical state of the pyrolysis oil and water in the offgases. Although the total leaving flow rates of water and pyrolys is oil were determined, the relative amount in the aerosol was not known. The mass balances for each of the test periods for the preliminary runs are given in Tables 32 through 34 .

The basis for the energy balance was the steady-flow energy equation. The enthalpies of gaseous argon, oxygen, nitrogen, and carbon dioxide were arbitrarily set equal to zero at $25{ }^{\circ} \mathrm{C}$. The enthalpy of liquid water at $25{ }^{\circ} \mathrm{C}$ was also taken to be zero. This was equivalent to assigning the of any combustible hydrocarbon at $25{ }^{\circ} \mathrm{C}$ a value equal to its higher heating value.

The energy balance was thus concerned with the heating values of the wood, conveying gas (may contain carbon monoxide and hydrogen), propane, char, $0 i 1$, and offgases. Also, consideration was given to heat losses, heat transferred to the condenser cooling air, and sensible heat. Strictly speaking, the state of the water entering and leaving the system should be taken into account (water vapor at $25^{\circ} \mathrm{C}$ on the basis used here would have an enthalpy equal to its heat of vaporization at that temperature). This effect 
TABLE 32. Mass Balances - Entering Streams - 1b/hr

\begin{tabular}{rrrrrrrr}
\hline $\begin{array}{l}\text { Run } \\
\text { No. }\end{array}$ & Wood (a) & $\begin{array}{r}\text { Conveying } \\
\text { Gas }\end{array}$ & $\begin{array}{r}\text { Moderating } \\
\text { Gas }\end{array}$ & Air & Propane & $\begin{array}{r}\text { Quench } \\
\text { Spray }\end{array}$ & Total \\
\hline $1-1$ & 42.0 & 67.6 & 70.4 & 70.0 & 4.5 & 34.0 & 288.5 \\
$1-2$ & 37.3 & 65.3 & 62.1 & 84.1 & 5.4 & 34.0 & 288.2 \\
$2-1$ & 54.8 & 80.3 & 53.4 & 113.4 & 6.6 & 34.0 & 342.5 \\
$2-2$ & 52.5 & 83.6 & 55.3 & 108.4 & 6.1 & 34.0 & 339.9 \\
$4-1$ & 53.8 & 62.0 & 0.0 & 120.5 & 7.6 & 13.9 & 257.8 \\
$4-2$ & 55.9 & 59.0 & 0.0 & 128.8 & 7.7 & 15.2 & 266.6 \\
$5-1$ & 54.7 & 63.9 & 39.7 & 103.1 & 6.5 & 6.5 & 274.4 \\
$5-2$ & 55.3 & 65.0 & 39.9 & 92.7 & 5.6 & 6.5 & 265.0 \\
$6-1$ & 48.6 & 88.6 & 0.0 & 136.1 & 8.7 & 11.5 & 293.5 \\
$6-2$ & 47.4 & 89.3 & 0.0 & 134.3 & 8.4 & 11.5 & 290.9 \\
$7-1$ & 48.1 & 76.4 & 0.0 & 121.7 & 7.7 & 15.0 & 268.9 \\
$7-2$ & 48.1 & 92.8 & 0.0 & 108.5 & 6.8 & 15.0 & 271.2 \\
8 & 55.2 & 57.9 & 39.6 & 101.4 & 6.9 & 9.8 & 270.8 \\
9 & 16.1 & 105.3 & 0.0 & 101.9 & 6.4 & 2.9 & 232.6
\end{tabular}

a - Total weight of wood including moisture and ash.

was not included in the offgas stream because of the uncertainty of the state of the water in that stream. Heat loss estimations were based on results obtained from running the PRU hot but without feed. Using temperature drops in 
TABLE 33. Mass Balances - Leaving Streams - $1 \mathrm{~b} / \mathrm{hr}$

Run No. Char (a) Condensates ${ }^{(b)}$ Offgases $^{(c)}$ Total

\begin{tabular}{|c|c|c|c|c|}
\hline $1-1$ & 6.8 & 75.2 & 209.1 & 291.1 \\
\hline $1-2$ & 6.6 & 62.0 & 215.2 & 283.8 \\
\hline $2-1$ & 12.7 & $8 i .5$ & 250.1 & 350.3 \\
\hline $2-2$ & 13.8 & 71.4 & 248.9 & 334.1 \\
\hline $4-1$ & 6.5 & 53.7 & 190.7 & 250.9 \\
\hline $4-2$ & 4.9 & 54.8 & 200.5 & 260.2 \\
\hline $5-1$ & 13.3 & 45.6 & 202.8 & 261.7 \\
\hline $5-2$ & 13.1 & 44.1 & 195.1 & 252.3 \\
\hline $6-1$ & 9.7 & 45.2 & 231.5 & 286.4 \\
\hline $6-2$ & 8.5 & 40.0 & 229.0 & 277.5 \\
\hline $7-1$ & 15.2 & 40.0 & 201.6 & 256.8 \\
\hline $7-2$ & 15.6 & 38.7 & 203.6 & 257.9 \\
\hline 8 & 13.8 & 49.3 & 199.7 & 262.8 \\
\hline 9 & 1.9 & 22.5 & 206.3 & 230.7 \\
\hline
\end{tabular}


TABLE 34. Mass Balances - Summary

\begin{tabular}{|c|c|c|c|}
\hline Run No. & $\begin{array}{r}\text { Entering } \\
\text { Streams } \\
\mathrm{lb} / \mathrm{hr}\end{array}$ & $\begin{array}{l}\text { Leaving } \\
\text { Streams } \\
\text { lb/hr }\end{array}$ & $\begin{array}{l}\text { Percent } \\
\text { Closure }\end{array}$ \\
\hline $1-1$ & 288.5 & 291.1 & 100.9 \\
\hline $1-2$ & 288.2 & 283.8 & 98.5 \\
\hline $2-1$ & 342.5 & 350.3 & 102.3 \\
\hline $2-2$ & 339.9 & 334.1 & 98.3 \\
\hline $4-1$ & 257.8 & 250.9 & 97.3 \\
\hline $4-2$ & 266.6 & 260.2 & 97.6 \\
\hline $5-1$ & 274.4 & 261.7 & 95.4 \\
\hline $5-2$ & 265.0 & 252.3 & 95.2 \\
\hline $6-1$ & 293.5 & 286.4 & 97.6 \\
\hline $6-2$ & 290.9 & 277.5 & 95.4 \\
\hline $7-1$ & 268.9 & 256.8 & $95 . .5$ \\
\hline $7-2$ & 271.2 & 257.9 & 95.1 \\
\hline 8 & 270.8 & 262.8 & 97.0 \\
\hline 9 & 232.6 & 230.7 & 99.2 \\
\hline
\end{tabular}


the flow, heat losses in various sections of the system were determined. These losses were related to temperatures measured at selected locations in the PRU. In essence, the thermal resistance to heat loss was determined for various sections of the system. These resistances were then used to determine the heat losses during pyrolysis runs by using the appropriate temperatures measured during the pyrolysis run. The energy inputs and outputs for the test periods for the preliminary runs are presented in Tables 35 through 37, and the energy balances, in Table 38 .

An estimate of the maximum error of the mass balance was made by means of an error analysis. The estimated error in input flow rate was based on the calculated flow rates for burner air, propane gas and inert gas. All of these flow rates were determined using orifice plates. The error in the air and propane orifice calculations was assumed to be caused by the measurement error of the pressure drop and the inherent error in the orifice coefficient itself (estimated to be one percent). Similar assumptions were made for the determination of the inert gas flow rate, and in addition, the error associated with the inert gas density caused by errors in composition measurements was included. The resulting estimated maximum error in inlet flow rate was \pm 2.5 percent.

The exit flow rate of the offgas stream (noncondensables, vapors and aerosols) was determined by a nitrogen balance. The estimated error in the offgas noncondensables flow rate was based on the estimated accuracy of the total inlet nitrogen flow rate and the estimated accuracy of the measurement of gas compositions. The exit aerosol, light oil, and water vapor flowrates are also subject to composition measurement error, since they were obtained by ratioing sample measurements to the calculated offgas flow rate. Using this procedure, the estimated maximum error in total output flow rate was \pm 6 percent. This was based on variations in the determination of the mass fraction of nitrogen determined by gas chromatography using "identical" samples (sample obtained from a relatively large volume of gases collected in the offgas sampling train).

A maximum error was estimated for the energy balance as was done for the mass balance. One of the assumptions made was that the measured heating values of the feed, char, and pyrolysis oils (condenser, demister, or aerosol) had a maximum absolute error of $100 \mathrm{Btu}$ (based on experience with these determinations). The maximum heating value error estimate for the offgas was 


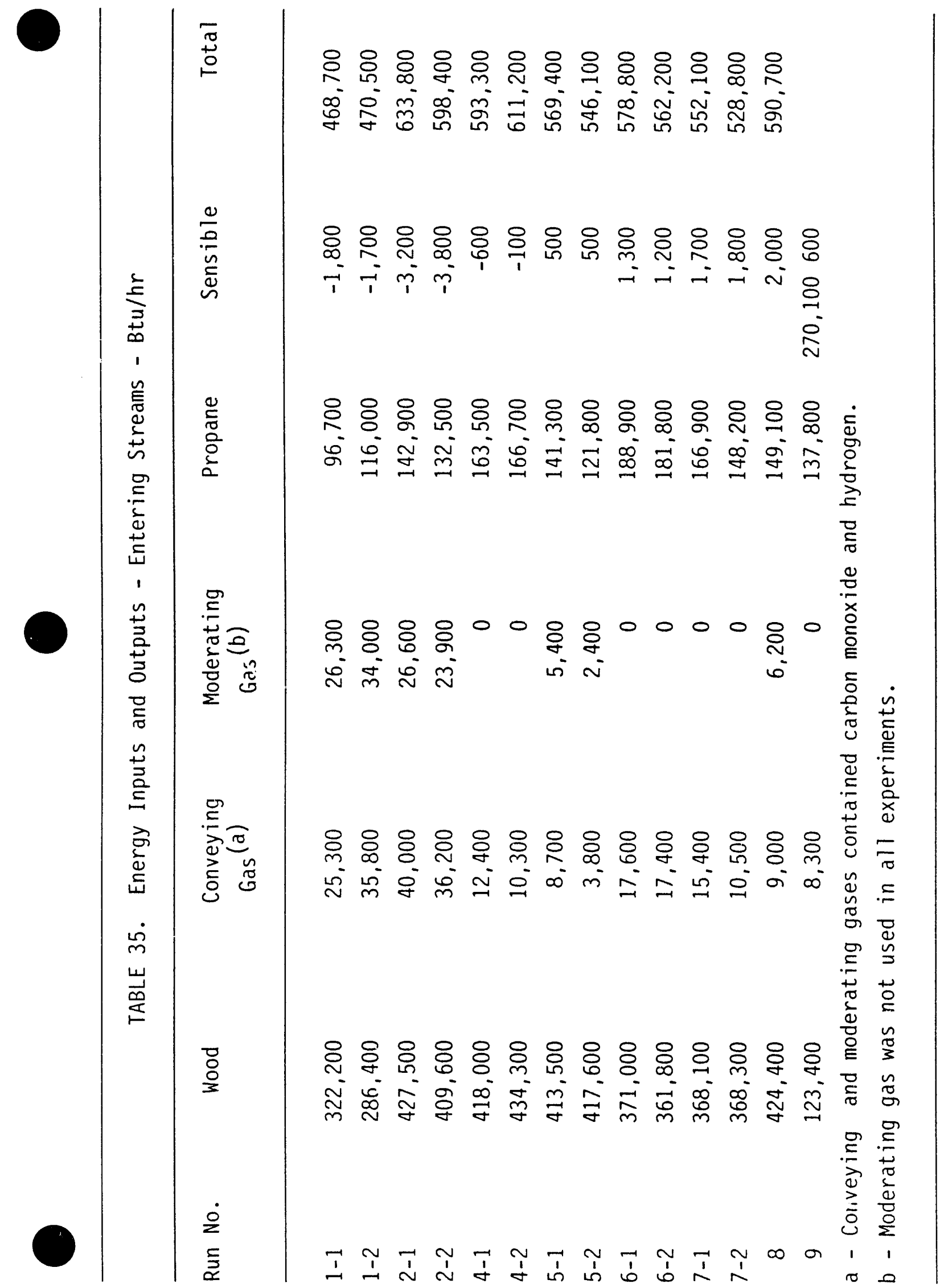




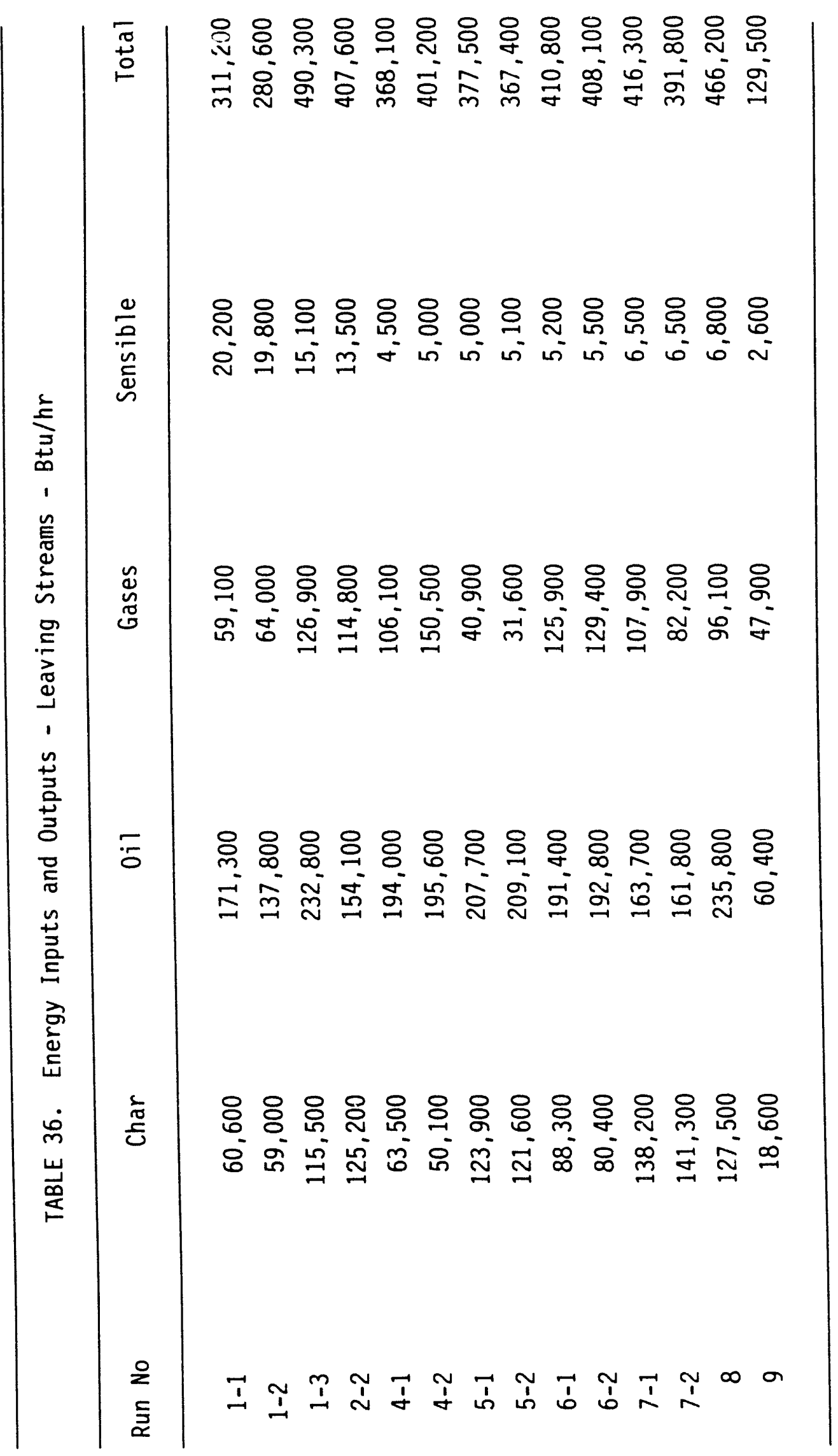

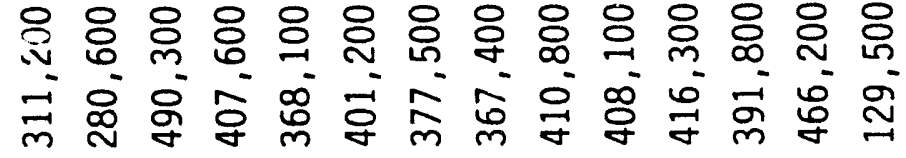

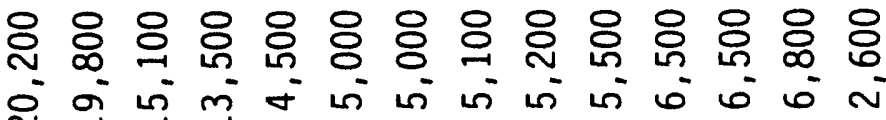

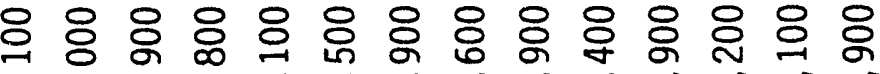
蚛

m $\infty$ ন

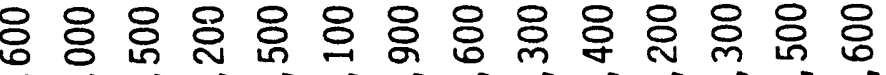
ర 
TABLE 37. Energy Inputs and Outputs - Btu/hr

\begin{tabular}{|c|c|c|c|c|}
\hline \multicolumn{5}{|c|}{ Heat Losses } \\
\hline Run No. & $\begin{array}{r}\text { Hot-gas } \\
\text { Generator }\end{array}$ & $\begin{array}{l}\text { System } \\
\text { Cooling Air }\end{array}$ & Condenser & Total \\
\hline $1-1$ & 49,400 & 50,300 & 22,700 & 122,400 \\
\hline $1-2$ & 52,300 & 51,900 & 31,100 & 135,300 \\
\hline $2-1$ & 51,900 & 75,700 & 57,100 & 184,700 \\
\hline $2-2$ & 53,900 & 80,500 & 51,800 & 186,200 \\
\hline $4-1$ & 57,800 & 53,400 & 37,500 & 148,700 \\
\hline $4-2$ & 68,000 & 52,400 & 30,400 & 150,800 \\
\hline $5-1$ & 54,100 & 36,200 & 34,500 & 124,800 \\
\hline $5-2$ & 58,800 & 39,600 & 33,500 & 131,900 \\
\hline $6-1$ & 52,600 & 51,900 & 24,000 & 128,500 \\
\hline $6-2$ & 57,100 & 48,800 & 26,900 & 132,800 \\
\hline $7-1$ & 46,500 & 44,400 & 35,500 & 126,400 \\
\hline $7-2$ & 54,300 & 43,100 & 35,500 & 132,900 \\
\hline 8 & 52,700 & 53,700 & 30,700 & 137,100 \\
\hline 9 & 60,700 & 52,300 & 19,700 & 132,700 \\
\hline
\end{tabular}


TABLE 38. Energy Balances Btu/hr

\begin{tabular}{|c|c|c|c|c|c|}
\hline Run $N$ & No. & $\begin{array}{l}\text { Entering } \\
\text { Streams }(a)\end{array}$ & $\begin{array}{l}\text { Leaving } \\
\text { Streams }(b)\end{array}$ & $\begin{array}{l}\text { Calculated } \\
\text { Heat Losses }(c)\end{array}$ & $\begin{array}{l}\text { Percent } \\
\text { Closure }\end{array}$ \\
\hline & -1 & 468,700 & 311,200 & 122,400 & 92.5 \\
\hline & -2 & 470,500 & 280,600 & 135,300 & 88.4 \\
\hline & -1 & 633,800 & 490,300 & 184,700 & 106.5 \\
\hline & -2 & 598,400 & 407,600 & 186,200 & 99.2 \\
\hline 4. & -1 & 593,300 & 368,100 & 148,700 & 87.1 \\
\hline 4. & -2 & 611,200 & 401,200 & 150,800 & 90.3 \\
\hline 5. & -1 & 569,400 & 377,500 & 124,800 & 88.2 \\
\hline 5 & -2 & 546,100 & 367,400 & 131,900 & 91.4 \\
\hline 6 & -1 & 578,800 & 410,800 & 128,500 & 93.2 \\
\hline 6 & -2 & 562,200 & 408,100 & 132,800 & 96.2 \\
\hline 7 & -1 & 552,100 & 416,300 & 126,400 & 98.3 \\
\hline 7. & -2 & 391,800 & 528,800 & 132,900 & 99.2 \\
\hline & 8 & 590,700 & 466,200 & 137,100 & 102.1 \\
\hline & 9 & 270,100 & 129,500 & 132,700 & 97.1 \\
\hline \multicolumn{6}{|c|}{$\begin{array}{l}\text { - Feed, conveying gas, moderating gas, propane, sensible heat. } \\
\text { - Char, oil, offgases, sensible heat. } \\
\text { - Hot-gas generator, system, condenser cooling air. }\end{array}$} \\
\hline
\end{tabular}


based on the maximum estimated errors in the offgas composition. Small errors in the measurement of relatively high molecular weight species ( $\mathrm{CH} 4$ and higher) result in substantial changes in the heating value of the noncondensable offgases. Since the value for the offgases was the largest leaving energy stream, the measurement of the offgas composition played a major role in determining the accuracy of the energy balance. Also, the mass balance calculations directly affected on the energy balance calculations. That is, an exit mass flow rate different from the inlet flow rate will automatically be reflected in the energy balance. The estimated maximum error in the energy balance based on these considerations was \pm 8 percent.

\subsection{DISCUSSION}

Two of the items that were added during the modification were a second demister and a draft fan in the offgas line. The reason for adding the second demister was to increase the efficiency of aerosol collection. Since the addition of this demister and the quench spray chamber, along with the reduction in reactor diameter, would increase the overall system pressure drop, the decision was made to add the blower. Unfortunately, the second demister did not operate as well as anticipated and as a result the blower could not be operated on an extended, continuous basis. The reason was that for this particular blower the aerosol collected, or deposited, inside the blower in such a way that binding of the shaft occurred, the motor overheated, and a control device turned off the motor. This did not create a major problem in obtaining experimental data. After operating for four to six hours, some buildup in the blower casing was present as evidenced by a decrease in blower performance. Compensation for the decreased performance was made by adjusting the blower controls to maintain the required operating conditions. However, the blower could not be relied on for experiinents of a longer duration (e.g. eight hours or more). Suitable steps could have been taken to alleviate this problem but it was deemed advisable not to undertake them until the Configuration II testing was completed.

The maximum flow rate per unit area in the eight-inch reactor was 327 $1 \mathrm{~b} / \mathrm{hr} \mathrm{ft} .{ }^{2}$ Through experimental run $\mathrm{P}-9$ the maximum flow rate per unit area in the six-inch reactor was $261 \mathrm{lb} / \mathrm{hr} \mathrm{ft} .^{2}$ Although the flow rate per unit area is of significance in design, it is not a complete index of performance. In 
comparing different types of reactor systems, other factors, such as the reactor cost per unit flow area, are more important than actual flow rate per unit area. Ultimately, the performance of the complete system must be considered in a full economic evaluation, after the system has been proven technically.

Tables 23 through 38 have been mentioned previously. However, additional comments are appropriate for Tables 35 through 37 . Run number $2-\hat{z}$ in this table is used as an example to illustrate these comments. The total heating value in the conveying gas, moderating gas and the propane was 192,600 Btu/hr. The total calculated heat losses were 186,200 Btu/hr. Of these calculated heat losses, 134,400 Btu/hr represent the heat losses from the entire system excluding the heat transfer to the condenser cooling air. This $134,400 \mathrm{Btu} / \mathrm{hr}$ represents about 70 percent of the inlet heating value. These losses could be substantially reduced by increased thermal insulation. This was not done because it was not considered essential for a research unit. This is emphasized here because the amount of propane used might be misleading. In addition, in a commercial system the heated air leaving the condenser would be used to preheat an input stream, such as the combustion air, further reducing the fuel needed for operation.

Based on the experimental runs conducted through P-9 with Corfiguration II, the significant experimental variables appeared to be reactor temperature, feed rate and gas residence time. A three factorial design of experiments is presented in Table 39, and in this table experiment number one is the center point. The remainder are factorial points. It was proposed to run two replications of the center point, thus making a total of eleven runs. The experimental design presented in Table 39 was intended to be a guide for the experiments conducted in the next phase of operation, in which the PRU was referred to as Configuration III.

A total of twenty-four experimental runs were made through 0ctober, 1985. The first ten of these were made on the eight-inch reactor and the remaining fourtee:l on the six-inch reactor. The eight-inch reactor provided valuable operating experience and data needed to upgrade the system by appropriate modifications. The fourteen experiments on the modified unit have provided additional data. $0 i 1$ yields as high as $51 \%$ wer 3 obtained with both reactors. 
TABLE 39. Design of Experiments for Determining Conditions for Optimum 0 il Yield

\begin{tabular}{lccc}
\hline $\begin{array}{l}\text { Experiment } \\
\text { Identification } \\
\text { No. }\end{array}$ & $\begin{array}{r}\text { Reactor } \\
\text { Temperature } \\
\left({ }^{\circ} \mathrm{C}\right)\end{array}$ & $\begin{array}{r}\text { Feed Rate } \\
(\mathrm{lb} / \mathrm{hr})\end{array}$ & $\begin{array}{r}\text { Gas } \\
\text { Residence Time } \\
(\mathrm{sec})\end{array}$ \\
\hline 1 & 500 & 30 & 2.5 \\
2 & 450 & 15 & 2.0 \\
3 & 550 & 15 & 2.0 \\
4 & 450 & 45 & 2.0 \\
5 & 550 & 45 & 2.0 \\
6 & 450 & 15 & 3.0 \\
7 & 550 & 15 & 3.0 \\
8 & 450 & 45 & 3.0 \\
9 & 550 & 45 & 3.0 \\
\hline
\end{tabular}


0 il yields considerably higher than $51 \%$ were believed possible under the $p$,oper operating conditions. The most expedient and economical way to determine these conditions was by means of the experiments proposed in Table 39 and parallel modeling efforts.

\subsection{OPERATING PROCEDURES FOR THE ENTRAINED-FLOW PYROLYSIS PROCESS RESEARCH UNIT}

The following section describes the preparations prior to a test run, the operating procedures for the day of a test run, and the inspection, recovery of products, and clean-up tasks after a test run. Several subsystems of the PRU system were provided as packaged units by a particular vendor. The operating and servicing instructions for these subsystems are located in the operating manuals supplied by the vendor. The reference and identifications numbers as well as the location of the manuals are indicated in the following text. A schematic flow diagram of the PRU system, the instruction drawings, elevation drawings, drawings of the locations of temperature and pressure sensing points and component assembly drawings are located in the project files.

\section{(1) PRU Preparation Prior To Start-Up}

(a) Day before pyrolysis run.

i) Check the burner system. Check the flame rod for buildup, clean as necessary; clean the pilot ignition spark plug.

ii) Check all manometers. visually inspect all pressure lines for presence of water or oil; drain or blow out liquid as necessary. Inspect manometers for proper fluid level; replenish with correct fluid as necessary (unity oil, water, or red gauge oil). Check condenser and quench tank pressure taps for proper operation. Clean if necessary.

iii) Clean all gas sampling probes.

iv) Prepare off gas sampling trains (see Article 8.1(7)(d).

v) Clean and tare char buckets and oil receivers.

vi) Weigh feed into tared barrels in 50-pound increments. Take a representative sample of the feed for laboratory analysis. 
vii) Visual inspection of PRU for leaks. Turn on combustion air; smoke bombs are placed at the combustion air intake. Any leaks in the unit are repaired.

viii) Turn on all recorders. Check operation $0_{i}$ all thermocouples. Check thermocouple element and wire junctions of any thermocouple that is shorted or that does not show a response.

ix) Open drain plugs on all orifices and remove any water due to condensation.

x) Fill the reservoir water tank for use with the quench water spray system.

(b) Morning of run - prior to start-up.

i) Make a general visual inspection of the PRU operating area.

ii) Turn on main water valve, the main electrical power, and auxiliary air compressor. Blow down condensate in air compressor cooler, as necessary. The air compressor is used to open and close the feed system and char cyclone knife gate valves.

iii) Inside the control room, turn on electrical power to the K-Tron loss-in-weight feeder, North American burner Panel, and control panel.

iv) Open the propane valve a.t the tank.

v) Place char buckets at char cyclone and check that the char knife gate valve is closed.

vi) Place oil receivers at the condenser and demister sumps and check that tre condenser and demister sump valves are closed.

vii) Ser up burner combustion gas sample probe.

viii) Turn on and calibrate oxygen analyzer with zero and $5 \%$ oxygen span gas.

ix) Record barometric pressure and psychrometer readings.

$x$ ) Take a propane sample to be analyzed by GC. 
$x i)$ Load the loss-in-weight feede:- Fifty pound increments of feed are placed in the upper hold-up bin using the electric chain hoist; the upper knife gate is opened and feed drops into the lower hold-up bin; two more 50-pound increments of feed are placed in the lower bin; the upper knife gate is closed, the lower knife gate is opened and the $150 \mathrm{lb}$ charge of feed drops into the loss-in-weight feeder bin. Additional feed is placed in upper and lower hold-up bins depending on the duration and feed rate for the test run.

\section{(2) Start-up}

(a) Turn on condenser fans.

(b) The start-up and operating procedures for the inert gas generator are included in the operations manual designated as Industrial Gas Systems No. M82-115-1 and the Wittemann Co. Reference No. IGS-00043. This manual is located in the control room of the PRU unit. Personnel should become familiar with the instructions in the manual before attempting to operate the equipment. The inert gas generator is brought on line according to the following procedure.

i) Close the conveying gas and moderating gas ball valves; open the inert gas generator dump valve.

ii) Open primary water valve on inert gas generator skid. Open water valve on inert gas generator spray chamber and set at $2 \mathrm{psi}$. This is required so that the cooling water flow limit switch is engaged.

iii) Open manually-operated main air valve to the setting $1 / 2$ open. (Graduations are marked $0,1 / 4,1 / 2,3 / 4$, and ful1). The air blower will not start at a lower setting.

iv) Turn on air blower, check all limit switches to ensure that the limits are met. 
v) Open manual air valve to the $3 / 4$ position and observe that the purge air pressure switch engages. If the manual air valve is left at the $1 / 2$ oper position, the blower will operate for 5 minutes and shut down. When the purge air pressure switch is engaged, the purge air timer is simultaneously energized. The combustion chamber is purged for 5 minutes before the purge timer times out- The pilot system ready indicator lamp lights up.

vi) Open pilot air and pilot gas valves.

vii) Light pilot by depressing pilot ignition switch.

viii) When the pilot timer times out $(2 \mathrm{~min})$ and the pilot flame has been established, the main fire switch and an indicator, ready light are energized.

ix) Close the manual air valve to the low fire position, about $1200 \mathrm{CFH}$ of air as indicated by the reading on the manometer on the unit.

$x$ ) Crack open the main fuel gas ball valve.

$x i)$ Open the block valve on the main fuel gas line.

$x i i)$ Slowly open the main fuel gas ball valve until the wide open setting is reached.

xiii) Let inert gas generator operate at these conditions for about five minutes to allow the system to warm up.

xiv) Close the pilot air and gas valves.

(c) Tho start-up and operating procedures for the hotgas burner system are included in the North American Manufacturing Co. operation bulletin, dated May 11, 1982, designated as Text No. DU36660, with a corresponding schematic labeled Drg. No. QA23-2023. These documents are located in the hot gas burner folder of the project file. Personnel should become familiar with the instructions in these documents before attempting to operate the equipment. The hot-gas burner system is started according to the following procedure.

i) Turn the "burner" panel selector switch to "gas. 
ii) Drive the air control valve to the high, or wide open, position by manually setting the temperature controller, which controls the air control valve motor operator, to 100

iii) Since the combustion blower is used during the purge cycle, manually start the combustion air blower.

iv) Reset the manual limits reset switch.

v) When all the prestart limits are met and the combustion air blower is being used for the purge, the "limits complete" light is energized.

vi) When the limits are complete and the blower is operating, the purge switch is made, the purge timer begins timing, and the "purging" light is energized.

vii) At the end of the preset purge time period (2 min), the "purging" light is de-energized.

viii) Drive the control motor on the air control valve to the low fire, start position by manually setting the temperature controller to $30 \%$ open.

ix) Manualiy open the pilot air and pilot gas cutoff valves.

x) With the purge complete and the low fire, start switch made, the burner circuit is powered. Then the flame supervisory system makes an internal safe start check (30 seconds).

$x i)$ The ignition transformer and ignition timer are energized.

$x i i)$ The pilot solenoid valve is energized.

$x i i i)$ When the ignition timer times out, the ignition transformer is de-energized, and the main fuel delay timer is energized. At this point the pilot flame is visible at the sight port on the burner.

xiv) After the flame-rod flame detector senses the flame and the main fuel delay relay times out, the main fuel block valve is energized. 
xv) Manually open the main fuel block valve. When the end switch on the main fuel block valve is "made", the low fire hold timer is energized.

$x v i)$ When the low fire hold timer times out, the control motor on the air control valve is released to the temperature control circuit.

xvii) The pilot solenoid valves are de-energized.

(d) Open the conveying gas ball valve to a setting of full open.

(e) Close the inert gas dump valve on the inert gas generator skid.

(f) Manually adjust the conveying gas and moderating gas flows using the ball valves, the main air valve on the inert gas generator unit, and the U-tube manometers which measure the differential and static pressures in the respective lines.

(g) Close the manual pilot air and pilot gas valves.

(h) Switch oxygen analyzer sampling valve to burner test port sampling line.

(i) Put char receiver under char cyclone knife gate valve discharge. Clamp and seal receiver to the system.

(j) Put oil receivers under condenser sumps and demister sumps. Using prover connectors, seal receivers to the system.

(k) Record barometric pressure and psychometric readings.

(1) Set temperature controller on manual at $40 \%$ open to allow the reactor to heat up.

(m) When the temperature indicated on the digital temperature controller reaches $900^{\circ} \mathrm{F}$, calculate the inert gas flow rates and adjust the conveying gas and moderating gas flow rates using the ball valves.

(n) Turn on the quench tank water spray pump and adjust the water flow rate to the desired setting.

(o) Reduce the setting on the temperature cortiroller to $30 \%$ open. 
(p) While the reactor comes up to temperature, record all differential and static pressure readings on the manometers and panel magnehelic gauges.

(q) Calculate the flow rates of air and fuel at the inert gas generator and at the hot-gas burner. If the flow rates are not at stoichiometric conditions adjust the flow rates as necessary to reach stoichiometric conditions.

( $r$ ) When the inert gas generator and hot-gas burner flow rates are calculated to be at stoichiometric conditions, take a gas sample, using a glass sample bulb, at the inert gas generator discharge test port and at the burner combustion gas sample station No. 1. Analyze for percent 02 by gas chromatograph.

(s) Check the $A C$ and $D C$ signal on the loss-in weight feeder, measured from test points TP1 and TP2 to ground, to verify that the loss-in weight feeder controller is operating properly

(3) Operation to Achieve Steady-State

(a) Reference temperatures are recorded with Type-K thermocouples. When the thermocouple at the reactor exit is within $50^{\circ} \mathrm{F}$ of the predetermined reference temperature for the test run, and when the thermocouple at the reactor entrance is in the range of set point to set point plus 200 ${ }^{\circ} \mathrm{F}$ the reactor is sufficiently heated so that feed can be added. There will normally be a $50^{\circ} \mathrm{F}$ to $100{ }^{\circ} \mathrm{F}$ temperature drop across the reactor (process side).

(b) All gauges, instruments, recorders and sampling equipment are checked for erratic indications, and the PRU is visually checked for abnormalities.

(c) Turn on loss-in-weight feeder discharge star valve. Check for proper shaft rotation.

(d) The start-up and operating procedures for the K-Tron loss-in-weight feeder are included in the operations manual designated as K-Tron Reference No. 6869E1, Unit Reference No. 
B3-81-036-S1, dated June 1, 1981. This manual is located in tive control room of the PRU unit-Personnel should become familiar with the instructions in the manual before attempting to overate the equipment.Turn on K-Tron feeder (LWF). Operating conditions are determined prior to start-up. Reset the LWF totalizer to zero and mark recorder charts to indicate feed start.

(e) At one minute intervals for the first ten mir.ytes record weight display on LWF digital indicator and calculate feed rate. Adjust thumbwheel switch as necessary to reach set point. When set point has been achieved, record weight display on Data Sheet at two minute intervals.

(f) If the calculated feed rate drops below the set point by ten percent or greater, a feed bridging condition exists. This is corrected by setting the LWF thumbwheel to a higher position (usually five units) or by tapping the feed bin. Check feed rate at one minute intervals as in $H(3)(e)$ above. When set point is reached, continue monitoring at two minute intervals.

(g) Feed from the LWF to the reactor increases from zero to set point in increments. As the amount of feed added to the reactor increases to the set point the temperatures in the reactor will tend to decrease since the wood is a thermal load on the system. Manually increase the burner settings as necessary to maintain the temperature at the set point temperature $\pm 10^{\circ} \mathrm{F}$.

(h) Burner air, burner propane, conveying and moderating inert gas and offgas orifice pressures are indicated on the U-tube manometers- Check and record differentia.3. and static -pressures on Data Sheet at five minute intervals.

(i) All critical temperatures are recorded on the multipoint temperature recorders- Reactor temperatures are visually checked at 2 to 5 minute intervals using the digital temperature indicators. The test run, reference temperature is shown on the digital temperature controller. This 
temperature is continuously observed and adjustments are made to keep this reference temperature at the set point temperature. The operating range for a test run is the set point temperature $\pm 5^{\circ} \mathrm{F}$.

(j) At two to five minute intervals observe pressure drops in reactor and condenser and remainder of system. Observe pressure indicators for condenser cooling fans. At 15 minute intervals record all pressure readings on the control panel, and gauges located on the inert gas generator, hot-gas burner air and fuel delivery system.

(k) Change char container every ten minutes or as needed depending upon feed rate.

(1) Drain condenser and demister sumps every fifteen minutes and replace receivers when full.

(m) After the desired feed rate is reached and the reactor operating temperature is at the set point, the system is allowed to operate at these conditions for 15 to 30 minutes to ensure that the system has stabilized and that steady-state has been achieved. The Data Test Run is then started.

(4) Test Run

(a) Simultalleously the char gate valve, condenser and demister valves ire closed- The quench tank is drained. The sampling train pump is started. Thermocouple recorder charts are marked to indicate the start of test run, and elapsed run time and LWF weight display are recorded on the Data Sheet.

(b) Replace char container and condenser and demister receivers.

(c) Record LWF weight display at two minute intervals.

(d) Manometer readings are recorded on data sheet.

(e) Condenser and demister sumps are checked and drained every 10 to 15 minutes. Ball valves on condenser sumps no. 1 and 2 
are left open to allow the more viscous material to drain into the receivers.

(f) Char containers are changed as often as necessary, depending on the feed rate and expected char yield. Change every 10 minutes for a feed rate of 50 to 60 pounds per hour.

(g) Integrated samples of the inert gas and offgas streams are collected over the entire perird of the test run. The samples are collected in gas sampling bags. Samples of inert gas and offgas are collected in glass bulbs at 20 minute intervals and are used as a backup for the integrated samples. Hot-gas burner samples are collected in glass bulbs at 20 minute intervals.

(h) At the end of the test period the following are done simultaneously (1isted in order of importance).

i) Shut down offgas sampling train pump.

ii) Remove char container and close condenser and demister valves. Open valve on quench tank, drain and close valve.

iii) Turn off loss-in-weight feeder at switch in control room.

iv) Remove all product containers to the product weighing and storage area in the control building.

(5) Shutdown

(a) Put loss-in-weight feeder mode selector switch in off position. Allow star valve to continue operating for a few minutes to allow feed chuce to empty then turn off star valve.

(b) Turn the burner to low fire position.

(c) Open moderating and conveying lines wide open to blanket the reactor with inert gas.

(d) Close char knife gate valve.

(e) Allow the reactor to cool.

(f) Turn off burner blower.

(g) Turn off quench tank water spray. 
(h) Open the dump valve on the inert gas generator, close the conveying gas and moderating gas ball valves, turn off the main gas valve, allow water to continue to circulate around the shell of the combustion chamber and. air to cool the combustion chamber for one half to one hour.

(i) Turn off auxiliary air compressor.

(j) Turn off inert gas generator main power and allow water to circulate for an additional one half hour.

(k) Turn off recorders, oxygen monitor, K-Tron LWF, North American burner panel, and condenser cooling fans.

(1) Close propane valve at the tank.

(m) Turn off main water valve and main electrical power.

\section{(6) Clean Up}

(a) Immediately after run:

i) Empty K-Tron bin and weigh unused feed.

ii) Allow oil to drain into receivers with the sump valves open.

iii) Store feed barrels, char and oil containers in building.

iv) Move samples into work-up area to be weighed.

v) Seal gas sampling trains and move to work area.

(b) Day after run:

i) Vacuum star valve (LWF).

ii) Place bucket under char cyclone; open gate valve to collect any residual char carried over during cool down. Record weight on data sheet.

iii) Remove bucket while gate is open, check inside with a light to ensure that no char is left in the cyclone, Inspect for bridging or building.

iv) Inspection and cleaning of condenser. 
a) Remove condenser top plate and scrape residue, if present, into sample container. Record weight on data sheet.

b) If a mixtlire of char, tar, and coked oil is present, scrape as much as possible into separate sample containers. Record weight on data sheets.

c) Close condenser sump valves, and using approximately one gallon total of acetone, clean as follows: pour on condenser side walls, inlet chute and on distributor plate, pour an equal amount into each tube and allow it to stand for one half hour.

d) Open the sump valves and collect the acetone solution in containers; let the solution stand for a few minutes to allow solids and heavy tar to settle.

e) Decant the acetone solution and repeat article $H(6)(c)$ as necessary. Perform the final acetone wash using fresh acetone.

f) After last acetone washing collect the material in a container, seal and let it stand overnight before analysis.

g) Check the condenser gaskets for wear; replace if necessary; replace condenser top plate.

v) Inspection and cleaning of the quench tank.

a) Remove quench tank top section and inspect water spray nozzles. Remove and clean if necessary. Scrape residue, if present, from vessel walls, top section, and inner cylinder. Collect material in a sample container. Record weight on data sheet.

b) Check quench tank top section gaskets for wear; replace if necessary. Reinstall water spray nozzle assembly. Check for proper orientation of 
spray nozzle discharge. Replace quench tank top section.

\section{(7) Product Recovery}

(a) Char product is weighed and retained for chemical analysis.

(b) Condensates from condenser and demister sumps and quench tank are weighed and retained for chemical analysis.

(c) Solids and tar removed by acetone wash from the condenser, quench tank and 2nd demister are weighed and retained for recovery of tar and oil and chemical analysis.

(d) Condensation train (see Section 4-G) for offgas streami sampling downstream of demister cyclone.

i) The day before the test run, tare flasks from the ambient module. Pack and tare the glass wool aemister. Pack and tare the drierite column. Replenish the magnesium perchlorate tube.

ii) Immediately before the test run connect the three sampling modules and plug the sample inlet port with a stopper. Turn on the main sampling pump and check all fittings for leaks. Chill traps in ambient module with ice. Chill traps in cold trap module with dry ice and acetone. Start the circulating pumps. When no leaks are present the dry test meter will stop. Turn off the main sampling pump and reset meter to zero.

iii) When the test run starts the stopper in the sample inlet port is removed and is replaced with the tube from the sampling probe. Start the main sampling pump and adjust the flow to 10 liters per minute.

iv) An integrated offgas sample is continuously collected in a gas sampling bag. Grab samples of the offgas are taken at 20 minute intervals using glass bulbs to serve as a backup for the integrated bag sample. 
v) When the test run is completed the main sampling pump is stopped and the total volume of gas is recorded at the dry test meter.

vi) The modules are separated and moved to the work-up area.

vii) The glass wool and drierite columns are weighed.

viii) Light oil fractions from the dry ice traps are coliected and weighed.

ix) The flasks in the ambient module are allowed to stand overnight so that the oil and water phases will separate. Decant and weigh the water from the flasks in the ambient module. weigh the oil remaining in the flasks from the ambient module. 


\section{REFERENCES}

1. Knight, J. A., C. W. Gorton and R. J. Kovac, "Research on the Pyrolysis of Hardwood in an Entrained-Bed Process Development Unit, Interim Technical Report-" Submitted to PNL, November 30, 1983.

2. Knight, J. A., C. W. Gorton and R. J. Kovac, "Entrained-Flow Pyrolysis Screening Runs, Special Technical Report No. 1." Submitted to PNL, June, 1984 .

3. Knight, J. A., C. W. Gorton and R. J. Kovac, "Entrained-Flow Pyrolysis of Biomass." In Proceedings of the 15th Biomass Thermochemical Conversion Contractors' Meeting, Atlanta, Georgia 1983, p. 409. CONF-830323/PNL-SA-11306. Available from the National Technical Information Service, U.S. Department of Commerce, 5285 Port Royal Road, Springfield, VA 22161.

4. Knight, J. A., C. W. Gorton and R. J. Kovac, "Entrained-Flow Pyrolysis of Biomass." In Proceedings of the 16th Biomass Thermochemical Conversion Contractors 'Meeting, Portland, Oregon, 1984. p. 287.

CONF-8405157/PNL-SA-12403. Available from the National Technical Information Service, U.S. Department of Commerce, 5285 Port Royal Road, Springfield, VA 22161. 


\subsection{TASK 3A. EXPERIMENTAL PYROLYSIS PROGRAM \\ PYROLYSIS PRU CONFIGURATION III}

\subsection{INTRODUCTION}

The goal of the project was to experimentally investigate the process conditions for optimum yields of pyrolysis oils in an entrained-flow Process Research Unit (PRU). The entrained-flow PDU, that is Configuration I, was completed in March, 1983. A series of 23 runs were conducted using Configuration I of the PDU, with reactor reference temperatures in the range of $400{ }^{\circ} \mathrm{C}\left(751{ }^{\circ} \mathrm{F}\right)$ to $550{ }^{\circ} \mathrm{C}\left(1021^{\circ} \mathrm{F}\right)$, and at feed rates of $33 \mathrm{lb} / \mathrm{hr}(24 \mathrm{~kg} / \mathrm{hr})$ to $113 \mathrm{lb} / \mathrm{hr}(51.3 \mathrm{~kg} / \mathrm{hr})$, based on moisture and ash-free feed. The results of the experimental runs demonstrated that dry oil yields of greater than $50 \%$ based on moisture and ash-free feed could be obtained. The experimental runs also showed that the entrained-flow PRU could be operated at steadystate for extended periods, at desired process conditions. Based on operational experience, experimental results and reactor modeling efforts, modification of the PDU was necessary to optimize the yield of pyrolytic oil. Those modifications were 3 made during the period April, 1984 to November, 1984.

Nine test runs (16 experiments) were conducted from December, 1984 to October, 1985 using the PRU Configuration II. The results of those tests were discussed in Section 7. During those experiments a draft fan was used to increase system flowrate (and decrease residence time). Process conditions and variables in the quench spray system were varied so as to maximize pyrolytic oil collection and minimize degradation or polymerization of the pyrolytic oil. A maximum oil yield of $51 \%$ was achieved at a reactor reference temperature of $477^{\circ} \mathrm{F}\left(891^{\circ} \mathrm{F}\right)$.

However, results from the modeling effort indicated that oil yields as high as $60 \%$ should be obtainable using the current pyrolysis system. In addition, it became evident that the sets of process conditions necessary to produce even higher oil yields were beyond the design limitations of the PRU. A number of operational and minor design modifications were implemented in the final set of experiments. As expected, those modifications resulted in higher oil yields which reached $60.0 \%$. Eleven experimental runs were conducted from 
Apri1, 1986 to December, 1987. These eleven runs make up Task 3A. Reactor reference temperatures ranged from $475^{\circ} \mathrm{C}\left(887^{\circ} \mathrm{F}\right)$ to $525^{\circ} \mathrm{C}\left(977^{\circ} \mathrm{F}\right)$, and the dry $0 i 1$ yields ranged from $43.4 \%$ to $60.0 \%$. The results of these experiments are discussed in the following section.

\subsection{PRU OPERATION - CONFIGURATION III}

The experimental results from the Configuration II resting and the advanced model, with the incorporation of the Configuration II test data, indicated that increased pyrolysis oil yields could be achieved by operating the PRU at process conditions which were beyond the original design parameters of the PRU system. During the period which included tests $3 / 10$ through $3 / 12$, a number of equipment modifications and operational adjustments were made to: (1) optimize the PRU system parameters to approach the desired parameters for maximum oil production, as predicted by the model, (2) improve the oil collection system so that the expected, higher, pyrolytic oil production could be collected and measured. In Run $3 / 12$ process and operational conditions were optimized, within the constraints of the then current PRU system, to match the set of conditions which the model indicated would result in maximum oil production. That experiment resulted in the highest pyrolytic oil yield achieved to that date, $53.8 \%$ (dry oil/ moisture- and ash-free feed).

In examining the experimental data through run $3 / 12$, two points must be emphasized. First, the maximum oil yield of $53.8 \%$ in Run $3 / 12$ represents the maximum, "collected" oil yield for that configuration of the PRU. The modeling effort predicted that for certain sets of process conditions, which were not achievable with that version of the PRU, 0 il yields in the mid-60\% range, and even up to $70 \%$, could be produced. Second, the model showed that for a given test (for certain sets of operating conditions), the maximum oil would be reached at a location in the interior of the reactor. As the oil flowed through the rest of the reactor and into the oil collection system, the oil degradation reactions became a factor and the resulting, "collected" oil yield was reduced. (The model indicated that an oil yield of $60 \%$ had been produced locally in the reactor but that a portion of the oil had degraded before reaching the reactor exit, thus resulting in the lower measured oil yield.) A typical curve based on the results of Table 40, Predicted Reactor Profile, is presented in Figure 12, Typical Local $0 i 1$ Yields in the PRU Reactor. 
TABLE 40. Predicted Reactor Profile

Reactor Outlet Temperature $-1527^{\circ} \mathrm{F}\left(575^{\circ} \mathrm{C}\right)$

Feed Rate - $30.0 \mathrm{lb} / \mathrm{hr}$ (moisture free) $(13.61 \mathrm{~kg} / \mathrm{hr}$ )

Inlet Gas Rate - $250 \mathrm{lb} / \mathrm{hr}$ (includes water vapor) $(113.4 \mathrm{~kg} / \mathrm{hr}$ )

Ash $-0.8 \%$ by weight of moisture-free feed

Particle Diameter $-8.3 \times 10-4 \mathrm{ft}(2.53 \times 10-4$ meters $)$

Reactor Inside Diameter - $0.505 \mathrm{ft}$ (0.154 meters)

Reactor Height - $23.7 \mathrm{ft}$ (7.22 meters)

\begin{tabular}{|c|c|c|c|c|c|}
\hline $\begin{array}{l}\text { Height } \\
(f t)\end{array}$ & $\begin{array}{c}\text { Normalized } \\
\text { Reactor } \\
\text { Height }\end{array}$ & $\begin{array}{l}\text { Gas } \\
\text { Temp. } \\
(\mathrm{R})\end{array}$ & $\begin{array}{c}\text { Particle } \\
\text { Temp. } \\
(\mathrm{R})\end{array}$ & $\begin{array}{c}\text { Particle } \\
\text { Residence } \\
\text { Time }\end{array}$ & $\begin{array}{l}\text { Fractional } \\
0 i 1 \text { Yield }(a)\end{array}$ \\
\hline 0.00 & 0.00 & 1800 & 537 & 0.00 & 0.000 \\
\hline 2.37 & 0.10 & 1551 & 1421 & 0.20 & 0.105 \\
\hline 4.74 & 0.20 & 1527 & 1524 & 0.41 & 0.482 \\
\hline 7.11 & 0.30 & 1527 & 1527 & 0.60 & 0.616 \\
\hline 9.48 & 0.40 & 1527 & 1527 & 0.78 & 0.633 \\
\hline 11.85 & 0.50 & 1527 & 1527 & 0.95 & 0.613 \\
\hline 14.22 & 0.60 & 1527 & 1527 & 1.13 & 0.582 \\
\hline 16.59 & 0.70 & 1527 & 1527 & 1.31 & 0.547 \\
\hline 18.96 & 0.80 & 1527 & 1527 & 1.48 & 0.514 \\
\hline 21.33 & 0.90 & 1527 & 1527 & 1.66 & 0.481 \\
\hline 23.70 & 1.00 & 1527 & 1527 & 1.83 & 0.451 \\
\hline
\end{tabular}




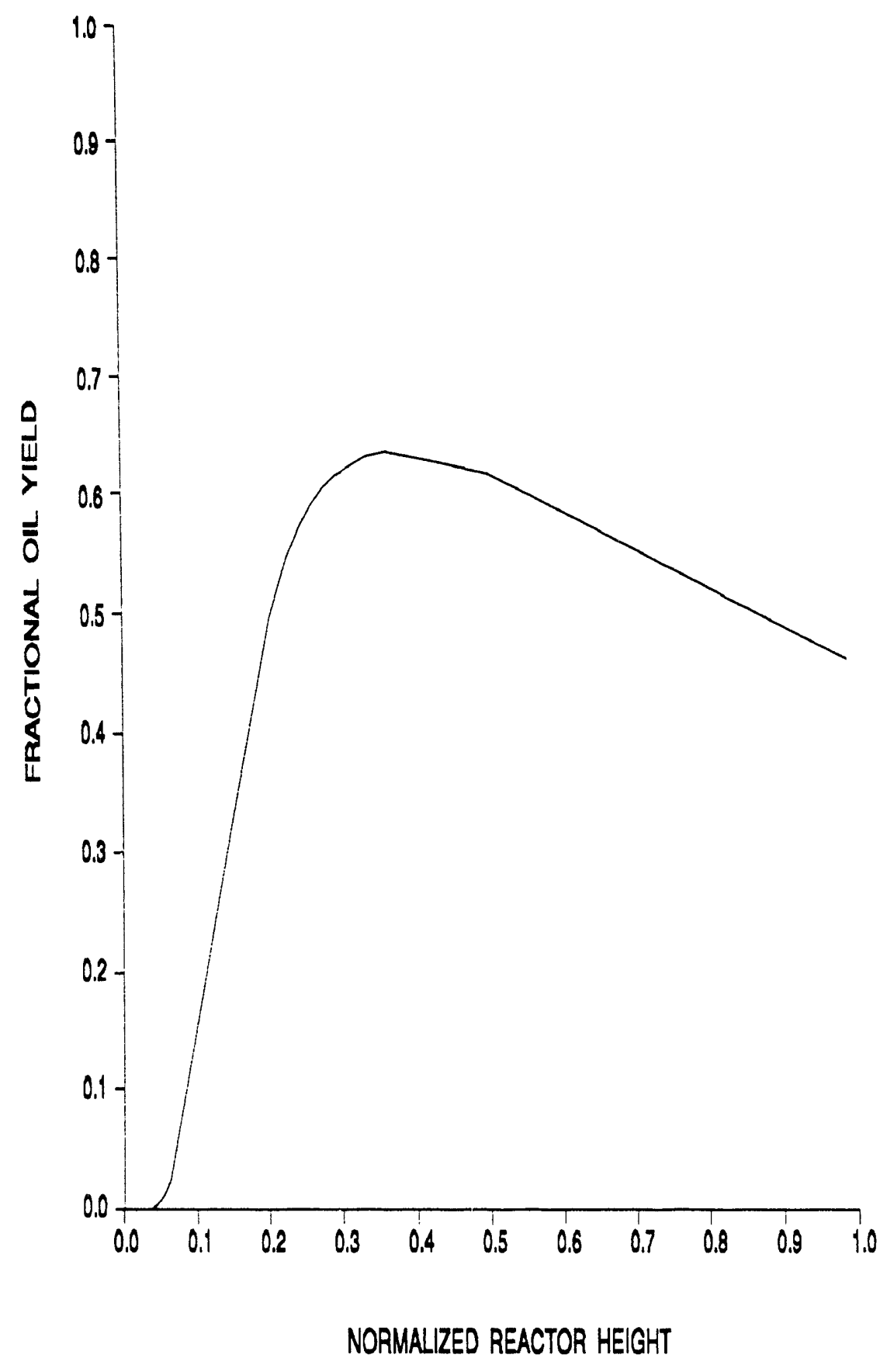

FIGURE 12. Typical Local 0il Yields 
The curve in Figure 12 shows that, for the stated set of conditions, a maximum oil yield of $63.3 \%$ (moisture- and ash-free basis) was predicted for the PRU. This maximum yield was produced at a normalized reactor height of 0.4 . For the vertical PRU reactor, which is 23.7 feet $(7.22 \mathrm{~m})$ in length, that normalized height corresponds to a reactor length of 9.48 feet $(2.89 \mathrm{~m})$ and a particle residence time of 0.78 seconds. Other profiles indicated that local oil yields of $70.0 \%$ were achievable with a redesigned pyrolys is system.

As stated previously, the modeling effort clearly indicated that an increased oil yield could be achieved in the PRU if the residence time was reduced. Since neither the time nor the capital was available to design and install a new reactor system, lower residence times could be achieved with the current PRU in two ways: (1) by increasing the gas flow rate through the reactor or, (2) by reducing the length of the reactor. In order to overcome the limitations of the PRU, and to achieve the desired combinations of process temperature and reactor residence time, an alternative operating procedure was introduced. Whereas the wood feed had previously been conveyed into the refractory lined mixing section, which was located below the reactor tube, the wood feed was now injected directly into the reactor tube. Reactor tube feed locations were located downstream of the previously used mixing section feed injection port. The use of feed ports in the reactor tube reduced the effective length of the reactor, allowing shorter residence times to be achieved.

The results of this modification were extremely impressive. As predicted, very high pyrolytic oil yields reaching $60.0 \%$ were achieved. In addition, very little difficulty was experienced in repeatedly producing oil yields of $55 \%$ on a routine basis. Mass and energy balance closures ranged from $100.3 \%$ - $104.3 \%$ and $97.7 \%$ - $104.5 \%$, respectively.

Incorporation of the modifications made to the PRU from Run 3/i0 to Run $3 / 19$ resulted in a system arrangement which was referred to as Configuration III. The quench tank was removed from the system. The quench spray system was retained and three additional spray injection ports were installed. Hexane was used as the quench spray fluid in some of the experiments instead of water. The use of moderating gas was discontinued after Run 3/13. The condenser was bypassed with piping which effectively removed it from the system. Two 
high-efficiency, jacketed cyclones were installed between the char cyclone and the demister. In tests thirteen through nineteen the wood feed was injected into the reactor tube, allowing shorter residence times to be investigated.

Eleven pyrolysis tests were conducted with oak hardwood feed to obtain data on the operation of the PRU - Configuration III. Each of the tests was conducted for a continuous four-hour test period, except Run 17 which was conducted for two hours. Test sixteen was divided into two test periods, Run $16 \mathrm{~A}$ and Run 16B. The experimental procedures and data acquisition for the tests, are similar to those of the PRU Configuration II, and have been discussed previously.

\subsection{DESCRIPTION OF SYSTEM}

The entrained-flow research unit, with the modifications described above incorporated into the system, was referred to as Configuration III. A flow diagram of the Process Research Unit Configuration III is given in Figure 13, and its operation is described below. Propane gas (1) and air (2) are burned stoichiometrically in an inert gas generator, and the combustion products are cooled in a water spray chamber (3) so that the combustion gases leave saturated with water vapor, at about ambient temperature. The exit stream from the inert gas generator is split into two streams. One of these (4) provides moderating gas for the hot-gas burner and the other (5) provides convoying gas for the feed particles (6). (Moderating gas was not used in all of the experiments.) Propane (7) also fuels the hot-gas burner which operates stoichiometrically with air (8) supplied by a blower. The mixture consisting of moderating gas, convoying gas, burner combustion products, and wood particles moves vertically upward through the reactor tube in which the pyrolysis takes place. The resulting mixture (9) consists of noncondensable gases, water vapor (entering moisture plus combustion and pyrolysis products), pyrolysis oil vapors and char. In the char cyclone, almost all of the char particles (10) are removed, and the stream (11) leaving the char cyclone consists of noncondensable gases, water vapor, pyrolysis oil vapor, and some char fines. This mixture flows toward the first jacketed cyclone (12). A liquid (e.g. water or other solvent) is sprayed into the piping, upstream of the jacketed cyclone inlet, so that the mixture can be quenched rapidly. Three additional sites are available for the injection of quench spray liquid. 


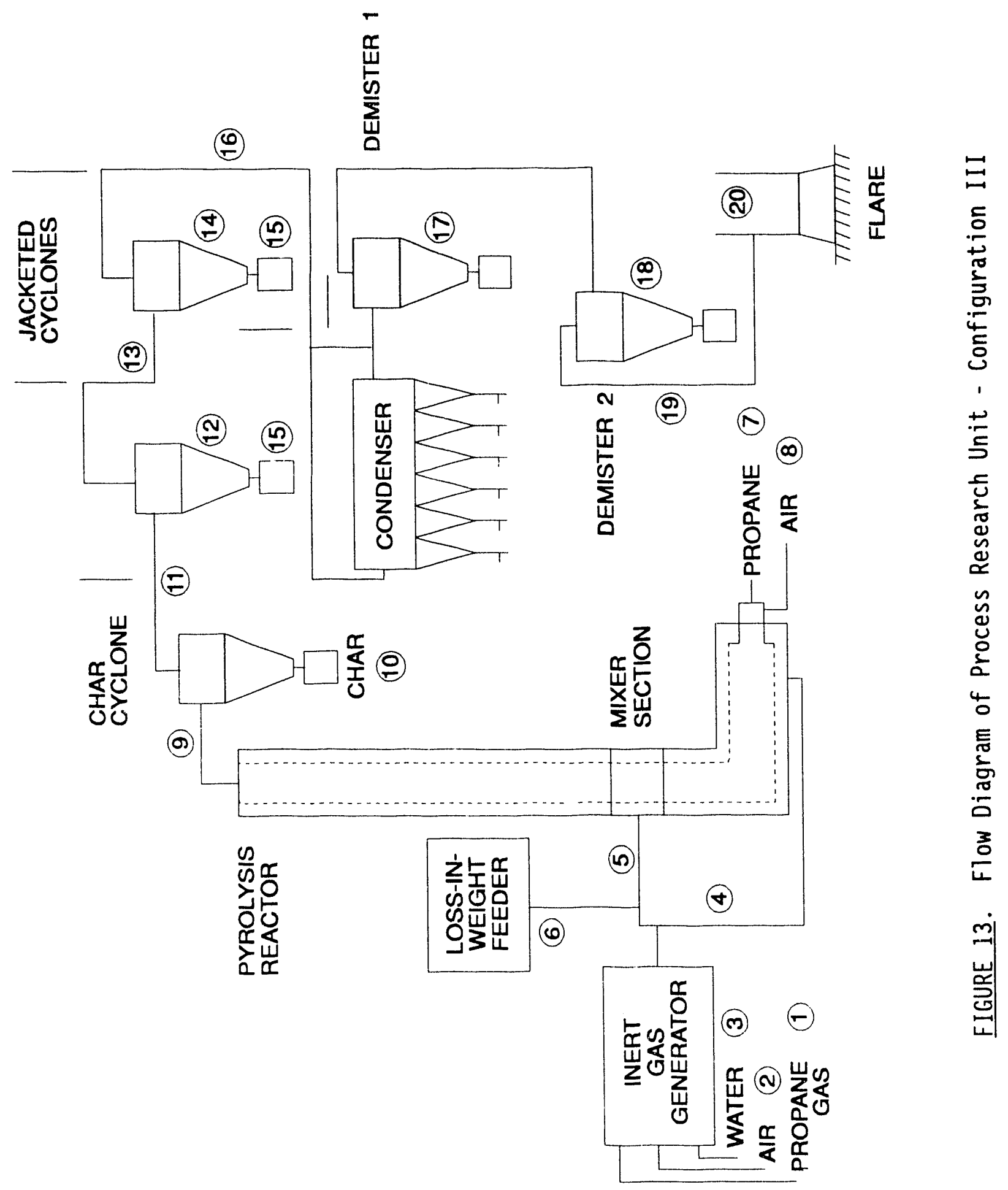


These sites are upstream of and at the exit of the second jacketed cyclone, and upstream of the first demister. The mixture (13) then enters the second jacketed cyclone (14), and the pyrolysis vapors (and some water vapor in the second cyclone) are condensed. (The previous air-cooled condenser was bypassed.) The condensed phases (15) are removed via sumps and collection receivers, and the existing mixture (16) consisting of noncondensable gases, water vapor, light oil vapors, and an aerosol of oil passes through two demisters connected in series (17) and (18). Most of the aerosol is removed in the demisters. The resulting mixture (19) consisting mainly of noncondensable gases, water vapor, and remaining aerosol, enters the flare where air is introduced. The mixture is burned, and the products of combustion (20) are exhausted to the atmosphere.

\subsection{PYROLYSIS EXPERIMENTS - CONFIGURATION III}

The PRU operation data for these eleven experiments are presented in Table 41, and the percent yield of pyrolytic oil and char, in Table 42 . The percent water and the higher heating value (HHV) of representative samples from the condensates of each of the collection sumps and the demisters are presented in Table 43. Data on representative samples of the char from each of the test runs are given in Table 44 . Table 45 shows the dry feed rate, the actual testing period, the total inlet gas rate, the percent oil yield, and the reactor reference temperature. Pertinent comments concerning each test are given in Table 46 .

\subsection{MASS AND ENERGY BALANCES - CONFIGURATION III}

The inputs to the PRU system are: wood feed with moisture and ash, inert gas from the inert gas generator, propane (commercial grade), combustion air, and water for the offgas quench spray system. The output streams consist of char, condensates and offgases. All inputs and outputs are weighed or measured directly. The equipment and methods used to determine the input and output flow rates have been discussed previously ${ }^{3}$. The mass balances for pyrolysis tests ten through nineteen are given in Tables 47 through 49 . The basis for the energy balance is the steady-flow energy equation. The energy balance includes the energy content of the wood feed, inert gas (which may contain carbon monoxide and hydrogen), propane, and the char, pyrolytic oil, and 


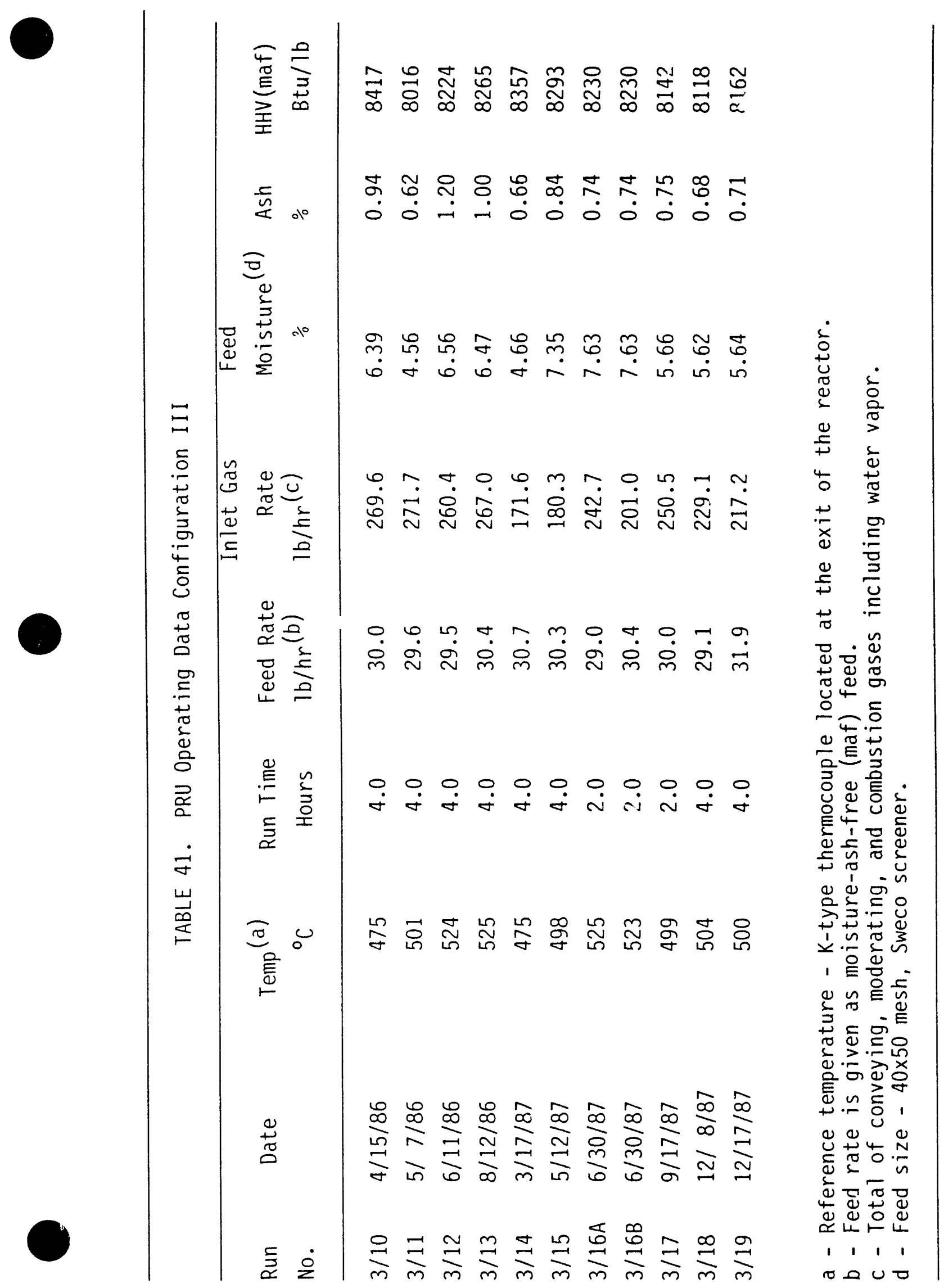


TABLE 42. Percent $0 i 1$ and Char Yield Data Configuration III

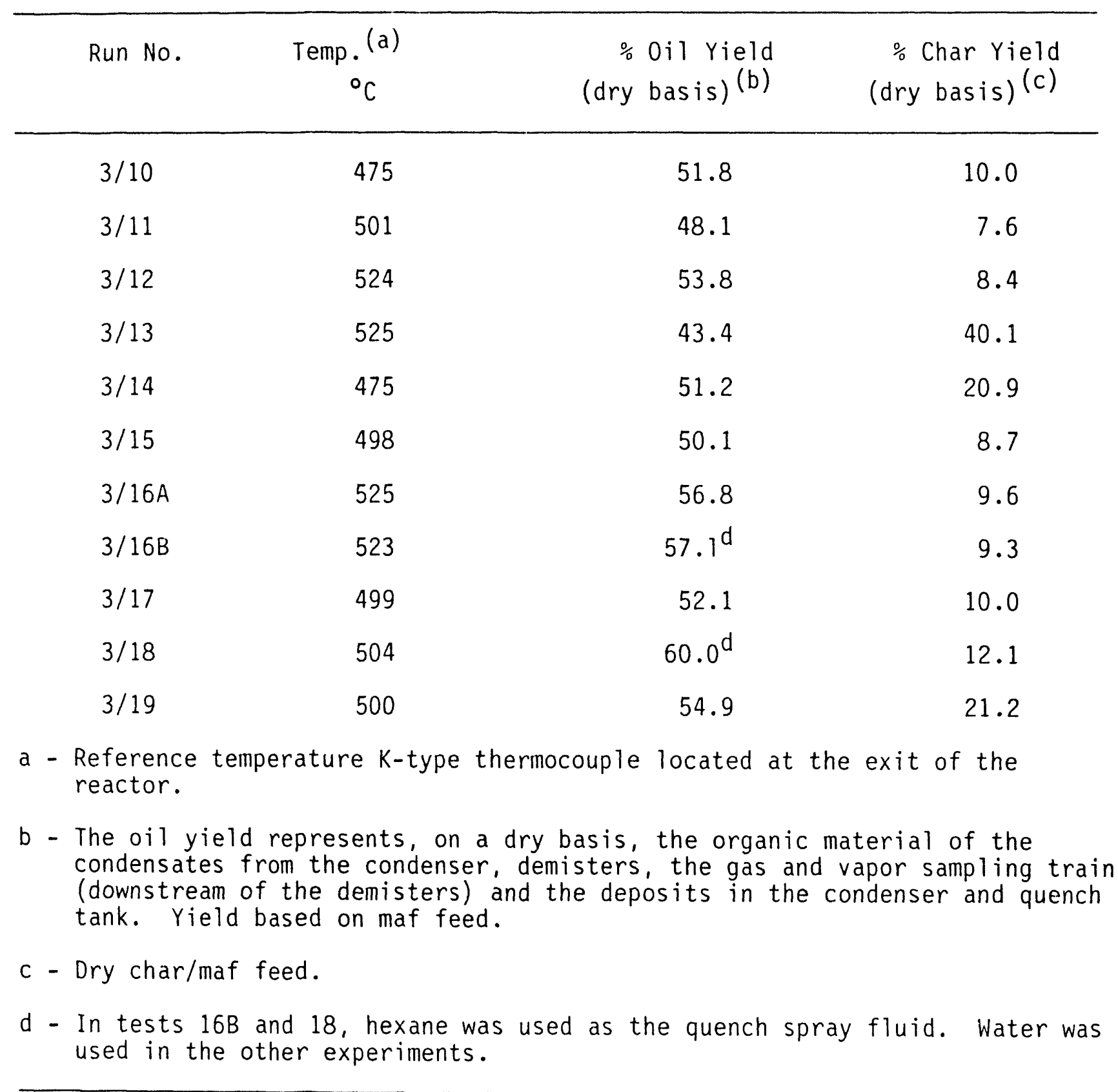




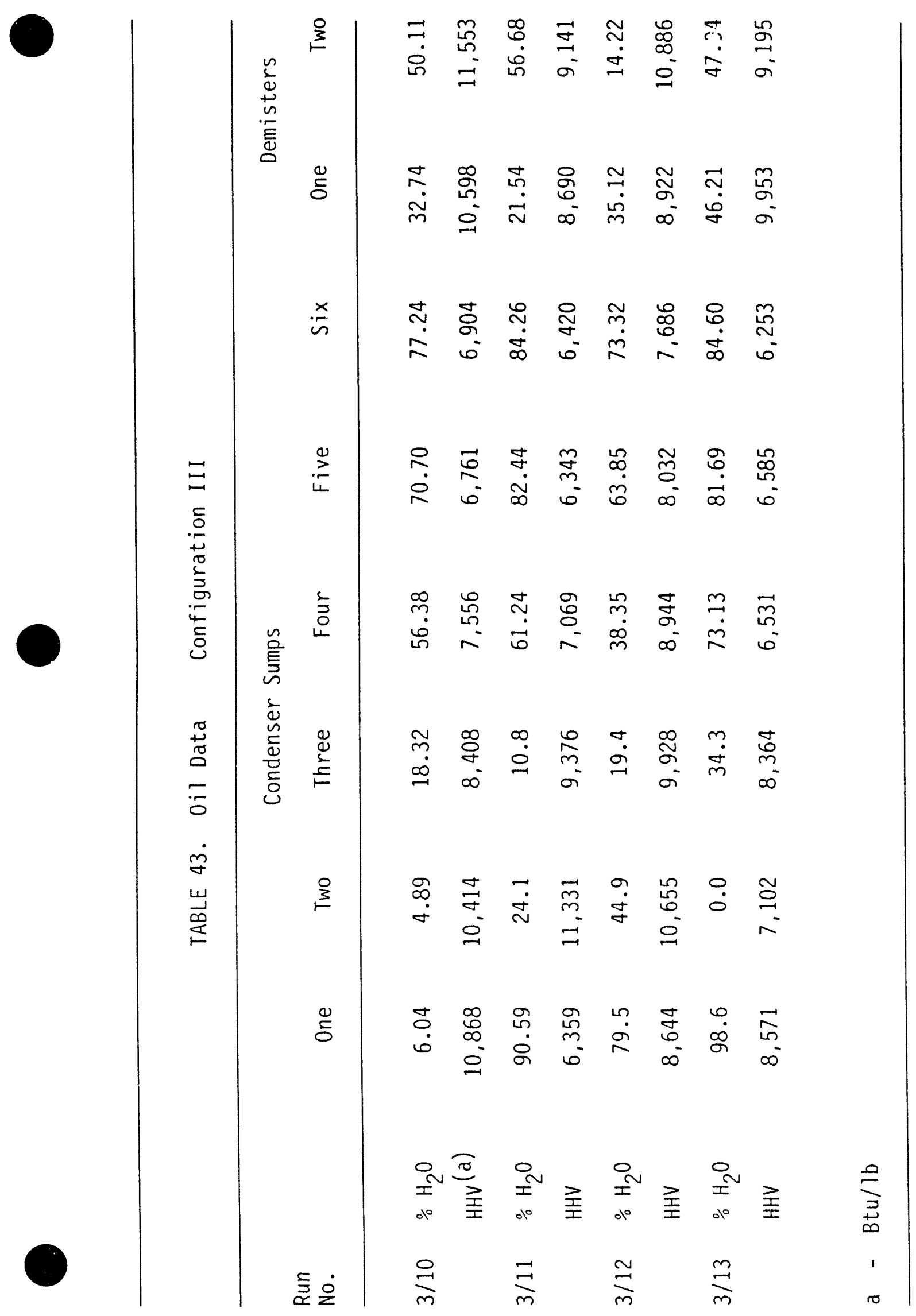




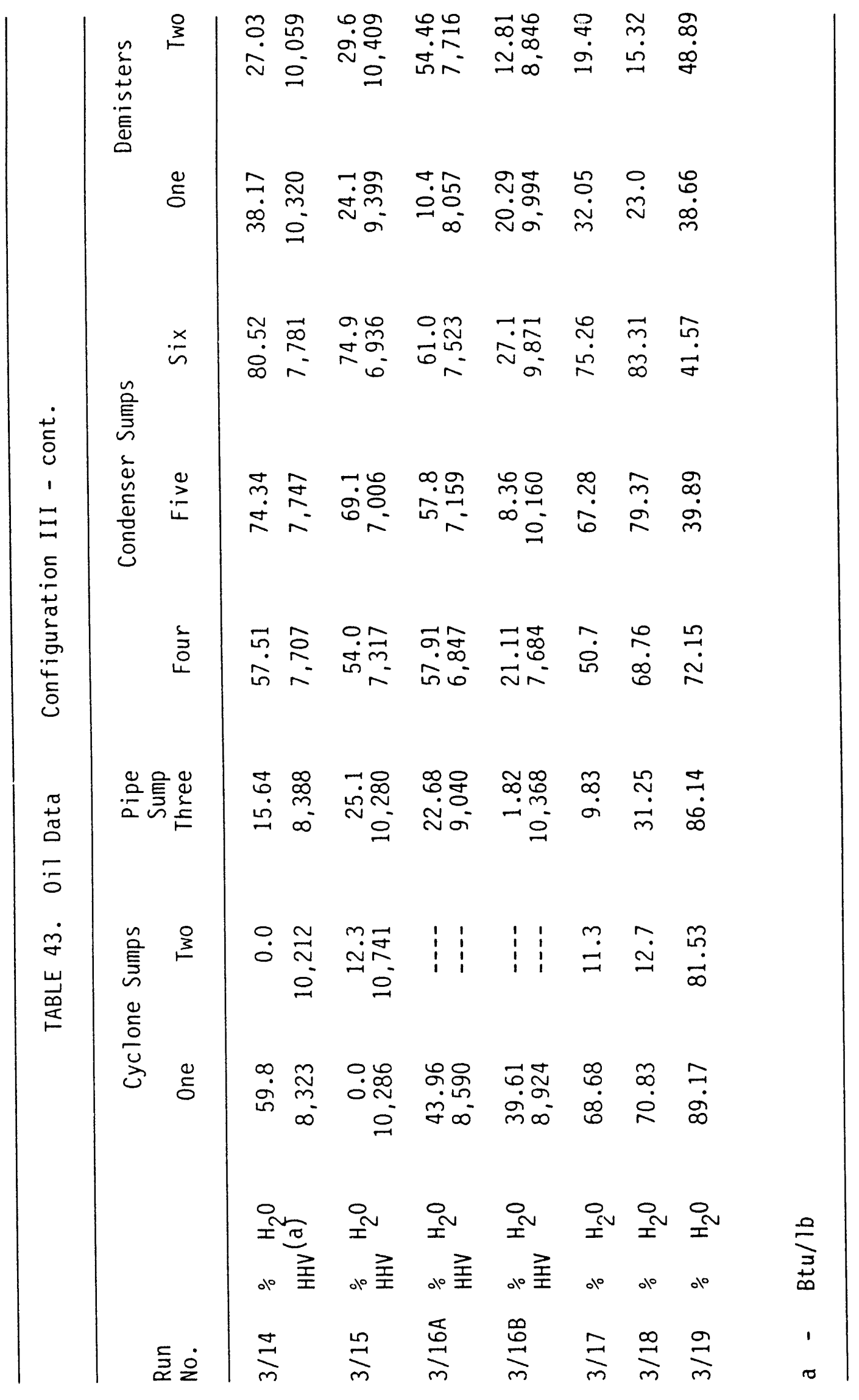


TABLE 44. Char Data - Configuration III

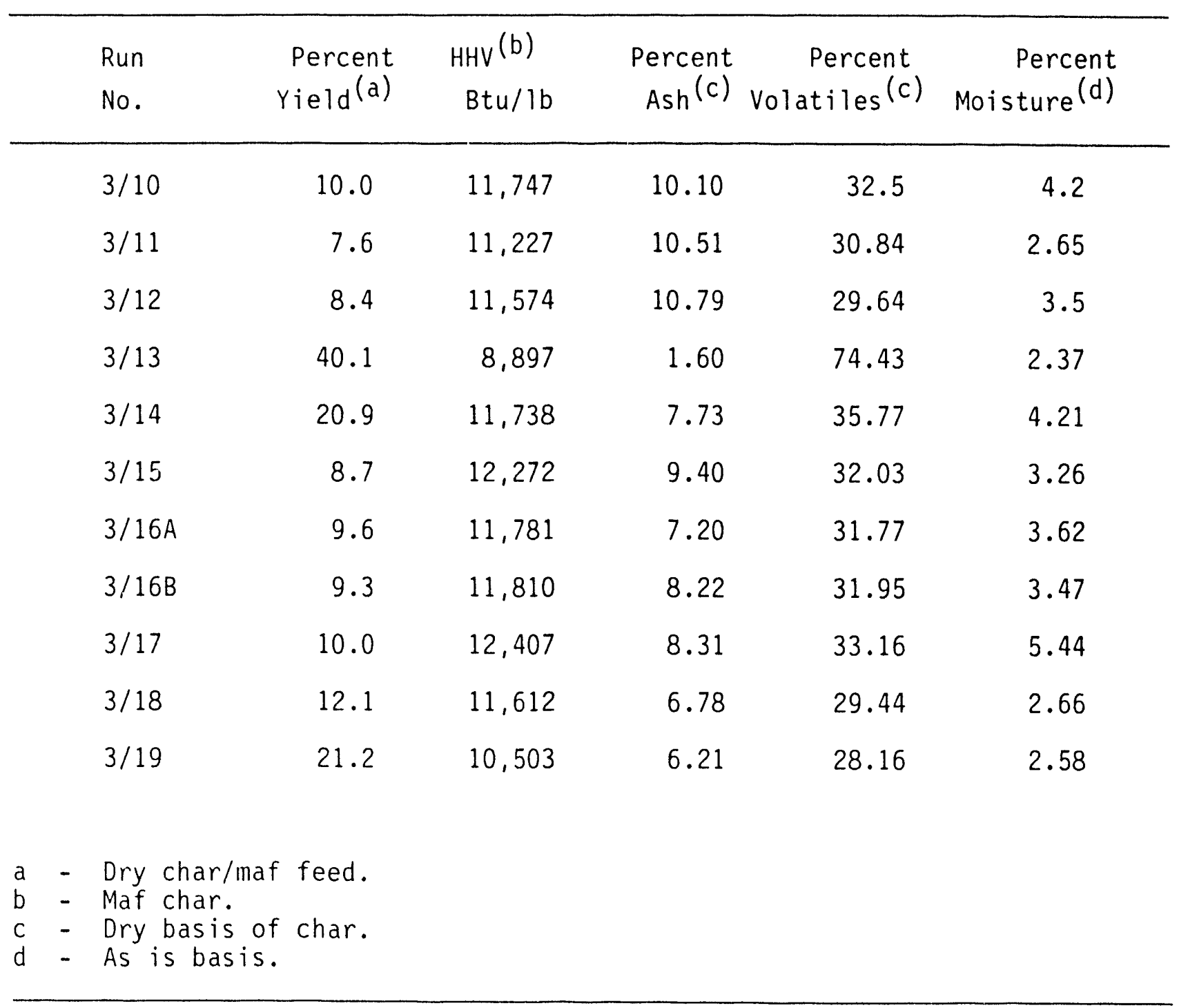


TABLE 45. Pyrolysis Runs With PRU - Configuration III

\begin{tabular}{lcccccc}
\hline Run & Date & $\begin{array}{c}\text { Feed } \\
\text { dry }) \\
\text { lb/hr }\end{array}$ & $\begin{array}{c}\text { Run Time } \\
\text { (min) } \\
\text { Rate }\end{array}$ & $\begin{array}{c}\text { Total } \\
\text { Inlet Gas }\end{array}$ & $\% 0 i 1$ & $\begin{array}{c}\text { Temp. } \\
{ }^{\mathrm{F} /} \mathrm{C}\end{array}$ \\
\hline $3 / 10$ & $4 / 15 / 86$ & 30.2 & 4.0 & 269.6 & 1.8 & $887 / 475$ \\
$3 / 11$ & $5 / 7 / 86$ & 29.8 & 4.0 & 271.7 & 8.1 & $934 / 501$ \\
$3 / 12$ & $6 / 11 / 86$ & 29.9 & 4.0 & 260.4 & 3.8 & $975 / 524$ \\
$3 / 13$ & $8 / 12 / 86$ & 30.7 & 4.0 & 267.0 & 3.4 & $977 / 525$ \\
$3 / 14$ & $3 / 17 / 87$ & 30.9 & 4.0 & 171.6 & 1.2 & $887 / 475$ \\
$3 / 15$ & $5 / 12 / 87$ & 30.6 & 4.0 & 180.3 & 0.1 & $928 / 498$ \\
$3 / 16 \mathrm{~A}$ & $6 / 30 / 87$ & 29.2 & 2.0 & 242.7 & 6.8 & $977 / 525$ \\
$3 / 16 \mathrm{~B}$ & $6 / 30 / 87$ & 30.6 & 2.0 & 201.0 & 7.1 & $973 / 523$ \\
$3 / 17$ & $9 / 17 / 87$ & 30.2 & 2.0 & 250.5 & 2.1 & $930 / 499$ \\
$3 / 18$ & $12 / 8 / 87$ & 29.3 & 4.0 & 229.1 & 0.0 & $939 / 504$ \\
$3 / 19$ & $12 / 17 / 87$ & 32.1 & 4.0 & 217.2 & 4.9 & $932 / 500$ \\
\hline & & & & & & \\
\hline
\end{tabular}


TABLE 46. Comments on Experimental Runs - Configuration II

Run $3 / 10$

Run $3 / 11$

Run $3 / 12$

Run $3 / 13$

Run $3 / 14$

Run $3 / 15$
Moderating gas used. Quench tank in place; much fluid collected from quench tank due to higher spray rate. Draft fan in use. All condenser sumps flowed well, no buildup or plugging. Two condenser fans in use. No operating problems. Feeding system very steady. Moved loss-in-weight feeder to 4 th level of PRU tower to reduce system pressure drop and improve feed delivery system.

Moderating gas used. Draft fan in operation. Quench spray in operation; no liquid collected from quench tank. Feed very steady. No. 2 condenser sump plugged during test. A heat gun was used to unplug sump and maintain oil flow. Two condenser fans in use. Draft fan failed near end of run; blew out condensate trap with air and restarted.

Higher reactor reference temperature than Runs $3 / 11$ or $3 / 12$. Last test in which wood feed was injected into the reactor mixer section. Moderating gas used. Draft fan in operation. Giench spray in operation. Three condenser fans in use. PRU system conditions optimized to give maximal oil production. Highest oil yield to date, $53.8 \%$, achieved.

Feed injected into reactor 8.5 feet above reactor inlet. Effective reactor length, 12.5 feet. $0 i 1$ yield of $43.4 \%$ was lower than expected. Char yield of $40.1 \%$ much higher than expected. Inspection of "char" showed that product was on 1y partially pyrolyzed. Draft fan in operation. Quench spray in operation. Three conaenser fans in use. Quench tank removed from PRU system.

Feed injected into reactor 6.5 feet above reactor inlet. Effective reactor length, 14.5 feet. 0 il yield much better at $51.2 \%$, but still lower than expected. Char product appeared to be completely charred, but char yield still higher than expected at $20.9 \%$. No moderating gas used. No quench spray used. Draft fan not used. No. 2 condenser sump plugged during run; a heat gun was used to unplug and maintain flow from the sump.

Feed injected into reactor 6-5 feet above reactor inlet. Effective reactor length, 14.5 feet. Reactor reference temperature higher than previous run. No moderating gas used. No quench spray used. Draft fan not used. Three condenser cooling fans used. Char yield in expected range at $8.7 \%$. 0il yield lower than expected at $50.1 \%$, probably due to degradation of oil. 
TABLE 46. Comments on Experimental Runs - Configuration III, Continued

Run $3 / 16 A$

Run $3 / 16 B$

Run $3 / 17$

Run $3 / 18$

Run $3 / 19$
Feed injected into reactor 6.5 feet above reactor inlet. Effective reactor length, 14.5 feet. Reactor reference temperature again higher than previous run. Water used as quench spray fluid. Condenser bypassed, jacketed cyclones installed. No moderating gas used. No draft fan used. Significant increase in oil yield, at $56.8 \%$.

Feed injected into reactor 6.5 feet above reactor inlet. Effective reactor length, 14.5 feet. Hexane used as quench spray fluid. Reactor reference temperature same as in Run 16A. Condenser bypassed. No moderating gas used. No draft fan used. Again significantly increased oil yield, at $57.1 \%$.

No moderating gas used. No quench spray used. No draft fan used. Reactor reference temperature lower than Runs 16A and 16B. Reactor feed injection port same as previous run. Char yield in expected range, at $10 \%$. 0 il yield lower than expected, at $52.1 \%$, probably due to degradation of oil. Very little fluid collected at first jacketed cyclone.

No moderating gas used. Hexane used as quench spray fluid. No draft fan used. Reactor reference temperature same as previous test. Reactor feed injection port same as previous run. Char yield in expected range, at $12.1 \%$. Highest 011 yield to

date produced, as expected, as predicted by mode1, $60.0 \%$

Water used as quench spray fluid. No moderating gas used. No draft fan used. Reactor reference temperature same as previous test. Reactor feed injection port same as previous run. Very high rate of quench spray. Char yield highe: than expected, at $21.2 \%$. 0 il yield high, at $54.9 \%$, but still lower than expected. 


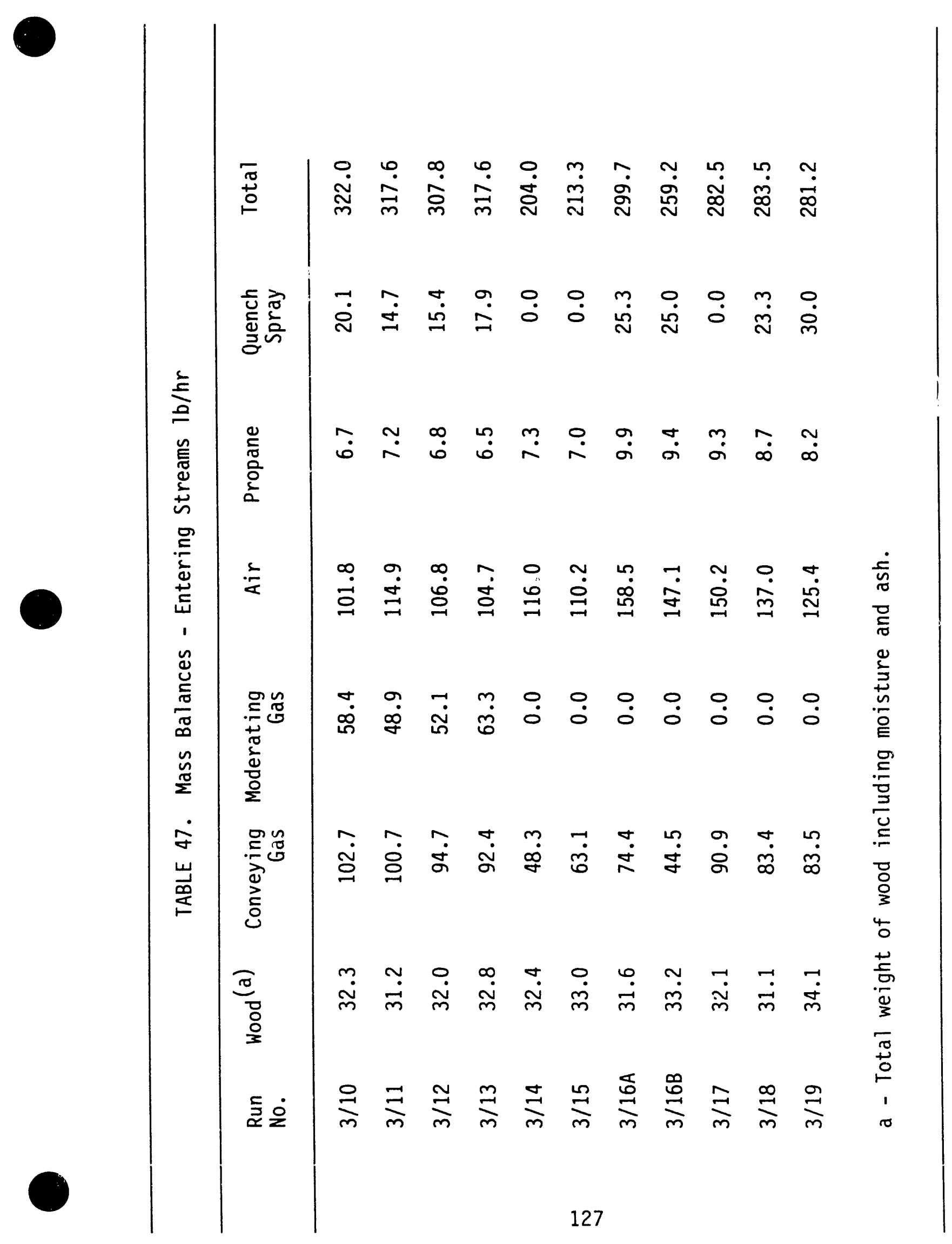


TABLE 48. Mass Balances - Leaving Streams - $1 \mathrm{~b} / \mathrm{hr}$

\begin{tabular}{lrrrr}
\hline Run No. & Char (a) & Condensates $(b)$ & Offgases $(c)$ & Total \\
\hline $3 / 10$ & 3.1 & 55.8 & 265.2 & 324.1 \\
$3 / 11$ & 2.3 & 52.8 & 264.4 & 319.5 \\
$3 / 12$ & 2.6 & 54.6 & 252.1 & 309.3 \\
$3 / 13$ & 12.5 & 56.1 & 251.8 & 320.4 \\
$3 / 14$ & 6.7 & 34.7 & 165.3 & 206.6 \\
$3 / 15$ & 2.7 & 42.0 & 177.7 & 222.4 \\
$3 / 16 \mathrm{~A}$ & 2.9 & 70.2 & 230.8 & 303.9 \\
$3 / 16 \mathrm{~B}$ & 2.9 & 68.6 & 189.0 & 260.5 \\
$3 / 17$ & 3.2 & 43.0 & 237.3 & 283.5 \\
$3 / 18$ & 3.6 & 62.8 & 220.4 & 286.8 \\
$3 / 19$ & 6.9 & 69.3 & 209.9 & 286.1 \\
& & & & \\
a - Char as produced. & & & & \\
C - Mass flow of dry offgas determined by a nitrogen balance. & & \\
\hline
\end{tabular}


TABLE 49. Mass Balances, Configuration III, Summary

\begin{tabular}{lrrr}
\hline Run No. & $\begin{array}{r}\text { Entering } \\
\text { Streams } \\
\text { 1b/hr }\end{array}$ & $\begin{array}{r}\text { Leaving } \\
\text { Streams } \\
\text { lb/hr }\end{array}$ & $\begin{array}{c}\text { Percent } \\
\text { Closure }\end{array}$ \\
\hline $3 / 10$ & 322.0 & 324.1 & 100.7 \\
$3 / 11$ & 317.6 & 319.5 & 100.6 \\
$3 / 12$ & 307.8 & 309.3 & 100.5 \\
$3 / 13$ & 317.6 & 320.4 & 100.9 \\
$3 / 14$ & 204.0 & 206.6 & 101.3 \\
$3 / 15$ & 213.3 & 222.4 & 104.3 \\
$3 / 16 \mathrm{~A}$ & 299.7 & 303.9 & 101.4 \\
$3 / 16 \mathrm{~B}$ & 259.2 & 260.5 & 100.5 \\
$3 / 17$ & 282.5 & 283.5 & 100.3 \\
$3 / 18$ & 283.5 & 286.8 & 101.2 \\
$3 / 19$ & 281.2 & 286.1 & 101.7 \\
\hline
\end{tabular}


offgases. The energy removed from the system by the condenser cooling air is also considered, as well as the sensible heat. System heat losses are calculated based on the results obtained from operating the PRU hot, but without feed. A more detailed discussion of energy balance considerations has been reported. The energy inputs and outputs for tests ten through fifteen are presented in Tables 50 through 52, and the energy balances in Table 53. Carbon balances were performed in addition to overall mass balance calculations so as to determine the distribution of the carbon in the various products. Using the mass balances, presented previously, the amount of carbon in each input and output stream was determined. For each of the gaseous streams, the amount of each component was calculated using gas chromatographic composition data. Further, the amount of carbon in each carbon bearing component was determined using its chemical formula. The carbon content of the wood feed, char, and liquid products was determined using a Perkin Elmer Model $240 \mathrm{C}$ elemental analyzer coupled to a Perkin Elmer Data Station. This analyzer is commonly used to determine the carbon, hydrogen and nitrogen content of organic compounds. The nitrogen content of the wood and the pyrolysis products was taken to be zero. The oxygen content of the samples was calculated by difference. Carbon balances for experiments $3 / 10,3 / 11,3 / 12,3 / 14$, and $3 / 15$ are shown in Tables 54 through 56 .

\subsection{DISCUSSION}

In previous experiments using the six-inch reactor (in test runs $2 / 1-1$ to $2 / 9)$ the feed was introduced into the refractory-lined mixing section, located below the reactor tube. In tests $3 / 10$ to $3 / 12$ of the Configuration III series, the feed was also introduced into the mixing section. In experimental run 3/12 the highest oil yield to that date, 53.8 percent, was achieved. Examination of the experimental data and the computer modeling results indicated that increased oil yields (greater than 60 percent) could be achieved by operating the PRU at higher reactor temperatures and by reducing particle (feed) residence time in the reactor. These "new" operating conditions were outside the design limitations of the existing PRU. The simplest method of testing these "new" operating conditions was to reduce reactor residence time by reducing the effective length of the reactor. This was accomplished by 


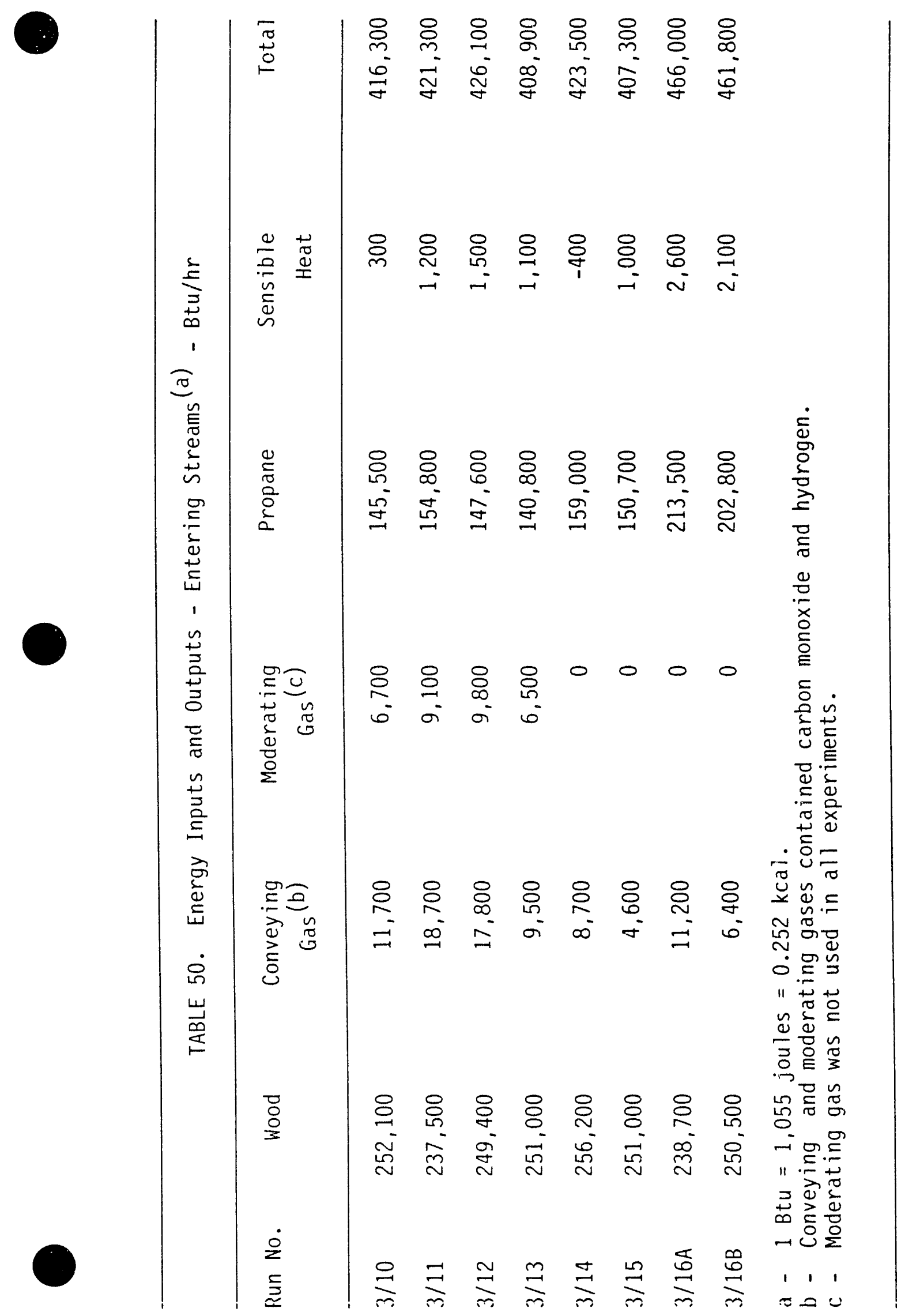




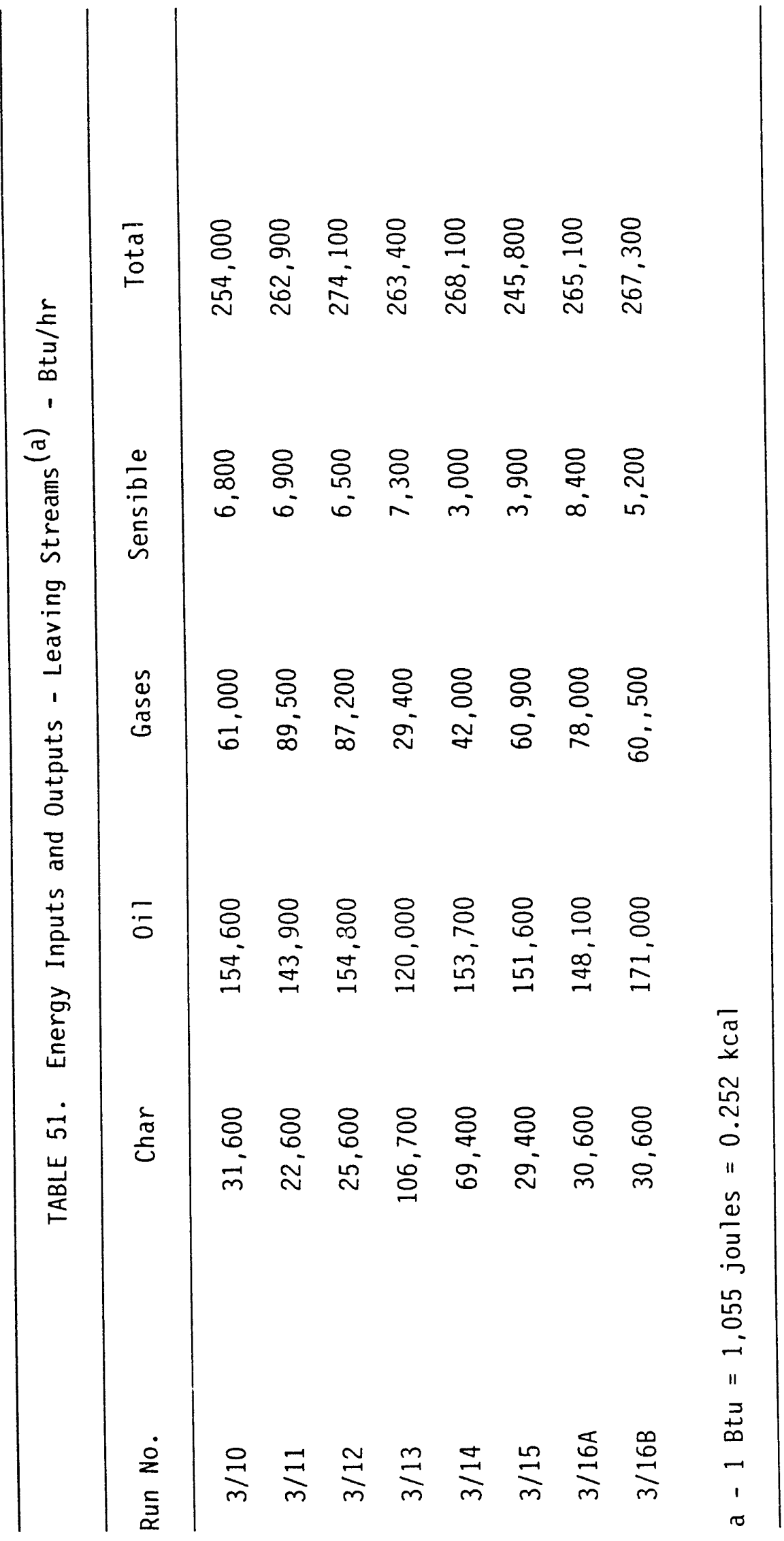




\section{TABLE 52. Energy Inputs and Outputs - Btu/hr Heat Losses (a)}

\begin{tabular}{ccccc}
\hline Run No. & $\begin{array}{c}\text { Hot-gas } \\
\text { Generator }\end{array}$ & System & $\begin{array}{c}\text { Condenser } \\
\text { Cooling Air }\end{array}$ & Total \\
\hline $3 / 10$ & 77,000 & 51,500 & 21,100 & 149,600 \\
$3 / 11$ & 80,200 & 46,400 & 20,600 & 147,200 \\
$3 / 12$ & 77,800 & 49,000 & 28,300 & 155,100 \\
$3 / 13$ & 76,300 & 43,000 & 35,700 & 155,000 \\
$3 / 14$ & 78,300 & 42,800 & 37,300 & 158,400 \\
$3 / 15$ & 97,200 & 48,700 & 34,000 & 179,900 \\
$3 / 16 \mathrm{~A}$ & 83,2 C0 & 69,300 & 37,900 & 190,400 \\
$3 / 16 \mathrm{~B}$ & 84,900 & 80,900 & 36,200 & 201,300 \\
$\mathrm{a}-1 \mathrm{Btu}=1,055$ joules & 0.252 kcal & & \\
\hline
\end{tabular}




\begin{tabular}{|c|c|c|c|c|}
\hline TABLE & 53. Energy & Balances - & Configuration III & - Btu/hr \\
\hline Run No. & $\begin{array}{l}\text { Entering } \\
\text { reams }(a, d)\end{array}$ & $\begin{array}{l}\text { Leaving } \\
\text { Streams }(b)\end{array}$ & $\begin{array}{l}\text { Calculated } \\
\text { Heat Losses }(c)\end{array}$ & $\begin{array}{l}\text { Percent } \\
\text { Closure }\end{array}$ \\
\hline $3 / 10$ & 416,300 & 254,000 & 149,600 & 97.0 \\
\hline $3 / 11$ & 421,300 & 262,900 & 147,200 & 97.3 \\
\hline $3 / 12$ & 426,100 & 274,100 & 155,100 & 100.7 \\
\hline $3 / 13$ & 408,900 & 263,400 & 155,000 & 102.3 \\
\hline $3 / 14$ & 423,500 & 268,100 & 158,400 & 100.7 \\
\hline $3 / 15$ & 407,300 & 245,800 & 179,900 & 104.5 \\
\hline $3 / 16 \mathrm{~A}$ & 466,000 & 265,100 & 190,400 & 97.7 \\
\hline $3 / 16 B$ & 461,800 & 267,300 & 201,300 & 101.5 \\
\hline \multicolumn{5}{|c|}{$\begin{array}{l}\text { a - Feed, conveying gas, moderating gas, propane, sensible heat. } \\
\text { b - Char, oil, offgases, sensible heat. } \\
\text { c - Hot-gas generator, system, condenser cooling air. } \\
\text { d- } 1 \text { Btu }=1,055 \text { joules }=0.252 \mathrm{kcal} \text {. }\end{array}$} \\
\hline
\end{tabular}




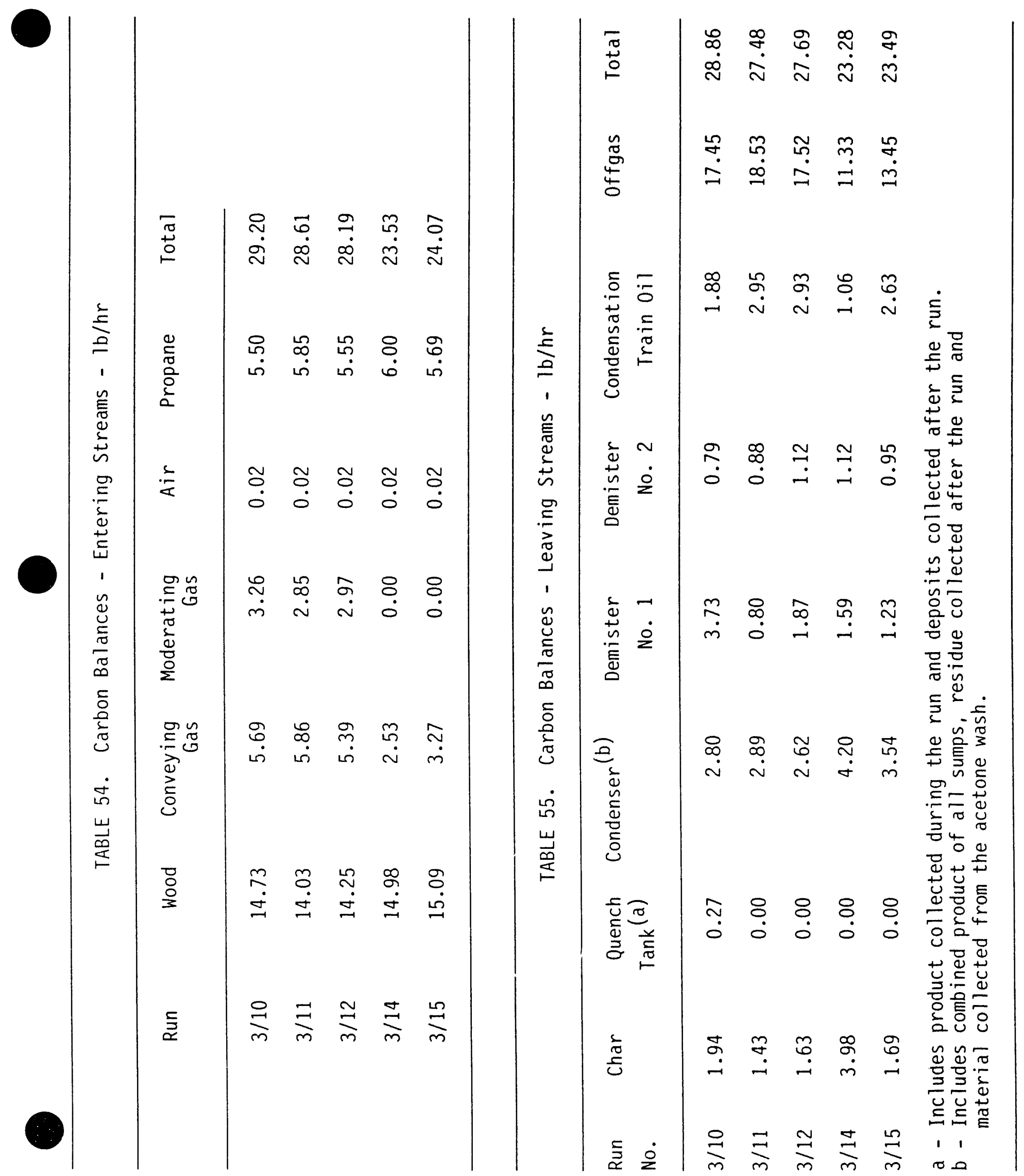




\begin{tabular}{lccc}
\hline & TABLE 56. Carbon Balances & Configuration III - Summary \\
\hline Run No. & $\begin{array}{r}\text { Entering } \\
\text { Streams } \\
1 \mathrm{~b} / \mathrm{hr}\end{array}$ & $\begin{array}{r}\text { Leaving } \\
\text { Streams } \\
1 \mathrm{~b} / \mathrm{hr}\end{array}$ & $\begin{array}{c}\text { Percent } \\
\text { Closure }\end{array}$ \\
\hline $3 / 10$ & 29.20 & 28.86 & 98.8 \\
$3 / 11$ & 28.61 & 27.48 & 96.1 \\
$3 / 12$ & 28.19 & 27.69 & 98.2 \\
$3 / 14$ & 23.53 & 23.28 & 99.0 \\
$3 / 15$ & 24.07 & 23.49 & 97.6 \\
\hline
\end{tabular}

injecting the feed into the reactor tube, at points (a single feed injection point was used during an experiment) downstream of the original feed injection location in the mixing section. The above modification resulted in very high pyrolytic oil yields. As predicted by the model, oil yields reaching $60.0 \%$ were produced, and $0 i 1$ yields of $55 \%$ or better were routinely produced. 


\section{REFERENCES}

1. Knight, J. A., C. W. Gorton and R.J.Kovac. 1983. "Entrained-Flow Pyrolysis of Biomass," p. 409 In Proceedings of the Fifteenth Biomass Thermochemical Conversion Contractors Meeting, Atlanta, Georgia. CONF-830323/ PNL-SA-11306. Available from the National Technical Information Service, U.S. Department of Commerce, 5285 Port Royal Road, Springfield, VA 22161.

2. Knight, J. A., C.W. Gorton and R. J. Kovac. 1984. "Entrained-Flow Pyrolys is of Biomass," p. 287 In Proceedings of the Sixteenth Biomass Thermochemical Conversion Contractors Meeting, Portland, Oregon. May 89, 1984. CONF-8405157/ PNL-SA-12403. Available from the National Technical Information Service, U.S. Department of Commerce, 5285 Port Royal Road, Springfield, VA 22161.

3. Knight, J. A., C. W. Gorton, R. J. Kovac and C. J. Newman. 1985. "Entrained-Flow Pyrolys is of Biomass." In Proceedings of the 1985 Biomass Thermochemical Conversion Contractors' Meeting, p. 99. Minneapolis, Minnesota. CONF-8510167/PNL-SA-13571.

4. Weekman, V. W. 1979. "Lumps, Models, and Kinetics in Practice." Monograph Series, No. 11, vol. 75, p. 1-29. American Institute of Chemical Engineers, New York, N. Y. 


\subsection{TASK 3B. COMPUTER MODELING OF PYROLYSIS REACTOR}

\subsection{SUMMARY}

A model of the reactor based on the numerical solution of simultaneous differential equations is discussed. The experimental oil yields obtained from the operation of the entrained-flow pyrolysis reactor (both Configuration I and Configuration II), using oak as the feed, were used as input for the model. Model predictions for oil yields are given and compared with experimental results. Although the maximum oil yield for all Configuration I and Configuration II experimental runs (from May 1982 through March 1986) was $51 \%$, the model indicated that oil yields as high as $60 \%$ were possible. After some modifications to improve pyrolytic oil collection (the PRU was then referred to as Configuration III), dry oil yields in the upper 50 per cent range were achieved regularly. In addition, the model prediction of a $60 \%$ dry pyrolytic oil yield was also achieved.

\subsection{INTRODUCTION}

Research in the area of entrained-flow pyrolysis of hardwoods had previously been carried out for several years in order to maximize the oil yield in direct liquefaction of biomass. The technical feasibility of production and use of pyrolysis oil has been demonstrated and is discussed elsewhere. 1 This section describes a computer model of the pyrolys is reactor which was used to aid interpretation of experimental results, and which was used as a tool to plan additional experiments. Although other researchers $2,3,4,5$ have reported on the rapid pyrolysis of biomass, only the work conducted at the Georgia Tech entrained-flow process research unit was concerned with maximizing the dry pyrolytic oil yield. The research effort described in this section is a revised and updated version of an earlier, preliminary mode ${ }^{6}$ which is described in Appendix $F$ Preliminary Reactor Modeling - Configuration I.

\subsection{PHYSICAL/EXPERIMENTAL INPUT FOR REACTOR MODEL}

In the model, the key component of the reactor system is the reaction chamber. In the first version (Configuration I) of the PRU, the reaction 
chamber consisted of a refractory inlet section followed by a 21 foot $(6.40 \mathrm{~m})$ section of eight-inch, schedule $40(0.203 \mathrm{~m}$ inside diameter) stainless-steel pipe. In the subsequent version (Configuration II), the eight-inch pipe was replaced with a six-inch, schedule 40 (0.154 $\mathrm{m}$ inside diameter) stainless-steel pipe. Other changes were made to the system, including changes to the refractory inlet section, the addition of a quench vessel and the addition of a second demister. These changes were described in Section 6 Modification of the PDU. A flow diagram of Configuration II of the PRU, and a description of the operation of the PRU is given in Section 7.2.

The experimental data resulting from tests using the reactor system described in Configuration I are summarized in Table 57. The temperatures listed are the readings of a reference thermocouple located near the entrance to the reactor tube. This temperature is referred to as the reactor reference temperature for the experiment. This approach was used as a way of identifying the temperature level in the reactor and has no physical significance other that the fact that it refers to a particular thermocouple location just after the inlet to the stainless-steel pipe which constitutes the major length of the reactor. The feed was introduced prior to this thermocouple location. In operation, the temperature of the gas-vapor mixture decreases throughout the reactor due to heat transfer to the feed and to heat losses from the reactor. Gas-vapor mixture temperatures were measured at selected locations along the reactor during experimental runs. The feed rates and oil yields were based on moisture and ash-free feed, and the oil yield given does not include any water. The screen sizes were based on the results from a Sweco screener.

The corresponding data for Configuration II is given in Table 58 . The temperatures given are those indicated by a thermocouple near the entrance to the six-inch pipe section of the reactor.

The version of the POU referred to as Configuration I had as its main features: a hot-gas generator (operating stoichiometrically with propane and air), an eight-inch reactor tube, a char cyclone, an air-cooled condenser, a demister cyclone and a flare. Configuration II was a modified version of Configuration $I$, with a six-inch reactor tube (to reduce residence times), a spray chamber upstream of the condenser (to reduce deposits in the condenser), 


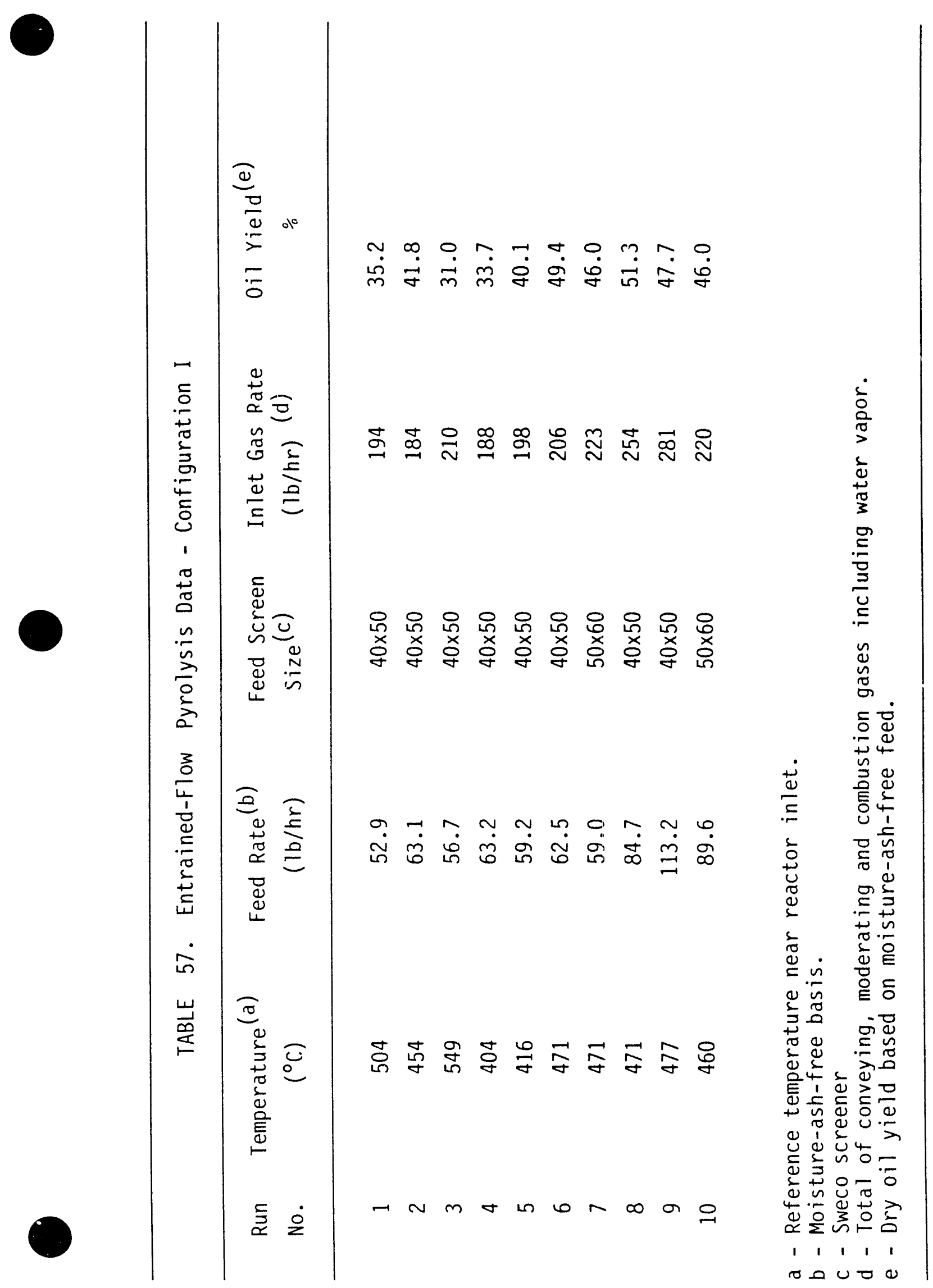




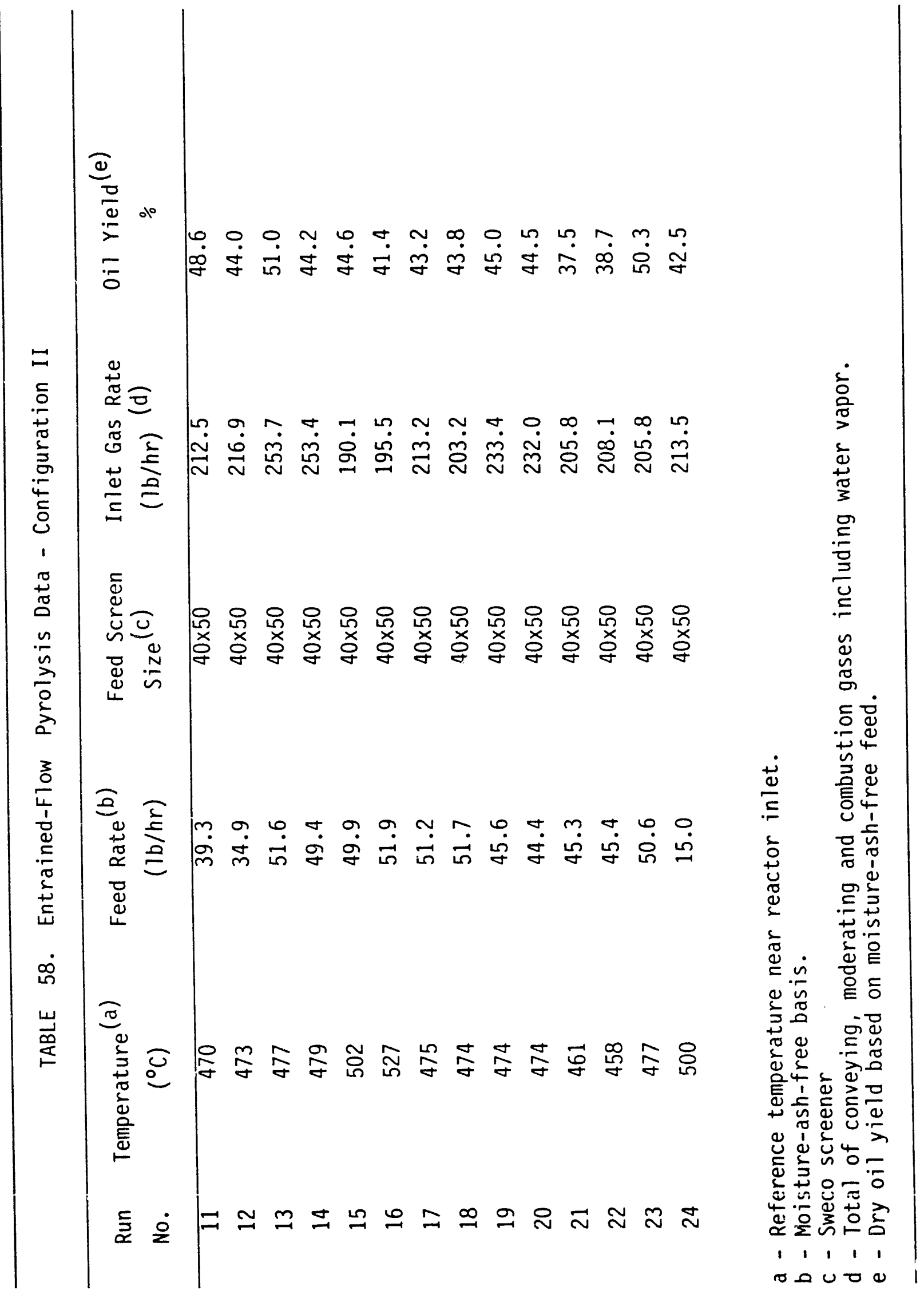


and a second demister (to further collect the oil aerosol in the offgas stream). The operating procedure for both systems were essentially the same. The system was operated without feed until the operating temperatures were near the desired temperatures for the test. Feed was then introduced and the unit was operated until steadystate conditions were obtained. The length of a test was approximately one hour for the tests conducted on Configuration I, and was increased from an initial two hours to four hours for the experiments with Configuration II. The data needed to determine all input and output flow rates, as well as temperatures and pressures in the unit, were recorded.

In general, the data reduction and data analyses can be categorized as material balances, energy balances and reactor modeling. An overall material balance was made, which included all input and all output streams. The results of this material balance was used to demonstrate that steady-state conditions existed during the run, and to indicate the overall consistency of the flow-rate measurements. The energy balances were made for similar reasons and were based on (in addition to the flow rates) measured heating values of solids and liquids, calculated heating values of gaseous mixtures, sensible heat effects and heat losses. The techniques used to calculate the heat losses for tests with feed were developed using operating data obtained from runs without feed at approximately the same temperature level as that for the actual runs. Details of these types of calculations have been presented elsewhere ${ }^{6}$.

\subsection{REACTOR MODELING RESULTS}

The results of the preliminary modeling effort, based on an idealized isothermal reactor were presented in previous publication, ${ }^{7}$ and are also shown in Appendix F. In contrast, the revised (current) model incorporated a means of predicting a gas and a particle temperature profile. In addition, the particle velocity as a function of position in the reactor was determined so that a true particle residence time could be obtained. The reactor model consisted of a coupled set of three, first-order, ordinary differential equations along with auxiliary relations. The revised model incorporated the exit temperature of the gas as one of the input parameters. The model is summarized below. 
The first of the three ordinary differential equations is an energy equation for the particles:

$$
\frac{d T_{p}}{d z}=\frac{6}{V_{p} D_{p} C_{p p} p}\left[h\left(T_{g}-T_{p}\right)+\sigma\left(T_{g}^{4}-T_{p}^{4}\right)\right]
$$

The second ordinary differential equation is the expression for the pyrolysis of the particles:

$$
\frac{d Y}{d z}=-\frac{Y}{V_{p}} k_{o 1} \exp \left(-E_{1} / R T_{p}\right)
$$

Finally the third ordinary differential equation relates to the production and decomposition of the oil vapors formed:

$$
\frac{d m_{0}}{d z}=-m_{f}\left(1-w_{a}\right)\left(1-w_{c}\right) F_{0} \frac{d Y}{d z}-\rho_{g} S k_{02} \exp \left(-E_{2} / R T_{g}\right)
$$

A detailed theoretical description of the model is given in Section 10.6. A list of nomenclature used for the reactor model and for the computer programs is given in Section 10.5 .

A11 of the experiments in Tables 57 and 58 were used to determine the four kinetic parameters, two pre-exponential factors and two activation energies, by using the computer model as the objective function for an available nonlinear leastsquares computer code.

The input to the computer program consists of: the reactor outlet temperature, the moisture-free feed rate, mass fraction of ash in the feed, the total gas-vapor inlet rate (consisting of feed, conveying gases and vapors, combustion products and moisture in the feed), average particle diameter, reactor inside diameter, reactor height, and six kinetic parameters. 
Four of these kinetic parameters are determined by the nonlinear leastsquares program. The other two parameters are fixed at specified input values. Physically these two parameters are the fractional, instantaneous, differential yields of char and gases (noncondensable gas and water produced by pyrolysis). The remaining product is pyrolysis oil vapor. The values used for the instantaneous differential yields of char and gases were selected as 0.08 and 0.15 respectively as mass fractions of moisture-ash-free wood. The values selected are average values based on work done at Georgia Tech and also on work reported by others in the literature. Prescribing these values automatically sets the value for the fractional instantaneous differential yield of pyrolysis oil vapors as 0.77 . These values are not necessarily the corresponding values for the products leaving the reactor. The fractional char yield represents the lowest value of char possible leaving the reactor. The fractional gas yield, in general, will be greater than 0.15 . and the fractional oil yield will be less than 0.77 because the model includes decomposition of the oil vapor. The first four parameters are the two activation energies and two preexponential factors for the rate constants for the pyrolysis reaction and for the oil vapor decomposition reaction. Initial estimates for these four parameters are inputs.

The computations proceed by first calculating the inlet gas temperature, assuming that heat losses are negligible. Then a marching procedure up the reactor is used to predict the particle temperature (which is then used to calculate the gas-vapor mixture temperature) and flow rates of char, wood, gases and pyrolysis oil vapors as a function of reactor height. This is continued until the reactor exit is reached. In general, the calculated oil yield is different from the corresponding experimental oil yield value. The difference between the two is referred to as the deviation. The entire procedure is repeated for each experimental run (i.e. each set of input data). After this is done, the nonlinear least-squares routing adjusts the initial guesses of the two activation energies and the two pre-exponential factors and the procedure is repeated until some criteria of convergence is satisfied. The criteria used was that from iteration to iteration all of the parameter estimates agreed to three significant figures. The general approach taken is 
similar to that used by Kosstrin ${ }^{8}$ for fluidized-bed pyrolysis. The final values determined for the kinetic parameters are given in Table 59.

TABLE 59. Kinetic Parameters

\section{Pyrolysis of Wood}

0il Vapor

Decomposition

Preexponential

Factor $\left(\mathrm{sec}^{-1}\right)$

$1.02 \times 10^{5}$

10.3

Activation Energy

(Btu/lb mol)

29,800

10,000

An advantage of modeling the reactor is that it provides insight into the phenomena and provides a basis for interpreting the data and in planning experiments. Modeling will provide equations for use in the design of commercial plants. Reactor profiles are variations in particle temperatures, particle residence time and oil yield. Note that In Table 60, an oil yield of about $60 \%$ is indicated for a fractional reactor height 0.50 which corresponds to about 11.8 feet from the reactor inlet and a residence time of 1.05 seconds. A graphical representation of the data is given in Figure 12 (p.118). Two separate computer codes were used. One was designed to determine the kinetic parameters while the other was used to predict results based on input kinetic para-meters. Both of these codes are discussed further in Section 9.7.

In order to provide guidance in planning future experiments, a series of computer runs where made and oil yields were predicted. The results from these computer runs are presented in Table 61. The calculated fractional oil yields are plotted versus gas flow rates in Figure 14. This figure indicates that for a given reactor outlet temperature, there is an inlet gas rate that results is a maximum oil yield. As mentioned earlier, the model predicts an oil yield of $60 \%$ for a local particle residence time of 1.05 seconds. The 
TABLE 60. Predicted Reactor Profiles

\begin{tabular}{|c|c|c|c|}
\hline \multicolumn{4}{|c|}{$\begin{array}{l}\text { Reactor Outlet Temperature }-1436^{\circ} \mathrm{R}\left(525^{\circ} \mathrm{C} \text { ) }\right. \\
\text { Feed Rate }-30.0 \mathrm{lb} / \mathrm{hr} \text { (moisture free) } \\
\text { Inlet Gas Rate }-250 \mathrm{lb} / \mathrm{hr} \text { (includes water vapor) } \\
\text { Ash }-0.8 \% \text { by weight of moisture-free feed } \\
\text { Particle Diameter }-8.3 \times 10^{-4} \mathrm{ft} \\
\text { Reactor Inside Diameter }-0.505 \mathrm{ft} \\
\text { Reactor Height }-23.7 \mathrm{ft}\end{array}$} \\
\hline $\begin{array}{l}\text { Fractional } \\
\text { Height }\end{array}$ & $\begin{array}{r}\text { Particle } \\
\text { Temperature } \\
\left({ }^{\circ} \mathrm{R}\right)\end{array}$ & $\begin{array}{r}\text { Particle } \\
\text { Residence Time } \\
(\mathrm{sec})\end{array}$ & $\begin{array}{l}\text { Fractional } \\
0 \text { il Yield* }\end{array}$ \\
\hline 0.00 & 53 & 0.00 & 0.000 \\
\hline 0.10 & 1347 & 0.22 & 0.068 \\
\hline 0.20 & 1432 & 0.45 & 0.352 \\
\hline 0.30 & 1436 & 0.66 & 0.513 \\
\hline 0.40 & 1436 & 0.86 & 0.579 \\
\hline 0.50 & 1436 & 1.05 & 0.598 \\
\hline 0.60 & 1436 & 1.24 & 0.593 \\
\hline 0.70 & 1436 & 1.43 & 0.576 \\
\hline 0.80 & 1436 & 1.62 & 0.553 \\
\hline 0.90 & 1436 & 1.81 & 0.527 \\
\hline 1.00 & 1436 & 2.00 & 0.501 \\
\hline
\end{tabular}


TABLE 61. Predicted 0 il Yields

\begin{tabular}{|c|c|c|c|}
\hline \multicolumn{4}{|c|}{$\begin{array}{c}\text { Feed Rate }-30.0 \mathrm{lb} / \mathrm{hr} \text { (moisture free) } \\
\text { Ash }-0.8 \% \text { by weight of moisture-free feed } \\
\text { Particle Diameter }-8.3 \times 10-4 \mathrm{ft} \\
\text { Reactor Inside Diameter }-0.505 \mathrm{ft} \\
\text { Reactor Height }-23.7 \mathrm{ft}\end{array}$} \\
\hline $\begin{array}{l}\text { Inlet Gas Rate } \\
\qquad(1 b / h)\end{array}$ & \multicolumn{2}{|c|}{$\begin{array}{cc}\text { Particle } & \text { Reactor Outlet } \\
\text { Residence Time } & \text { Temperature } \\
(\mathrm{sec}) & { }_{\mathrm{o}}\left({ }^{\circ} \mathrm{C}\right)\end{array}$} & $\begin{array}{l}\text { Fractional } \\
\text { 0il Yield* }\end{array}$ \\
\hline $\begin{array}{l}250 \\
300 \\
350 \\
400 \\
450 \\
500 \\
550\end{array}$ & $\begin{array}{l}2.10 \\
1.76 \\
1.51 \\
1.33 \\
1.18 \\
1.06 \\
0.97\end{array}$ & $\begin{array}{ll}1391 & (500) \\
1391 & (500) \\
1392 & (500) \\
1391 & (500) \\
1391 & (500) \\
1391 & (500) \\
1391 & (500)\end{array}$ & $\begin{array}{l}0.522 \\
0.555 \\
0.570 \\
0.572 \\
0.560 \\
0.549 \\
0.520\end{array}$ \\
\hline $\begin{array}{l}250 \\
300 \\
350 \\
400 \\
450 \\
500 \\
550\end{array}$ & $\begin{array}{l}2.00 \\
1.68 \\
1.44 \\
1.27 \\
1.13 \\
1.02 \\
0.93\end{array}$ & $\begin{array}{ll}1436 & (525) \\
1436 & (525) \\
1436 & (525) \\
1436 & (525) \\
1436 & (525) \\
1436 & (525) \\
1436 & (525)\end{array}$ & $\begin{array}{l}0.501 \\
0.545 \\
0.574 \\
0.589 \\
0.595 \\
0.591 \\
0.581\end{array}$ \\
\hline $\begin{array}{l}250 \\
300 \\
350 \\
400 \\
450 \\
500 \\
550\end{array}$ & $\begin{array}{l}1.91 \\
1.60 \\
1.38 \\
1.22 \\
1.08 \\
0.98 \\
0.89\end{array}$ & $\begin{array}{ll}1481 & (550) \\
1481 & (550) \\
1481 & (550) \\
1481 & (550) \\
1481 & (550) \\
1481 & (550) \\
1481 & (550)\end{array}$ & $\begin{array}{l}0.476 \\
0.526 \\
0.563 \\
0.588 \\
0.605 \\
0.613 \\
0.613\end{array}$ \\
\hline \multicolumn{4}{|c|}{ * Weight fraction based on moisture-ash-free feed. } \\
\hline
\end{tabular}




\section{Predicted Oil Yields}

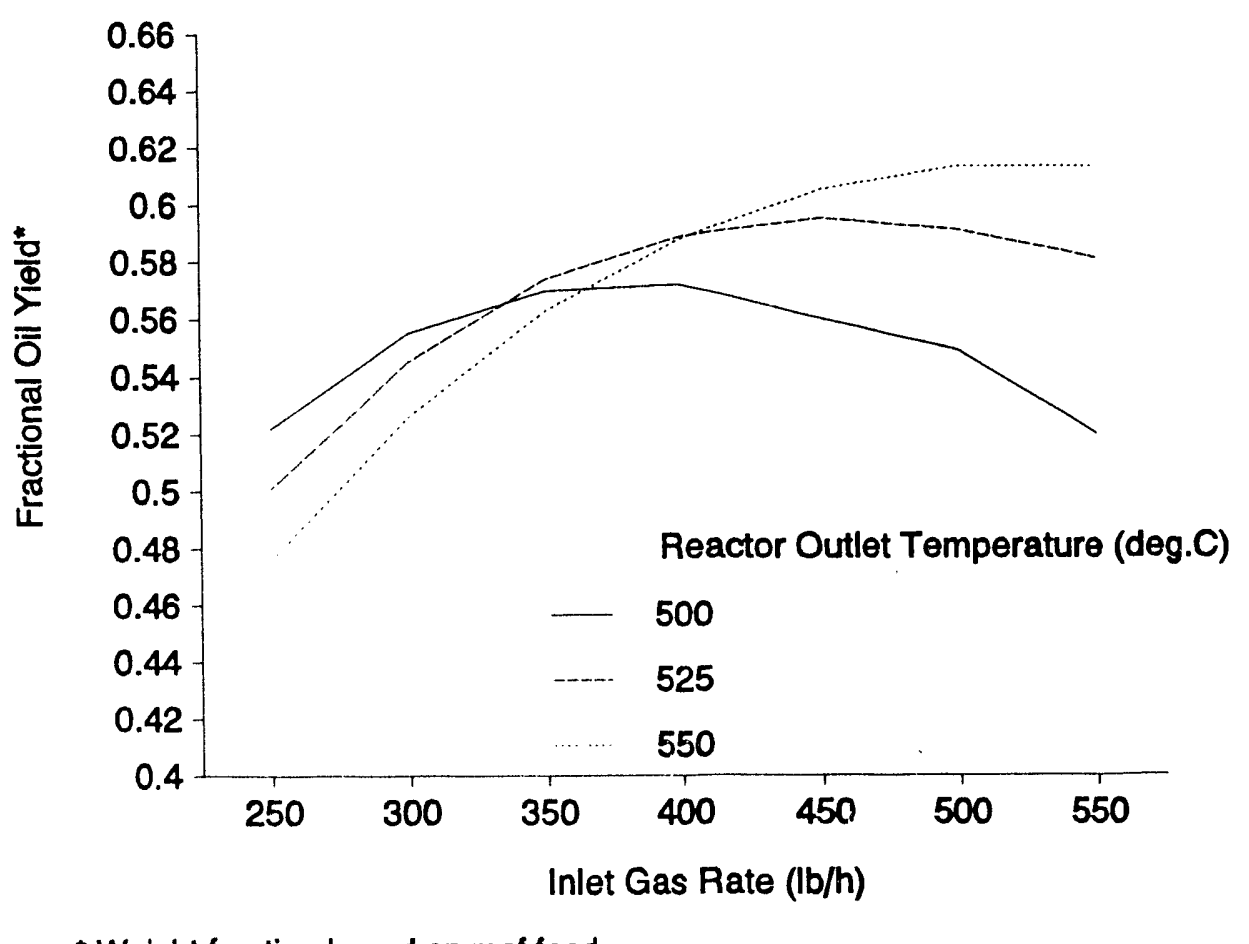

- Weight fraction based on maf feөd

FIGURE 14. Predicted 0il Yields 
maximum experimental (collected) oil yield for the experiments using the PRU Configuration I and Configuration II was $51 \%$. Based on this information it was clear that the particle residence time should be reduced substantially. After some modifications to reduce residence time and improve pyrolytic oil collection (the PRU was then referred to as Configuration III), dry oil yields were increased significantly. In addition, the model prediction of a $60 \%$ dry pyrolytic oil yield was also achieved.

\subsection{NOMENCLATURE}

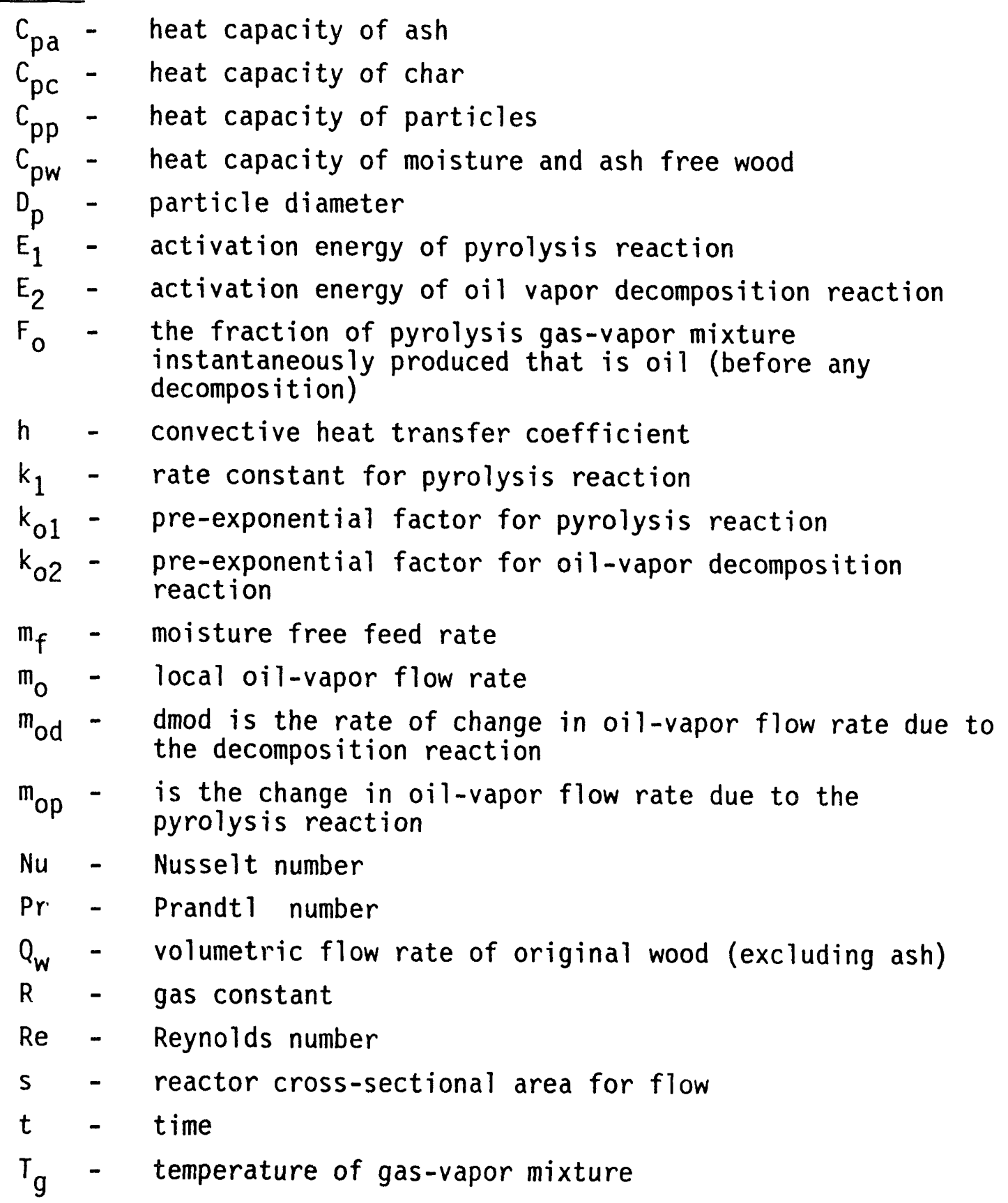




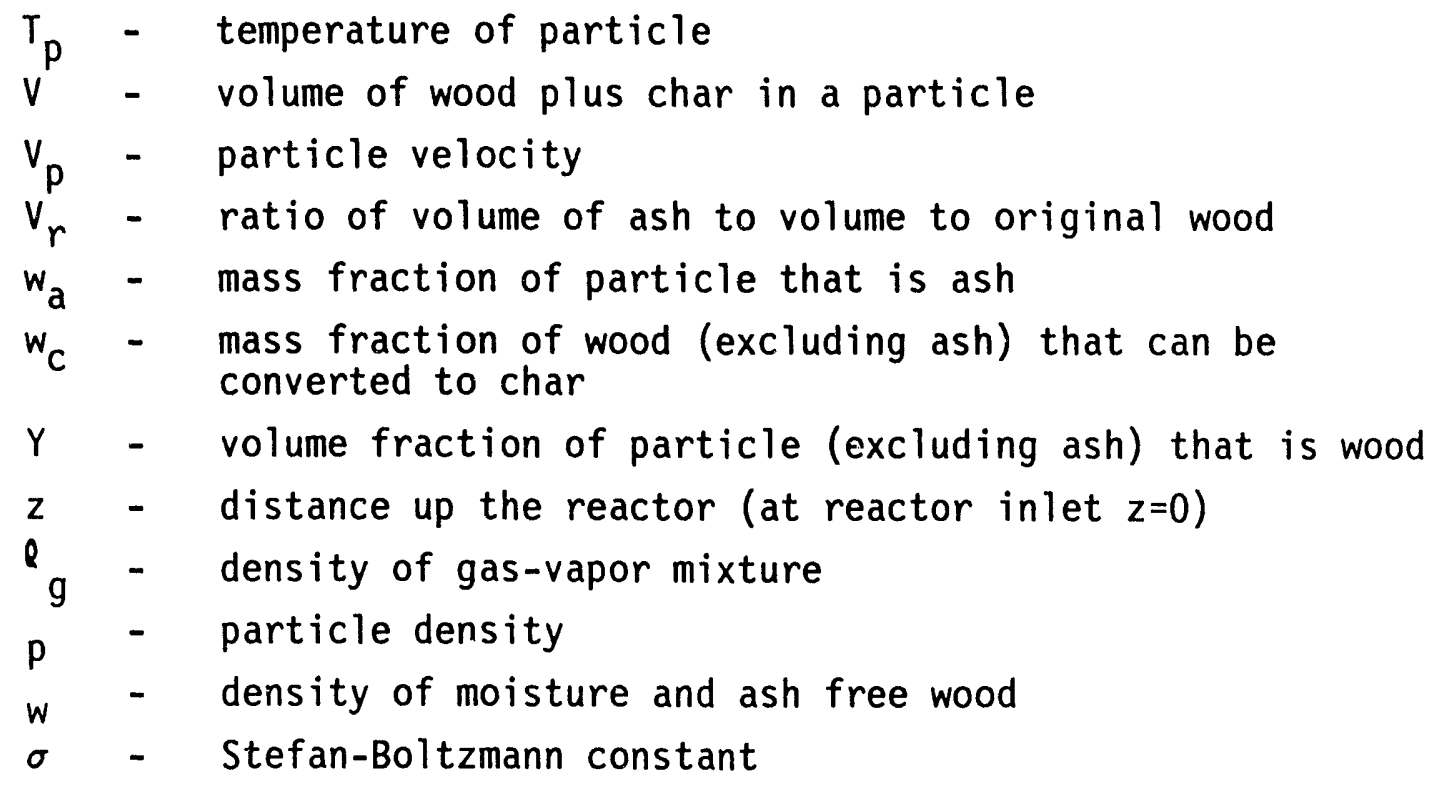

\subsection{THEORETICAL DESCRIPTION OF COMPUTER MODEL}

Input to the computer model includes the reactor exit temperature, dry feed rate, particle size, reactor inside diameter, total inlet gas rate (including moisture in the inlet feed, which rapidly evaporates), reactor height, and ash content in the feed. Also input are reaction rate parameters, which will be discussed subsequently.

The simulation begins with the calculation of the reactor inlet temperature, assuming an adiabatic reactor and also assuming that the exiting particle and gas temperatures are the same. Both of these assumptions are believed to be reasonable and could be relaxed, if desired. The simulation proceeds by the simultaneous solution of the three ordinary differential equations given in Section 9.4. These coupled, ordinary differential equations are solved using a Fourth-order RungeKutta method.

The equations will now be discussed in turn. Equation (1) given in the main body of the report is:

$$
\frac{d T_{p}}{d z}=\frac{\sigma}{V_{p} D_{p} C_{p p} p}\left[h\left(T_{g}-T_{p}\right)+\sigma\left(T_{g}^{6}-T_{p}^{6}\right)\right]
$$


This equation predicts the particle temperature, $T p$, as a function of reactor height, $z$. The equation is based on the assumption that the particle temperature is uniform throughout. The particle velocity, $v_{p}$, is found by calculating the local terminal velocity (based on conditions at a particular height, $z_{1}$ ) and subtracting the local terminal velocity from the local gas velocity. The local gas velocity calculation takes into account gas temperature changes and the addition of pyrolysis vapors and gases to the gas phase. The assumption that the particle velocity lags the gas velocity by the local terminal velocity neglects any particle acceleration affects and eliminates the need for an additional differential equation. Estimates based on computer output indicate that the effect of the acceleration of gravity is dominant over the particle acceleration. The effect of mass transfer on the drag coefficient is neglected in the calculating of the terminal velocity. The forced convection heat transfer coefficient, $h$, is calculated from the well-known expression.

$$
\mathrm{Nu}=2.0+0.60 \mathrm{Re}^{0.5} \mathrm{Pr}^{0.333}
$$

Again, the effect of mass transfer was not included. Both $C_{p p}$ and $\rho$ depend on the extent of pyrolysis. The way in which these variations are taken into account will be discussed later. The heat of pyrolysis was not taken into account because its effect is believed to be small, and there is disagreement and uncertainty as to its value. Since accurate values for emissivity and absorptivity are not available the particle was assumed to be a black body.

The model for the pyrolysis kinetics is a first-order rate expression based on moisture-ash-free wood. Thus the assumption is given by

$$
\frac{d w}{d t}=k_{1} W
$$

where $W$ is the mass of uncharred wood (excluding ash) remaining at any time $t$. As a wood particle chars, some shrinkage occurs, but this shrinkage has not 
been quantified. The assumption is made that the total volume of uncharred wood plus char (excluding ash), $V$, is constant so that

$$
W=V Y \rho_{w}
$$

where $\rho_{W}$ is the density of the completely dry, original wood excluding ash, and $Y$ is the volume fraction of original wood, excluding ash. The substitution of $W$ from equation (A3) into equation (A2) results in:

$$
\frac{d y}{d t}=k_{1} Y
$$

Assuming the temperature dependance of $k_{1}$ to be of the familiar Arrhenius form results in:

$$
k_{1}=k_{0,} \exp \left(-E_{1} / R T_{p}\right)
$$

Using the particle velocity, $v_{p}$, to change the reference from time to distance gives equation (2) shown earlier in section 9.4:

$$
\frac{d y}{d z}=-\frac{Y}{V_{p}} k_{01} \exp \left(-E_{1} / R T_{p}\right)
$$

At this point it is convenient to introduce the equation for $\rho_{\mathrm{p}}$ used in equation (1). Assuming that the true density of the ash is twice that of the original wood (this is a reasonable and not critical assumption), it can be shown that the volume ratio of ash to original wood, $v_{r}$, is given by the following expression: 


$$
V_{x}=\frac{1}{2\left(1 / w_{e}-1\right)}
$$

Assuming that the total volume of wood plus char as well as the volume of ash remains constant, results in:

$$
P_{D}=\frac{\left(Y_{V}+(1-Y) P_{V} W_{C}+2 P_{W} V_{I}\right)}{1+V_{z}}
$$

Correspondingly, the equation for $C_{p p}$ is:

$$
C_{p p}=\frac{\left(Y C_{p w}+(1-Y) w_{c} C_{p c}+2 V_{I} C_{p R}\right) P_{Y}}{P_{p}}
$$

The net oil yield is assumed to be the result of oil produced by pyrolysis with subsequent decomposition of the oil vapors. The differential equation used to predict the oil yield was based on the oil flow rate and specified fractional yields of char $\left(w_{c}\right)$ and gas $\left(w_{g}\right)$. Water vapor was included in the gas. Based on the assumption of zero shrinkage, the volumetric flow (under steady conditions) for wood plus char at any location in the reactor must be the same as at the inlet:

$$
Q_{w}=m_{l}\left(1-w_{2}\right) / p_{w}
$$

so that

$$
\frac{d m_{o p}}{d z}=-Q_{w} \frac{d Y}{d z} p_{w}\left(1-w_{c}\right) F_{0}
$$


where $F_{0}$ is the fraction of the pyrolysis gas-vapor mixture instantaneously produced that is oil (before decomposition).

The oil vapor are assumed to decompose by a first order irreversible reaction based on the density of oil vapor in the gas phase. The temperature dependance of the rate constant is assumed to be of Arrhenius form, yielding:

$$
\frac{d m_{o d}}{d z}=-\rho_{g} s k_{02} \theta \operatorname{xp}\left(-E_{2} / R T_{\rho}\right)
$$

combining equations (A9) to (A11) results in equation (3):

$$
\frac{d m_{0}}{d z}=-m_{l}\left(1-w_{a}\right)\left(1-w_{c}\right) F_{0} \frac{d Y}{d z}-\rho_{g} S k_{02} \theta \exp \left(-E_{2} / R T_{g}\right)
$$

In summary, three key differential equations were used in the modeling effort. Expression (3) shows the pyrolysis oil flowrate at any given point in the reactor. The next major improvement in the reactor model would be to incorporate reactor heat losses into the model. This aspect would be of particular value in developing design data for scale-up to large commercial systems.

\subsection{COMPUTER PROGRAMS}

The kinetic parameters were determined from the experimental results obtained on 24 experiments of the PRU Configuration I and Configuration II. Ten of these were obtained on the eight-inch reactor and fourteen were obtained on the six-inch reactor. The approach taken was to specify the mass fraction yields of char and gases (including water vapor) and, using the computer model as the objective function, determine the preexponential factors (ko1 and ko2) and activation energies (El and E2) needed for the implementation of the model.

An available subroutine, ZXSSQ, from the International Mathematics and Science Library (IMSL), was used for the nonlinear regression analysis. This subroutine was incorporated into a computer code written in FORTRAN and called 
TSQMAX. A listing of TSQMAX is given in Appendix $H$. The results have been presented in Table III. The sum of the squares of the deviations for these results is $3.80 \times 10-2$ (based on moisture- ash-free feed fractional oil yield.

A second program, PYRGRAF, using the essential features of TSQMAX was developed to predict results using input values for the kinetic constants. PYRGRAF also includes a subroutine to provide input to a plot routine. A listing of PYRGRAi is given in Appendix I. The nomenclature for these computer codes, as well as the model equations, is given in Section 10.5. The nomenclature excludes most of SUBROUTINE RK4SUB which is a standard fourth-order Runge-Kutta code and also excludes SUBROUTINE PPLOT which is the particular plotting routine used. 
1. J.A. Knight, C.W. Gorton, and R.J. Kovac, "0il Production by Entrained Flow Pyrolysis of Biomass", Biomass, 6, (1984), pp. 69-76.

2. G.M. Simmons and W.H. Lee, "Kinetics of Gas Formation from Cellulose and Wood Pyrolysis", in Fundamentals of Thermochemical Biomass Conversion, R.P. Overend, T.A. Milne, and L.K. Mudge, Eds. (Elsevier Applied Science Publishers, London and New York, 1982), pp. 385-395.

3. M. Steinberg, P.T. Fallon, and M.S. Sundaram, "Flash Pyrolys is of Biomass with Reactive and Non-Reactive Gases", In the Proceedings of the 15th Biomass Thermochemical Conversion Contractors 'Meeting, Atlanta, Georgia, March 16-17, 1983. CONF-830323. National Technical Information Service, U.S. Department of Commerce, 5285 Port Royal Road, Springfield, VA 22161.

4. J. Diebold and J. Scahill, "Ablative Pyrolysis of Biomass to 0lefins and Aromatic Liquids in a Vortex Reactor", presented at Winter National Meeting of the AIChE, Atlanta, GA, 1984.

5. D.S. Scott and J. Piskorz, "The Continuous Flash Pyrolys is of Biomass", Canadian Journal of Chemical Enginearing, 62, (1984), pp. 404-412.

6. J.A. Knight, C.W. Gorton, and R.J. Kovac, "Entrained Flow Pyrolysis of Biomass", p. 287 In the Proceedings of the 16th Biomass Thermochemical Conversion Contractors' Meeting, Portland, Oregon, 1984. CoNF-830323. National Technical Information Service, U.S. Department of Commerce, 5285 Port Royal Road, Springfield, VA 22161.

7. C.W. Gorton and J.A. Knight, "Oil from Biomass by Entrained-Flow Pyrolysis", Biotechnology and Bioengineering Symp., No. 14, (1984), pp. $15-20$.

8. H.M. Kosstrin, "Direct Formation of Pyrolys is .. . oll Biomass", Proceedings, Specialists' Workshop on Fast Pyrolysis of Biomass, Copper Mountain, Colorado, October 19-22, 1980, pp. 105-121. 


\subsection{TASK 4.CONCEPTUAL DESIGN AND ECONOMIC ANALYSIS FOR A COMMERCIAL}

ENTRAINED-FLOW PYROLYSIS FACILITY

\subsection{SUMMARY}

The Georgia Tech Research Institute has developed an atmospheric flash pyrolys is process for the conversion of biomass to liquid fuels. The successful demonstration of pyrolysis oil production of $60 \%$ (moisture and ash-free) has been achieved in a large-scale Process Development Unit (1.4 DRY TONNE/DAY). Nearly fifty steady-state trials have confirmed the technological reliability of the process. The liquid biofuel product is a uniform mixture of oxygenated hydrocarbons and modest levels of stably bound water. Char and noncondensable gases are ancillary products. Gross product thermal efficiency of 94\% and a net thermal process energy efficiency of $73 \%$ are achieved. $0 i 1$ and char recovery exceeds $70 \%$ (moisture and ash-free). A conceptual manufacturing process and an economic analysis for oil production for a 200 TPD plant is presented. The plant proves to be profitable even at current fuel costs and investment costs (June, 1989 basis). Rate of return on investment is $39.4 \%$. The payout period is 2.1 years. Total capital investment is $\$ 2.28$ million. Manufacturing cost per $G J$ is $\$ 2.70$. The process is being prepared for further scale-up from the PDU stage to a commercial prototype.

\subsection{INTRODUCTION}

During the 1960's the Georgia Institute of Technology (Georgia Tech) began the successful design and development of a patented Moving-Bed (VerticalBed) Pyrolysis System for the conversion of biomass, municipal wastes and sludge to high-energy density, transportable fuels (pyrolysis oil and char) and a low-energy process gas which was used on-site for drying of feedstocks (1). In the 1970's the Georgia Tech Moving-Bed Pyrolysis Process was licensed to the Tech-Air Corporation (which became a subsidiary of American Can Company) which, through a sub-license to American Carbons Co., has commercialized the technology. This technology was developed by Georgia Tech and Tech-Air in four largescale pilot plants and a commercial prototype of fifty tonnes per day (TPD) which was operated continuously at a sawmill, around the clock (24 hours per day) over a period of eighteen months before the demonstration was terminated. That research, development and demonstration program, spanning 1968-1978, 
confirmed the reliability and high efficiency of pyrolysis technology with biomass and municipal wastes, and the economic viability of vertical-bed pyrolysis plants of 50-250 TPD. That Georgia Tech Moving Bed Pyrolysis Process, in commercial form, remains the standard for commercial biomass pyrolysis technology.

The design for the Georgia Tech Entrained Flow Pyrolys is Process originated in 1978 with an internally-sponsored project for the development of an innovative process for the thermochemical conversion of biomass to synthesis gas via a combined pyrolysis-gasification process. Following a contract award from the U.S. Department of Energy in 1980, and after completion of bench-scale studies and the construction of a preliminary conceptual design and preliminary economic studies, which indicated very high potential for an economically viable, stand-alone process for liquid biofuel production, continuing research and development focused on the design and development of a new pyrolysis process. With the revised objectives, the new Georgia Tech Entrained Flow Pyrolysis Process was focused on the maximal production of the liquid biofuel, pyrolytic oil. A 1.5 TPD Process Development Unit (PDU) was designed and installed in 1983. The purpose of the experimental PDU was to investigate the entrained pyrolysis of wood under steady-state conditions. The experimental parameters which have been studied included feed material characteristics, particle size, pyrolysis temperature and residence time. The data was analyzed in parallel and interactively, to develop mathematical models of the kinetic and transport processes occurring in the pyrolysis process. By this methodology the process model was progressively refined and improved process parameter predictions were developed for maximal oil production. In the later stages of program development, after identification of key parametric parameters, oil yields (dry basis) consistently in excess of $55 \%$ and achieving $60 \%$ were demonstrated in steady-state operation of the PDU. Modeling indicates that $63 \%$ oil yields are achievable in the PDU. The prospect of reaching $70 \%$ yields was indicated with process design modification in future prototypes. The program consistently demonstrated mass and energy closures of $100 \pm 5 \%$ in which all elements of the applicable equations were measured. The validity of engineering data is unlike that of most other pyrolysis projects. It is of significance that the excellent closures have been achieved in a large-scale process 
demonstration unit. The experimental results have demonstrated a gross product thermal efficiency of $94 \%$ and an overall process efficiency of $73 \%$. $0 i 1$ and char yields (dry mass) exceed $70 \%$. A detailed summary of the development of the Georgia Tech Entrained Flow Pyrolysis Process has recently been presented (2). This paper will focus on the conceptual design for a manufacturing process using the proprietary Georgia Tech Process for the production of liquid biofuel and co-products. The results of a detailed economic analysis for a 200-dry TPD plant will be presented.

\subsection{PROCESS DESCRIPTION}

A manufacturing flow diagram which highlights the key pieces of equipment and systems for commercial scale operation of the Georgia Tech Entrained Flow Pyrolysis Process is given in Figure 15. There are three principal sections to the manufacturing process: feed preparation, pyrolysis, and product collection. A process flow block diagram is presented in Figure 16. The incoming feed and outgoing product streams are identified in relationship to the key process operations of a 200-dry TPD plant. by reference to both figures, the manufacturing process may be described.

Green wood chips at 50\% moisture (wet basis) are brought from a receiving and storage area and conveyed to a wood-burning dryer using a front-end loader. The dryer is a fan-circulatory design fitted with a metering bin and a particle collector. The burner is a co-fuel design and uses wood and product gas. (The exhaust gases from the wood dryer burner will be passed through, and air-cooled in, a heat exchanger and used as a conveying carrier gas for the reactor feedstock.) The wood chips are dried to less than $10 \%$ moisture (wet basis) and are transferred to a storage bin which supplies feed to the pyrolysis unit on demand and provides surge capacity. The feed is next comminuted in a hammer mill, fitted with a vibratory screening circuit, where grinding reduces the average particle size of the wood and the moisture content to $6 \%$ (wet basis). The dried feedstock is screened to segregate oversized pieces which are recycled to the hammer mill for re-grinding. The screened dry wood feedstock is transported to an enclosed feed bin mounted on a loss-in-weight feeder. The particulate feed is dropped into a conveying "inert" (non-reacting) gas carrier stream which consists of the combustion products 


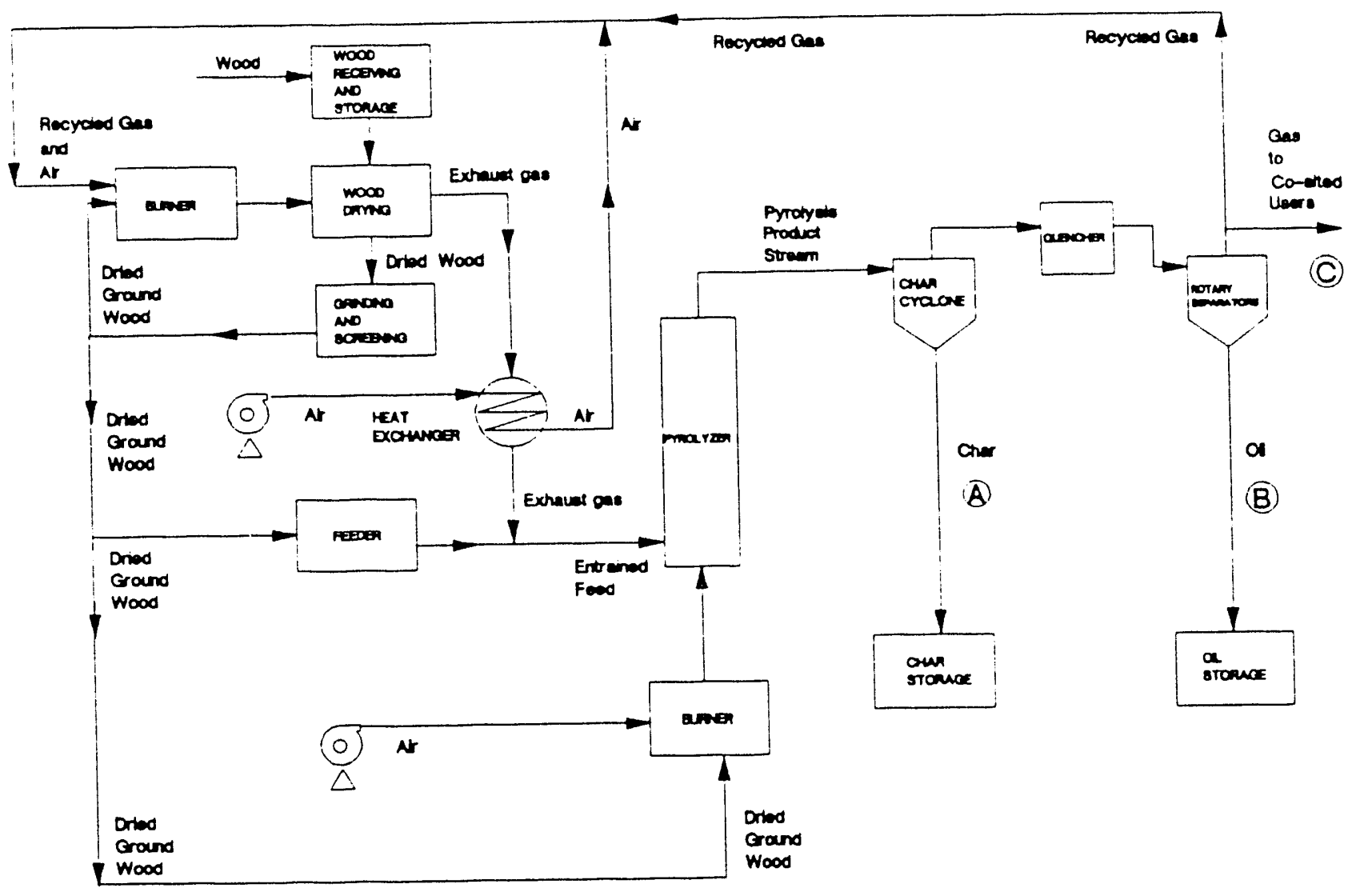

GIT ENTRAINED FLOW PYROLYSIS SYSTEM : 200 DRY T/d

FIGURE 15. Manufacturing Flow Diagram of the Georgia Tech Entrained Flow Pyrolysis Process

\begin{tabular}{|c|c|c|c|c|c|c|}
\hline \multirow[t]{2}{*}{$\begin{array}{l}\text { DRY OLL YEDD } \\
\text { Ko dy ol/ } \\
\text { Kg mat foed }\end{array}$} & \multicolumn{2}{|c|}{$\begin{array}{l}\text { TOTAL CHAR } \\
\text { (A) }\end{array}$} & \multicolumn{2}{|c|}{$\begin{array}{c}\text { TOTAL OL }\left(15 \% \mathrm{H}_{2}\right) \\
\text { (B) }\end{array}$} & \multicolumn{2}{|c|}{$\begin{array}{l}\text { TOTAL GASEOUS } \\
\text { FUEL (DUUTED) } \\
\text { (C) }\end{array}$} \\
\hline & $\begin{array}{l}\text { MASS } \\
\mathrm{Kg} / \mathrm{hr}\end{array}$ & $\begin{array}{c}\text { ENERGY } \\
\text { GN/hr }\end{array}$ & $\begin{array}{l}\text { MASS } \\
\mathrm{Kg} / \mathrm{hr}\end{array}$ & $\begin{array}{c}\text { ENERQY } \\
\text { GU/r }\end{array}$ & $\begin{array}{l}\text { MASS } \\
\mathrm{Kg} / \mathrm{hr}\end{array}$ & $\begin{array}{l}\text { ENERQY } \\
\text { GJ/hr }\end{array}$ \\
\hline 0.6 & 1056 & 28.8 & 5837 & 111.4 & 15003 & 13.3 \\
\hline
\end{tabular}

FIGURE 16. Process Flow Block Diagram of the Georgia Tech Entrained Flow Pyrolysis Process 
exhausted from the dryer-burner. This stream is fed into the pyrolysis reactor mixing zone where thewood and conveying gas are mixed with the entraining hot, inert (non-reacting) combustion gases of a wood-fired burner. The wood is rapidly transported upwardly through the vertical pyrolysis reactor and is completely pyrolyzed before exiting the reactor. For a 200 TPD plant the entrained flow reactor will consist of a cluster of five vertical tubes. The stream leaving the pyrolyzer consists of newly-formed char, pyrolysis gases, water vapor (water of reaction, feedstock-associated water, and combustion product water), and conveying/entraining combustion gases. The char is removed by cyclone separation and is cooled before being discharged into a sealed conveyor, whence it is fed via a rotary airlock to a char conveyor. The char is conveyed to a storage bin from which it may be retrieved by gravity flow for subsequent shipment. The char bin incorporates a pressure-relief system. The hot pyrolysis gas and vapor stream passes through a multiple organic spray (pyrolysis oil) quench system to condense vapors. The pyrolysis oil is collected in a series of patented high-efficiency, Georgia Tech proprietary rotary separators (3) as a relatively narrow molecular-weight fraction. This oil consists of a total liquid product in total yield of $70.6 \%$ with moisture content of $15 \%(60 \%$ dry $0 i 1$ yield). The water is uniformly dispersed and bound in the pyrolysis oil fraction. Maintenance of operating conditions above the dew point of water prevents major condensation and water vapor is exhausted with the product gas so that there is no wastewater stream to treat. The product pyrolysis oil is discharged to a small holding tank where it is cooled by recirculation. When the oil level in the holding tank increases, oil is pumped to the bulk storage tank. The non-condensable gas stream, containing water vapor, conveying/entraining combustion gases, and the non-combustible and combustible (hydrogen, methane, $\mathrm{C}_{2}-\mathrm{C}_{4}$ hydrocarbons, etc.) product compounds of pyrolysis are principally directed for sale to a co-sited user to use in a burner which provides heat for a boiler, or another device, with a portion being recycled before distribution for co-firing of the dryer-burner.

\subsection{DESIGN BASIS}

Mass and energy balances were calculated for a 200-dry TPD in support of the economic analyses. The product mass and energy yields for a 200-dry TPD plant, based on a mixed hardwood feedstock, is included in Figure 12 . The 
product yields and other design conditions for purposes of performance of the economic analyses are given in Table 62 .

\subsection{ECONOMIC ANALYSIS}

For purposes of the economic analysis, the entrained flow pyrolysis system was divided into six sections according to the operations performed: wood delivery, wood drying, size reduction and storage, entrained pyrolysis in the reactor, char removal, handling and storage, and oil removal, handling and storage.

\section{Capital Costs}

Both Purchased and installed capital equipment costs were specified (Table 63.). A number of sources of information were used to arrive at capital equipment costs. For some of the equipment the requirements were discussed with manufacturers and vendors and direct quotes were obtained. The most accurate information was used for critical items, that is, the ones which had a major influence on the total cost. A rotary separator had been recently specified and purchased, giving accuracy to that estimate. The installation cost for each item was determined separately rather than by using a uniform rate of the capital equipment cost to determine installation costs. Installation costs were obtained by estimating material and labor requirements directly for each capital item or by using estimated installation material and labor for various classes and types of equipment. The major reference for the economic analysis was the monograph of Peters and Timmerhaus (4).

The total capital investment for the 250-day TPD plant (60\% dry oil yield) is given in Table 64 . No land cost is estimated since (a) the pyrolysis process is based on a rural location where purchase cost is minimal, (b) land may be leased at modest cost, (c) land is provided, and/or (d) the plant only occupies $4,460 \mathrm{sq} . \mathrm{m} .(48,000 \mathrm{sq} . \mathrm{ft}$.$) on a 1.0$ ha $(2.5$ acre $)$ site which accommodates a thirty-day supply of wood feedstock.

The total direct plant cost amounts to $\$ 1.35$ million and the total capital investment (TIC) amounts to $\$ 2.3$ million for the $200-$ dry TPD pyrolysis plant. The total purchased cost of equipment was $\$ 0.88$ million and the installed equipment cost, as noted in Table 63., amounted to $\$ 1.1$ million. 
TABLE 62. Design Basis - GT Entrained Flow Pyrolysis Plant

$$
200 \text { - dry TPD }
$$

\begin{tabular}{|c|c|}
\hline Location & Southeast USA \\
\hline \multicolumn{2}{|l|}{ FEEDSTOCK (MIXED HARDWOODS) } \\
\hline Average Moisture Content, Wet Basis & $50 \%$ \\
\hline Ash Content, Moisture Free & $0.77 \%$ \\
\hline Higher Heating Value, Moisture Free & $19.5 \mathrm{MJ} / \mathrm{kg}$ \\
\hline \multicolumn{2}{|l|}{ PRODUCT YIELDS } \\
\hline Pyrolytic 0i1, Dry Wt/Wt Dry Wood & 0.60 \\
\hline Char, Dry wt/Wt Dry Wood & 0.12 \\
\hline Pyrolysis Gas, Dry Wt/Wt Dry Wood & 0.10 \\
\hline Water of Reaction, Wt/Wt Dry Wood & 0.18 \\
\hline \multicolumn{2}{|l|}{ PRODUCT SPECIFICATIONS } \\
\hline \multicolumn{2}{|l|}{ Pyrolytic $0 i l$} \\
\hline Specific Gravity & 1.10 \\
\hline Higher Heating Value, Moisture Free & $22.4 \mathrm{MJ} / \mathrm{kg}$ \\
\hline Product 0il Moisture Content, Wet Basis & $15 \%$ \\
\hline \multicolumn{2}{|l|}{ Char } \\
\hline $\begin{array}{l}\text { Higher Heating Value, Moisture Free } \\
\text { Pyrolysis Gas (Diluted) }\end{array}$ & $29.0 \mathrm{MJ} / \mathrm{kg}$ \\
\hline Higher Heating Value, Dry Basis & $0.9 \mathrm{MJ} / \mathrm{kg}$ \\
\hline \multicolumn{2}{|l|}{ COOLING AND COMBUSTION AIR } \\
\hline Temperature & $25^{\circ} \mathrm{C}$ \\
\hline Relative Humidity & $40^{\circ}$ \\
\hline Pressure & 1 bar \\
\hline \multicolumn{2}{|l|}{ PYROLYSIS REACTOR CONDITIONS } \\
\hline Temperature & $550^{\circ} \mathrm{C}$ \\
\hline Pressure & c.1 bar \\
\hline Throughput, $\mathrm{kg} / \mathrm{hr}-\mathrm{m}^{2}$ & 2200 \\
\hline
\end{tabular}


TABLE 63. Equipment Costs

200-dry TPD

Purchase

Installed

Cost $(\$)$

Cost (\$)

WOOD DELIVERY

Front-End Loader

100,000

100,000

Conveyor

10,000

11,700

DRYING

Metering Bin

1,650

2,250

Dryer (with Fan)

119,800

166,600

Dryer Particle Collector

9,700

13,500

Dry Wood Storage Bin

34,650

38,100

Dryer-Burner System

15,500

21,600

SIZE REDUCTION

Hammer Mill (with Screening)

141,650

198,300

Feed Storage Bin

105,900

116,500

PYROLYSIS

Pyrolysis Reactor System

41,400

55,700

Feeder System

22,000

27,500

Gas Blower

26,950

35,050

CHAR REMOVAL

Cyclone Separators

Storage Bin

43,600

60,600

71,100

78,200

OIL COLLECTION

Rotary Separators

30,500

42,450

Quench Spray System

12,000

16,650

Hold-Up Tank

19,000

22,850

0il Storage Tank

$\underline{73,600}$

91,250

TOTAL

$\$ 879,000$

$\$ 1,098,800$ 
TABLE 64. Total Capital Investment

200-dry TPD

\section{DIRECT COST}

Installed Equipment Cost

$1,098,800$

Building and Services (5\% of Total

Purchased Equipment Cost)

44,000

Yard Improvements (4\% of Total

Purchased Equipment Cost)

35,200

Service Facilities (14\% of Total

Purchased Equipment Cost)

123,100

Land: 1.0 ha (2.5 acres)

N.C.

TOTAL DIRECT PLANT COST

$1,301,100$

INDIRECT COST

Engineering and Supervision (15\% of

Total Purchased Equipment Cost)

131,900

Construction Expense (10\% of Total

Direct Plant Cost)

130,100

262,000

TOTAL INDIRECT PLANT COST

TOTAL DIRECT AND INDIRECT PLANT COST

CONTRACTOR'S FEE ( $5 \%$ of Total Direct Plant Cost)

$\underline{1,563,100}$

65,100

CONTINGENCY ( $8 \%$ of Total Direct and Indirect Cost)

125,000

FIXED CAPITAL INVESTMENT (FCI)

$1,753,200$

WORKING CAPITAL (3 months total labor expenses +

2 months, all other operating expenses +

1 month feedstock supply)

389,200

START-UP COSTS ( $8 \%$ OF FCI)

TOTAL CAPITAL INVESTMENT (TCI)

140,300

$\$ 2,282,700$ 
2. Manufacturing (Product) Costs

The total manufacturing costs for a 200-dry TPD plant amounted to $\$ 3.25$ million as described in Table 65. The operating labor cost is based on four men per shift, three-shift operation, and a labor rate of $\$ 8.00 / \mathrm{hr}$.

3. Sales Revenue

The total annual sales revenue for the products of 200-dry TPD (Table 66.) wood pyrolysis plant includes sale of the pyrolytic oil, the char, and the sale of product pyrolysis gas to a co-sited commercial or industrial user. The oil-revenue was based on a selling price indexed on an energy-equivalence basis to a barrel of crude oil at $\$ 21.00 /$ barrel, i.e. $\$ 0.132$ per liter ( $\$ 0.50 /$ U.S. gallon). This is clearly a conservative value for the pyrolysis oil since petroleum heating fuel derivatives of crude oil, for which it will substitute, will have a higher value than the crude oil itself. No. 2 fuel oil was priced in the market at $\$ 0.93 /-$ U.S. gallon in 1981 (Wall St. Journal, Oct. 12, 1981). Current inventories, based on earlier cheaper supplies of crude oil, have a depressed current market price. At an expected mid-1990 stabilization price of $\$ 25.00$ per barrel of crude oil, No. 2 fuel oil could range from $\$ 0.63$ $\$ 0.75 /$ U.S. gallon (i.e. $\$ 0.166-\$ 0.20$ per liter). The char revenue was based on a market price of $\$ 80 /$ ton for briquette charcoal (the sales price of the Tech-Air charcoal in 1976-78). The gas revenue is based on a value of $\$ 5.00 /$ MMBTU $(\$ 4.74 / G J)$ which is significantly less than liquid propane which it would displace $(\$ 9.25 / \mathrm{MMBTU} ; \$ 8.77 / \mathrm{GJ})$. The total projected sales revenue is expected to be $\$ 4.44$ million per annum at current market prices.

4. Profitability Analysis

Three methods were used for the evaluation of profitability: (a) the (engineering) rate of return (ROR) on investment expressed on an annual percentage basis, (b) payout (payback) period, and (c) discounted cash flow (DCF) rate of return (ROR) on investment for the book life of the plant (taken as ten years, based on depreciation). 
TABLE 65. Total Manufacturing (Product) Costs

$60 \%$ 0il Yield

RAW MATERIAL ( $\$ 24.25 / D T)$

$200 \mathrm{MT} / \mathrm{d}$

OPERATING LABOR

$2,145,400$

OPERATING SUPERVISION (15\% of Operating Labor)

268,800

UTILITIES

40,300

MAINTENANCE AND REPAIRS ( $4 \%$ of Fixed Capital

252,300

Investment)

70,100

OPERATING SUPPLIES (15\% of Maintenance and

Repairs)

10,500

LABORATORY CHARGES (10\% of Operating Labor)

26,900

DIRECT PRODUCTION COST

$\underline{2,184,300}$

FIXED CHARGES (Depreciation, Taxes, Insurance, Rent; $10 \%$ of Total Product Cost)

PLANT OVERHEAD COSTS (30\% of Operating Labor, Supervision, Clerical and Maintenance + Repairs)

113,800

TOTAL MANUFACTURING (PRODUCT) COST

$\$ 3,253,400$ 
TABLE 66. Annual Sales Revenue

$60 \% 0$ il Yield, 200-dry TPD

OIL PRODUCTION (15\% Moisture)

liters per annum

gals (US) per annum

44.6 million

CHAR PRODUCTION

Tonnes per annum

11.8 million

Tons (short) per annum

9,325

10,260

GAS PRODUCTION

GJ per annum

94,750

MMBTU per annum

89,800

OIL REVENUE

$\$ 3,167,200$

CHAR REVENUE

820,500

GAS REVENUE

449,000

TOTAL REVENUE

$\$ 4,436,700$ 
The engineering rate of return on investment analysis is presented in Table 67. Both a "before income tax" and an "after income tax" case were used. The before-tax case could arise in subsidized situations. The after tax case assumed a net income tax rate of $35 \%$. The plants were depreciated over ten years with an accelerated rate applicable in years 1-5 per U.S. Internal Revenue Service directives. The law provides for depreciation of plant equipment over a five-year period and, for buildings and services, over a ten year period. The results for both cases demonstrate excellent rates of return on investment: $39.4 \%$ (after tax), $51.8 \%$ (without tax). The respective net annual profits were $\$ 526,000$ and $\$ 809,000$.

The payout period analysis and the discounted cash flow-rate of return analys is (DCF-ROR) are summarized in Table 68. Both "before tax" and "after tax" cases were used as cited above.

The results of payout period analysis indicate that the capital investment can be "paid back" in 1.6 years in the case of no income taxes, and in only 2.1 years for the "after tax" case. The payout period corresponds to the minimum length of time necessary to recover the original capital investment in the form of cash flow to the project based on total income, less all costs excepting depreciation.

\subsection{SUMMARY}

The Georgia Tech Entrained Pyrolys is Process is a technically proven and cost-effective method for the production of liquid biofuels and related bioenergy products. Based on a detailed economic study for: 200-dry TPD wood pyrolysis manufacturing process the Georgia Tech process should be scaled-up to a commercial prototype scale and be actively commercialized. A summary of the results of the economic analysis is given in Table 69. 
TABLE 67. Annual Rate of Return on Investment 200-dry TPD

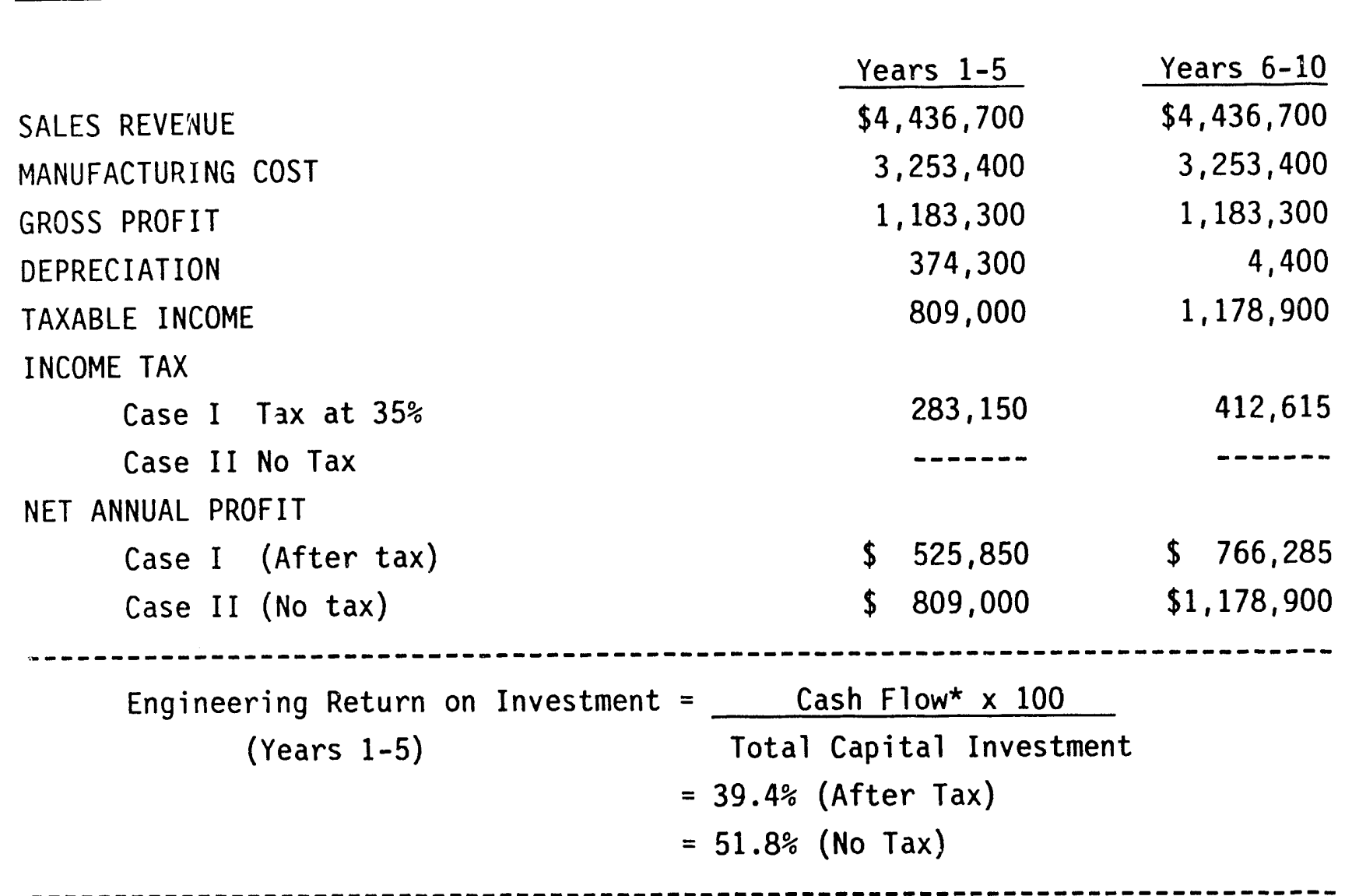

*Cash Flow $=$ Net Annual Profit + Depreciation 
TABLE 68. Payout Period and Discounted Cash Flow-Rate of Return on Investment

200-dry TPD

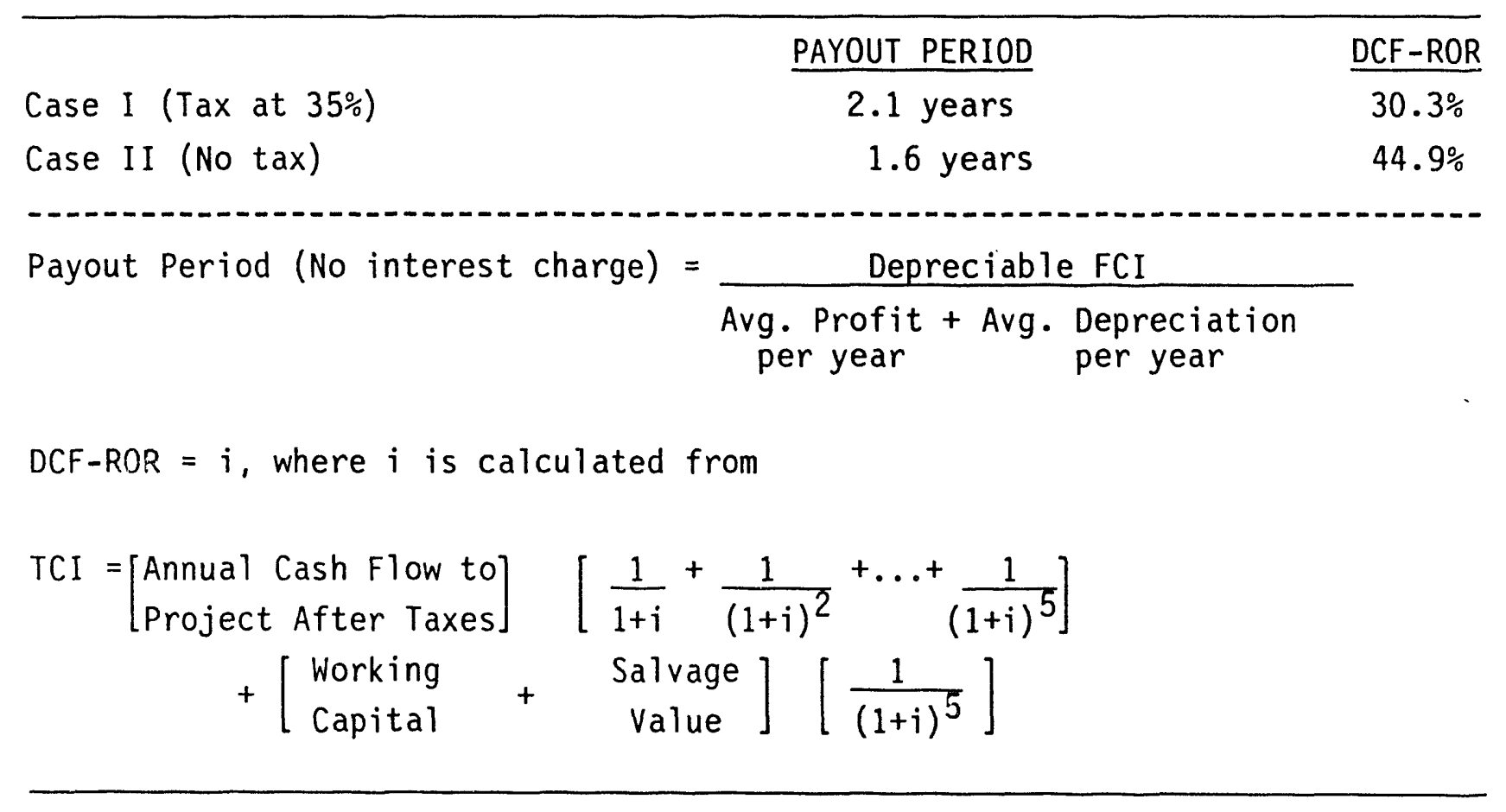


TABLE 69. Summary of Economic Analys is

200-dry TPD Plant, 60\% 0 il Yield

TOTAL CAPITAL INVESTMENT

MANUFACTURING (PRODUCT) COST (ANNUAL)

SALES REVENUE (ANNUAL)

AVERAGE ANNUAL RATE OF RETURN

PAYOUT PERIOD

DISCOUNTED CASH FLOW RATE OF RETURN

MANUFACTURING COST, PER GJ

FIXED CAPITAL INVESTMENT, PER GJ
$\$ 2.2$ million

$\$ 3.25$ million

$\$ 4.44$ million

$39.4 \%(51.8 \%)$ *

$2.1(1.6) *$ years

$30.3 \%(44.9 \%)$ *

$\$ 2.56$

$\$ 1.38$

*Before (or no) tax case. 


\section{REFERENCES}

1. Bowen, M.D. et al. (1978). A Vertical-Bed Pyrolysis System. Chapter 6 in Solid Wastes and Residues: Conversion by Advance Thermal Processes (ed. Jones, J.L. and Radding, S.B.), ACS Symposium 76, American Chemical Society, Washington, D.C.

2. O'Nei1, D.J., Kovac, R.J. and Gorton, C.W. (13-17 February 1989). Liquid Biofuels Production by an Entrained Flow Pyrolysis Process. Paper presented at Energy from Biomass and Wastes XIII, New Orleans, Institute of Gas Technology.

3. Elston, W.E., Kovac, R.J. and O'Nei1, D.J. (7-9 October 1986). Proceedings of the Fourth Southern Biomass Energy Research Conference. University of Georgia, Athens, Georgia.

4. Peters, M.S. and Timmerhaus, K.D. (1980). Plant Design and Economics for Chemical Engineers. Third Edition. McGraw-Hill Book Co., New York. 
A limited series of screening runs were conducted to identify candidate catalysts for future evaluation as deoxygenating agents for the chemical upgrading and stabilization of pyrolysis oils. Model compounds were used in the screening runs and a list of catalysts which were tested follows:
(a) KETJEN $\left(\mathrm{Ni} / \mathrm{Mo} / \mathrm{Al}_{2} \mathrm{O}_{3}\right)$
(b) $\quad$ ZSM-5 (AI-90)
(c) ZSM-5 (Medium Al content)
(d) ZSM-5 with $\mathrm{Ni} / \mathrm{Mo}$
(e) ZSM-5 with $\mathrm{Ni} / \mathrm{W}$
(f) SKA 8987 (Proprietary)
(g) SILICALITE (S-115)
(h) S-115 with Co/Mo
(i) S-115 with $\mathrm{Ni} / \mathrm{Mo}$
(j) $\quad Y-82$
(k) $\quad Y-82$ with $\mathrm{Co} / \mathrm{Mo}$
(1) $\quad Y-82$ with $\mathrm{Ni} / \mathrm{W}$

The preliminary qualitative results suggested that the ZSM-5 with $\mathrm{Ni} / \mathrm{W}$ and the $\mathrm{Y}-82$ with $\mathrm{Ni} / \mathrm{W}$ were potential catalysts for upgrading of pyrolysis oil. 
APPENDIX A

ENERGY AND MATERIAL BALANCES FOR THE EXPERIMENTAL

ENTRAINED PYROLYSIS SYSTEM --

COMPUTER PROGRAM - "MODEL 1" 


\section{ENERGY AND MATERIAL BALANCES FOR}

THE EXPERIMENTAL PYROLYSIS SYSTEM

\section{* COMPUTER PROGRAM - MODEL 1 *}

This is program MODEL 1. It simulates conditions within the pyrolyzer tube to evaluate heat losses, temperatures, heating requirements, and finally flow rates at various points on a flow diagram used by the programer. If desired, this program will further calculate the gas and particle temperature profiles within the tube. Along with the temperature profiles, the gas and particle velocities, and the particle density are profiled for the conditions within the tube.

The input to the program is entered via a series of questions to the operator. The questions are fairly self explanatory. The feed rate asked for is the rate of prepared feed at 6 o moisture fed to the pyrolyzer per hour. The feed carrier gas velocity is the velocity in a $3 / 4$ inch tube used to convey the feed into the pyrolyzer. If extra gas is to be used to maintain entrainment, then allowances for it can be made by increasing the velocity. The pyrolyzer temperature is the temperature of the products as they exit the pyrolyzer. The hot-gas temperature is the temperature of the hot gases produced in the hot-gas generator which is located beneath the pyrolyzer.

The output is also fairly self explanatory. The table of flow rates produced contains the temperature, mass flow rates and volumetric flow rates of all the streams within the system. (See Table 1.) The volumetric flow rate (i.e. CFM - 'Cubic Feet Per Minute') is calculated at the temperature of the particular stream in question. In the table shown, containing the various stream profiles, the variables are printed at one foot intervals for the length of the tube $(20 \mathrm{ft}$.$) . The temperatures are in$ degrees Fahrenheit, the density in pounds per cubic foot, and the velocity in feet per second. 
In the text of the program, there are several operating parameters which are built into the program and are not readily changed. They include the following items:

* The pyrolyzer is an 8 -inch, schedule 40, stainless steel tube.

* The pyrolyzer is wrapped in a 6-inch insulation blanket.

* The feed is introduced in a 'mixer' section located between the hot-gas generator and the pyrolyzer tube.

* The fuel to the hot-gas generator is natural gas (methane).

* The wood feed is at $77^{\circ} \mathrm{F}$.

* All excess gases used to moderate the hot-gas generator and all carrier gases are produced in an inert gas generator. This gas is therefore composed of the combustion products of natural gas with air. The inert gas is assumed to be saturated with water vapor at the exit temperature of the inert gas generator $\left(120^{\circ} \mathrm{F}\right)$.

* Air at $77^{\circ} \mathrm{F}$ is used in combustion in the hot-gas generator.

* The ambient air temperature is $77^{\circ} \mathrm{F}$.

* Temperature distributions within the particle are assumed to be negligible.

In running the program, the operator must first attach the IMSL (International Math-Science Library) library of subroutines. One of these subroutines is used within the program so the library must be available for access. The operator can then continue to compile and execute the program on a FORTRAN 5 compiler. The output will be output to the terminal unless the operator specifies differently in the execution statement.

Within the text of the program there are many variables which were isolated to allow the user to readily change them, so that the program can be versatile. By studying the nomenclature section which follows, the user can become familiar with the program. Below are a few highlights of parameters that can be changed by using any text editor in order to change the operating parameters of the program. They include: 
* To change the yields of the products - simply change CCHAR, COIL, CH2O and CGAS to reflect the new yields on a moistureash-free basis.

* To change the diameter of the wood particles - Change DP to reflect the new diameter in the statement 'DP in feet.

* To change the density of the wood feed - Change the statement "PP (1) = " to the new initial density.

* To change the density of the final char product - change the statement "PP $(*+1)=-$. Here * is any one of several counting variables. In this statement, there is the density difference that drives the pyrolysis "PP(*) - 5." Here "5' is the final density or the char density as written in the program. Simply change this density to reflect the new condition wherever it occurs. NOTE: this statement appears several times within the program. It is recommended that the user use the text editor to scan the program and change all occurrences of "PP(*) 5.", where * can be either "M" or "L."

* To change the activation energy - Change the statement "ACT = " to the new value in calories per mole per degree Kelvin.

* To change the pyrolysis rate constant - Change the statement $" \mathrm{RC}=$ " to the new value in inverse seconds.

Finally, a discussion if the nomenclature is necessary to aid the user. The following is a list of the major variables within MODEL 1. While units are not given in every case, most all calculations are in pounds, pound-moles, BTUs, feet and seconds. 


\section{NOMENCLATURE}

AMOIST

AVM

CC

CCHAR

$C D$

CG

CGAS

$\mathrm{CH}$

$\mathrm{CHI}$

$\mathrm{CHO}$

$\mathrm{CH} 2 \mathrm{O}$

Co

COIL

CON1\&

CON2

CONV \&

CONV2

$\mathrm{CP}$

CPG

CPV

DELX

DP
- The flow rate of moisture in the particles as part of the entrained flow

- The average molecular weight of the gases in the pyrolyzer

- Amount of char produced per pound of feed

- Weight percent of char in product

- The drag coefficient for the entrained particles

- Amount of noncondensable gases produced per pound of feed

- Weight percent of noncondensable gases in product

- Amount of water produced per pound of feed

- The convection heat transfer coefficient for the inside surface of the pyrolyzer section under study

- The convection heat transfer coefficient for the outside surface of the pyrolyzer section under study

- Weight percent of water in product

- Amount of oil produced per pound of feed

- Weight percent of oil in product

- Fractional conversions of wood to char

- Fractions of unpyrolyzed wood

- The heat capacity of the particles at their fractional conversion

- The heat capacity of the gases immediately underneath the entrained particle that will be flowing past the particle. These gases include any pyrolysis products.

- The heat capacity of the vapors that are being produced by the pyrolysis of the particles

- The step size of the iteration in feet

- The diameter of the particles 


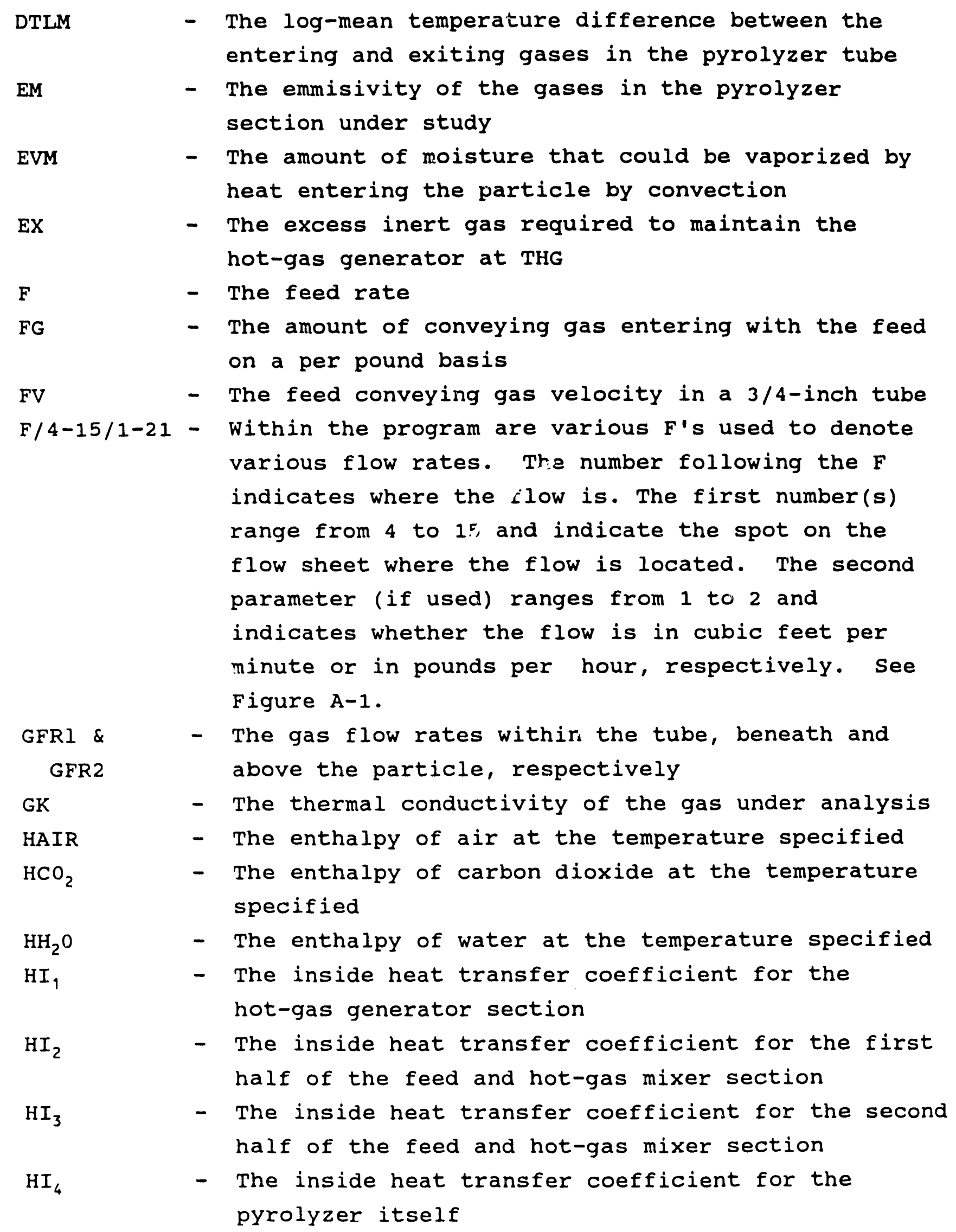




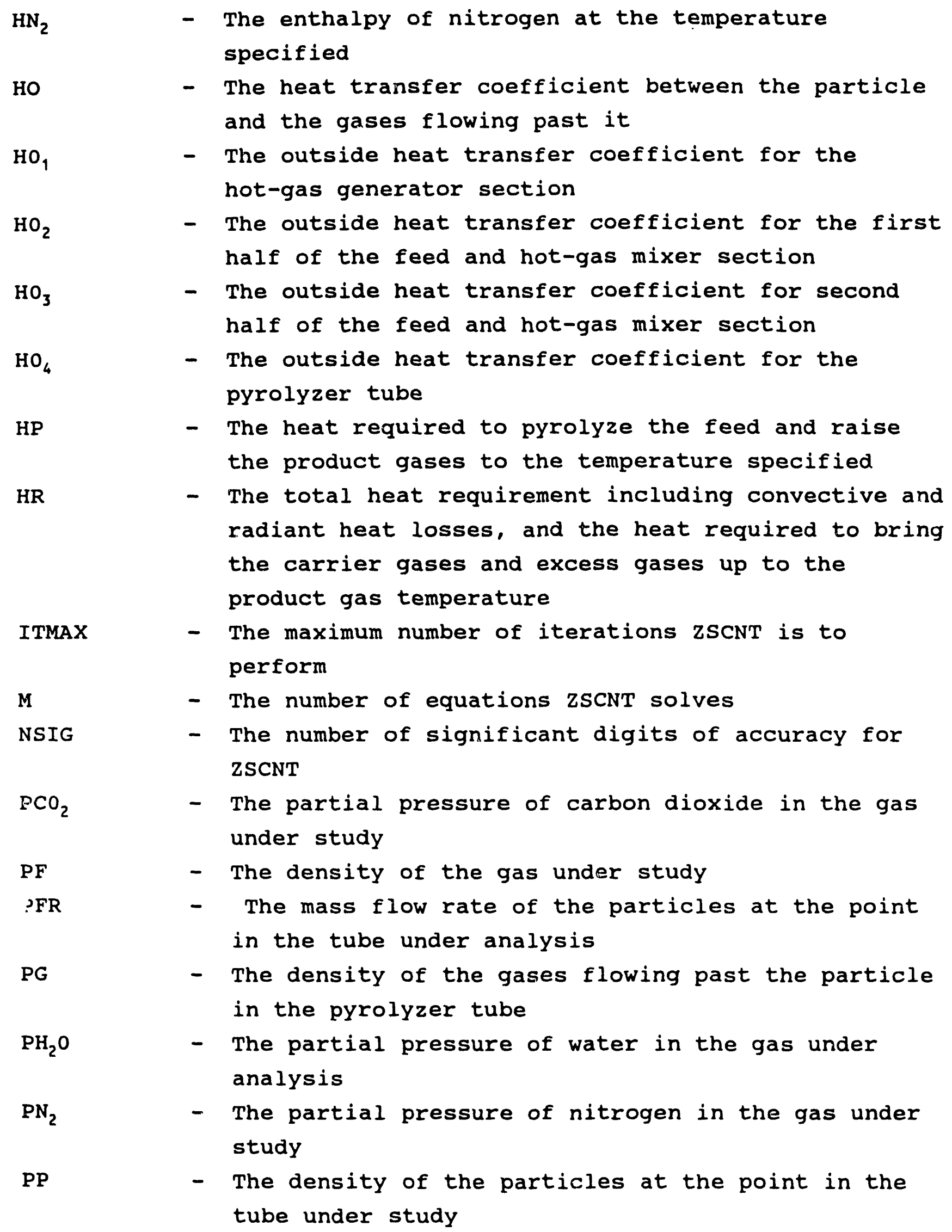

- The total heat requirement including convective and radiant heat losses, and the heat required to bring the carrier gases and excess gases up to the product gas temperature

- The maximum number of iterations ZSCNT is to perform

- The number of equations ZSCNT solves

- The number of significant digits of accuracy for ZSCNT

- The partial pressure of carbon dioxide in the gas under study

- The density of the gas under study

- The mass flow rate of the particles at the point in the tube under analysis

- The density of the gases flowing past the particle in the pyrolyzer tube

- The partial pressure of water in the gas under analysis

- The partial pressure of nitrogen in the gas under study

- The density of the particles at the point in the tube under study 
- The total convective and radiant heat losses for all the sections of the pyrolyzer

QP

Q1

Q2

Q3

Q4

RE

RHI

RHO

TA

TG

TGF

TGM

THG

TM

TMAS

TMH

T01

- The rate of heat transfer into the particle

- The convective and radiant heat loss through the hot-gas generator section

- The convective and radiant heat loss through the first half of the feed and hot-gas mixer section

- The convective and radiant heat loss through the second half of the feed and hot-gas mixer section

- The convective and radiant heat loss through the pyrolyzer tube

- The Reynold's number for the gas under study

- The contribution to the inside heat transfer coefficient due to radiation

- The contribution to the outside heat transfer coefficient due to radiation

- The average of the product exit and mixer section temperatures

- The temperature of the gases at the point in the tube under analysis

- The film temperature between the particle and the gases flowing past the particle

- The total number of moles of water, oil, and noncondensable gases produced by pyrolysis, per pound of feed

- The hot-gas generator temperature

- The temperature in the second half of the feed and hot-gas mixer section, after the feed has been introduced

- The total mass of vapors produced by the pyrolysis of one pound of feed

- The total number of moles of water produced by pyrolysis per pound of feed

- The outside surface temperature of the hot-gas generator section 
T02

T03

T04

TP

TPR

$\mathrm{U}$

U

V

VF

VG

VOLF

VP

VPG

ZSCNT
- The outside surface temperature of the first half of the feed and hot-gas mixer section

- The outside surface temperature of the second half of the feed and hot-gas mixer section

- The outside surface temperature of the pyrolyzer tube

- The temperature of the particle at the point in the tube under analysis

- The exit temperature of the products

- The viscosity of the gas under study

- The overall heat transfer coefficient for pyrolyzer tube wall

- The velocity of the gas under study

- The volumetric flow rate of the gas under study

- The velocity of the gases at the point in the tube under analysis

- The volumetric flow rate of the particles

- The velocity of the particles with respect to the tube at the point in the tube under analysis

- The velocity of the particles with respect to the gases at the point in the tube under analysis

- A subroutine in the 'International Mathematics and Statistics Library.' It solves a rather complicated function, as a seed in subroutine $F C N$, that determines the temperature of the gases after the hot gases mix with the feed and carrier gases. 
Below is a typical output from the computer program MODEL1. The questions listed below were prompted by the computer program and answered by the operator at the terminal. The replies are given following the question mark. Then two tables were produced containing the results of the calculations. These tables, Table A-1, Pyrolyzer system Flov Rates, and Table A-2, Pyrolysis Reactor Stream Profiles, are also given below.

- INPUT THE FEED RATE IN LB/HR.

? 150 .

- INPUT THE FEED CARRIER GAS VELOCITY IN FT./SEC.

? 50 .

- INPUT THE PYROLYZER TEMPERATURE IN F. ? 1202 .

- INPUT THE HOT GAS TEMPERATURE IN F. ? 2750 .

- SELECT OUTPUT: TYPE 1 FOR ONLY THE FLOW RATES, TYPE 2 FOR ONLY THE TEMPERATURE PROFILE, TYPE 3 FOR BOTH. ? 3 


\begin{tabular}{llccc}
\hline \multicolumn{7}{c}{ TABLE A-1 } & PYROLYZER SYSTEM FLOW RATES & \\
\hline POINT & MATERIAL & $\begin{array}{c}\text { FLOW } \\
(\text { CFM })\end{array}$ & $\begin{array}{c}\text { FLOW } \\
(\text { LB } / \text { HR })\end{array}$ & $\begin{array}{c}\text { TEMP } \\
\left({ }^{\circ} \mathrm{F}\right)\end{array}$ \\
\hline 4 & INERT GAS & 28.35410 & 114.61587 & 120 \\
5 & INERT GAS & 11.11730 & 44.93948 & 120 \\
6 & INERT GAS & 17.23681 & 69.67639 & 120 \\
7 & WOOD FEED & 0.0 & 150.00000 & 77 \\
8 & WOOD FEED & 0.0 & 150.00000 & 77 \\
9 & FEED STREAM & 11.11730 & 194.93948 & 120 \\
10 & AIR & 33.05524 & 146.68025 & 77 \\
11 & AIR & 0.02314 & 8.51860 & 77 \\
13 & HOT GAS & 313.65726 & 224.87524 & 2750.0 \\
14 & HOT GAS & 329.59482 & 419.81472 & 2359.9 \\
15 & F FEED & 266.93872 & 419.81472 & 1202.0 \\
& GAS \& CHAR & & & \\
\hline & & & & \\
\hline
\end{tabular}


TABLE A-2. PYROLYSIS REACTOR STREAM PROFILES

\begin{tabular}{|c|c|c|c|c|c|}
\hline LOCATION & $\begin{array}{r}\text { GAS } \\
\text { TEMP }\end{array}$ & $\begin{array}{l}\text { PART } \\
\text { TEMP }\end{array}$ & $\begin{array}{l}\text { PART } \\
\text { DENS }\end{array}$ & $\begin{array}{l}\text { PARTICLE } \\
\text { VELOCITY }\end{array}$ & $\begin{array}{r}\text { GAS } \\
\text { VELOCITY }\end{array}$ \\
\hline 0 & 2359.9 & 77.0 & 50.0 & 1.0 & 15.8 \\
\hline 1 & 1207.0 & 1141.5 & 42.6 & 6.0 & 9.8 \\
\hline 2 & 1192.7 & 1180.4 & 37.1 & 7.0 & 10.1 \\
\hline 3 & 1195.9 & 1191.1 & 32.8 & 7.6 & 10.4 \\
\hline 4 & 1199.5 & 1196.7 & 29.2 & 8.1 & 10.7 \\
\hline 5 & 1202.3 & 1200.6 & 26.3 & 8.5 & 10.9 \\
\hline 6 & 1204.2 & 1203.2 & 23.8 & 8.9 & 11.1 \\
\hline 7 & 1205.5 & 1204.9 & 21.7 & 9.2 & 11.2 \\
\hline 8 & 1206.2 & 1205.9 & 19.8 & 9.4 & 11.3 \\
\hline 9 & 1206.4 & 1206.3 & 18.2 & 9.7 & 11.4 \\
\hline 10 & 1206.1 & 1206.2 & 16.8 & 9.8 & 11.5 \\
\hline 11 & 1205.6 & 1205.8 & 15.6 & 10.0 & 11.6 \\
\hline 12 & 1204.7 & 1204.9 & 14.5 & 10.2 & 11.7 \\
\hline 13 & 1203.5 & 1203.8 & 13.6 & 10.4 & 11.7 \\
\hline 14 & 1202.1 & 1202.5 & 12.7 & 10.5 & 11.8 \\
\hline 15 & 1200.6 & 1201.0 & 12.0 & 10.6 & 11.8 \\
\hline 16 & 1198.9 & 1199.2 & 11.3 & 10.7 & 11.3 \\
\hline 17 & 1197.0 & 1197.4 & 10.7 & 10.8 & 11.9 \\
\hline 18 & 1195.0 & 1195.4 & 10.2 & 10.9 & 11.9 \\
\hline 19 & 1192.9 & 1193.3 & $9-7$ & 10.9 & 11.9 \\
\hline 20 & 1190.7 & 1191.1 & 9.2 & 11.0 & 11.9 \\
\hline
\end{tabular}




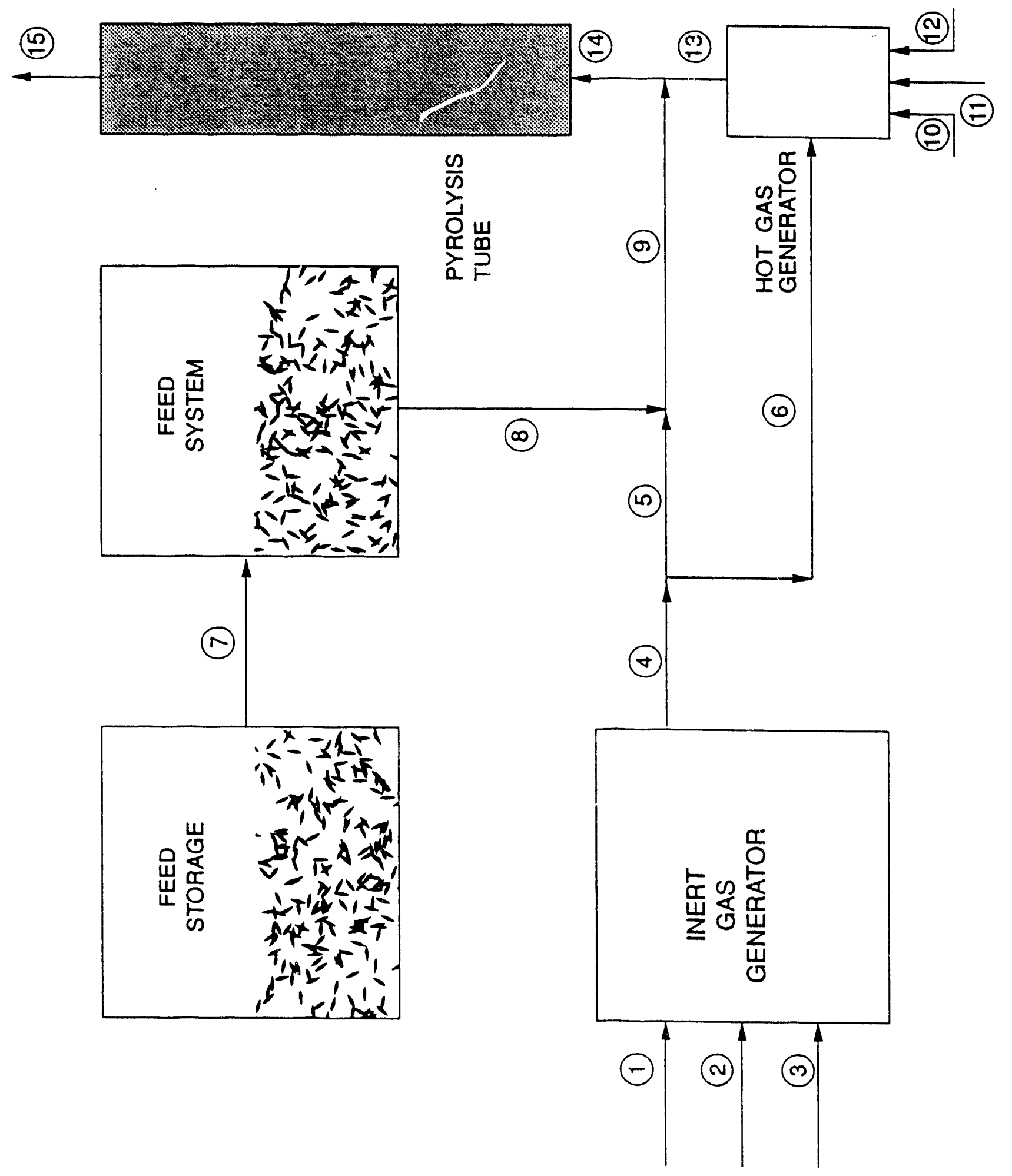

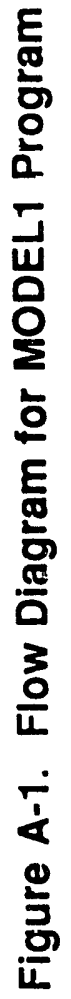


PROGRAM MODELI (INPUT, OUTPUT, TAPE $5=$ I NPUT, TAPE $6=0 U T P U T$ )

DIMENSION QI(101),Q2(101),Q3(101),Q4(101),T01(101)

2.T02(101), T03(101), T04(101),HR(101),TM(101), F13(101),

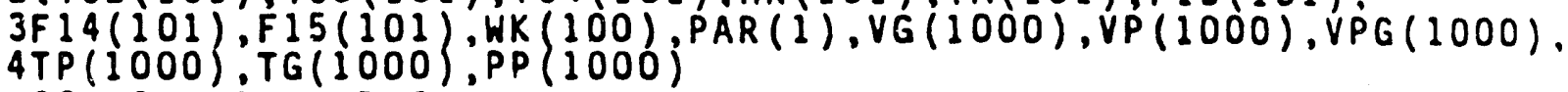

COMMON FG,EX,THG

EXTERNAL FCN

WRITE $(6, *)$ 'INPUT THE FEED RATE IN LB./HR.'

READ $(5, *) F$

WRITE $(6, \star)$ 'INPUT THE FEED CARRIER GAS VELOCITY IN FT./SEC.'

READ $(5, \star) F V$

WRITE $(6, *)$ 'INPUT THE PYROLYZER TEMPERATURE IN F.'

READ $(5, \star) T P R$

WRITE $(6, *)$ 'INPUT THE HOT GAS TEMPERATURE IN $F$. '

READ $(5, *) T H G$

WRITE $(6, *)$ 'SELECT OUTPUT: TYPE I FOR ONLY THE FLOW'

WRITE $(6, *)$ 'RATES, TYPE 2 FOR ONLY THE TEMPERATURE'

WRITE $(6, \star)$ 'PROFILE, TYPE 3 FOR BOTH.

READ $(5, \star)$ NANS

$H R(1)=.06$

$\operatorname{TOI}(1)=300$.

$\mathrm{TO2}(1)=300$.

$\mathrm{T} 03(1)=250$.

TO4 (1) $=200$.

CCHAR $=.15467$

COIL $=.40254$

$\mathrm{CH} 2 \mathrm{O}=.21938$

CGAS $=.22341$

$T M(1)=T H G-(T H G-T P R) / 4$.

$C C=C$ CHAR $.9341+.0059$

$\mathrm{CO}=\mathrm{COIL} .9341$

$\mathrm{CH}=\mathrm{CH} 20 \star .9341+.06$

$C G=C G A S^{\star} .9341$

$E X=(344032 .-1 . *(H C O 2(T H G)-H C O 2(77))-.2 . \star(H H 2 O(T H G)$

$2-H H 20(77)).-7.52 \star(H N 2(T H G)-H N 2(77))$.

$3 /(.1040 *(H C O 2(T H G)-H C O 2(120))+..7810 *(H N 2(T H G)-H N 2(120))$.

$4+.1150 *(H H 20(T H G)-H H 2 O(120))$.

$D T=T P R-392$.

$T G M=C O / 150 .+C H / 18 .+C G / 31$.

$T M H=C H / 18$.

$H P=255.03-109.42+C C * .2 * O T+C O \star .6 * D T+C H / 18 *(H H 2 O(T P R)-H H 2 O(392))+$.

$2 C G *((H C O(T P R)-H C O(392)) / 101.71+.(H C O 2(T P R)-H C O(392)) / 68.2+$.

$3(H H 2$ (TPR) - HH2 (392.)) $/ 534.76+(H C H 4(T P R)-H C H 4(392)) / 286.07+$.

$4(H C 2(T P R)-H C 2(392)) / 2568.5+.(H C 3(T P R)-H C 3(392)) / 8224.3+$.

$5(H C 4(T P R)-H C 4(392)) / 20567.4$.

$F G=F V \star .0315 / F$

$N=0$

$370 N=N+1$

$F 13(N)=(E X+10.52) \star H R(N) \star F / 3600$.

$F 14(N)=F 13(N)+F G \star F / 3600$.

$F 15(N)=F 14(N)+T G M-F / 3600$.

IF (N.LT.2)GO TO 440

IF (ABS( (TM(N) -TM(N-1))/TM(N-1)).LT..0001.AND.ABS((HR(N)-HR(N-1))

$2 / H R(N-1)) . L T . .0001) G 0$ TO 770 
440 IF (N.GE.101)GO TO 750

CALL HHO(TOI (N),HOI)

CALL HHI (THG,FI3(N),EX,HII)

$Q I(N+1)=7.3304 *(T H G-77) /(4.80 / H I 1+6.428+1.2973 / H O 1)$

TOI $(N+1)=T H G-Q I(N+1) *(4.80 / H I I+5.428) / 7.3304$

CALL HHO(T02(N),$H 02)$

CALL HHI (THG,FI3(N),EX,HI2)

$Q 2(N+1)=3.1416 *(T H G-77) /.(4.0 / H I 2+6.0314+1.2973 / H O 2)$

TO2 $(N+1)=T H G-Q 2(N+1) *(4.0 / H I 2+6.0314) / 3.1416$

CALL HHO(TO3 (N),H03)

CALL M2HI (TM(N) FI4(N),EX FG,HR,HI3)

$Q 3(N+1)=8.901 *(T M(N)-77) /.(4.0 / H I 3+6.0314+1.2973 / H O 2)$

$T 03(N+1)=T M(N)-Q 3(N+1) *(4.0 / H I 2+6.0314) / 8.901$

$\operatorname{DTLM}=(T P R-T M(N)) / A L O G((T P R-77) /.(T M(N)-77)$.

CALL PHO (TO4 (N).HO4)

$T A=(T P R+T M(N)) / 2$

CALL PHI (TA,FI5(N),EX,FG,HR,TGM,TMH HI4)

$Q 4(N+1)=125.66 \star D T L M /(3.007 / H I 4+14.5323+1.1636 / H O 4)$

$T 04(N+1)=T A-Q 4(N+1) *(3.007 / H I 4+14.5323) / 125.66$

$Q=Q 1(N+1)+Q 2(N+1)+Q 3(N+1)+Q 4(N+1)$

$Q=Q / F$

$H R(N+1)=(Q+H P+.1040 * F G \star(H C O 2(T P R)-H C O 2(120))+..7810 * F G \star$

$2(H N 2(T P R)-H N 2(120))+..1150 \star F G *(H H 20(T P R)-H H 20(120)).) /$

$3((1 .+.1040 \star E X) *(H C O 2(T H G)-H C O 2(T P R))+(2+.1150 \star E X) \star$

$4(H H 2 O(T H G)-H H 2 O(T P R))+(7.52+.7810 * E X) \star(H N 2(T H G)-H N 2(T P R)))$

$M=1$

NSI $G=5$

I TMAX $=4000$

$\operatorname{PAR}(1)=H R(N+1)$

$X=T M(N)$

CALL ZSCNT (FCN, NSIG, M, I TMAX, PAR, X,FNORM, WK, IER)

$\operatorname{TM}(N+1)=X$

GO TO 370

750 WRITE (6,*) 'THE PROGRAM DIDN"T REACH A SOLUTION,BUT HERE

2IS FINAL STATUS '

$770 F 72=F$

$F 82=F$

$F 51=F G \star F \star 7.0586$

$F 52=F G * F \star 28.533$

$F 6 I=E X * H R(N) \star F \star 7.0586$

$F 62=E X \star H R(N) \star F \star 28.533$

$F 41=F 51+F 61$

$F 42=F 52+F 62$

$F 91=F 51$

$F 92=F 52+F 82$

$F 101=H R(N) \star F \star 62.241$

$F 102=H R(N) \star F \star 276.19$

$F 111=H R(N) \star 6.5353$

$F 112=H R(N) \star F \star 16.04$

$F 131=F 13(N) * 43.812 *(T H G+460$.

$F 132=F 102+F 112+F 62$

Fi $41=F 14(N) \star 43.812 \star(T M(N)+460$.

$F 142=F 132+F 92$

$F 151=F 15(N) * 43.812 *(T P R+460$. 


\section{$F 152=F 142$}

IF (NANS.EQ.1.OR. NANS . EQ.3) THEN

965 FORMAT $(1,5 \times, / / / / /)$

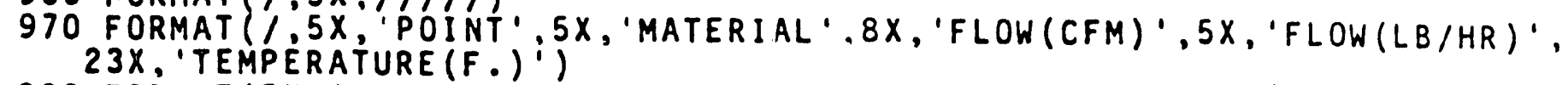

990 FORMAT ( $5 X, \ldots . . .5 X, 1,-$

$23 X$

1010 FORMAT $\left(/, 5 X, 4^{\prime}, 9 X\right.$, 'INERT GAS', $\left.6 X, F 10.5,4 X, F 10.5,4 X,{ }^{\prime} 120^{\prime}\right)$

1020 FORMAT $1,5 x,: 5,9 x$, INERT GAS $, 6 x, F 10.5,4 x, F 10.5,4 x, 1,120:\}$

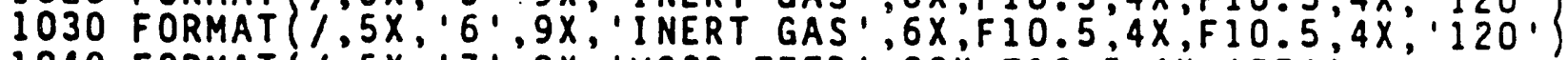

1040 FORMAT $\left(1,5 x, 7 \%, 9 x\right.$, WOOD FEED'.20X,F10.5,4x, $77^{\prime} j$

1050 FORMAT $\left(1,5 x, 81,9 x\right.$, WOOD FEED',20X,F10.5,4X, $\left.77^{\prime}\right)$

1060 FORMAT ( $/ .5 x, 9{ }^{\prime}, 9 x$, 'FEED STREAM $\left.4 \dot{X}, F 10.5,4 \dot{x}, F 10.5,4 x .10^{\prime}\right)$

1070 FORMAT $\left(/, 5 X,{ }^{\prime} 10^{\circ}, 8 X, x^{\prime} A I R,, 12 x, F 10.5,4 x, F 10.5,4 X, 77^{\prime}\right)$

1080 FORMAT $\left(1,5 X, 111, .8 X,{ }^{\prime}\right.$ GAS' $\left.12 x, F 10.5,4 X, F 10.5,4 X, 77^{\prime}\right)$

1090 FORMAT $/, 5 X, ' 13, .8 X, '$ HOT GAS'.8X,F10.5,4X,F10.5,4X.F10.5)

1100 FORMAT $\left(/, 5 X, ' 14,, 8 X,{ }^{\prime}\right.$ 'HOT GAS\&FEED' .3X,F10.5, $\left.4 X, F 10.5,4 X, F 10.5\right)$

1110 FORMAT $\left(/, 5 X, 15^{\prime}, 8 X, X^{\prime}\right.$ GAS\&CHAR' $\left.7 X, F 10.5,4 X, F 10.5,4 X, F 10.5, / / / / / /\right)$

WR ITE $(6,965)$

WRITE $(6,970)$

WRITE $(6,990)$

WRITE $(6,1010) F 41, F 42$

WRITE $(6,1020) F 51, F 52$

WRITE $(6,1030) F 61, F 62$

WR ITE $(6 ; 1040) F 72$

WRITE $(6,1050) F 82$

WRITE $(6,1060) F 91, F 92$

WRITE $(6,1070) F 101, F 102$

WRITE $(6,1080) F 111, F 112$

WR ITE $(6.1090) F 131, F 132$, THG

WRITE $(6,1100)$ F $141, F 142, T M(N)$

WRITE $(6,1110) F 151, F 152$. TPR

WRITE $\left(6,{ }^{\star}\right) N$

END IF

IF (NANS . EQ . 2.OR . NANS .EQ.3) THEN

$D P=3.2808 E-3$

$V G(1)=F 141 / 20.845$

$V P G(1)=V G(1)-1$.

$V P(1)=V G(1)-V P G(1)$

$T P(1)=77$.

$T G(1)=T M(N)$

$P P(1)=50$.

$V O L F=F /(3600 * P P(1))$

$P C 02=(H R(N) *(1 .+.1040 \star E X)+.1040 * F G) /(H R(N) \star(E X+10.52)+F G)$

$P H 20=(H R(N) *(2+.1150 * E X)+.1150 * F G) /(H R(N) *(E X+10.52)+F G)$

$P N 2=1 .-P C O 2-P H 2 O$

$A V M=P C 02 * 44 .+P H 20 * 18 .+P N 2 \star 28$.

$A M O I S T=.06 * F / 3600$.

DO $1400 \quad L=1,960$

IF (VP (L).LT.0.0)THEN

WRITE $(6 . *)$ 'THE PARTICLE LOST ENTRAINMENT ON ITERATION'

WRITE $6, \star\}$ 'NUMBER ',L

GO TO 1410

END I $F$ 


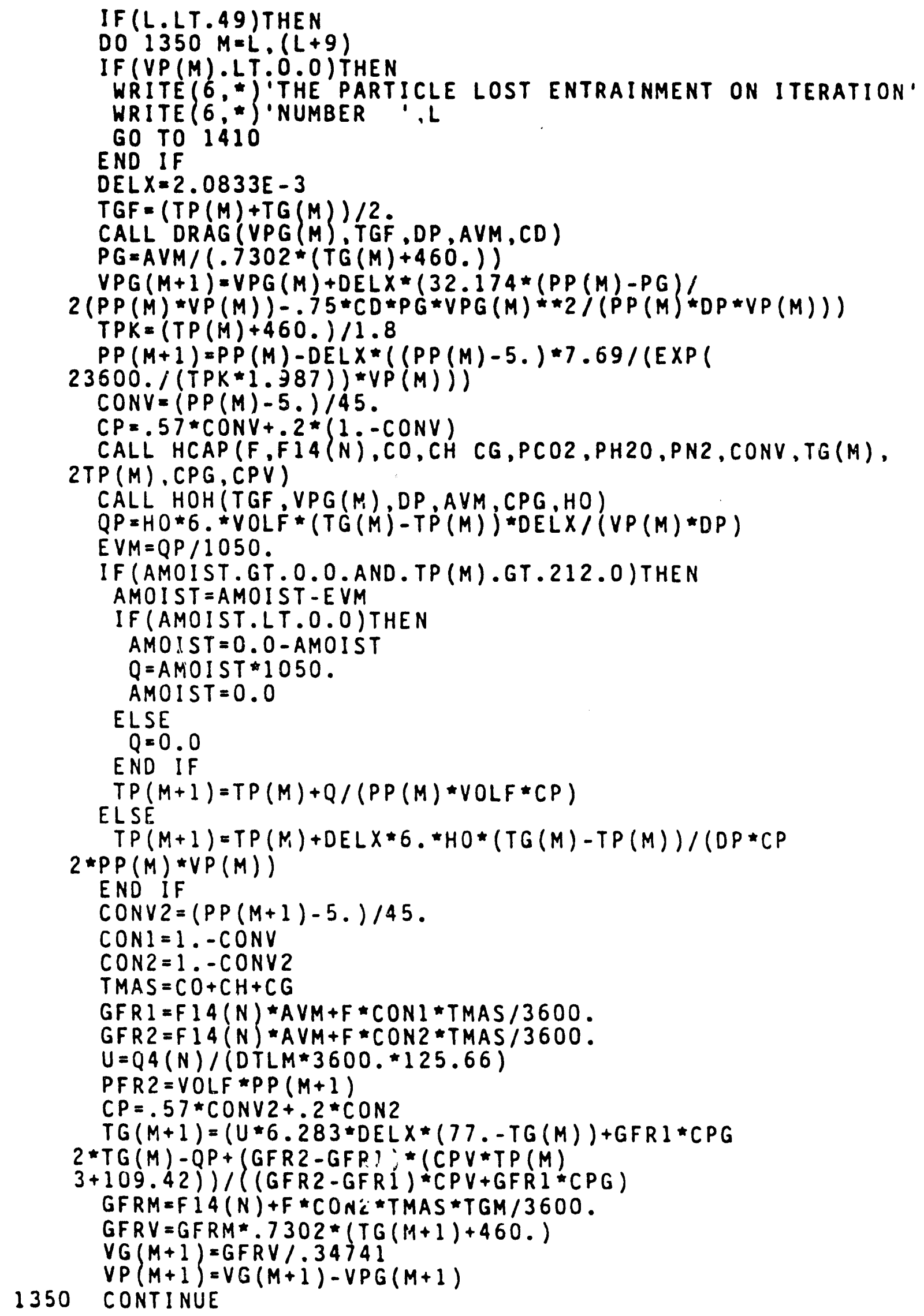




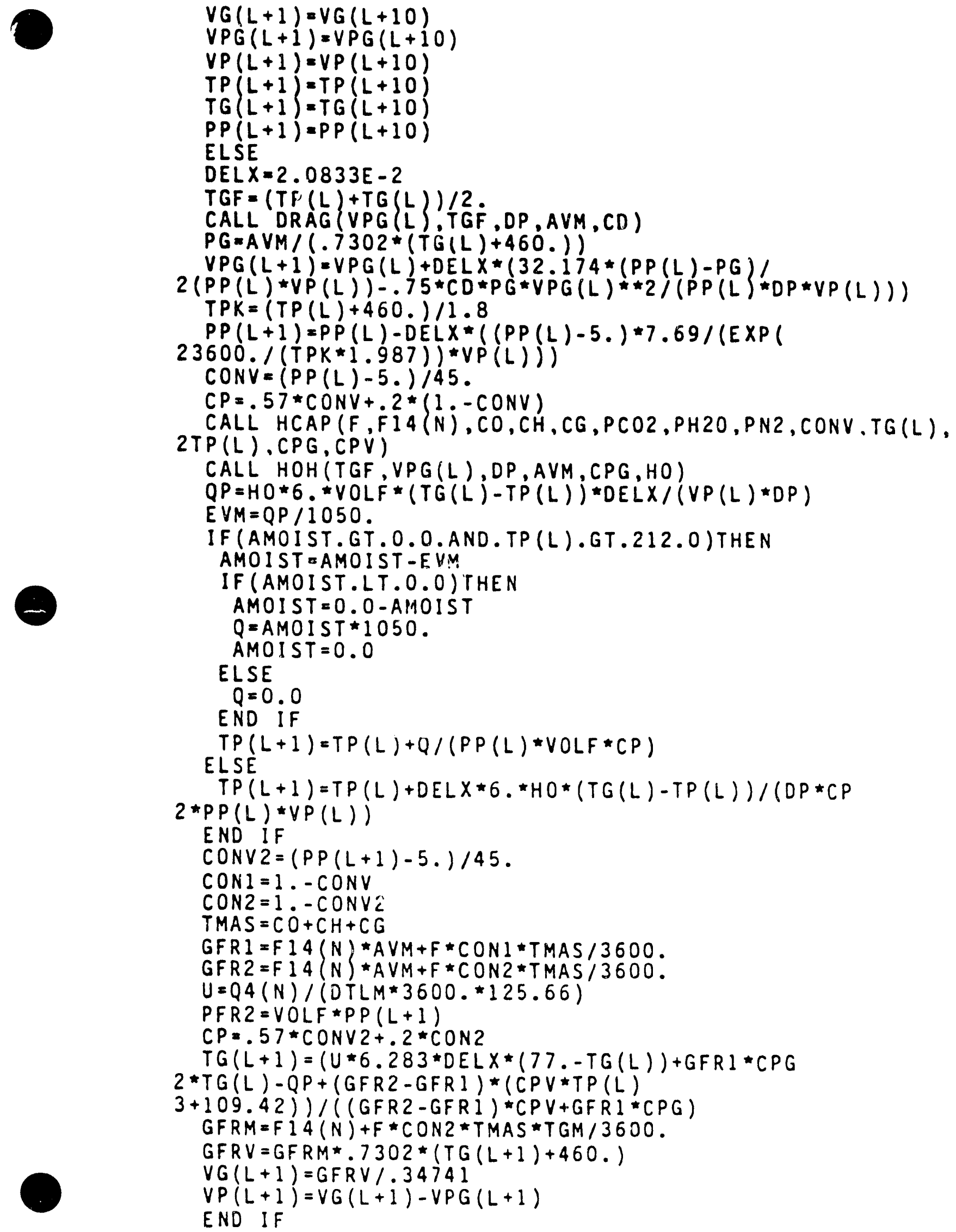




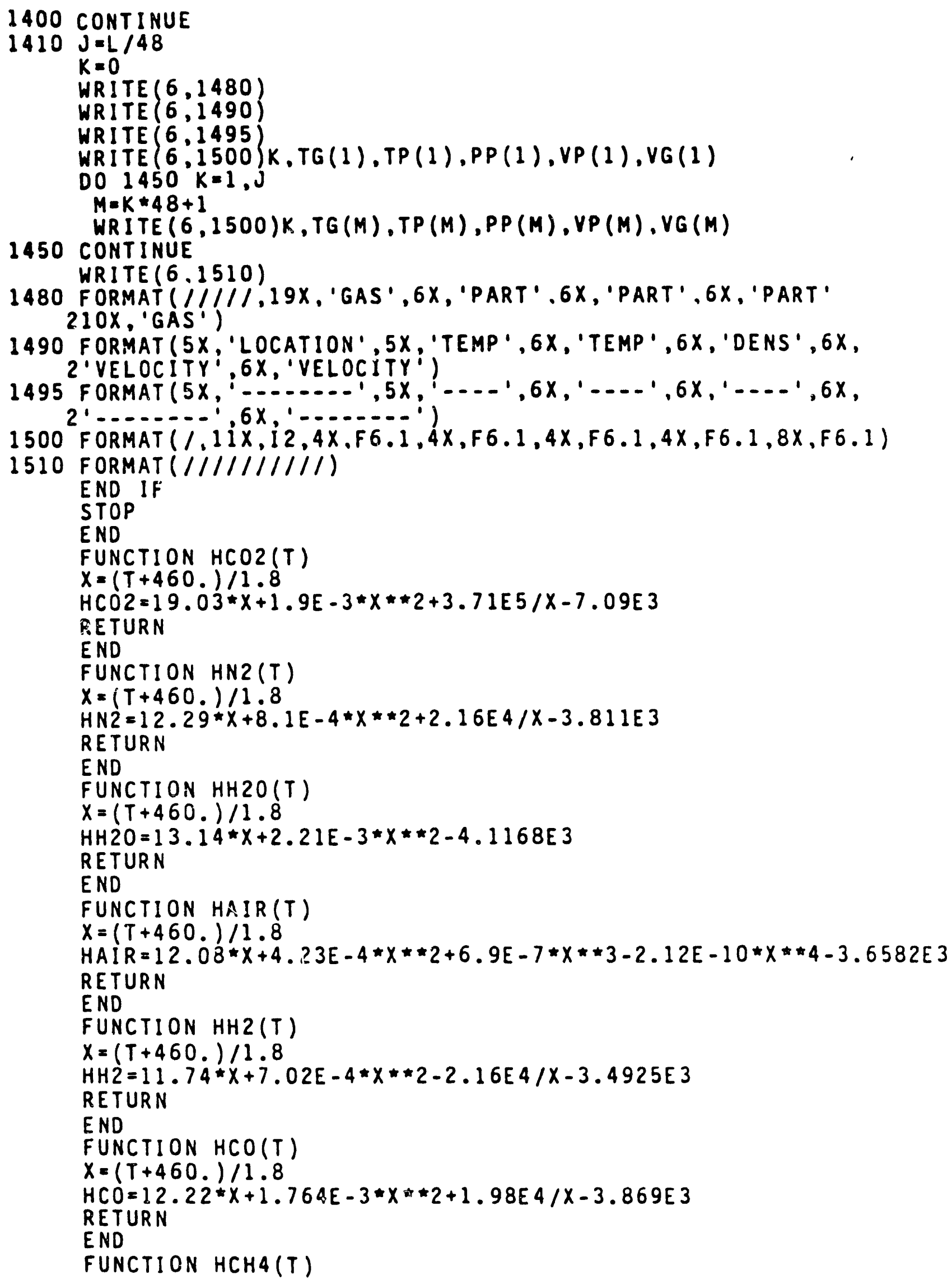




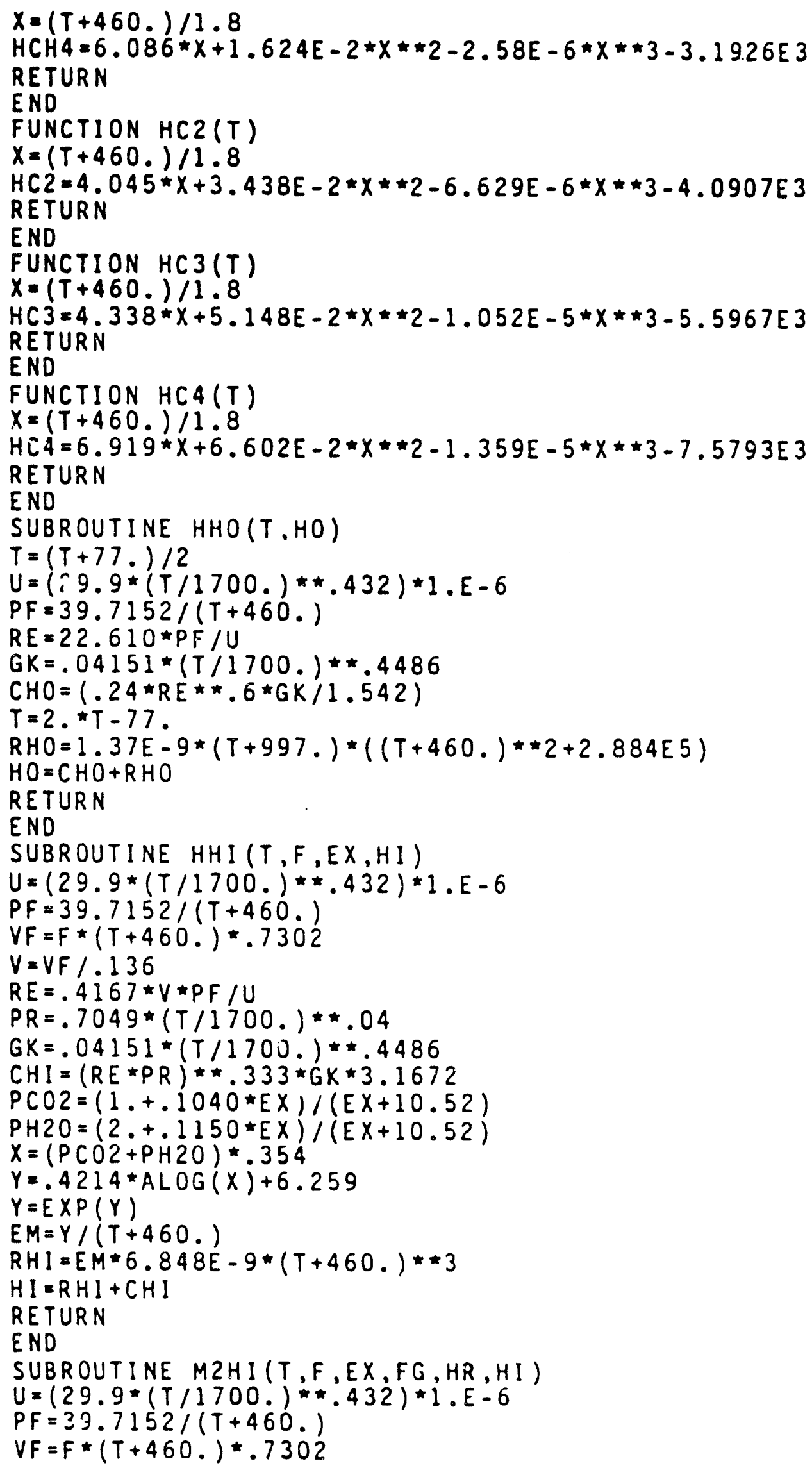


$V=V F / .196$

$R E=.5000 * V \star P F / U$

$P R=.7049 *(T / 1700). * \star 04$

$G K=.04151 *(T / 1700.) \star \star .4486$

$C H I=(R E+P R) * * .333 * G K * 2.6832$

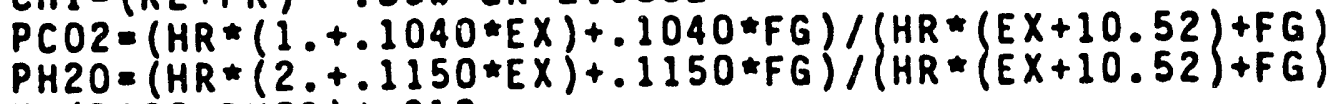

$X=(P C O 2+P H 20) * .313$

$Y=.4214 * A L O G(X)+6.259$

$Y=E X P(Y)$

$E M=Y /(T+460$.

$R H I=E M \star 6.848 E-9 *(T+460.) \star * 3$

$H I=C H I+R H I$

RETURN

END

SUBROUTINE PHO $(T, H O)$

$T=(T+77) /$.2 .

$U=(29.9 *(T / 1700). * \star .432) * 1 . E-6$

$P F=39.7152 /(T+460$.

$R E=25.208 * P F / U$

$G K=.04151 *(T / 1700.) \star .4486$

$H O=(.24 \star R E \star .6 \star G K / 1.719)$

$T=2 . \star T-77$.

RETURN

END

SUBROUTINE PHI (T,F,EX,FG,HR, TGM, TMH, HI)

$U=(29.9 *(T / 1700) * * 432) * 1 . E-$.

$P F=39.7152 /(T+460$.

$V F=F \star(T+460.) \star .73 ن 2$

$V=V F / .3474$

$R E=.665 * V \star P F / U$

$P R=.7049 *(T / 1700) * *$.

$G K=.04151 *(T / 1700) *$.

$P C O 2=(H R *(1 .+.1040 * E X)+.1040 * F G) /(H R *(E X+10.52)+F G+T G M)$

$P H 20=(H R *(2 .+.1150 \star E X)+.1150 * F G+T M H) /(F G+T G M+H R *(E X$

$2+10.52))$

$X=(P C O 2+P H 2 r) \star .613$

$Y=.4214 \star A L G(X)+6.259$

$Y=\operatorname{EXP}(Y)$

$E M=Y /(T+460$.

$C H I=R E \star .333 * F R \star .333 * G K \star 2.003$

$R H I=E M * 6.848 E-9 *(T+460.) \star \star 3$

$\mathrm{HI}=\mathrm{CHI}+\mathrm{RHI}$

RETURN

END

SUBROUTINE FCN $(X, F, N, P A R)$

DIMENSION $X(1), F(1), P A R(1)$

COMMON FG, EX, THG

$T=X(1)$

$H R=P A R(1)$

$F(1)=F G * .1040 *(H C O 2(T)-H C O 2(120))+.F G * .7810 *(H N 2(T)-H N 2(120)$.

$2+F G * .1150 *(H H 20(T)-H H 20(120))+.H R *(1 .+.1040 * E X) *(H C O 2(T)$

$3-H C 02(T H G))+H R *(7.52+.7810 * E X) *(H N 2(T)-H N 2(T H G))$

$A+H R *(2 .+.150 * E X) *(H H 20(T)-H 420(T H G))$ 


\section{RETURN}

\section{END}

SUBROUTINE HCAP (F,FI4,CO,CH,CG,PC, PH, PN, CONV ,TG, TP, CPG, CPV) CON=1. - CONV

CPVI $=(.304 *(H C O(T G)-H C O(T P))+.454 *(H C O 2(T G)-H C O 2(T P))+$

$2.116 *(\mathrm{HH} 2(\mathrm{TG})-\mathrm{HH} 2(\mathrm{TP}))+.108 *(\mathrm{HCH} 4(\mathrm{TG})-\mathrm{HCH} 4(\mathrm{TP}))+.012 *$

$3(H C 2(T G)-H C 2(T P))+.004 *(H C 3(T G)-H C 3(T P))+.002 *(H C 4(T G)$

4-HC4 (TP) ) )/(TG-TP)

$T M=C O+C H+C G$

$C P V=(C O / T M) \star .6+(C G / T M) *(C P V 1 / 31)+.(C H / T M) \star(H H 2 O(T G)$

$2-H H 2 O(T P)) /(18 *(T G-T P))$

$C P G 1=(.304 *(H C O(T G)-H C O(T G-5))+..454 *(H C O 2(T G)-H C O 2(T G-5))+$.

$2.116 \star(H H 2(T G)-H H 2(T G-5))+..108 *(H C H 4(T G)-H C H 4(T G-5))+..012 \star$

$3(H C 2(T G)-H C 2(T G-5))+..004 *(H C 3(T G)-H C 3(T G-5))+..002 *(H C 4(T G)$

$4-H C 4(T G-5)).) /(5 . \star 31$.

$A V M=P C \star 44 .+P H \star 18 .+P N \star 28$.

$C P G 2=(P C \star(H C O 2(T G)-H C O 2(T G-5))+.P H \star(H H 2 O(T G)-H H 2 O(T G-5))$.

$2+P N *(H N 2(T G)-H N 2(T G-5)).) /(5 * A V M)$

$C P H=(H H 2 O(T G) \cdots H H 2 O(T G-5)) /.(5 . * 18$.

$F R=F 14 \star A V M+F * C O N * T M / 3600$.

$C P G=(F 14 \star A V M / F R) \star C P G 2+F \star C U N \star C O \star .6 /(3 \sigma 00 . * F R)+F \star C O N \star C G$

$2 \star C P G I /\left(3600 *{ }^{*} F R\right)+F \star C O N \star C H \star C P H /(3600 . \star F R)$

RETURN

END

SUBROUTINE DRAG ( $V G, T G, D P, A V M, C D)$

$T G K=(T G+460) /$.

$P G=A V M /(.7302 *(T G+460)$.

$U G=1.9943 E-2 \star(T G K / 673.) \star \star 1.5 /(T G K+548.31)$

$R E=D P \star V G \star P G / U G$

IF (RE.LE.2.) THEN

$C D=24 . / R E$

ELSE IF (RE.LE.500.) THEN

$C D=18.5 / R E \star \star .6$

ELSE

$C D=.44$

END I $F$

RETURN

END

SUBROUTINE HOH(TGF, VG,DP, AVM, CP, HO)

$P G F=A V M /(.7302 *(T G F+460)$.

$T G F K=(T G F+460) /$.

$U G F=1.9943 E-2 \star(T G F K / 673.) \star 1.5 /(T G F K+548.31)$

$R E=D P \star V G \star P G F / U G F$

$G K=8.1111 E-6 *(T G F / 800) \star \star .7046$

$P R=C P \star U G F / G K$

$H O=(2 .+.6 \star(R E \star .5) \star(P R \star .333)) \star G K / D P$

RETURN

END 
APPENDIX B

ESTIMATION OF CYCLONE PARAMETERS 


\section{ESTIMATION OF CYCLONE PARAMETERS}

* COMPUTER PROGRAM - CYCLONE *

This is the computer program CYCLONE. Its purpose is to determine the size of a cyclone and its efficiency when given certain parameters. The program will also determine the pressure drop across the cyclone.

The input to the program is achieved through a series of questions asked of the user.

The output is self explanatory, as all the units are specified. A table will be produced, as output of the computer program, that will list the screen diameters used to describe the screen analysis of the feed to the cyclone. For each size of particle, the efficiency of the cyclone on that size particle and the fraction of the particles, that are not collected, that would be retained on that size screen opening or larger (similar to a cumulative screen analysis) is listed.

The design of the cyclone that is dimensioned here is not fully described here. The design is very lengthy and is similar to that of a "standard cyclone" in which all dimensions within the cyclone can be related to the overall diameter. The user is referred to Perry's "Chemical Engineer's Handbook" (McGraw Hill; 1972 ) for a complete description.

The program is designed to handle any incoming feed screen analysis. To use the program on a specific cumulative screen analysis, the user must use a text editor to change certain variables within the program. The program is written to handle a screen analysis with eight screen sizes but it can be expanded to handle more. The screen sizes should be listed with the largest size first in the series of statements within the program which appear as "DP $(1)=\ldots \ldots \ldots D P(8)=. "$ I'he various screen sizes should appear on the right of the equalities mentioned here. It is assumed that the smallest size screen will have all of the 
analysis sample retained on either it or larger screen sizes. Next, the fraction of analysis sample that is retained on a given screen or on the larger screens (cumulative analysis) will have to be listed in the statements $P(1)=\ldots \ldots P(8)=$. "Here $P(N)$ is the traction of sample retained on screen size DP(N) or larger. The program can be run using any FORTRAN 5 compiler. Below is a lint of the major variables and their function in the program. With a knowledge of the nomenclature it is hoped that the user can understand the program and use it to the fullest. 


\section{NOMENCLATURE}

AO - An area calculated that will allow evaluation of the fraction of particles that are not caught by the

AR - The array containing the cumulative screen analysis of the particles not caught.

AREA - The area under the curve of efficiency vs. the cumulative fraction at a specific screen size. This area is used to calculate the overall efficiency.

DC - The calculated cyclone diameter.

DDP - The calculated pressure drop across the cyclone.

DP - The array of screen sizes used in the accumulative screen analysis.

DPC - The cut diameter input by the user.

EFFO - The overall efficiency of the cyclone.

$P \quad$ - The cumulative fractions obtained from the screen analysis.

PG - The density of the gas that is conveying the particles.

QI - The volumetric flow rate of the gas entering the cyclone.

$\mathrm{T}$ - The temperature of the gas entering the cyclone.

$\mathrm{U}$ - The viscosity of the entering gas, at the temperature of the entering gas.

VG - The velocity in the entrance of the cyclone with the dimensions calculated by the program.

$Y \quad-\quad T h e$ efficiency of the cyclone at each of the individual screen sizes. 
Below is a typical output from CYCLONE. The questions listed below first were asked of the operator at the terminal. The replies can be seen following the question mark. Then the output, as a result of the calculations, is given below.

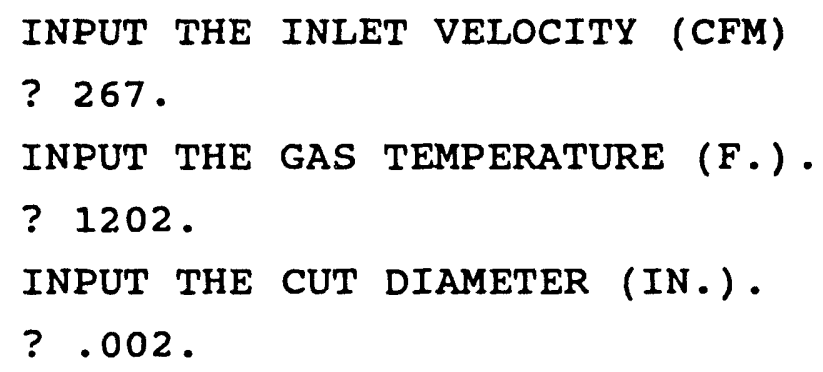

THE CYCLONE DIAMETER WILL BE

1.38716 FT.

THE PRESSURE DROP WILL BE

THE OVERALL EFFICIENCY WILL BE

.19631 IN. H2O

THE CYCLONE INLET VELOCITY WILL BE

85.2421714 \%

$18.5012 \mathrm{FT} / \mathrm{SEC}$

$$
\begin{aligned}
& \text { DIAMETER } \\
& .003908 \\
& .001950 \\
& .000975 \\
& .000492 \\
& .000242 \\
& .000125 \\
& .000067 \\
& .000033
\end{aligned}
$$

$$
\begin{array}{r}
\text { EFFICIENCY } \\
1.00000000 \\
1.00000000 \\
.99973666 \\
.95307861 \\
.66520036 \\
.34383740 \\
.15600431 \\
.06028828
\end{array}
$$

FRACT. OUT

0.00000000

0.00000000

.00025071

.03462134

.20274815

.48477076

.76431292

1.00000000 
PROGRAM CYCLONE (INPUT, OUTPUT, TAPE $5=$ I NPUT, TAPE $6=0 U T P U T$ )

DIMENSION $X(9), Y(9), P(9), D P(9), A O(16), A R(9$.
$P(1)=.008$

$P(2)=.196$

$P(3)=.477$

$P(4)=.692$

$P(5)=.822$

$P(6)=.906$

$P(7)=961$

$P(8)=1.00$

$D P(1)=.00390833$

$D P(2)=.00195$

$D P(3)=.000975$

$D P(4)=.00049167$

$D P(5)=.00024167$

$D P(6)=.000125$

$D P(7)=.000066667$

$D P(8)=.000033333$

WRITE 6 READ (5, 'INPUT THE INLET VELOCITY(CFM)'

WRITE $\left.(6,)^{*}\right)$ 'INPUT THE GAS TEMPERATURE(F.)'

READ $\left(5 \star^{*}\right) T$

WRITE $(\dot{6}, *)$ 'INPUT THE CUT DIAMETER(IN.)'

$\operatorname{READ}(5, *) D P C$

$D P C=D P C / 12$.

$Q I=Q I / 60$.

$P G=39.7152 /(T+460$.

$U=(29.9 *(T / 1700). * \star .432) * 1 . E-6$

$D C 1=D P C \star(64 . * 3.1415 \star 5 . *(5 .-P G) \star Q 1 /(9 . * U)) \star \star .5$

$D C=D C 1 * \star .6667$

$D D P=.024 \star P G \star(8 . \star Q I) \star \star 2.1 D C \star \star 4$.

$V G=8 . * Q I / D C * \star 2$

DO $50 \quad I=1,8$

$X(I)=D P(I) / D P C$

I $F(X(1) . L T .6$.$) THEN$

$Y(I)=1 .-E X P(-.639 * X(1) * \star 1.4476)$

ELSE

$Y(I)=1.0$

END IF

50

CONTINUE

AREA $=0$.

$A 3=P(1) *(Y(1)+.5 *(1 .-Y(1)))$
$D 0100 J j=1,7$

$A 1=(P(J+1)-P(J)) *(Y(J+1)+.5 *(Y(J)-Y(J+1)))$

$A R E A=A R E A+A 1$

100 CONTINUE

$A O(J+1)=P(J+1)-A R E A-A 3$

$E F F O=A R E A+A 3$

$A O(1)=P(1)-A 3$

DO $125 \quad K=1,8$

125 CONTINUE

$A R(K)=A O(K) / A O(8)$

WRITE $(6,490)$

WRITE $(6,500) D C$ 


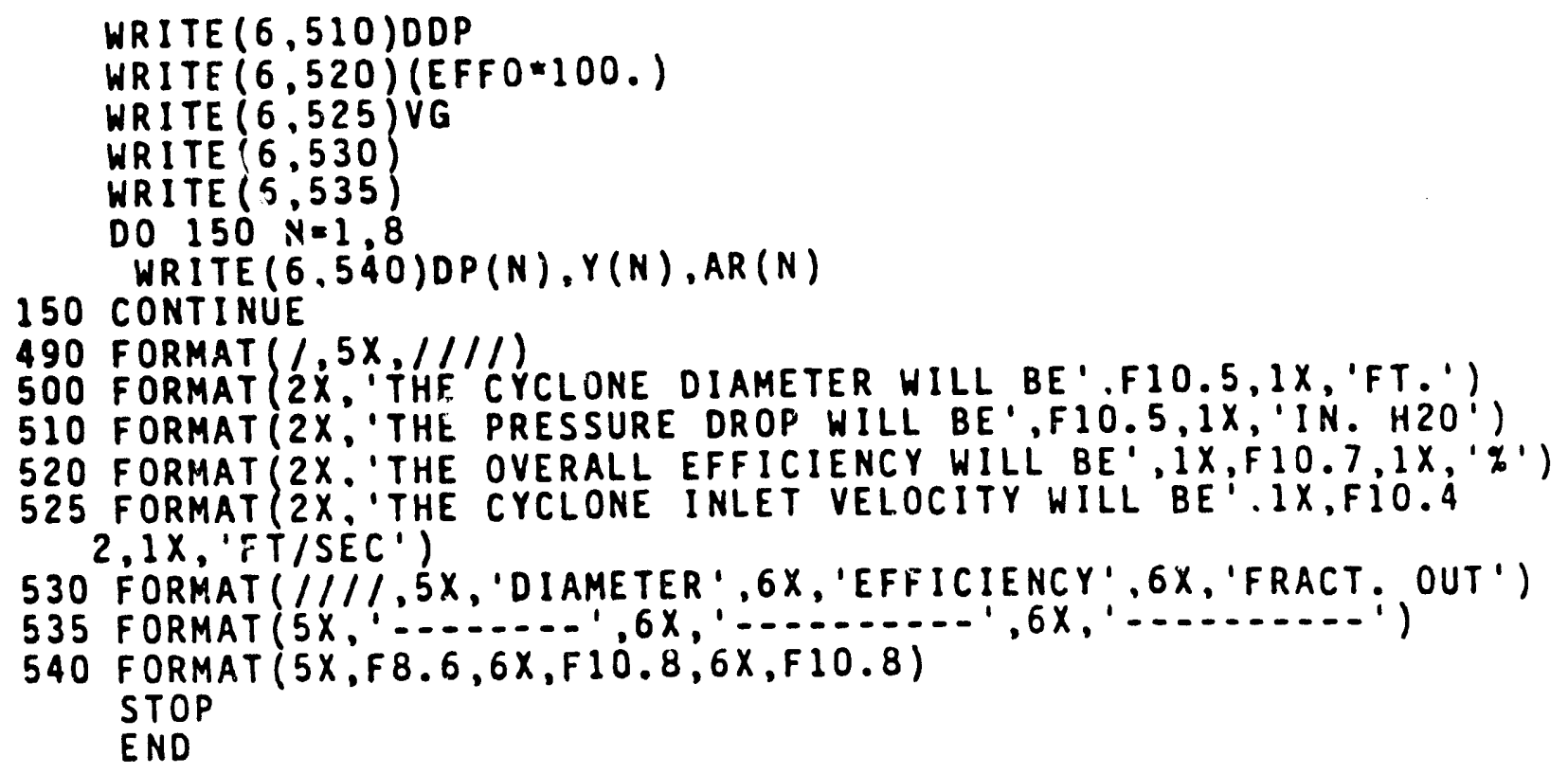




\section{APPENDIX C}

QUALITY ASSURANCE SYSTEM 


\section{APPENDIX C \\ QUALITY ASSURANCE SYSTEM}

The quality assurance system consists of the calibration and performance checks of instruments and equipment, data collection, and recording of experimental data test results in a permanent traceable manner. The manner in which these tasks were accomplished on this program is discussed below.

\section{A. PERFORMANCE CHECKS AND CALIBRATION}

\section{(1) PDU Components}

(a) Loss-in-Weight Feeder - The loss-in-weight feeder is a K-Tron Model T-35, twin screw, volumetric feeder with a maximum capacity of 200 pounds per hour. This equipment was checked by filling the feed hopper with wood particles of a specific size, e.g. 50 x 60 mesh, and operating at outputs of approximately 100, 125, 150, and $200 \mathrm{lbs} / \mathrm{hr}$. The output rates were verified by collecting a series of timed samples at each output rate, which were then weighed and compared to the selected weight setting on the loss-in-weight feeder.

(b) Inert Gas Generator - The inert gas generator is a Model LE-24 generator, manufactured by Industrial Gas Systems, Inc., and was designed to produce a maximum output of $2,400 \mathrm{SCFH}$. The operation of the generator was checked according to the manufacturer's instructions. The composition of representative samples of the inert gas output were checked by gas chromatography. The output flow rate was checked by measuring the flow rate of moderating gas stream to the burner and the flow rate of the gas stream for conveying the wood particles.

(c) Burner - The complete gas burner system including and controls was supplied by North American

$$
\mathrm{C}-1
$$


Manufacturing Company. The burner system was checked by following the start-up and operational instructions supplied by the manufacturer. Representative samples of the combustion products were taken during the operation and analyzed by gas chromatography to determine the composition of the gas.

(2) Instrumentation

(a) Pressure and Flow Measurement: - The pressure gauges ("Magnehelic" gauges, from Dwyer Instrument Corporation) were calibrated with a Merriam Instrument Company Model 34FB2 TM precision manometer. The "Magnehelic" gauges were used to make both static and differential pressure measurements. The calibration supplied by the manufacturer for each orifice plate was used to calculate the flow rates at the specified locations in the system. Pressure transducers (Leeds and Northrup), which were used to make pressure measurements along the reactor tube, were also chocked with the Merriam precision manometer and compared with the factory calibrations. The propane gas meters, Singer Model A-425 (American National Standards Institute class 400), were checked with a calibrated singer Model DTM 200 dry test meter. This dry test meter is regularly checked with a "standard" vet test meter certified by Precision scientific to be within 0.5 per cent of delivered volume and used only for calibrating other wet and dry test meters. The additional wet and dry test meters used in the offgas sampling systems were also checked periodically with the "standard" meter.

(b) Temperature Measurements - T-Type, K-Type and RType thermocouples were used to make temperature measurements at appropriate points throughout the PDU, and the thermocouple signals were recorded continuously 
on strip chart recorders. The thermocouples were checked by placing them in laboratory ovens or furnaces at selected temperatures and measuring their output voltages with a potentiometer. The millivolt outputs were compared with values in the temperature/millivolt tables from the National Bureau of standards (NBS) Circular 561.

(c) Recorders - The strip chart recorders used to record temperatures were checked with a potentiometer. The 1 millivolt and 10 millivolt recorders used with the chromatographs, thermal analysis equipment and spectrophotometers were chocked periodically with a "Recorder Check" instrument (Alltech Associates, Inc.). The recorder used with the pressure transducers was considered to be a component of the pressure transducer system. Its response to the signal from each of the transmitting elements (transducers) was checked concurrently with the touting of that particular element with a Merriam Instrument Company Model 34 FB2 TM precision manometer. These simultaneous tests of the pressure recorder and transducers were performed as needed.

(3) Chemical Analytical Instrumentation

(a) Integrators - The integrators used on this project were Spectra-Physics Minigrators and Hewlett Packard 3390A Reporting Integrators. Calibration was accomplished by observing their responses to repeated injections of Matheson certified calibration gas mixtures in the gas chromatographs to which they were attached. The concentrations of the gases in the calibration gas mixtures were specified to resemble those concentrations in the gas streams which were being analyzed. The calibration procedure was 
performed before each series of analyses and repeated as required.

(b) Analytical Balances - Analytical balances were serviced annually by Rite-Weight, Inc., Tucker, Georgia, and were regularly calibrated with class $\mathbf{S}$ weight sets including fractional weights. Specifications and tolerances for Class $S$ weights are given in National Bureau of Standards (NBS) Handbook 105-1 and NBS Circular 547.

(c) Triple Beam and Solution Balances - These balances were used with standard brass weight sets meeting the specification of the International organization for Legal Metrology (I.O.L.M.). The beam riders on these balances were regularly compared with the standard weights.

(d) Parr Bomb Calorimeters - The calorimeters were calibrated with benzoic acid pellets certified for calorimetry following the instructions in Parr Manual No. 147, Parr Instrument Company, Moline, Illincis. The calorimeter was standardized at regular intervals.

(e) Gas Chromatographs - The gas chromatographs were each standardized with a Matheson Certified Calibration Mixture each time a sample or group of samples were analyzed. The composition of the calibration mixture was in the same range as that of the gas being analyzed.

(f) Portable platform Scales - The portable platform scales which were used on the project were serviced and calibrated by Wiggins Scales Company, an Atlanta company which sells and services commercial weighing equipment. The scales were used for weighing input 
feed and the pyrolytic products, oil and char. The scales were checked at regular intervals with known weights.

\section{B. DATA COLLECTION}

A system of operating log books, data operating sheets and the outputs from the strip chart recorders were used to record, in a permanent and traceable manner, the inputs and outputs for each experiment conducted with the PDU. Each experiment was identified by a specific number which was used to identify all experimental ciata for that particular experiment. Dates and researchers for each experiment, feed preparation task, and chemical analytical work, etc., was also recorded. A permanent file was maintained for the log books, original data operating sheets and recorder tracings so that information could be retrieved when required.

Separate log books were used and maintained to record information and data on: check-out and calibration of components, instruments, and equipment; feedstocks and preparation of feed material; PDU operation; and chemical analysis of feedstocks and products.

The operational information for the PDU were kept in a log book. The information that was recorded included the experiment number, names of operating personnel, dates, inputs to the system, operating conditions, product yields, and samples taken for chemical analysis. Data operating sheets, which were used to record instrumentation data that were not recorded continuously on a strip chart recorder, were noted in the $\log$ book and filed as part of the permanent file. Instrumentation data, e.g., temperature measureme.ts, which were recorded continuously on strip chart recorders, were noted in the log books. These recorder tracings were identified with experiment number and date, and filed as part of the permanent record. Any other pertinent information and observations made during an experiment were entered in the log book.

A log book was maintained to record the samples of feed materials, offóas streams and pyrolytic products that were taken 
APPENDIX D

OPERATING PROCEDURES FOR THE ENTRAINED-FLOW PROCESS RESEARCH UNIT - CONFIGURATION I 
The procedures that are followed for preparing the PDU (Configuration I) prior to a test run, during start-up and operation, data collection, product recovery, sampling during a run, shutdown, and clean-up are presented below. The data sheets used during a pyrolysis run are shown in Appendix E. A discussion and a schematic of the sampling train used to sample the offgas stream downstream of demister is included in section 4 - Task 2A Pyrolysis PDU operation -- start-up, steady-state operation, Preliminary Experiments - Configuration I.

1. PDU Preparation Prior to start-up

1.1 Day before pyrolysis run.

1.1.1 Check the burner system. Clean the UV flame detector; clean the pilot ignition spark plug.

1.1.2 Check all manometers. Visually inspect all pressure lines for presence of water; drain or blow out water as necessary. Inspect manometers for proper fluid lever; replenish with correct fluid as necessary (unity oil, water, or reg gauge oil). Remove any solid obstructions in condenser pressure taps.

1.1.3 Clean all gas sampling probes.

1.1.4 Clean and tare char buckets and oil receivers.

1.1.5 Weigh feed into tarred barrels. Feed is weighed out in 50 pound increments and placed into barrels.

1.2 Morning of run - prior to start-up.

1.2.1 Visual inspection of PRU for leaks. Smoke bomb is placed at combustion air intake and any leaks in the unit are repaired. 
1.2.2 Turn on main water valve and main electrical power. Turn on heating tape for conveying and moderating gas lines. Turn on auxiliary air compressor. The air compressor is used to open and close the feed system and char cyclone knife gate.

1.2.3 Inside the control room, turn on electrical power to the K-Tron loss-in-wight feeder, North American burner panel, and control panel.

1.2.4 Open the propane valve at the tank.

1.2.5 Place char buckets at char cyclone and check that the char knife gate valve is closed.

1.2.6 Place oil receivers at the condenser and demister and check that the condenser and demister sump valves are closed.

1.2.7 Open drain plugs on all orifices and remove any water due to condensation.

1.2.8 Set up burner combustion gas sample probes.

1.2.9 Turn on and calibrate oxygen analyzer with zero and 5\% span gas.

1.2.10 Record barometric pressure and psychrometer readings.

1.2.11 Take a propane sample to be analyzed by GC.

1.2.12 Load the loss-in-weight feeder. Fifty-pound increments of feed are placed in upper hold-up bin using chain hoist; the knife gate is opened and feed drops into the lower hold-up bin; two more 50-pound increments of feed are placed in the lower bin; the lower knife gate is opened and the feed drops into the loss-in-weight feeder. Additional feed is place in upper and lower hold-up bins depending on the duration and feed rate for the run. 


\section{Start-up}

\subsection{Turn on condenser fans.}

2.2 Bring inert gas generator on line. This is accomplished by the following procedure.

2.2.1 Close conveying gas and moderating ball valves; open inert gas generator dump valve.

2.2.2 Open primary water valve on inert gas generator skid. Open water valve on inert gas generator spray chamber and set at two psi. This is required so that the cooling water flow limit switch is engaged.

2.2 .3 Open manually-operated, main air valve to setting $1 / 2$ open. (Graduations are marked 0 , $1 / 4,1 / 2,3 / 4$, and full). The air blower will not start at a lower setting.

2.2.4 Turn on air blower, check all limit switches to ensure that limits are met.

2.2.5 Open manual air valve to the $3 / 4$ position and observe that the purge air pressure switch engages. If the manual air valve is left at the $1 / 2$ open position, the blower will operate for five minutes and shut down. When the purge air pressure switch is engaged, the purge air timer is simultaneously energized. The combustion chamber is purged for five minutes before the purge timer times out. The pilot system ready indicator lamp lights up.

2.2.6 Open pilot air and pilot gas valves.

2.2.7 Light pilot by depressing pilot ignition switch. 2.2.8 When the pilot timer times out (two min) and the pilot flame has been established, the main fire switch and an indicator, ready light are energized. 
2.2.9 Close the manual air valve to the low fire position, about $1200 \mathrm{CFH}$ of air as indicated by reading the manometer on the unit.

2.2.10 Crack open the main fuel gas ball valve.

2.2.11 Open the block valve on the main fuel gas line.

2.2.12 Slowly open the main fuel gas ball valve until the wide open setting is reached.

2.2.13 Let inert gas generator operate at these conditions for about five minutes to allow the system to warm up.

2.2.14 Close the pilot air and gas valves.

2.3 Start hot-gas burner system

2.3.1 Turn the "burner" panel selector switch to "gas"

2.3.2 Drive the air control valve to the "high" or wide open position by manually setting the temperature controller, which controls the air control valve motor operator, to $100 \%$.

2.3.3 Since the combustion air blower is used during the purge cycle, manually start the combustion air blower.

2.3.4 Reset the manual limits reset switch.

2.3.5 When all the pre-start limits are met and the combustion air blower is being used for the purge, the "limits complete" light is energized.

2.3.6 When the limits are complete, and the blower is operating; the purge switch is made; the purge timer begins timing; and the "purging" light is energized.

2.3.7 At the end of the pre-set purge time period (two min), the "purging" light is de-energized.

2.3.8 Drive the control motor on the air control valve to the low fire start position by manually setting the temperature controller to $30 \%$.

2.3.9 Manually open the pilot air and pilot gas cutoff valves. 
2.3.10 With the purge complete and the low fire start switch made, the burner circuit is powered. Then the flame supervisory system makes an internal safe start check (30 sec).

2.3.11 The ignition transformer and ignition timer are energized.

2.3.12 The pilot solenoid valve is energized.

2.3.13 When the ignition timer times out, the ignition transformer is de-energized, and the main fuel delay timer is energized. (At this point the pilot flame is visible at the sight port on the burner).

2.3.14 After the ultraviolet flame detector senses flame and the main fuel delay relay times out, the main fuel block valve is energized.

2.3.15 Manually open the main fuel block valve. When the end switch on the main fuel block valve is made, the low fire hold timer is energized.

2.3.16 When the low fire hold timer times out, the control motor on the air control valve is released to the temperature control circuit.

2.3.17 The pilot solenoid valves are de-energized.

2.4 Open the conveying gas and moderating gas ball valves to a setting of $1 / 4$ to $1 / 2$ of full open.

2.5 Close the inert gas dump valve on the inert gas generator skid.

2.6 Manually adjust the conveying gas and moderating gas flows using the ball valves and the U-tube manometers which measure the differential and static pressures in the respective lines.

2.7 Open air bleeder valve which allows cooling air to flow past the ultraviolet detector sensing tube, preventing 
condensation and loss of ultraviolet signal which would shut down the burner system.

2.8 Close manual pilot air and pilot gas valves.

2.9 Switch oxygen analyzer to burner test port sampling line.

2.10 Put char receiver under char cyclone knife gate valve discharge.

2.11 Put oil receivers under condenser sumps and demister sump.

2.12 Record barometric pressure and psychrometric readings.

2.13 Set temperature controller on manual at $40 \%$ open to allow the reactor to heat up.

2.14 When the temperature indicated on the digital temperature controller is in the range $500^{\circ} \mathrm{F}-1000^{\circ} \mathrm{F}$, open the conveying gas and moderating gas valves to the full open position.

2.15 Reduce the setting on the temperature controller to $30 \%$ open.

2.16 While the reactor comes up to temperature, record all differential and static pressure readings on the manometers and control panel magnehelic gauges.

2.17 Calculate the flow rate of air and fuel at the inert gas generator and at the gas burner. If the flows are not at stoichiometric conditions adjust the flows as necessary to reach stoichiometric conditions. 
2.18 When the inert gas generator and hot-gas burner flows are calculated to be at stoichiometric conditions take a gas sample, using a glass sample bulb, at the inert gas generator discharge test port and at the burner combustion gas sample station No. 1. Analyze for percent $\mathrm{O}_{2}$ by gas chromatograph.

2.19 Check the AC and DC signal on the loss-in-weight feeder, measured from test points TP1 and TP2 to ground, to verify that the loss-in-weight feeder controller is operating properly.

3. Operation to Achieve Steady state

3.1 Reference temperatures are recorded with Type-K thermocouples. When the thermocouple at the reactor exit is within $50^{\circ} \mathrm{F}$ of the predetermined temperature for the run and when the thermocouple at the reactor entrance is at the set point plus $200^{\circ} \mathrm{F}$, the reactor is sufficiently heated so that feed can be added. There will normally be a $50^{\circ} \mathrm{F}-100^{\circ} \mathrm{F}$ temperature drop across the reactor (process side).

3.2 All personnel check gauges, instruments, recorders and sampling equipment for erratic indications and visually check unit for abnormalities.

3.3 Turn on K-Tron loss-in-weight feeder (LWF). Operating conditions have been determined prior to start up. Zero the LWF totalizer and mark recorder charts to indicate start of feed.

3.4 At one minute intervals for the first ten minutes record weight display on LWF digital indicator and calculate feed rate. Adjust thumbwheel switch as necessary to reach set point. When set point has been achieved, 
record weight display on Data Sheet at two minute intervals.

3.5 If the calculated feed rate drops below the set point by ten percent or greater, a feed bridging condition exists. This is corrected by setting the LWF thumbwheel to a higher position (usually five units) or by tapping the feed bin. Check feed rate at one minute intervals as in 3.4. When set point is reached, continue monitoring at two minute intervals.

3.6 Feed from the LWF to the reactor increases from zero to set point in increments. As the amount of feed added to the reactor increases to the set point the temperatures in the reactor will tend to decrease since the wood is a thermal load on the system. Increase the burner settings to maintain the set point temperature $\pm 10^{\circ} \mathrm{F}$.

3.7 Burner air, burner propane, conveying and moderating inert gas and offgas are indicated on the U-tube manometers. Check and record differential and static pressures on Data Sheet at five minute intervals.

3.8 All critical temperatures are recorded on the multipoint temperature recorders. Reactor temperatures are visually checked at two to five minute intervals using the digital temperature indicators. The test run reference temperature is shown on the digital temperature controller. This temperature is continuously observed and adjustments are made to keep this reference temperature at the set point temperature. The operating range is set point temperature $\pm 5^{\circ} \mathrm{F}$.

3.9 At two to five minute intervals observe pressure drop in reactor and condenser and remainder of system. Observe pressure indicators for condenser cooling fans. At 15 
minute intervals record all pressure readings on the control panel, and record pressure readings from gauges located outside on the PRU. For example: gauges on the inert gas generator skid, hot-gas burner air and fuel delivery systems.

3.10 Change char container every ten minutes or as needed depending upon feed rate.

3.11 Drain condenser and demister slumps every fifteen minutes and replace receivers when full.

3.12 After the desired feed rate is reached and the reactor operating temperature is at the set point, the system is allowed to operate at these conditions for 15 - 30 minutes to ensure that the system has stabilized and that steady state has been achieved. The Data Test Run is then started.

4. Test Run

4.1 Simultaneously the char gate valve, condenser and demister valves are closed. The sampling train pump is started. Thermocouple recorder charts are marked to indicate start of test run and elapsed run time and LWF weight display are recorded on the data sheet.

4.2 Replace char container and condenser and demister receivers.

4.3 Record LWF weight display at two minute intervals.

4.4 Manometer readings are recorded on data sheet.

4.5 Condenser and demister sumps are drained every five minutes. 
4.6 Char containers are changed depending upon the feed rate and expected char yield. Change every 10 minutes for 60 $\mathrm{lbs} / \mathrm{hr}$; every 5 minutes for $120 \mathrm{lbs} / \mathrm{hr}$.

4.7 Burner gas and inert gas are sampled at twenty minute intervals.

4.8 Data-test-point interval is normally sixty minutes. When test period is over remove char container and close condenser and demister valves.

4.9 Shut offgas sampling train pump.

4.10 Turn off LWF.

5. Shutdown

5.1 Put loss-in-weight feeder mode selector switch in off position. Allow star valve to continue operating for a few minutes to allow feed chute to empty then turn off star valve.

5.2 Turn the burner to low fire position.

5.3 Open moderating and conveying lines wide open to blanket the reactor with inert gas.

5.4 Close char knife gate valve.

5.5 Allow the reactor to cool.

5.6 Turn off burner blower.

5.7 Open the dump valve on the inert gas generator, turn of $f$ the main gas valve, allow air to cool the combustion 
chamber and continue to circulate water around the shell for one half to one hour.

5.8 Turn off auxiliary air compressor.

5.9 Turn off inert gas generator main power, allow water to circulate if necessary.

5.10 Turn off recorders, oxygen monitor, K-Tron LWF, North American burner panel, and condenser cooling fans.

5.11 Close propane valve at the tank.

5.12 Turn off main water valve and main electrical power.

6. Clean-up

6.1 Immediately after test run

6.1.1 Empty K-Tron bin and weigh unused feed.

6.1.2 Allow oil to drain into receivers with the sump valves open.

6.1.3 Store feed barrels, char and oil containers in building.

6.1.4 Move samples into work-up area to be weighed.

\subsection{Day after run}

6.2.1 Vacuum star valve (LWF).

6.2.2 Change filter on LWF vent.

6.2.3 Remove burner back plate and collect char or ash if present, weigh and save samples. Record weight on data sheet.

6.2.4 Place bucket under char cyclone; open gate valve to collect any residual char carried over during cool down. Record weight on data sheet. 
6.2.5 Remove bucket while gate is open, check inside with a light to ensure that no char is left in the cyclone. Inspect for bridging or buildup.

6.2.6 Remove condenser top plate and scrape residue, if present, into sample container. Record weight on data sheet.

6.2.7 If a mixture of char, tar, and coked oil is present, scrape as much as possible into separate sample container. Record weight on data sheet.

6.2.8 Close condenser sump valves and, using approximately one gallon of acetone, pour on condenser side walls, inlet chute and on distributor plate, pour an equal amount into each tube and allow it to stand for one half hour.

6.2.9 Open the sump valves and collect acetone solution in containers; let the solution stand for a few minutes to allow solids and heavy tar, if any, to settle.

6.2.10 Decant the acetone solution and repeat 6.2 .8 twice.

6.2.11 After last acetone washing collect the material in a container, seal and let it stand overnight before analysis.

6.2.12 Check the condenser gaskets for wear; replace if necessary; replace condenser top plate.

7. Product Recovery

7.1 Char samples are weighed and retained for chemical analysis.

7.2 Condensates from condenser and demister slumps are weighed and retained for chemical analysis. 
7.3 Condenser solids and tar removed by acetone wash are weighed and retained for recovery of tar and oil and for chemical analysis.

7.4 Sampling train for offgas stream located downstream of demister cyclone.

7.4.1 The day before the test run, tare flasks from the ambient module. Pack and tare the glass wool demister. Pack and tare the drierite column. Replenish the magnesium perchlorate tube.

1.4.2 Immediately before the test run connect the three sampling modules and plug the sample inlet port with a stopper. Turn on the main sampling pump and check all fittings for leaks. Chill traps in ambient moduie with ice. Chill traps in cold trap module with dry ice and acetone. start the circulating pumps. When no leaks are present the dry test meter will stop. Turn off the main sampling pump and reset meter to zero.

7.4.3 When the test run stars, the stopper in the sample inlet port is removed and is replaced with the tube from the demister outlet probe. start the main sampling pump and adjust the flow to 10 liters per minute.

7.4.4 Offgas samples are collected at ten minute intervals.

7.4.5 When the test run is completed the main sampling pump is stopped and the total volume of gas is recorded at the dry test meter.

7.4.6 The modules are separated and moved to the workup area.

7.4.7 The glass wool and drierite columns are weighed.

7.4.8 Light oil fractions from the dry ice traps are collected and weighed. 
APPENDIX E

DATA SHEETS 
Run No.

Date:

Pre-Run Data

Nominal Feed Rate ( $1 \mathrm{~b} / \mathrm{hr}$ maf)

Reference Temp

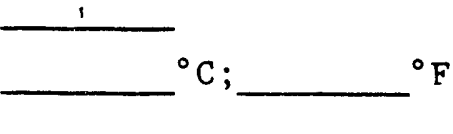

Moderating Gas

Draft Fan

Quench Spray Rate ( $1 \mathrm{~b} / \mathrm{hr}$ )

Wood Feed Sweco Screen Size

LWF Bin Weight Display (1b-tare)

Total Elapsed Time of Test Run
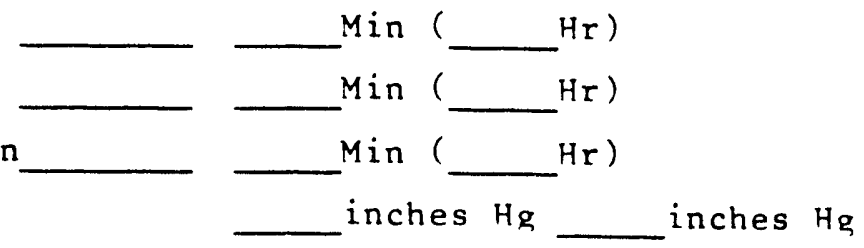

Barometric Pressure

Relative Humidity Data: (A.M. or P.M.)

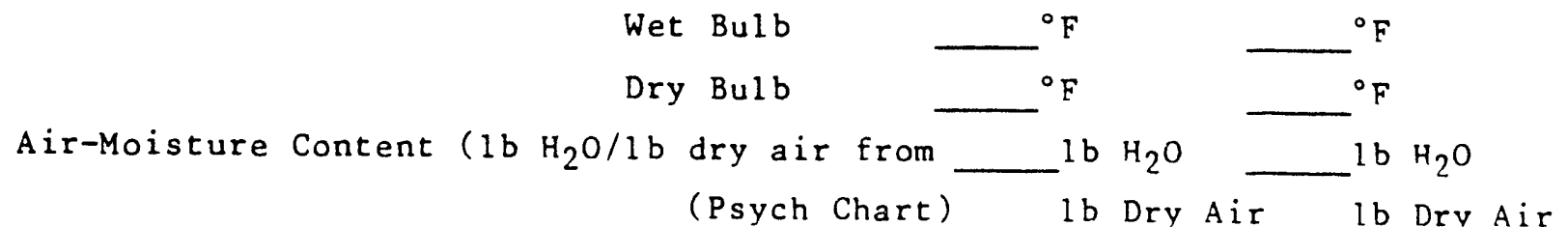

Inert Gas Gen ( $1 \mathrm{~b} \mathrm{H}_{2} \mathrm{O} / 1 \mathrm{~b}$ Dry Gas) Saturated)

Quench Water Temp. ( $\left.{ }^{\circ} \mathrm{F}\right)$

Gas Meter Readings:

Start

Fnd

Hot Gas Burner (cf)

Inert Gas Gen ( $c f$ )

Quench Spray

Pump Setting

Water Flow Rate
Nozzle Size psig GPM $\%$ Open Setting $\mathrm{lb} / \mathrm{hr}$. 
Run No.

1. Feed

Feed (Wet Basis, Total) $1 \mathrm{~b}$ $\mathrm{lb} / \mathrm{hr}$

HHV - (Wet Basis) Btu/lb wet

HHV - (Dry Basis)

HHV - (MAF) Btu/lb Dry $B t u / l b$ maf

$\% \mathrm{H}_{2} \mathrm{O}$ - (Wet Basis)

\% Ash - (Dry Basis)

Dry Weight

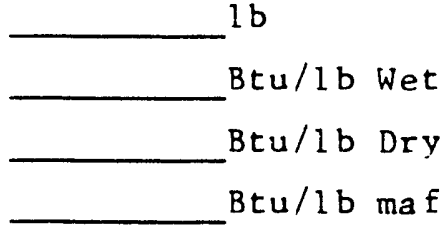

Wt. Moisture-Ash-Free (MAF)

$\mathrm{H}_{2} \mathrm{O}$ Weight

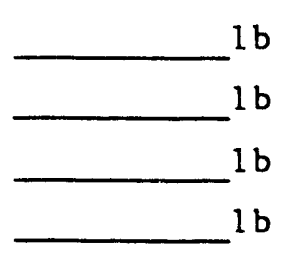

$\mathrm{lb} / \mathrm{hr}$ $1 \mathrm{~b} / \mathrm{hr}$

Ash Weight $\mathrm{lb} / \mathrm{hr}$ $1 \mathrm{~b} / \mathrm{hr}$

Feed Sieve Size

Sweco

Rotap Analysis

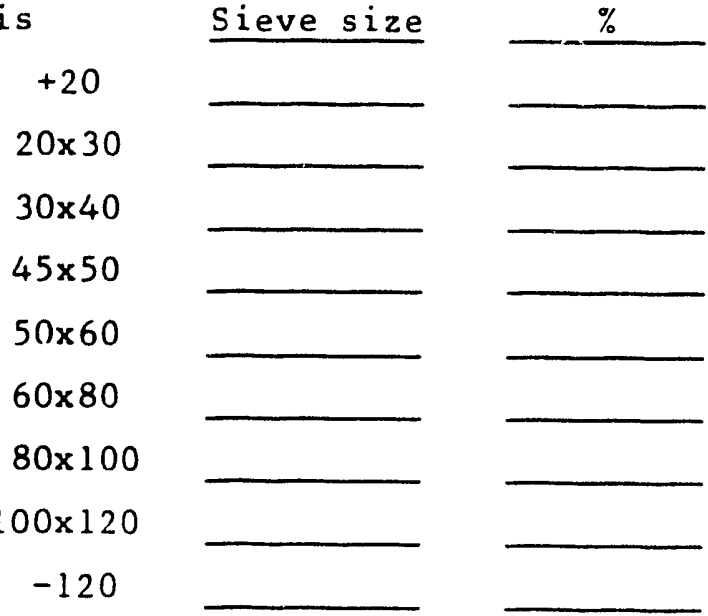

2. Char

Total Wt. (Wet Basis)

HHV (Wet Basis)

grams

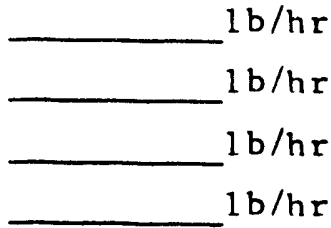

HHV (Dry Basis)

HHV (MAF)

$\% \mathrm{H}_{2} \mathrm{O}$ (Wet Basis)

$\%$ Volatiles (Dry Basis)

\% Ash (Dry Basis)

Btu/lb Wet

Btu/lb Dry

Btu/lb maf

$\%$

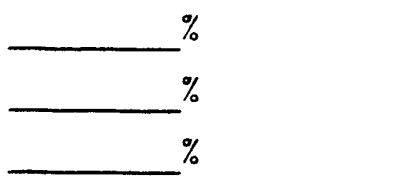

Dry Weight

Wt. Moisture-Ash-Free (MAF)

$\mathrm{H}_{2} \mathrm{O}$ Weight

Ash Weight

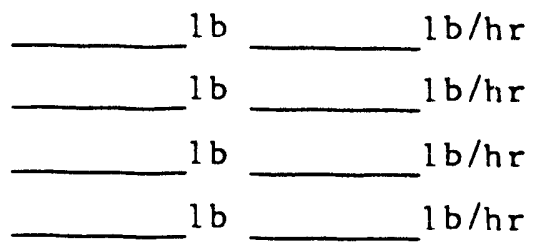

Char Yield

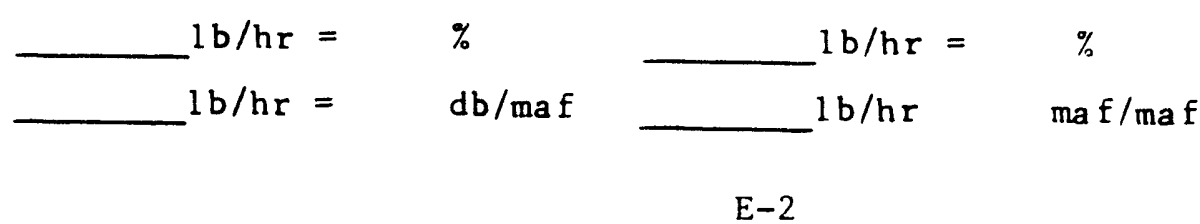




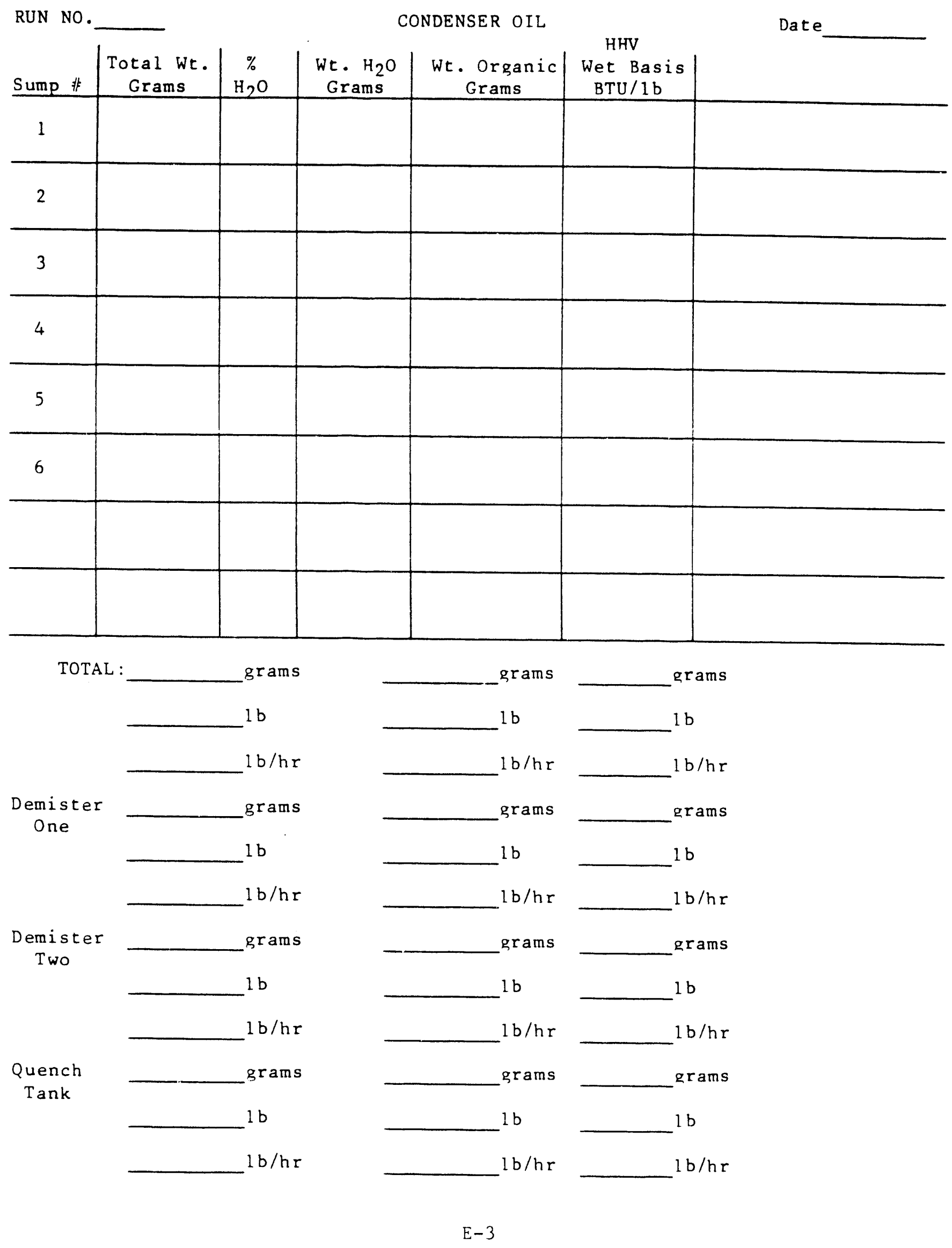


Run No.

Date

A. Condensate Train Liquids

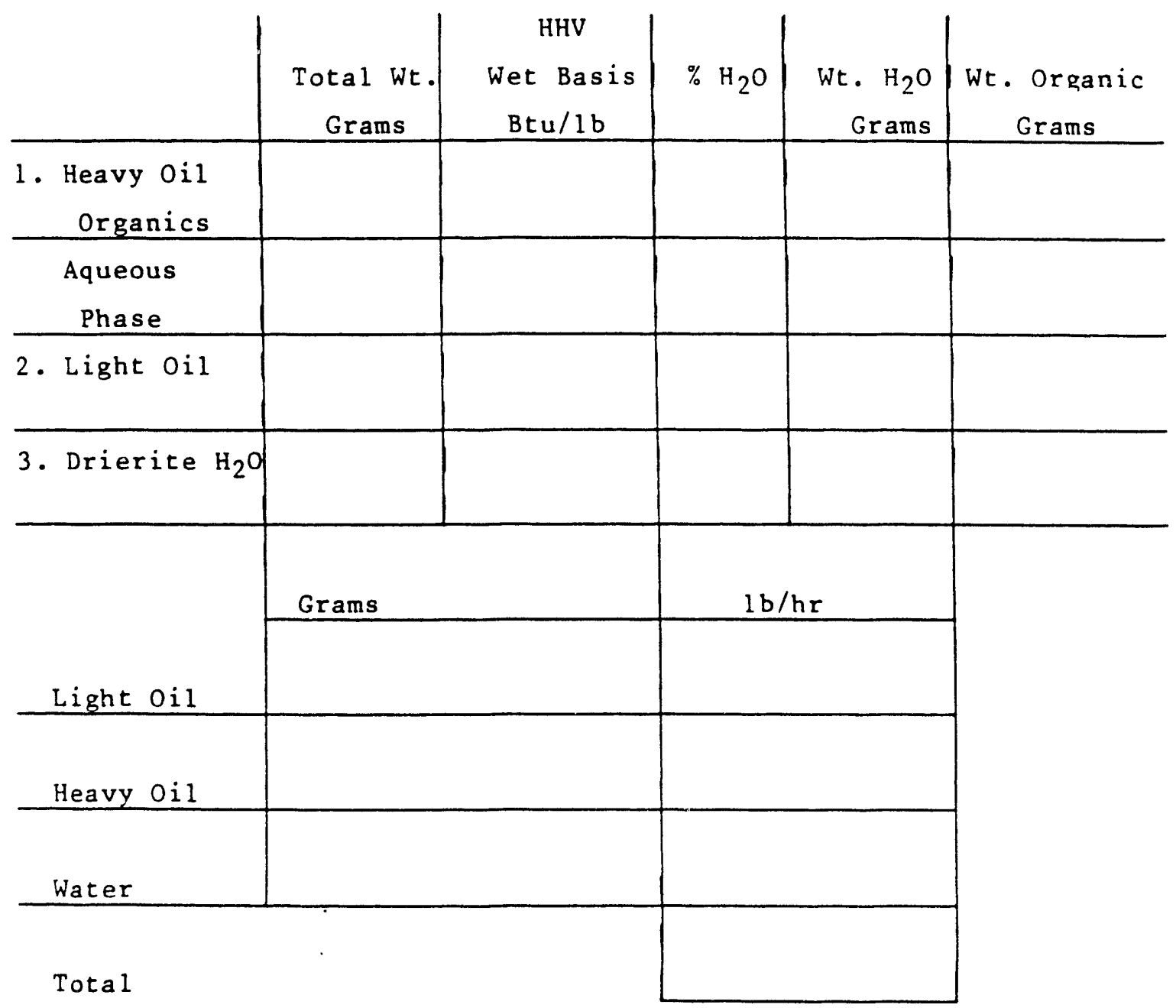

B. Non-condensible Gas Analysis

1. Total gas sample through test meter Liters

2. Temperature at gas test meter ${ }^{\circ} \mathrm{F} \quad{ }^{\circ} \mathrm{C}$

3. Pressure at gas test meter

4. Barometric pressure

5. Off-gas sample inches $\mathrm{Hg}$ grams 


\begin{tabular}{|c|c|c|c|}
\hline Compound & MW & $\begin{array}{c}\text { Burner Air } \\
\% \text { Vol }\end{array}$ & $\begin{array}{c}\text { Inert Gas } \\
\% \text { Vol }\end{array}$ \\
\hline Argon & 39.9480 & 0.00934 & \\
\hline $\mathrm{O}_{2}$ & 31.9988 & $0.2095^{6}$ & \\
\hline $\mathrm{N}_{2}$ & 28.0134 & 0.78084 & \\
\hline$\underline{\mathrm{CO}}$ & 28.0106 & 0 & \\
\hline $\mathrm{CO}_{2}$ & 44.0100 & 0.000360 & \\
\hline $\mathrm{H}_{2}$ & 2.0158 & & \\
\hline $\mathrm{CH}_{4}$ & 16.0428 & & \\
\hline $\mathrm{C}_{2} \mathrm{H}_{6}$ & 30.0697 & & \\
\hline $\mathrm{C}_{2} \mathrm{H}_{4}$ & 28.0539 & & \\
\hline $\mathrm{C}_{2} \mathrm{H}_{2}$ & 26.0381 & & \\
\hline $\mathrm{C}_{3} \mathrm{H}_{8}$ & 44.0967 & & \\
\hline $\mathrm{C}_{3} \mathrm{H}_{6}$ & 42.0809 & & \\
\hline$\underline{\mathrm{C}}_{4} \mathrm{H}_{10}$ & 58.1236 & & \\
\hline$\underline{\mathrm{C}}_{4} \mathrm{H}_{10}$ & 58.1236 & & \\
\hline$\underline{C}_{4} \mathrm{H}_{8}$ & 56.1078 & & \\
\hline \multicolumn{4}{|l|}{ TOTAL } \\
\hline \multicolumn{4}{|c|}{$\begin{array}{l}\text { Thermocouple } \\
\text { Gas Temp }\left({ }^{\circ} \mathrm{F}\right)\end{array}$} \\
\hline \multicolumn{4}{|c|}{$\begin{array}{l}\mathrm{H}_{2} \mathrm{O} \text { Content from } \\
\text { Psych Chart } 1 \mathrm{~b} \mathrm{H}_{2} \mathrm{O}\end{array}$} \\
\hline
\end{tabular}


Run No.

\begin{tabular}{|c|c|c|c|c|}
\hline Compound & NW & $\begin{array}{c}\text { Propane } \\
\% \text { Vol } \\
\end{array}$ & $\begin{array}{l}\text { Hot Gas } \\
\text { Burner } \\
\% \text { Vol } \\
\end{array}$ & $\begin{array}{c}\text { Demister } \\
\text { Outlet Gas } \\
\% \text { Vol } \\
\end{array}$ \\
\hline Argon & 39.948 & & & \\
\hline $\mathrm{O}_{2}$ & 31.9988 & & & \\
\hline $\mathrm{N}_{2}$ & 28.0134 & & & \\
\hline $\mathrm{CO}$ & 28.0105 & & & \\
\hline $\mathrm{CO}_{2}$ & 44.01 & & & \\
\hline $\mathrm{H}_{2}$ & 2.0158 & & & \\
\hline $\mathrm{CH}_{4}$ & 16.0428 & & & \\
\hline $\mathrm{C}_{2} \mathrm{H}_{6}$ & 30.0697 & & & \\
\hline $\mathrm{C}_{2} \mathrm{H}_{4}$ & 28.0539 & & & \\
\hline $\mathrm{C}_{2} \mathrm{H}_{2}$ & 26.0381 & & & \\
\hline $\mathrm{C}_{3} \mathrm{H}_{8}$ & 44.0967 & & & \\
\hline $\mathrm{C}_{3} \mathrm{H}_{6}$ & 42.0809 & & & \\
\hline$i-\underline{C}_{4} \underline{H}_{10}$ & 58.1236 & & & \\
\hline$n-\underline{C}_{4} \underline{H}_{10}$ & 58.1236 & & & \\
\hline $\mathrm{C}_{4} \underline{\mathrm{H}}_{8}$ & 56.1078 & & & \\
\hline \multicolumn{5}{|l|}{ TOTAL } \\
\hline $\begin{array}{l}\text { Thermocou } \\
\text { Gas Temp }\end{array}$ & & & $\mathrm{NA}$ & \\
\hline
\end{tabular}




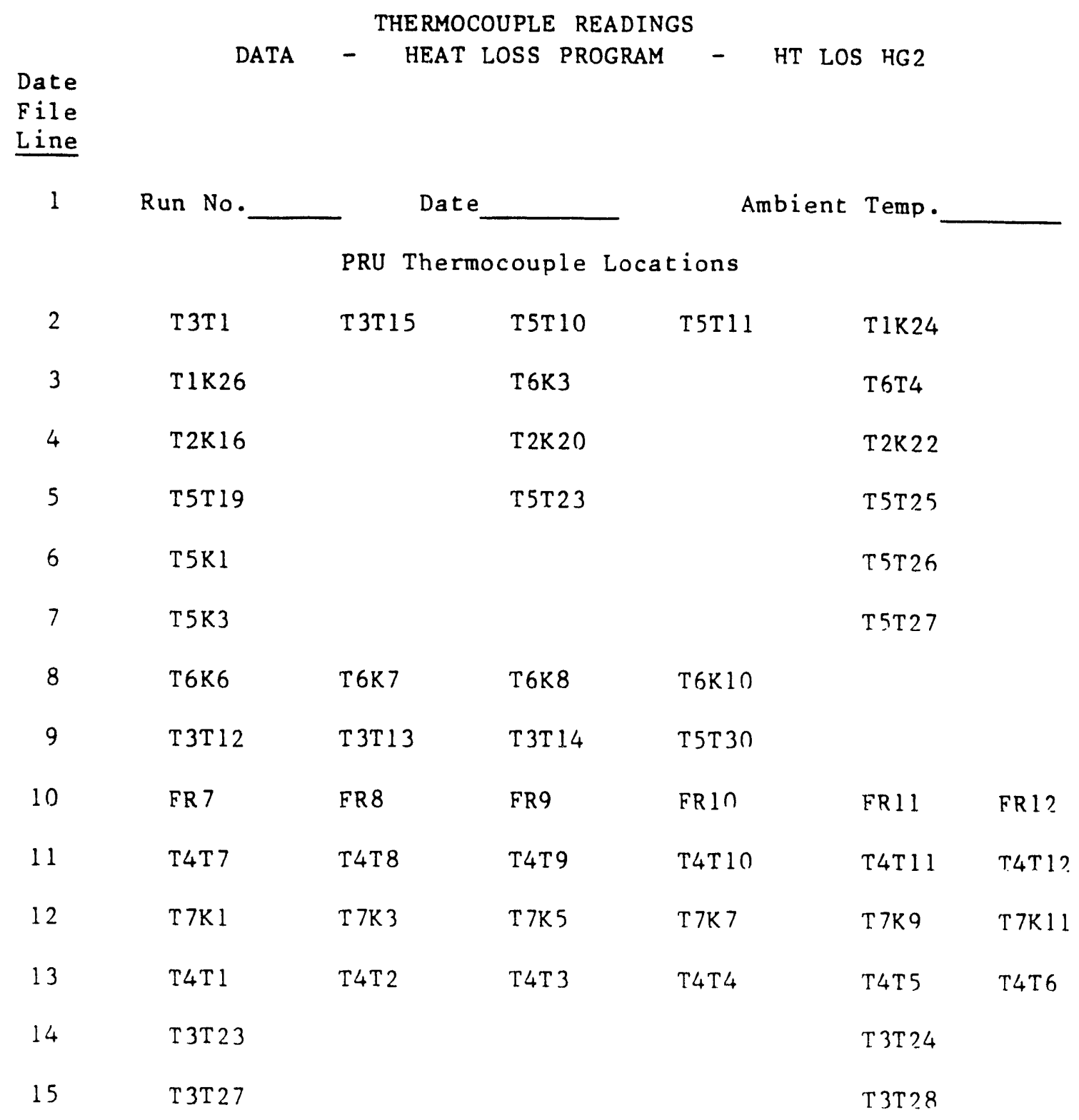


THERMOCOUPLE READINGS

DATA - SENSIBLE HEAT PROGRAM

Run No.

PRU Thermocouple Locations

Date

CHAR

T5K2

T $1 K 15$

QUENCH TANK

T 1K21

T6K9

TIK?

CONDENSER

SUMP 非

1

2

3

4

5

6
PROCESS

T 7KO

T 7K2

T 7K4

T 7K6

T 7K 8

T 7K 10

DEMISTER 1
T $1 K 23$

T 3 T 26

DEMISTER 2

T3\%29

E-8 


\section{INPUT}

Feed
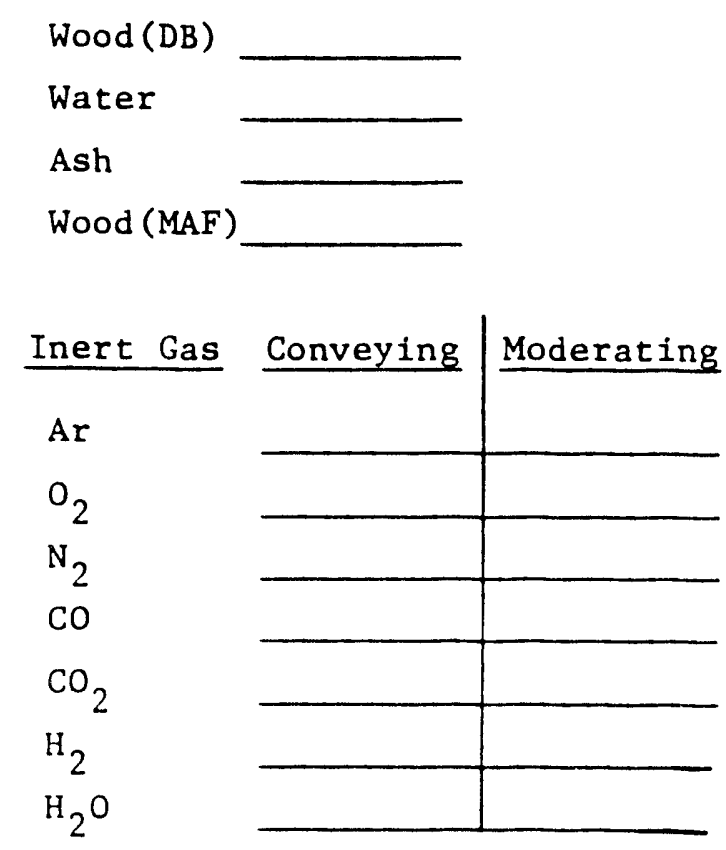

Air

$\mathrm{O}_{2}$

$\mathrm{N}_{2}$

Ar

$\mathrm{CO}_{2}$

$\mathrm{H}_{2} \mathrm{O}$

Commercial Propane

$\mathrm{C}_{2} \mathrm{H}_{6}$

$\mathrm{C}_{3} \mathrm{H}_{8}$

$\mathrm{C}_{3} \mathrm{H}_{6}$

$\mathrm{C}_{4} \mathrm{H}_{10}$

Oil Yield

$1 \mathrm{~b} / \mathrm{hr} \mathrm{db}$

lb/hr maf

$\%$

Char Yield

Quench Spray

$\mathrm{H}_{2} \mathrm{O}$

Acetone Wash

$0 i 1$
Mass

Recovery $\quad$ Off-Gas

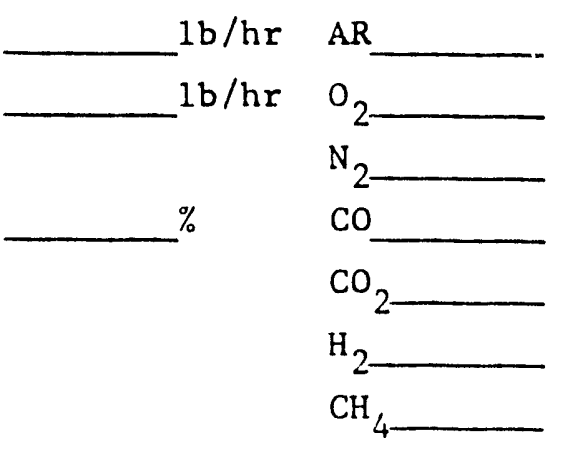

$\mathrm{C}_{2} \mathrm{H}_{6}$

$\mathrm{C}_{2} \mathrm{H}_{4}$

$\mathrm{C}_{2} \mathrm{H}_{2}$

$\mathrm{C}_{3} \mathrm{H}_{8}$

$\mathrm{C}_{3} \mathrm{H}_{6}$

$\mathrm{C}_{4} \mathrm{H}_{10}$

$\mathrm{C}_{4} \mathrm{H}_{8}$

\section{Condensate Train}

Light $0 i 1$

Oil

Water

Condenser

Oil

Water

Demister

oil

Water

Char

Dry Char

Water

Ash

Char (MAF)

Residue - Condenser

Residue - Quench Tank

Quench Tank

Oil

Water 
Run No.

\begin{tabular}{|c|c|c|}
\hline \multicolumn{3}{|c|}{$\underline{\text { INPUT }}$} \\
\hline & $\begin{array}{l}\text { HHV } \\
\text { Btu/hr }\end{array}$ & $\begin{array}{c}\text { Sensible } \\
\text { Heat } \\
\text { Btu/hr }\end{array}$ \\
\hline Feed & & \\
\hline $\begin{array}{l}\text { Moderating } \\
\text { Gas }\end{array}$ & & \\
\hline $\begin{array}{l}\text { Conveying } \\
\text { Gas }\end{array}$ & & \\
\hline Propane & & \\
\hline Air & 0 & \\
\hline $\begin{array}{r}\text { Quench } \\
\text { Spray }\end{array}$ & 0 & \\
\hline
\end{tabular}

Sub-total

\section{Btu/hr}

Input

Output

$\%$ Recovery

$\%$ Oil Recovery

$\%$ Heat Loss

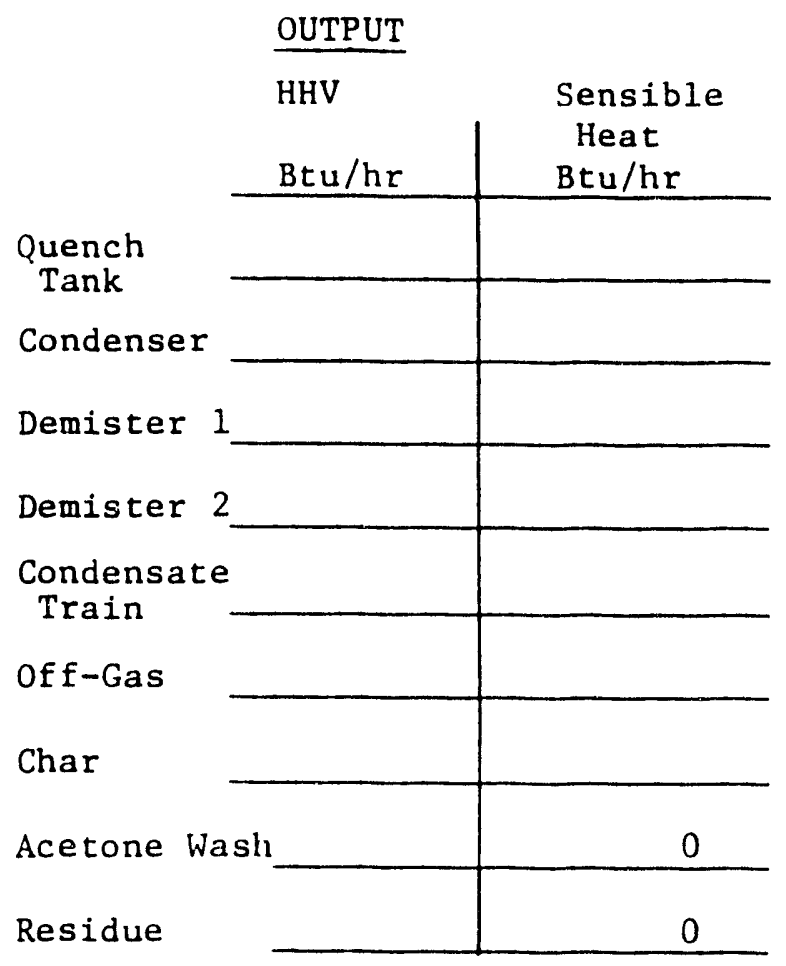

Sub-tota 1

HEAT LOSS

Btu/hr

Hot Gas Generator

Reactor

Pipe

Char Cyclone

Quench Tank

Condenser Cooling Air

Condenser

Demister 1

Demister 2

Sub-total 
Run No.

K-TRON LOSS-IN-FEEDER

Operating Data

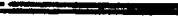

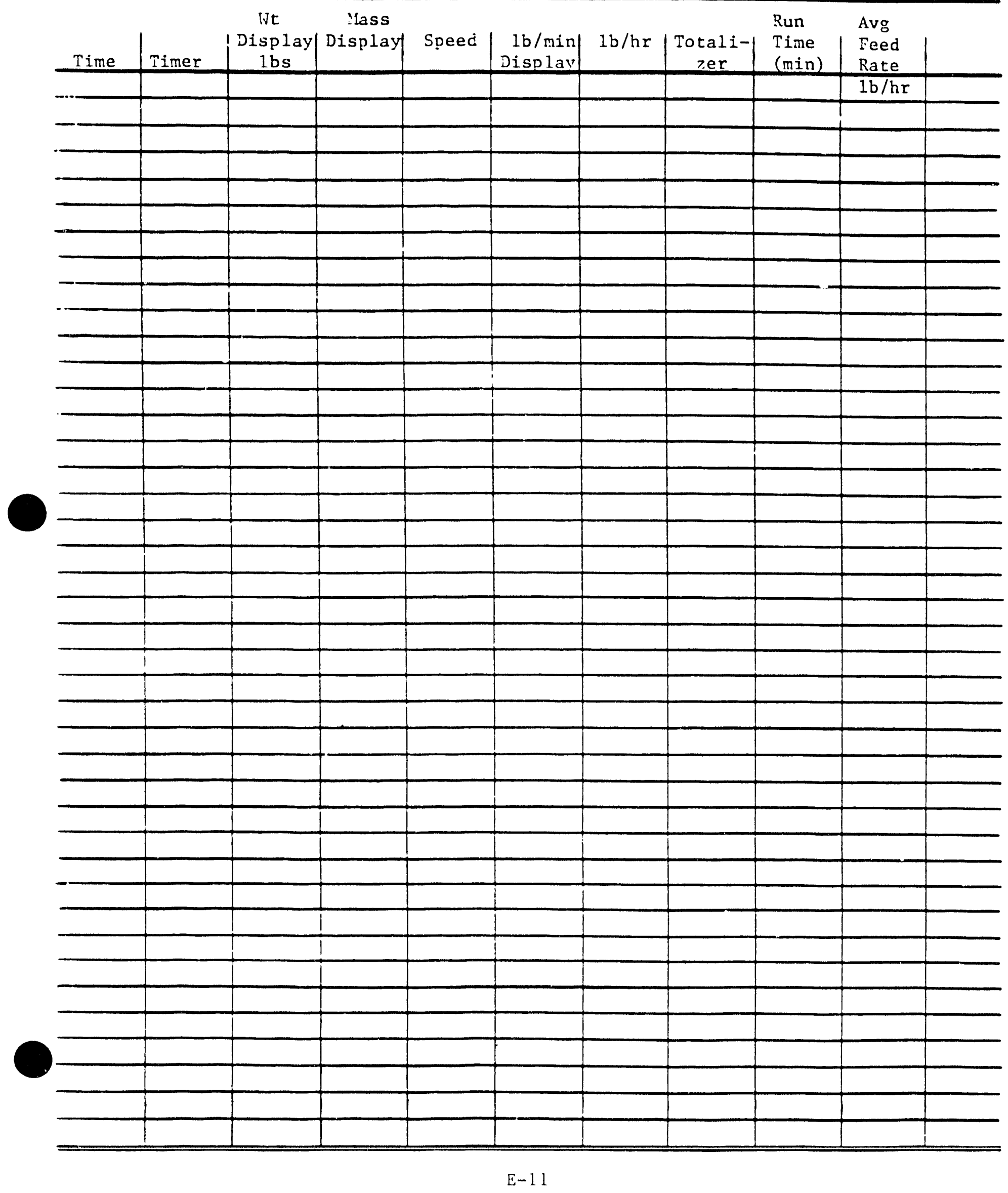

Date: 


\section{U-Tube and Inclined Manometers}

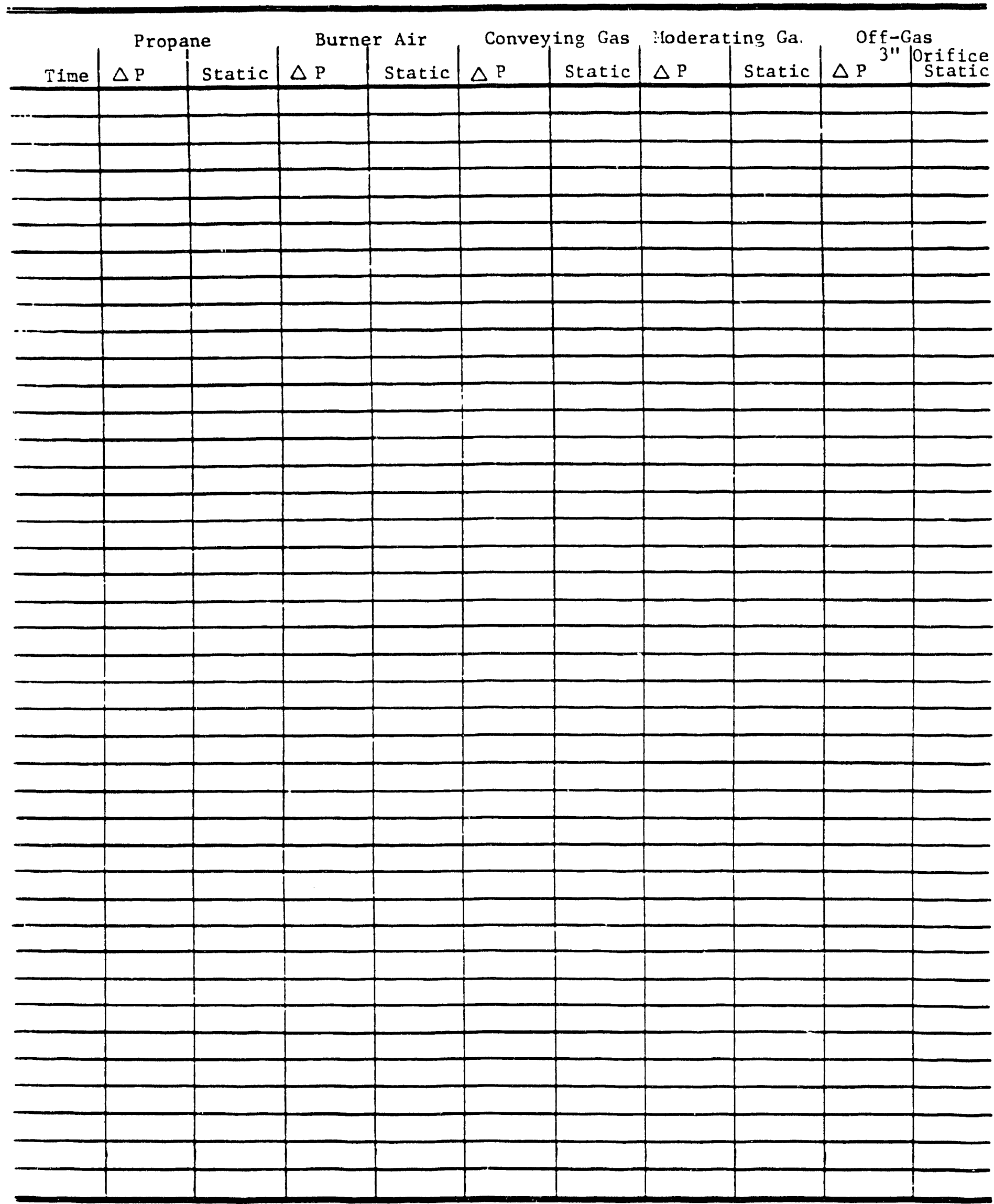


Run ivo.

INERT GAS

Date:

Inert Gas Generator Platform

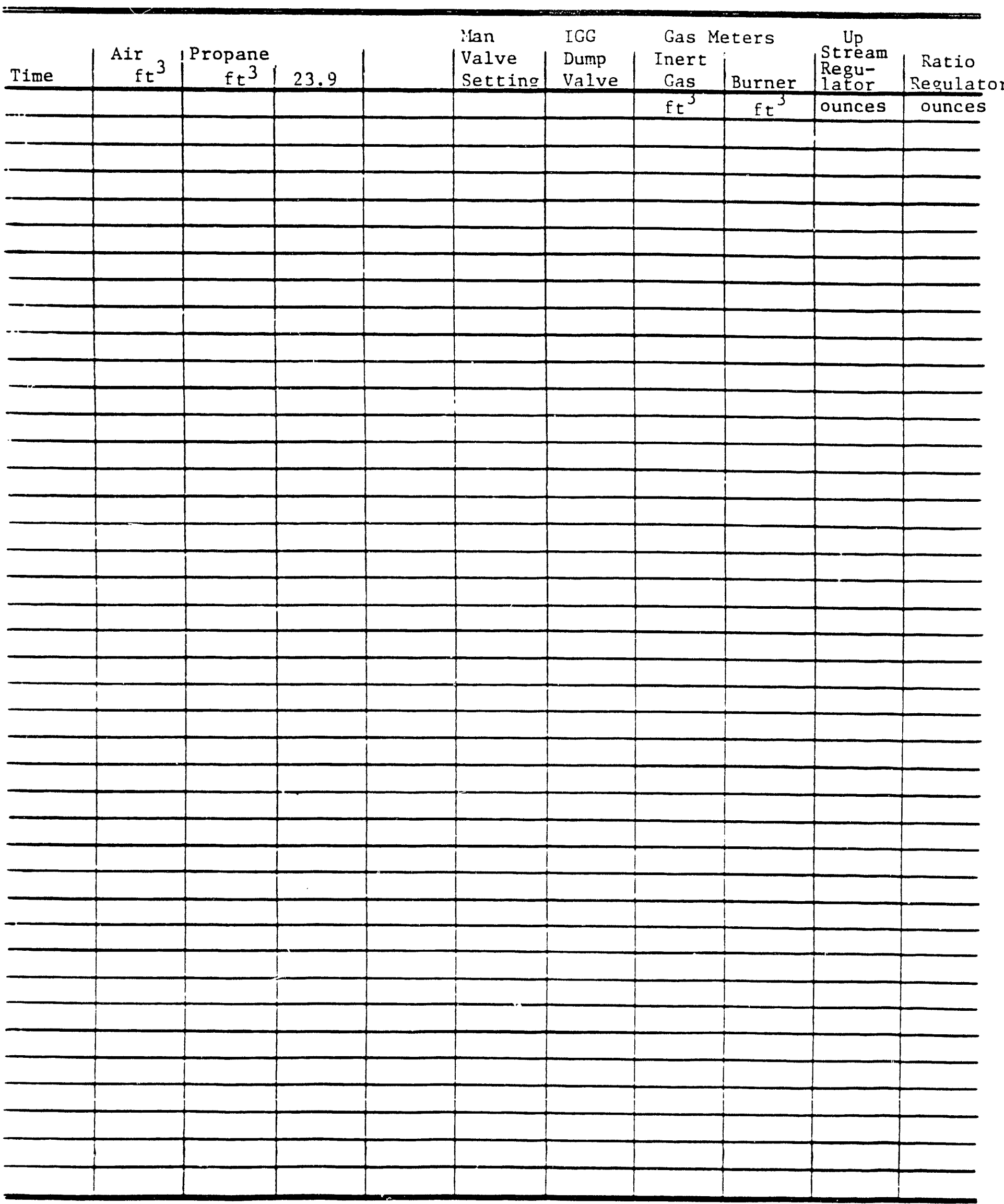




\section{Right Side - Pressure Galges}

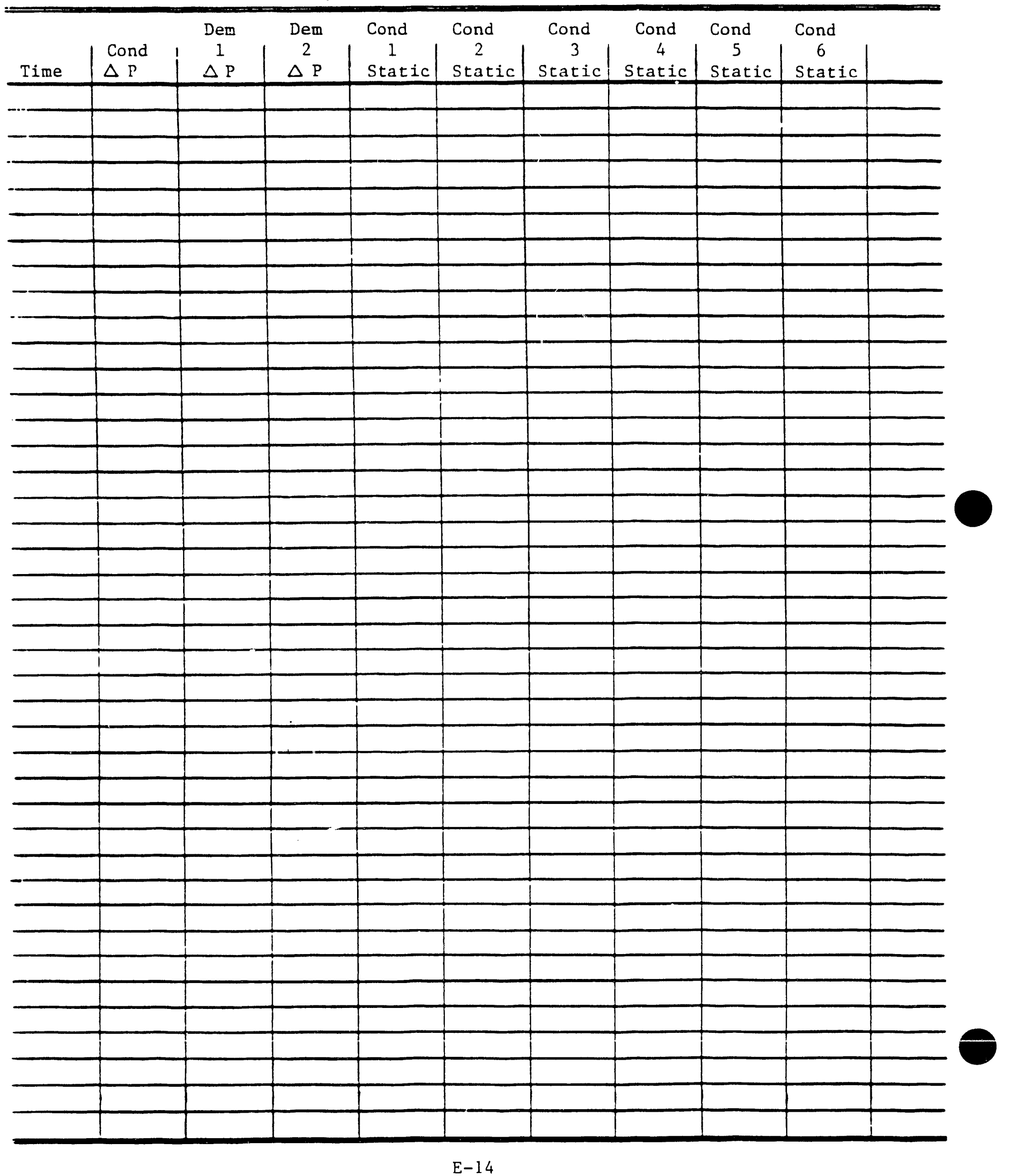


Run No.

Left Side - Pressure Gaures

\section{Com-}

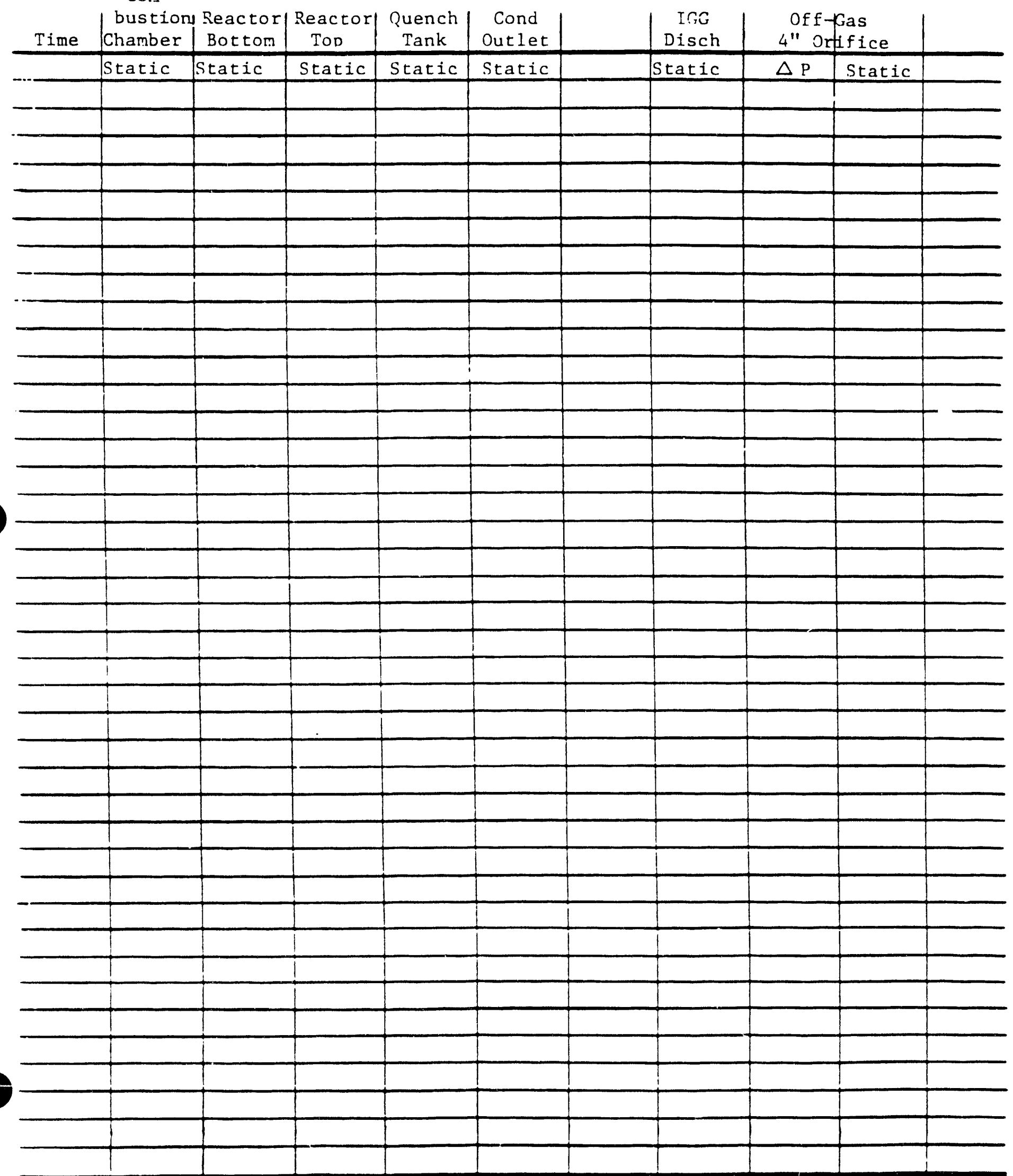




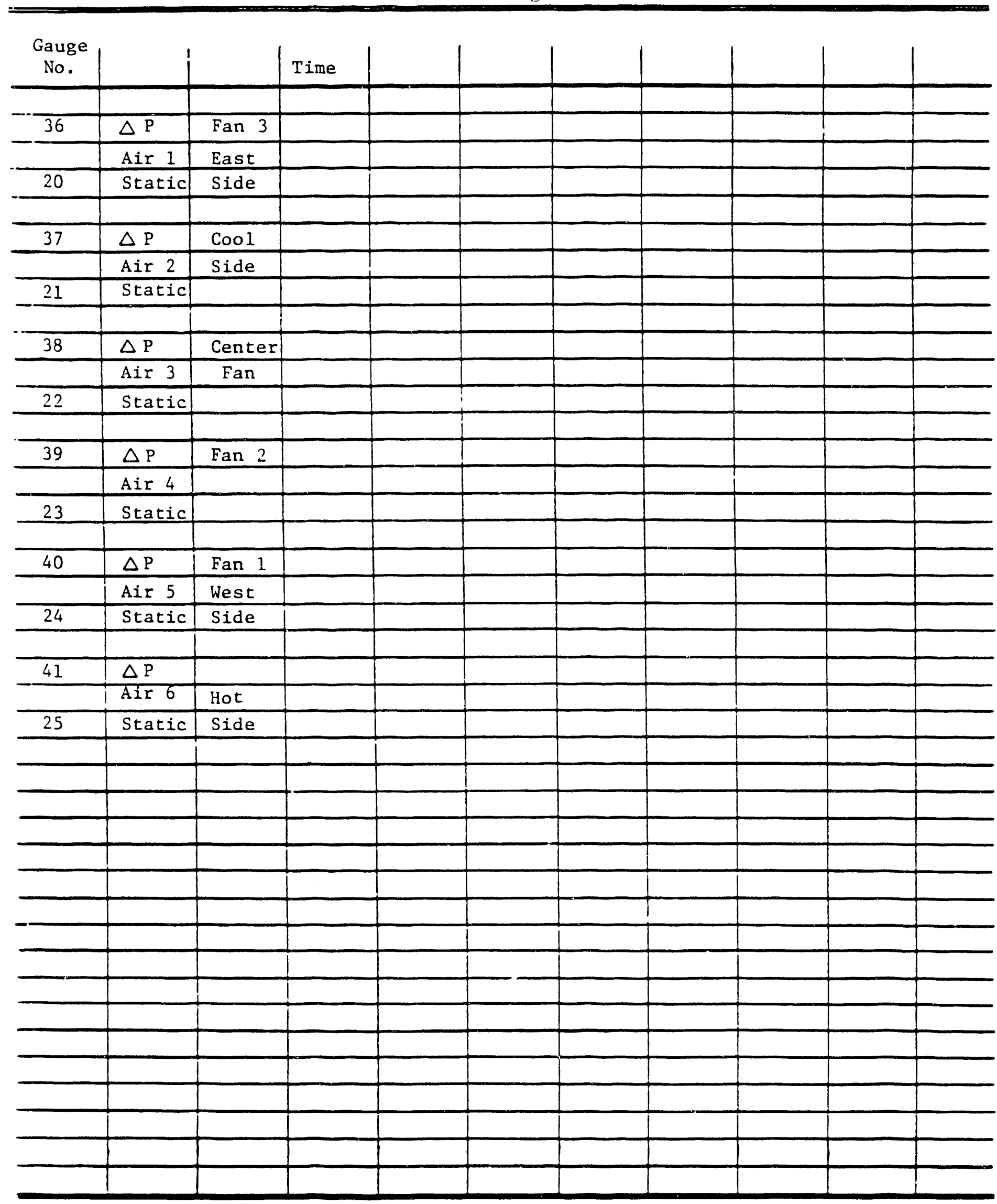


Run No.

CHAR

Jeight

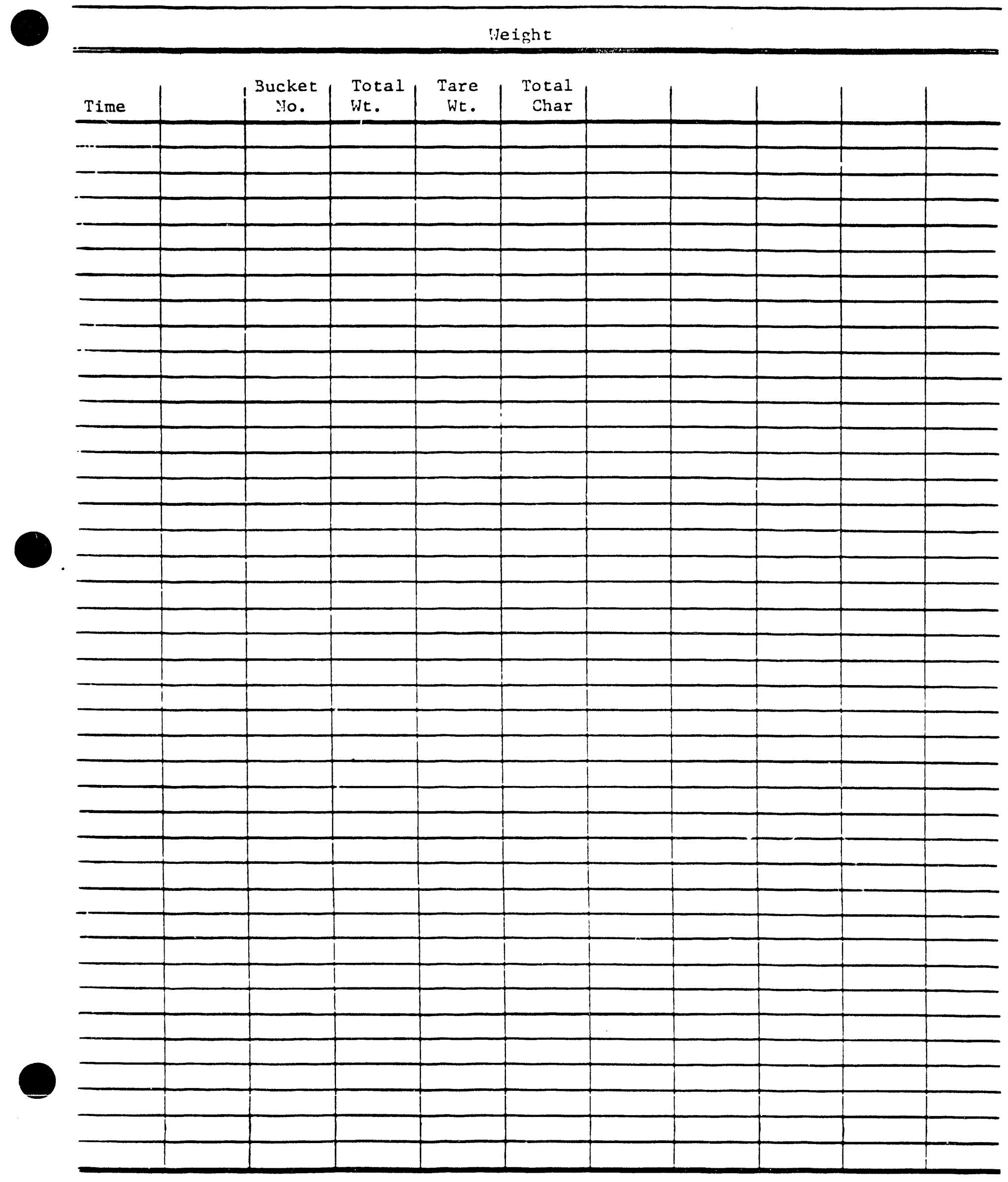

E-17

Date: 
Demisters and Quench Tank

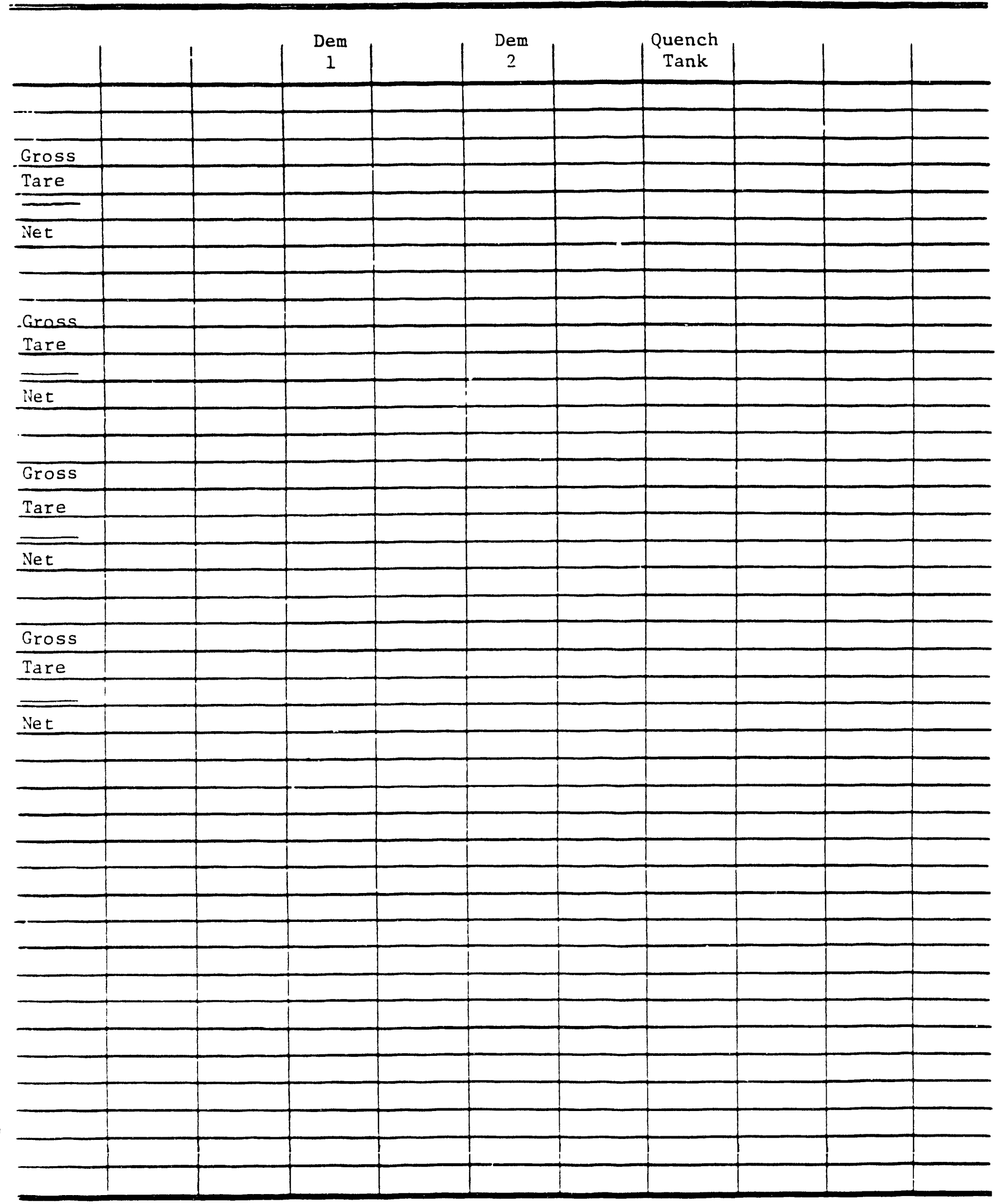




\section{APPENDIX F}

PRELIMINARY REACTOR MODELING - CONFIGURATION I OIL FROM BIOMASS BY ENTRAINED - FLOW PYROLYSIS 


\section{PRELIMINARY REACTOR MODELING - CONFIGURATION I \\ OIL FROM BIOMASS BY ENTRAINED - \\ FLOW PYROLYSIS}

\section{A. SUMMARY}

A pyrolysis kinetics model is presented which can be used for the prediction of pyrolysis oil yields for oak in an entrainedflow reactor. The parameters in the model were determined by a nonlinear least-squares computer code and experimental results. An interpretation of the model predictions is included. Although the maximum oil yield obtained experimentally was 51\%, the model predicts a maximum oil yield of $61 \%$ in the temperature range for which data are available.

A research effort at the Georgia Institute of Technology is concerned with maximizing the oil yield for the entrained-flow pyrolysis of hardwoods. Wood pyrolysis oil has been demonstrated to be a viable alternative commercial fuel for kiln operation and power boilers.' It has also been successfully burned with char and/or fuel oils. ${ }^{1,2}$ The technical feasibility for its use in gas turbines has been demonstrated ${ }^{3}$, and the use of pyrolysis oil as a chemical feedstock is a viable alternative. Although other researchers ${ }^{4,5}$ have been engaged in rapid pyrolysis of particulate biomass, the research effort at Georgia Tech is the only work actively attempting to maximize the oil yield by entrained-flow pyrolysis in a process research unit (PRU). This effort, in essence, concerns the direct liquefaction of biomass via pyrolysis (a noncatalytic process).

\section{B. BACKGROUND}

A description of the PRU and the resulting data from 11 preliminary runs was previously presented. ${ }^{6}$ The experimental results are shown in section 5. The pyrolysis modeling efforts associated with the above mentioned data are the subject of this appendix. 
The pyrolysis reactor section is the key component of the PRU, and its operation is described in the following. Wood particles are conveyed into the reactor by a low temperature gas mixture consisting primarily of nitrogen, carbon dioxide, and water vapor with possibly small amounts of carbon monoxide and hydrogen (due to incomplete combustion in the gas generator). This stream mixes rapidly with the combustion products formed by the stoichiometric combustion of propane and air. Very quickly the temperatures of the two streams equalize. The resulting mixture enters the bottom of the vertical reactor tube which is an eight-inch schedule 40 stainless steel pipe, 21 feet long.

The char is removed by a cyclone. Almost all of the pyrolysis oil is removed by an air-cooled condenser and a demister (a small cyclone which removes most of the aerosol formed). A small amount of pyrolysis oil leaves in the offgas stream.

\section{EXPERIMENTAL RESULTS}

A summary of the experimental results is given in Table $\mathrm{F}-1$. The test were identified and numbered consecutively, in chronological order. However, they were rearranged in Table F-1 in the order of increasing temperature. The temperature listed are those obtained by a thermocouple located at the reactor tube entrance. The feed rates given are on a moisture-ash-free basis, and the sieve cuts were obtained with a sweco screener. The oil yield is a weight per cent based on the moisture-ash-free feed. The oil yield indicated includes all of the oil produced, which includes the oil collected in the condenser, the demister, and that collected in the offgas stream as indicated by a sampling train. Water was collected along with the oil, but only the oil itself was reported as oil yield. 


\begin{tabular}{|c|c|c|c|c|c|}
\hline & TABLE & $\begin{array}{l}\text { F-1. Entrai } \\
\text { Prelimir }\end{array}$ & $\begin{array}{l}\text { ed-Flow Pyrol } \\
\text { ry Experiment }\end{array}$ & $\begin{array}{l}\text { Ysis Data - } \\
\text { s }\end{array}$ & \\
\hline $\begin{array}{l}\text { Run } \\
\text { No. }\end{array}$ & $\begin{array}{c}\text { Temperature } \\
\left({ }^{\circ} \mathrm{C}\right)\end{array}$ & $\begin{array}{c}\text { Feed Rate } \\
(1 \mathrm{~b} / \mathrm{hr})\end{array}$ & $\begin{array}{c}\text { Feed } \\
\text { Screen Size }\end{array}$ & $\begin{array}{c}\text { Inlet Gas Rate } \\
(1 \mathrm{~b} / \mathrm{hr})\end{array}$ & $\begin{array}{l}q \text { Oil } \\
\text { Yield }\end{array}$ \\
\hline 16 & 404 & 63.2 & $40 \times 50$ & 188 & 33.7 \\
\hline 17 & 416 & 59.2 & $40 \times 50$ & 198 & 34.6 \\
\hline 14 & 454 & 63.1 & $40 \times 50$ & 184 & 41.8 \\
\hline 18 & 471 & 62.5 & $40 \times 50$ & 206 & 49.4 \\
\hline 19 & 471 & 59.0 & $50 \times 60$ & 223 & 46.0 \\
\hline 20 & 471 & 84.7 & $40 \times 50$ & 254 & 51.3 \\
\hline 21 & 477 & 113.2 & $40 \times 50$ & 281 & 47.6 \\
\hline 22 & 460 & 89.6 & $50 \times 60$ & 220 & 46.0 \\
\hline 23 & 398 & 99.7 & $50 \times 60$ & 158 & 41.9 \\
\hline 13 & 504 & 52.9 & $40 \times 50$ & 194 & 35.0 \\
\hline 15 & 549 & 56.7 & $40 \times 50$ & 210 & 31.0 \\
\hline
\end{tabular}

\section{MODELING}

The purpose of the modeling effort was to give some insight into the chemical kinetics of hardwood pyrolysis, and to develop a means of using the results of the preliminary runs as a guide for planning future experiments. The decision was made to use a nonlinear least-squares procedure to determine numerical values for the pertinent parameters which could then be used to predict the oil yield. Rather than use a polynomial expression with no physical significance, the model was idealized to two series, first-order, irreversible reactions. Further, the assumption was made that the reactions took place under isothermal conditions (at the temperature at the reactor entrance). 
The first reaction is indicated symbolically by the following:

Hardwood ----> Oil + Char + Gases Similarly, the second reaction is given by the following:

oil ----> "Char" + Gases

The "char" in the second reaction is considered to be different from the usual pyrolytic char.

Instead of using a residence time, the space time based on the total inlet gas flow rate was used. The residence time cannot be determined without the use of a detailed mathematical model which includes the effect of pyrolysis gas and vapor evolution as well as particle lag (the particle velocity is not the same as the gas velocity). The development of such a detailed model had been initiated by the end of the testing period for configuration I, but the advanced model was not available at the time of the analysis.

The expressions for the rate constants used $\left(k_{1}, k_{2}\right)$ are:

$$
\begin{aligned}
& k_{1}=b_{1} \exp \left(-b_{2} / T\right) \\
& k_{2}=b_{3} \exp \left(-b_{4} / T\right)
\end{aligned}
$$

where $b_{1}$ and $b_{3}$ are pre-exponential factor, and $b_{2}$ and $b_{4}$ are the respective activation energies divided by the gas constant. Using the well-known solution to the idealized problem (see, for example, reference 7), the following expression was used to give the predicted fractional oil yield, where $b_{5}$ corresponds to the maximum fractional conversion of wood to oil (without a secondary reaction).

$$
F=\frac{k_{1} b_{5}}{k_{2}-k_{1}}\left[\exp \left(-k_{1} t\right)-\exp \left(-k_{2} t\right)\right]
$$

The objective function for the nonlinear least-square computer program consisted of an expression for the space time (which did not include any parameters to be determined) plus equations (3) through (5) which have a total of five parameters $\left(b_{1}\right.$ to $\left.b_{5}\right)$. An available computer code was used with the experimentally determined values of temperature, inlet gas flow 
rates, and corresponding oil yields for the 11 preliminary runs to determine the parameters. This computer code is based on the algorithm presented in reference 8 . The nonlinear least-squares results are given in Table $\mathrm{F}-2$.

TABLE F-2. Nonlinear Least-Squares Results

\begin{tabular}{ll}
\hline Parameter & \multicolumn{1}{c}{ Value } \\
\hline$b_{1}$ & $1.60 \times 10^{5} \mathrm{~s}^{-1}$ \\
$b_{2}$ & $9,485 \mathrm{~K}\left(E_{1}=18.8 \mathrm{kcal} / \mathrm{g}-\mathrm{mole}\right)$ \\
$b_{3}$ & $60.4 \mathrm{~s}^{-1}$ \\
$b_{4}$ & $4,097 \mathrm{~K}\left(\mathrm{E}_{2}=8.1 \mathrm{kcal} / \mathrm{g}-\mathrm{mole}\right)$ \\
$b_{5}$ & 0.979 \\
\hline
\end{tabular}

A comparison between the experimental and the calculated oil yields is given in Table $\mathrm{F}-3$. The average percent deviation between the experimental and calculated results listed in Table F3 is $6.5 \%$. In order to consider the trends based on the modeling results, Table F-4 was prepared using the range of temperatures covered in the experimental runs and also essentially the same range of total inlet gas flow rates.

As indicated by the results, for a given inlet gas rate, the oil yield increases as the temperature increases above $400^{\circ} \mathrm{C}$ and reaches a maximum before a temperature of $550^{\circ} \mathrm{C}$ is reached. Although it is not obvious from Table F-4, for a given temperature there is a flow rate which gives the maximum oil yield. As a matter of fact, this can be predicted analytically for the idealized model used (see, for example, reference 7). The results of such calculations are summarized in Table F-5. 


\begin{tabular}{|c|c|c|c|c|}
\hline \multirow[t]{2}{*}{ Run No. } & \multirow{2}{*}{$\begin{array}{c}\text { Temperature } \\
\left({ }^{\circ} \mathrm{C}\right)\end{array}$} & \multirow{2}{*}{$\begin{array}{c}\text { Inlet Gas Rate } \\
(1 \mathrm{~b} / \mathrm{h} x)\end{array}$} & \multicolumn{2}{|c|}{ Oil Yield } \\
\hline & & & Experimental & Calculated \\
\hline 16 & 404 & 188 & 33.7 & 30.6 \\
\hline 17 & 416 & 198 & 34.5 & 39.6 \\
\hline 14 & 454 & 184 & 41.8 & 43.2 \\
\hline 18 & 471 & 206 & 49.4 & 45.4 \\
\hline 19 & 471 & 223 & 46.0 & 46.7 \\
\hline 20 & 471 & 254 & 51.3 & 48.1 \\
\hline 21 & 477 & 281 & 47.6 & 48.6 \\
\hline 22 & 460 & 220 & 46.0 & 46.5 \\
\hline 23 & 398 & 158 & 41.9 & 38.7 \\
\hline 13 & 504 & 194 & 35.0 & 40.3 \\
\hline 15 & 549 & 210 & 31.0 & 30.1 \\
\hline
\end{tabular}

\begin{tabular}{cccc}
\hline TABLE F-4. & Model Predictions of Oil Yield \\
\hline $\begin{array}{c}\text { Temperature } \\
\left({ }^{\circ} \mathrm{C}\right)\end{array}$ & $\begin{array}{c}\text { Inlet Gas Rate }(1 \mathrm{~b} / \mathrm{hr}) \\
\text { Oil Yield }\end{array}$ & 250 \\
\hline 400 & 150 & 200 & 27 \\
425 & 33 & 30 & 36 \\
450 & 39 & 38 & 44 \\
475 & 40 & 44 & 48 \\
500 & 37 & 45 & 48 \\
525 & 30 & 41 & 44 \\
550 & 23 & 35 & 37 \\
\hline
\end{tabular}




\section{E. DISCUSSION}

The temperature range used in determining the results in Table F-5 is the same as that of the experimental results. Although some of the inlet gas rates in Table F-5 are greater than those used in the experiments, the results are not considered true extrapolations. The reason is that the true residence time, which is reflected in the space time, is the key parameter. Instead of increasing the gas flow, the residence time can be reduced by shortening the reactor, by decreasing the flow area, or both.

part of the plans for the research for configuration II was to reduce the reactor diameter while maintaining the length and flow rate capability about the same. These proposed modifications were used as a basis for calculating the oil yield using the maximum experimental temperature use to date $\left(550^{\circ} \mathrm{C}\right)$ and the maximum experimental inlet gas rate $(281 \mathrm{lb} / \mathrm{hr})$. The oil yield was calculated and found to be $59 \%$. It should be noted that this is only a sample calculation and higher oil yields would be predicted for other conditions.

Although the model used was highly idealized, the results were useful in the planning of future experiments. The parameters were updated as more data become available. As mentioned earlier, a more detailed modeling effort had been initiated which permitted more precise calculations. The results from the idealized model discussed here served as a starting point for the more sophisticated model. 


\section{REFERENCES}

1. Bowen, M. D., E. D. Smyly, J. A. Knight, and K. R. Purdy. "A Vertical-Bed Pyrolysis system," Solid Wastes and Residues, ACS Symposium Series, No. 76, 94-125. 1978.

2. Demeter, J. J., C. R. McCann, J. M. Ekmann, and D. Bienstock. "Combustion of Char form Pyrolyzed Wood Waste," Pittsburgh Energy Research Center, PERC/RI-77/9. $197 \%$.

3. Jasas, G., and J. Kasper. "Gas Turbine Demonstration of Pyrolysis-Derived Fuels," In Proceedings of the Fourteenth Biomass Thermochemical Conversion Contractors' Meeting, Arlington, Virginia. June 23-24, 1982. CONF-820685/PNLSA/10646. Available from the National Technical Information Service, U.S. Department of Commerce, 5285 Port Royal Road, Springfield, VA 22161 .

4. Diebold, J., and J. Scahill. "Ablative Pyrolysis of Biomass to Olefins and Aromatic Liquids in a Vortex Reactor," presentation at the Winter National Meeting of the AICHE, Atlanta, Georgia. 1984.

5. Scott, D. S., and J. Piskorz. "Flash Pyrolysis of Biomass," Klass, D. L. and G. H. Emert, eds., Fuels From Biomass and Wastes, pp. 421-434, Ann Arbor Science Publishers, Inc., Ann Arbor, Michigan. 1981.

6. J. A. Knight, C. W. Gorton and R. J. Kovac, "Entrained-Flow Pyrolysis of Biomass", p. 287 In the Proceedings of the Sixteenth Biomass Thermochemical Conversion Contractors, Meeting, Portland, Oregon. May 8-9, 1984. CONF-8405157/ PNL-SA-12403. Available from the National Technical Information Service, U.S. Department of Commerce, 5285 Port Royal Road, Springfield, VA 22161.

7. Cooper, A. R., and J. V. Jeffreys. Chemical Kinetics and Reactor Design, Prentice Hall, Inc., pp.94-97. 1973.

8. Marquardt, D. W. "An Algorithm for Least-Squares Estimation of Nonlinear Parameters," Journal of the Society of Industrial and Applied Mathematics, Vol. 11, No. 2 . 1963 . 
APPENDIX G

CHEMICAL AND GAS ANALYSIS 


\section{A. SAMPLE PREPARATION}

The methods of analysis for the feed and products of the entrained-flow pyrolysis PRU is discussed below. Included in the discussion is the application of the improved, automated $\mathrm{K}-\mathrm{F}$ titrimeter and the Parr bomb calorimeter.

oil samples brought into the laboratory for analysis were first placed in a $70^{\circ} \mathrm{C}$ water bath and were homogenized with a Fisher variable speed stirrer. An aliquot of the homogenized oil was taken using a wide tip serological pipet. Approximately five grams of oil was transferred into a tared $50 \mathrm{ml}$ flask and one gram samples were transferred into calorimeter cups. Representative char and feed samples were brought to the lab ready for analysis.

B. ANALYSIS OF PYROLYTIC CONDENSATES FOR WATER

The Fisher Automatic K-F Titrimeter system consisted of the Model 392 Titrimeter, the Model 395 Digital Burette, the Balance/Calculator Interface and the Hewlett Packard Model $97 \mathrm{~S}$ Calculator. Also included in the system is a Mettler AE 160 Analytical Balance. The system was assembled according to the instruction manual, and the balance was installed with the $B C D$ interface.

Prior to analysis of oil samples the titrimeter was purged of atmospheric moisture, and the $\mathrm{K}-\mathrm{F}$ reagent titer was determined using 150 to $200 \mathrm{mg}$ of deionized water. ACS certified methanol was used as the solvent for the oils. A solvent blank (mg water per gram methanol) was determined for each bottle of methanol.

The H-P $97 \mathrm{~S}$ calculated the value for each of the above procedures. For the sample analysis the calculator required the following operator input: multiplier value for the concentration (mg, ppm, $\frac{q}{2}$ mg water/ml solvent blank, extraction time, and titer value.

The weight of the oil sample was recorded, and io to $15 \mathrm{ml}$ of methanol was added to the flask. The weight of methanol was

$$
\mathrm{G}-1
$$


recorded. The flask was swirled vigorously to disperse the oil in the solvent. A 2-gram portion of the sample solution was drawn into a clean, dry hypodermic syringe. The syringe was weighed to the nearest $0.1 \mathrm{mg}$. The sample was injected into the $\mathrm{K}-\mathrm{F}$ reaction vessel. The run button on the H-P $97 \mathrm{~S}$ was pushed, and titration procedure was completed under the control of the calculator. When the titration endpoint was reached a printout containing the following data was obtained: sample number, titrant volume dispensed, titration time, sample weight, and calculated sample result (mg, ppm, or of water).

The Automatic K-F Titrimeter system improved the reproducibility of the condensate moisture determination. Results of one percent (relative) agreement for duplicate samples was achieved. Automated operation allowed the lab personnel to prepare other samples for analysis while the titrator was running and thus speeded up the sample output.

\section{HEATING VALUE DETERMINATION}

The automated Parr Bomb Calorimeter system consisted of the Model 1241 Adiabatic Bomb Calorimeter, Model 1720 Controller, and the Parr 1741 Balance Interface. The calorimeter was assembled according to the calorimeter manual with additional instructions and modifications noted in the 1720 controller manual. Automatic transfer of data from the AE 160 was controlled by the 1741 Interface which is capable of storing 100 sample weights. The 1720 Controller automates the calorimeter with the following functions: determines the temperature equilibrium point, fires the bomb, determines the net temperature rise, applies heat loss corrections, computes and prints a preliminary and final report of the heat of combustion for the sample.

The calorimeter was calibrated using NBS traceable benzoic acid pellets. Initially an energy equivalent ( $E$ value) was determined for the bomb and bucket in the intended mode of operation. In this case the isoperibol mode was used. Ten benzoic acid pellets were run and the results were averaged to 
obtain a reliable E value. Periodically a benzoic acid pellet was run to check for problems with the system.

The automated calorimeter improved the reproducibility of the heating value determination for solid and liquid products from the PRU. Sample output was also improved.

\section{GAS ANALYSIS}

Gas samples were taken at three points on the PRU: the burner, inert gas generator, and downstream from the second demister cyclone. The samples were analyzed for noncondensable gases, after passing through the appropriate clean-up train, using four gas chromatograph integrators as shown in Table G-1. The offgas from the second demister cyclone was cleaned up using the condensation train as shown in section 4.G.

\section{TABLE G-1. Gas Analysis}

1. Carle Model 111

$\mathrm{H}-\mathrm{P}$ Integrator

Thermal Conductivity Detector Silica Gel column

2. Carle Model 111

$\mathrm{H}-\mathrm{P}$ Integrator

Thermal Conductivity Detector Carbon Column

3. Perkin-Elmer Sigma 2 Thermal Conductivity Detector Molecular Sieve Column

4. Perkin-Elmer Sigma 3

Perkin-Elmer LCI

Flame Ionization Detector

Alumna Column
$\mathrm{H}_{2}$

CO (high concentrations)

$\mathrm{CH}_{4}$

$\mathrm{CO}_{2}$

Argon-oxygen

Nitrogen

Co (low concentrations)

Hydrocarbons

Ethane

Propane

Ethylene

Buthane
Propylene

Butenes 
APPENDIX H

COMPUTER PROGRAM LISTING -

"TSQMAX" 


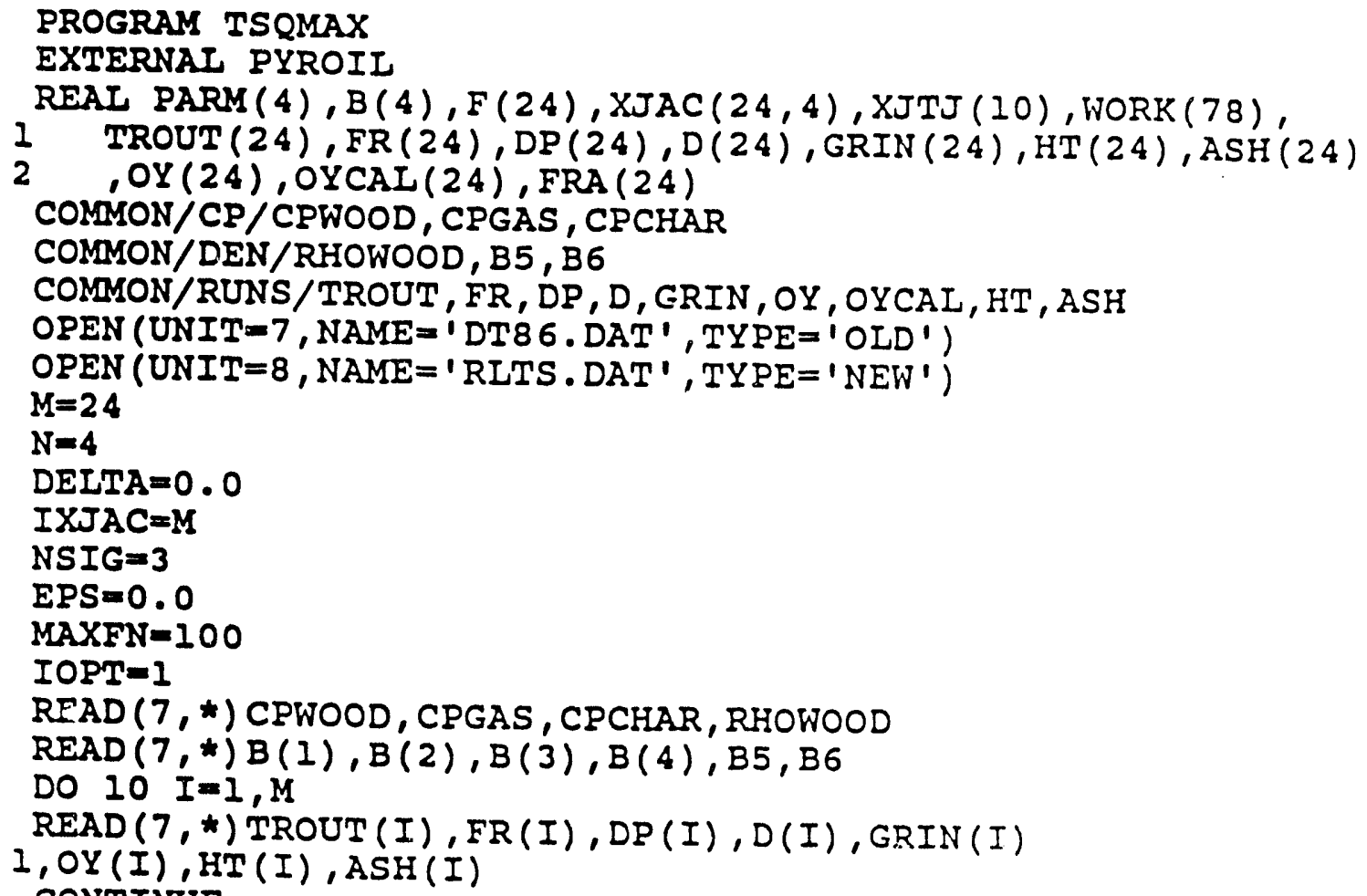

CAIL 2XSSQ (PYROIL, M, N , NSIG , EPS, DELTA, MAXFN, IOPT , PARM, $1 \mathrm{~B}, S S Q, F, X J A C, I X J A C, X J T J$, WORK, INFER, IER) DO $20 \quad I=I, N$

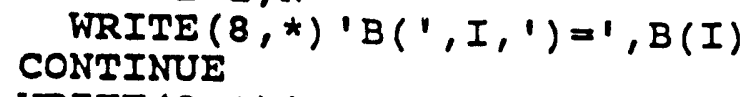

SUBROUTINE PYROIL $(B, M, N, F)$ INTEGER IWK(3)

REAL $Y(3)$, WK (52), B (4), TROUT (24), FR (24), DP (24),

$1 \mathrm{D}(24), \operatorname{GRIN}(24), \mathrm{HT}(24), \mathrm{OY}(24), \mathrm{OYCAL}(24), \mathrm{BI}(4), F(24), \mathrm{ASH}(24)$ COMMON/RUNS/TROUT, FR, DP, D, GRIN , OY, OYCAL , HT , ASH COMMON/PAR/BI

COMMON/IND/II, TGIN , VP, RHOP , TG , VM, VR COMMON/DEN/RHOWOOD, B5, B6

\section{$I I=0$}

DO $20, I=1, M$

$I I=I I+I$

$B I(1)=B(1)$

$B I(2)=B(2)$

$B I(3)=B(3)$ 


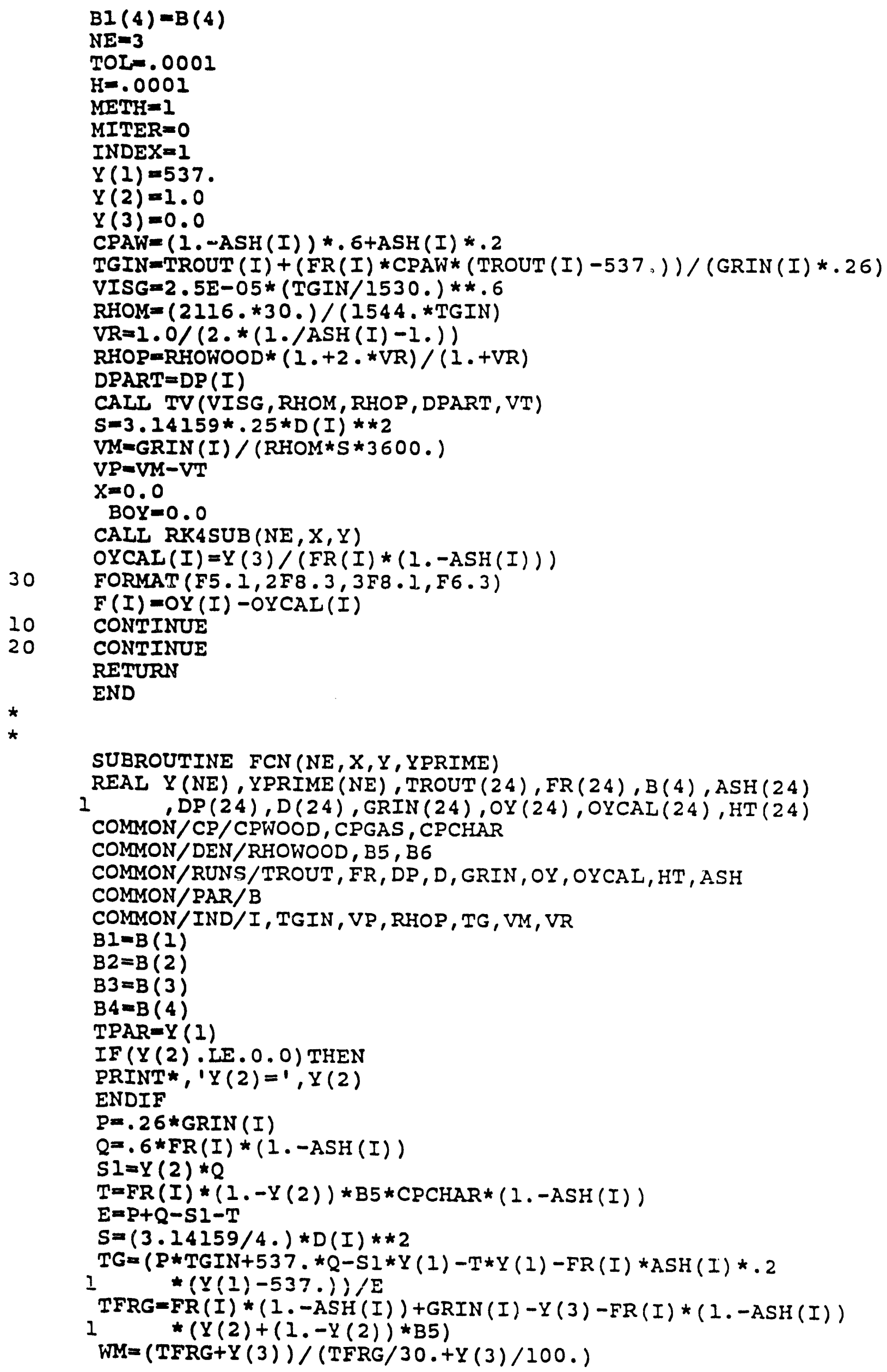




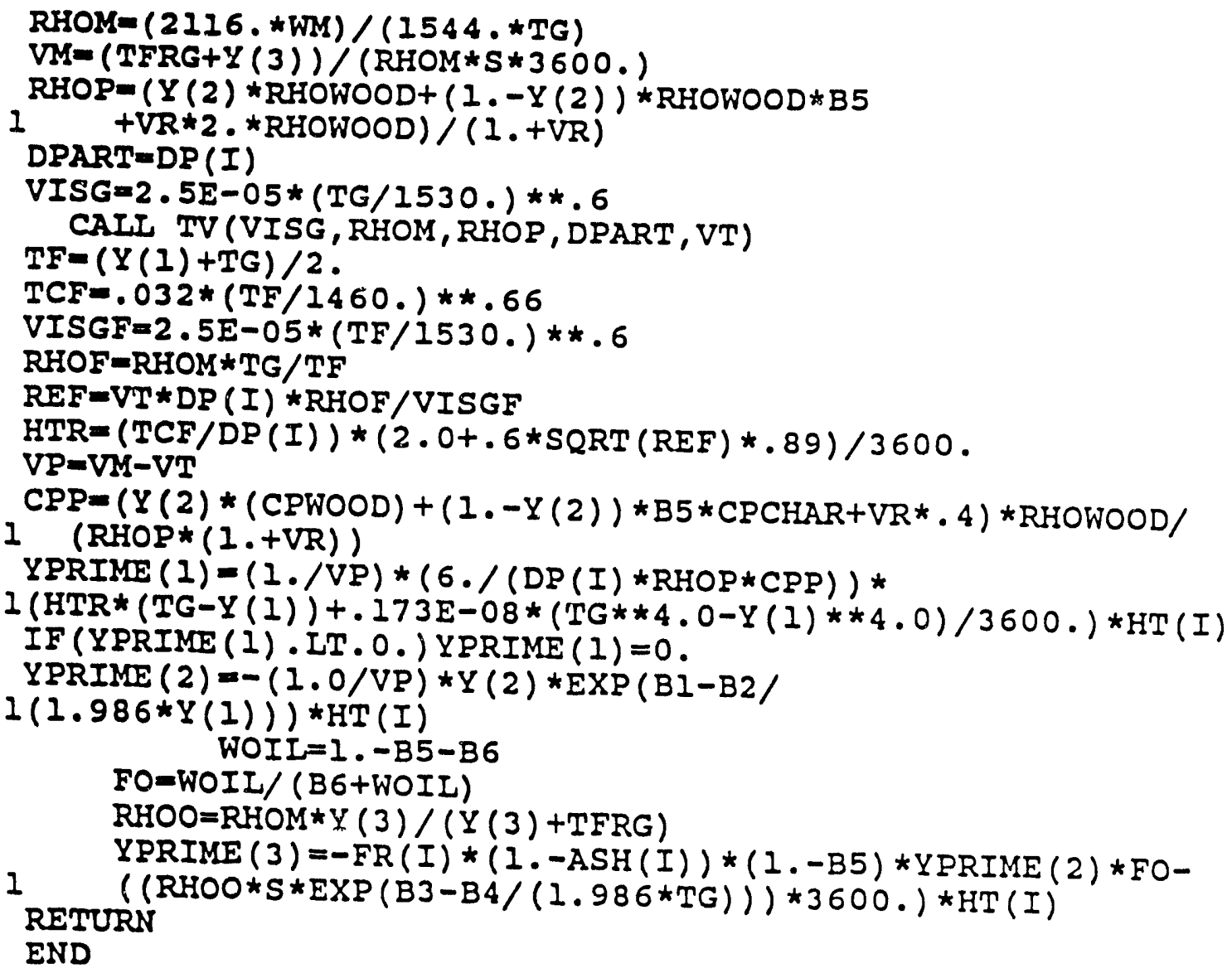

SUBROUTINE TV (VISG, RHOM, RHOP, DP, VT)

$A=32 \cdot 174 /($ VISG $* \star 2)$

$B=R H O M *(R H O P-R H O M)$

$A K=D P *((A * B) \star \star .333333)$

IF (AK.GT. 44.0) GO TO 100

IF (AK.GT.3.26)GO TO 200

GO TO 300

$C=(32.174 \star D P *(R H O P-R H O M)) / R H O M$

$V T=1.7408 \star S Q R T(C)$

GO TO 400

$200 \quad E=1.824 * D P * \star 1.14 *((R H O P-R H O M) * * .714)$

$G=(R H O M * \star .286) \star(V I S G * \star .428)$

$V T=E / G$

GO TO 400

$V T=((32.174) *(D P * \star 2) *(R H O P-R H O M)) /(18 . * V I S G)$
CONTINUE

RETURN

END

SUBROUTINE RK4SUB (NE, X,Y)

REAL $A(3), Y(3), Y$ YRIME (3)

DO $10 \quad I=1,100$

$\mathrm{H}=.01$

CALL FCN (NE, $X, Y, Y P R I M E)$

CII=YPRIME (I)

CI2 $=$ YPRIME ( 2 )

C13 $=$ YPRIME (3) 
$A(1)=X(1)+C I I * H / 2.0$

$A(2)=Y(2)+C 12 \star H / 2.0$

$A(3)=Y(3)+C 13 * H / 2.0$

CAIL FCN (NE, X, A, YPRIME)

C2 I =YPRIME (1)

C22 =YPRIME (2)

C23 $=$ YPRIME ( 3 )

$A(1)=Y(1)+C 21 * \mathrm{H} / 2.0$

$A(2)=Y(2)+C 22 * H / 2.0$

$A(3)=Y(3)+C 23 * H / 2.0$

CALI FCN (NE, $X, A, Y P R I M E)$

C31=YPRIME (1)

C32 - YPRIME (2)

CS3 =YPRIME ( 3 )

$A(1)=Y(1)+C 3 I * H$

$A(2)=Y(2)+C 32 * H$

$A(3)=Y(3)+C 33 * H$

CAIL FCN (NE, X, A, YPRIME)

C4 1-YPRIME (1)

C42=YPRIME (2)

C4 3=YPRIME (3)

$Y(1)=Y(1)+H *(C 11+2.0 * C 21+2.0 * C 31+C 41) / 6.0$

$Y(2)=Y(2)+H *(C 12+2.0 * C 22+2.0 * C 32+C 42) / 6.0$

10 $Y(3)=Y(3)+H *(C 13+2.0 * C 23+2.0 * C 33+C 43) / 6.0$ CONTINUE

RETURN

END 
APPENDIX I

COMPUTER PROGRAM LISTING "PYRGRAF" 
PROGRAM PYRGRAF

REAL ABS (2I) , ORD (2I)

REAL B (6)

COMMON/GRA/ABS, ORD

COMMON/CP/CPWOOD, CPGAS, CPCHAR

COMMON/DEN/RHOWOOD

COMONON/RUNS/TROUT , FR, DP , D , GRIN , HT , ASH

OPEN (UNIT=8, NAME = 'RLTS . DAT' , TYPE = 'NEW')

$C P W O O D=.6$

CPGAS $=.26$

CPCHAR $=.2$

RHOWOOD $=50$.

$\left.\operatorname{WRITE}(6,)^{\prime}\right) \mathrm{B}(1), \ldots, \mathrm{B}(6)$ '

$\operatorname{READ}(5, *) B(1), B(2), B(3), B(4), B(5), B(6)$

DO $10 \quad I=1,20$

WRITE $(6, *)$ ' TROUT, FR, GRIN, ASH '

$\operatorname{READ}(5, *)$ TROUT, FR, GRIN, ASH

$D P=8.3 E-04$

$D=.505$

$H T=23.67$

WRITE $(8, *)$ 'TROUT $=$ ', TROUT

$\operatorname{WRITE}(8, \star) ' F R=1, F R$

WRITE $(8, \star)$ ' GRIN $=1$, GRIN

WRITE $(8, *) ' D P=1, D P$

WRITE $(8, \star)^{\prime} D=1, D$

WRITE $(8, *) ' H T='$, HT

$\operatorname{WRITE}(8, *) ' A S H=1$, ASH

$\operatorname{WRITE}(8, *) ' B(1)=1, B(1)$

WRITE $(8, \star) ' B(2)=1, B(2)$

WRITE $(8, *)$ ' $B(3)=1, B(3)$

$\operatorname{WRITE}(8, *) ' B(4)=1, \mathrm{~B}(4)$

$\operatorname{WRITE}(8, *) ' B(5)=1, B(5)$

WRITE $(8, \star) ' B(6)=1, B(6)$

CAIL PYROIL(B)

WRITE $(6, \star)$ 'ENTER 1 TO STOP, 2 TO CONTINUE'

$\operatorname{READ}(5, *) I N$

IF (IN.EQ.1) GO TO 20

CONTINUE

CONTINUE

WRITE $(6, \star)$ 'ENTER I TO STOP, 2 TO MAKE A PLOT'

$\operatorname{READ}(5, *) I I$

IF (II.EQ.I) GO TO 30

30

CALI PPLOT (ABS, ORD)

CONTINUE

STOP

END

SUBROUTINE PYROIL (B)

REAL $Y(3), B(6), B I(6), A B S(21), O R D(21)$

COMMON/GRA/ABS, ORD

COMMON/RUNS/TROUT , FR, DP , D , GRIN , HT , ASH

COMMON/PAR/BI

COMMON/IND/TGIN , VP , RHOP , TG , VM, VR

COMMON/DEN/RHOWOOD

HTOT $=0.0$

TRES $=0.0$

DO $40 \quad I=1,6$

$B I(I)=B(I)$ 
$Y(1)=537$.

$Y(2)=1.0$

$Y(3)=0.0$

CPAW= $(1 .-\mathrm{ASH}) * .6+\mathrm{ASH} * .2$

TGIN $=$ TROUT $+($ FR $*$ CPAW $*($ TROUT -537.$)) /($ GRIN $* .26)$
VISG $=2.5 E-05 *($ TCIN $/ 1530.) \star \star .6$

RHOM $=(2116 . \star 30) /.(1544 . *$ TGIN $)$

$V R=1.0 /(2 . *(1 . / A S H-1)$.

$R H O P=R H O W O O D *(1 .+2 . * V R) /(1 .+V R)$

$D P A R T=D P$

CAIL TV (VISG, RHOM, RHOP, DPART, VT)

$S=3.14159 * .25 * D * * 2$

$V M=G R I N /(R H O M * S \star 3600$.)

VPAVM-VT

$X=0.0$

${ }_{1}$ WRITE $(8, *)^{\prime}$ Z/HT VP VM',

WRITE $(8,20)$ HTOT, VP TS TG OILYD TRES '

FORMAT (7FIO.3)

ABS (I) $=0.0$

$O R D(1)=0.0$

CAIL RK4SUB (NE, Y)

RETURN

END

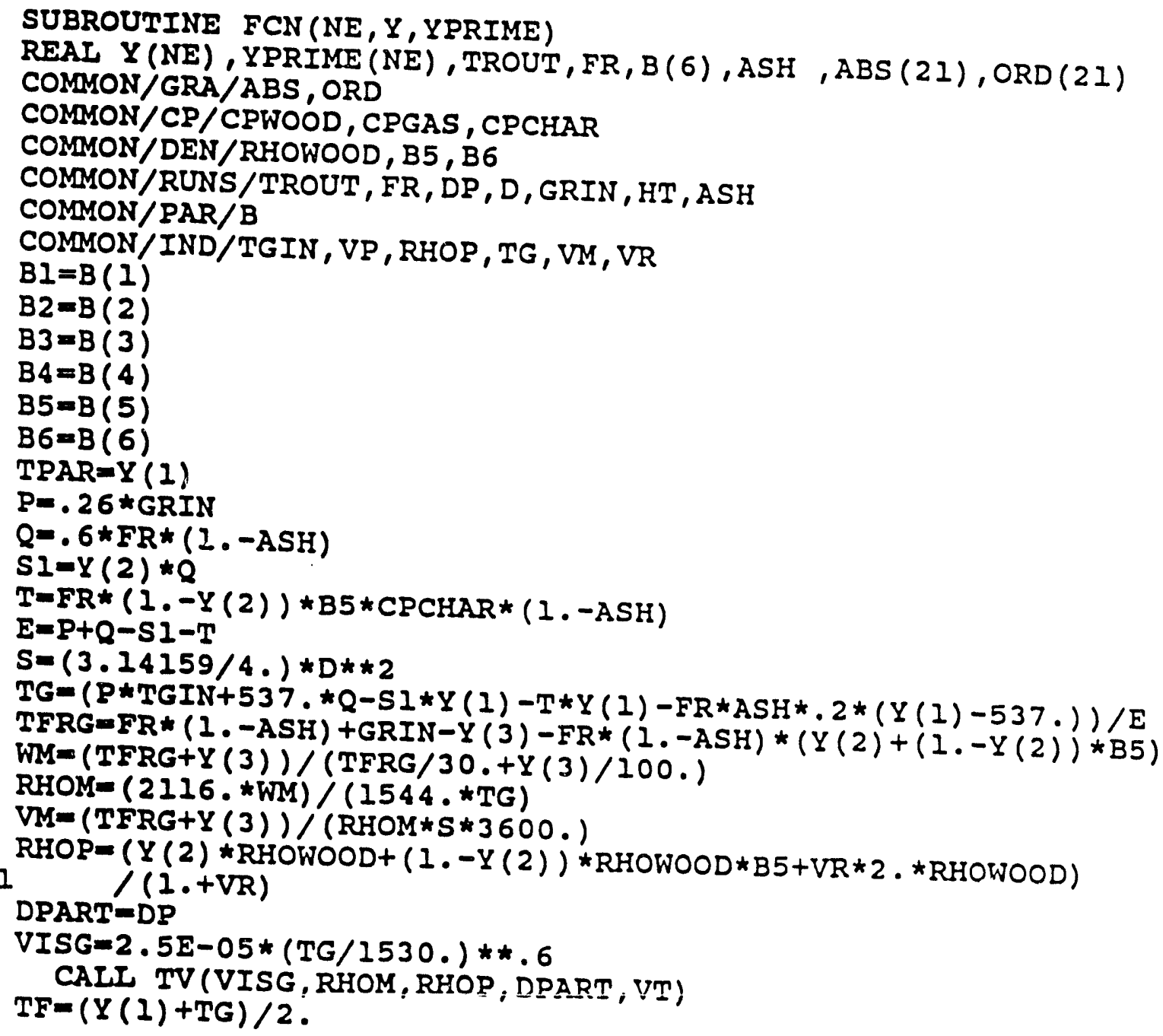




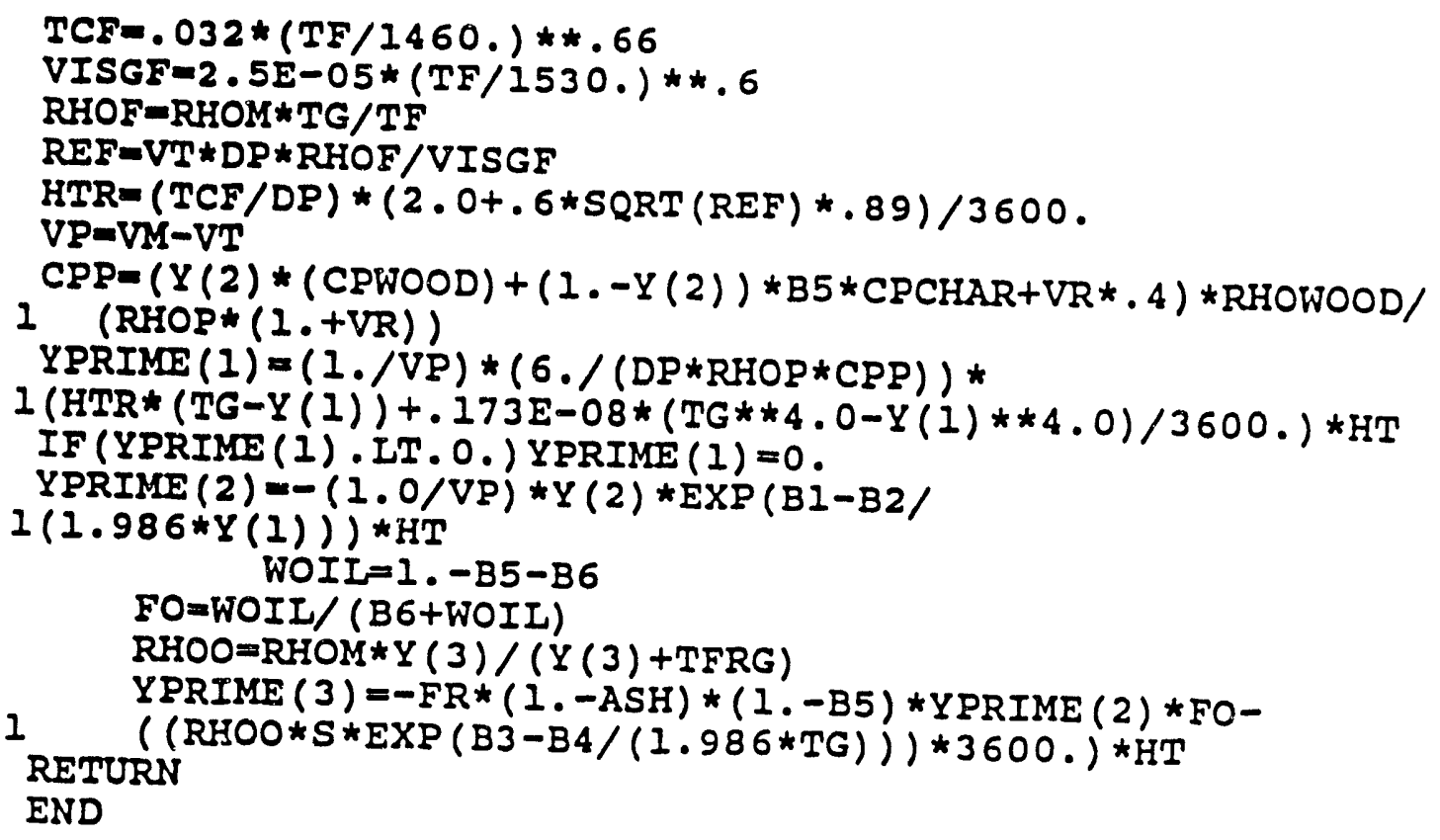


CII=YPRIMEE (I)

C12=YPRIME (2)

C13-YPRIME (3)

$A(1)=Y(1)+C I I * H / 2.0$

$A(2)=Y(2)+C l 2 * H / 2.0$

$A(3)=Y(3)+C 13 * H / 2.0$

CAIL FCN (NE, A, YPRIME)

C2 I =YPRIME (1)

C22-YPRIME (2)

C23 =YPRIME (3)

$A(1)=Y(1)+C 2 I * H / 2.0$

$A(2)=Y(2)+C 22 * H / 2.0$

$A(3)=Y(3)+C 23 * H / 2.0$

CAIL FCN (NE, A, YPRIME)

C3I-YPRIME (1)

C32=YPRIME (2)

C33=YPRIME (3)

$A(1)=Y(1)+C 31 * H$

$A(2)=Y(2)+C 32 * H$

$A(3)=Y(3)+C 33 * H$

CAIL FCN (NE, A, YPRIME)

C4 I =YPRIME (1)

C42=YPRIME (2)

C43=YPRIME (3)

$Y(1)=Y(1)+H *(C 11+2.0 * C 21+2.0 * C 31+C 41) / 6.0$

$Y(2)=Y(2)+H *(C 12+2.0 * C 22+2.0 * C 32+C 42) / 6.0$

CAIL FCN (NE, Y, YPRIME)

DTRES $=(1 . / \mathrm{VPOLD}+1 . / \mathrm{VP}) * .5 * \mathrm{HT} / 20$.

TRES=DTRES +TKES

$\operatorname{OILYD=Y}(3) /(F R *(1 .-A S H))$

20 WRITE $(8,20)$ HTOT, VP, VM, Y (1),TG, OII,YD, TRES

ABS $(I)=$ HTOT

$O R D(I)=O I L Y D$

5

CONTINUE

RETURN

END

\section{SUBROUTINE PPIOT $(X, Y)$}

REAI. $X(21), Y(2 I)$

PRINT*, 'ENTER OUTPUT DEVICE NUMBER'

PRINT*,' HP7550 1, SCREEN 2, VTI25 3, TEKTRONIX 4'
READ*, IAMDUM

IF (IAMDUM.EQ.1) CALL HP7550(1)

IF (IAMDUM.EQ.2) CALL PRTPIT

IF (IAMDUM.EQ.3) CALL REGIS $(1,0)$

IF (IAMDUM.EQ.4) CALI PTEKAL

CALI HWROT ('MOVIE')

CĀIL NŌBRDR

CALL AREA2D $(7.0,7.0)$

CALL XNAME ('NORMALIZED REACTOR HEIGHTS', 100)

CALI YNAME ('FRACTIONAL OIL YIELD\$', 100)

CALL GRAP $(0.0,0.1,1.0,0.0,0.1,1.0)$

CAII RASPLN ( 2 )

CALI CURTE $(X, Y, 22,0)$ 
CALI ENDPL(0)

CAIL DONEPI

RETURN

END

I -5 
APPENDIX J

ECONOMIC ANALYSIS

OIL PRODUCTION VIA ENTRAINED-FLOW

PYROLYSIS OF BIOMASS 


\section{OIL PRODUCTION VIA ENTRAINED \\ FLOW PYROLYSIS OF BIOMASS - ECONOMIC ANALYSIS}

At the Thirteenth Biomass Thermochemical Conversion Contractors' Meeting, held in 1981, the results of an economic analysis for oil production via the entrained-flow pyrolysis of biomass for both a 250 dry ton per day plant were presented. 1 Design of the two above commercial plants proceeded concurrently with the design of the entrained-flow PDU. The results were very encouraging and pointed out the outstanding commercial potential of the entrained-flow pyrolysis process.

\section{A. INTRODUCTION}

For the purposes of economic analysis, the entrained-flow pyrolysis system was divided into six sections according to the operations performed. The sections were: wood receiving, handling and storage; wood drying; size reduction and storage; entrained pyrolysis reactor; solids removal, handling and storage; and oil removal, handling and storage. Both purchased and installed capital equipment costs were specified. A number of sources of information were used to arrive at the capital equipment costs. For some of the equipment, the requirements were discussed with manufacturers and vendors and direct quotes were obtained. The most accurate information was used for critical items; that is, the ones which had a major influence on the total cost. The installation cost for each item was determined separately, rather than using a uniform percentage rate of the capital equipment cost, to determine the installation costs. Installation costs were obtained by estimating material and labor requirements directly for each capital item or by using estimated installation materials and installation labor (from references) for various classes and types of equipment. Two major references which were used extensively in this economic analysis were Peters and Timmerhaus? ana Fopper ${ }^{3}$. 
The results of this analysis are presented in the following sections. Detailed information is presented for the equipment for both the 250 dry ton per day plant and the 1,000 dry ton per day plant.

\section{B. PROCESS DESCRIPTION}

A schematic of the entrained-flow pyrolysis process is presented in Figure $\mathrm{J}-1$. Starting at the left on Figure $\mathrm{J}-1$, green wood chips at 50 percent moisture (wet basis) are brought into the wood storage section of the plant. The wood chips are conveyed (1) to the dryer. Dryer flue gases are exhausted to the atmosphere (2). The dryer is fueled by pyrolysis gases (15) and char (13). Preheated air (18) as well as ambient air (19) are used to supply the air requirements for the dryer. The wood chips are dried to 10 percent moisture (wet basis) and are conveyed (3) to the hammermill. Some moisture is evaporated (4) in the hammermill and the wood particles leave at 6 percent moisture (wet basis) (5) (the reduction in moisture content is associated with the size reduction process). Some of the char (7) is burned with ambient air (6) to supply the energy needs for the pyrolyzer. The stream leaving the pyrolyzer (8) consists of newly formed char, pyrolysis gases, pyrolysis vapors, water vapor, nitrogen and ash from the char combustion. The char and ash (9) are removed by cyclone separators and subsequently separated. The char stream (11) is split into two streams, one of them (7) provides the char for the pyrolyzer, the remainder (12) is char product. The ash (10) can be sold as an agricultural additive or landfilled. The pyrolysis vapors are removed from the mixture of pyrolysis gases, pyrolysis vapors, water vapor and nitrogen (14) by means of an air-cooled condenser and a demister. The entering ambient air (16) is heated in the condenser and supplies part of the combustion air. The product oil (17) contains about 10 percent moisture (this increases the fluidity of the oil, a desirable result). 


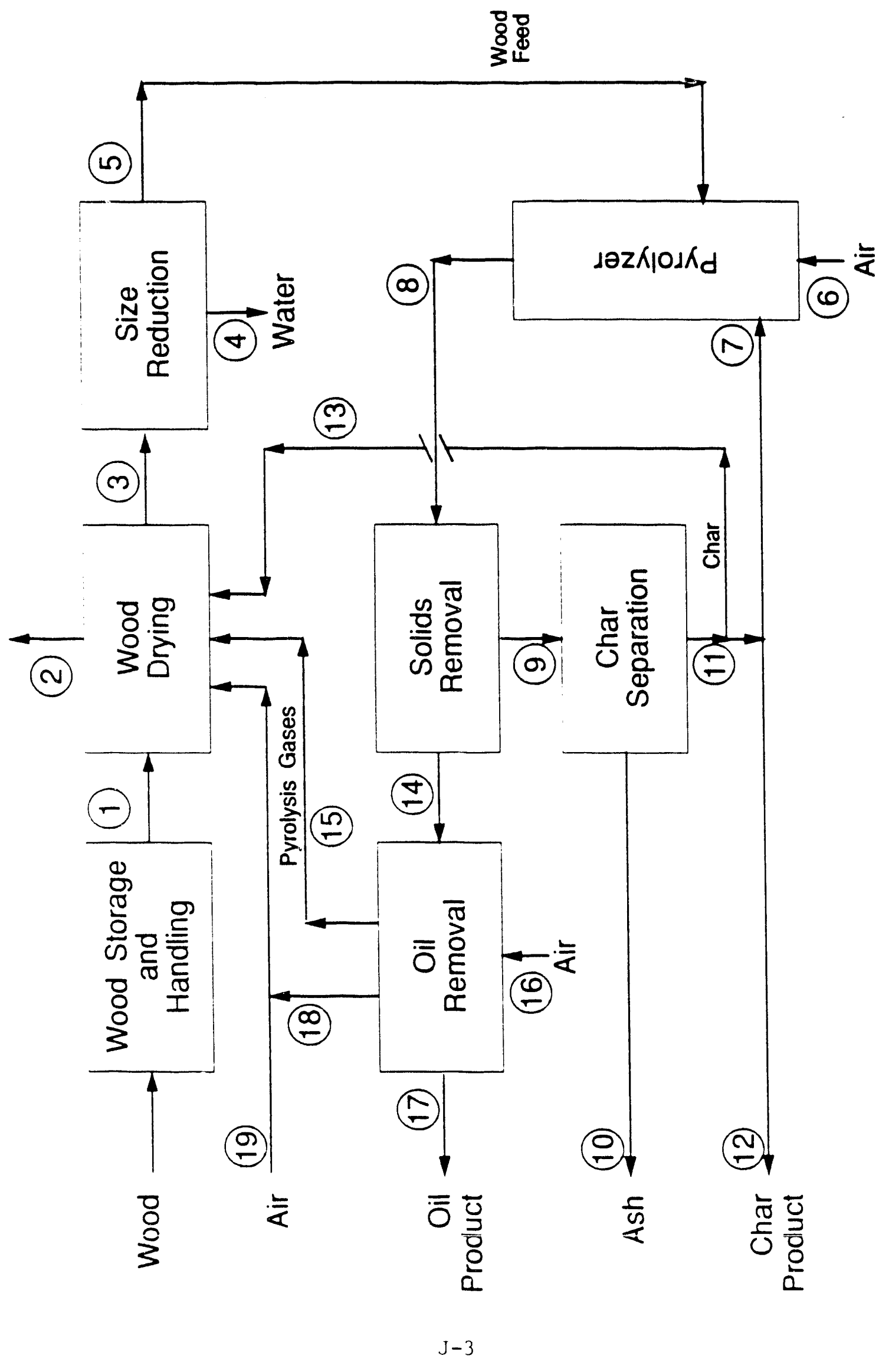

ह5 


\section{c. DESIGN CONSIDERATIONS}

The design basis was discussed in detail in the presentation at the Thirteenth Contractors' Meeting.' The product yields and other design conditions are summarized in Table J-1.

\section{ECONOMIC ANALYSIS}

The results of the economic analysis are presented in the following tables and sections. Table J-2 and Table J-3 list the purchased costs and total installed costs for equipment for the 250 dry ton per day $(\mathrm{dt} / \mathrm{d})$ and $1,000 \mathrm{dt} / \mathrm{d}$ plants, respectively. Following these tables, there is a section which provides detailed information about the equipment costs. Table J-10 and Table J-11 provide detailed information about the installation cost for the $250 \mathrm{dt} / \mathrm{d}$ and $1,000 \mathrm{dt} / \mathrm{d}$ plants, respectively.

The total capital investments for the two plants, the manufacturing costs, and the sales revenues are presented in section $G$ of this appendix. The profitability analysis, which includes percent rate of return on investment for the $250 \mathrm{dt} / \mathrm{d}$ and $1,000 \mathrm{dt} / \mathrm{d}$ plants, the payout period and discounted cash flow rate of return, is also given in section $G$.

\section{E. EQUIPMENT COSTS - 250 DRY TON PER DAY PLANT}

The costing of the equipment for the 250 dry tons per day plant is discussed below for each item as listed in Table J-2. Extensive use was made of references 2 and 3 in determining costs for both the 250 dry tons per day and the 1,000 dry tons per day plants. In the discussion for each of these plants, reference 3 , peters and Timmerhaus is referred to as P\&T and reference 4 as Popper. The Marshall and Swift (M\&S) equipment cost index was used to convert costs to $6 / 81$ dollars. The indexes are published monthly in Chemical Engineering by McGraw-Hill. Reference 4 is a report prepared (1979) by the Economic Development Laboratory, GTRI, Georgia Tech, for the Georgia Forestry Commission. Information and data from sections of the report, which addressed handling, conveying and storage of wood chips and residues, were used where applicable to this economic assessment. Reference 5 is 
TABLE J-1. Design Basis - Entrained-Flow Pyrolysis System

Location

Southeast

Feedstock - (Mixed Hardwoods)*

Average Moisture Content, Wet Basis

$50 \%$

Ash Content, Moisture Free

Higher Heating Value, Moisture Free, Btu/lb

$0.63 \%$

8,200

Product Yields

Pyrolytic oil, Dry wt/wt Dry wood

Char, Dry wt/Wt Dry Wood

Pyrolysis Gas, Dry wt/Wt Dry wood

water of Reaction, wt/Wt Dry wood

0.40

0.16

0.218

0.222

\section{Product Specifications}

Pyrolytic oil

Specific Gravity

Higher Heating Value, Moisture Free, Btu/lb

Product oil Moisture Content, Wet Basis

1.11

12,200

$10 \%$

Char**

Higher Heating Value, Moisture Free, Btu/lb

13,800

Pyrolysis Gas

Higher Heating Value, Dry Basis, Btu/lb

3,200

Cooling and Combustion Air

Temperature, ${ }^{\circ} \mathrm{F} /{ }^{\circ} \mathrm{C}$

$77 / 25$

Relative Humidity

$50 \%$

Pressure

Atmospheric

Pyrolysis Reactor Conditions

Temperature, ${ }^{\circ} \mathrm{F} /{ }^{\circ} \mathrm{C}$

Pressure

Throughput, $1 \mathrm{~b} / \mathrm{hr}-\mathrm{ft} \mathrm{t}^{2}$

$1022 / 550$

Near Atmospheric

450

* Feedstock would be received as chips or as wood residues no larger than wood chips. Bulk densities: wet wood chips, $25 \mathrm{lbs} / \mathrm{ft}^{3} ;$ dried chips, $15 \mathrm{lbs} / \mathrm{ft}^{3} ;$ and dried ground wood, $13 \mathrm{lbs} / \mathrm{ft}^{3}$.

** Bulk char density, $11.25 \mathrm{lbs} / \mathrm{ft}^{3}$. 
TABLE J-2. Equipment Costs*

$250 \mathrm{dt} / \mathrm{d}, 40 \%$ oil Yield

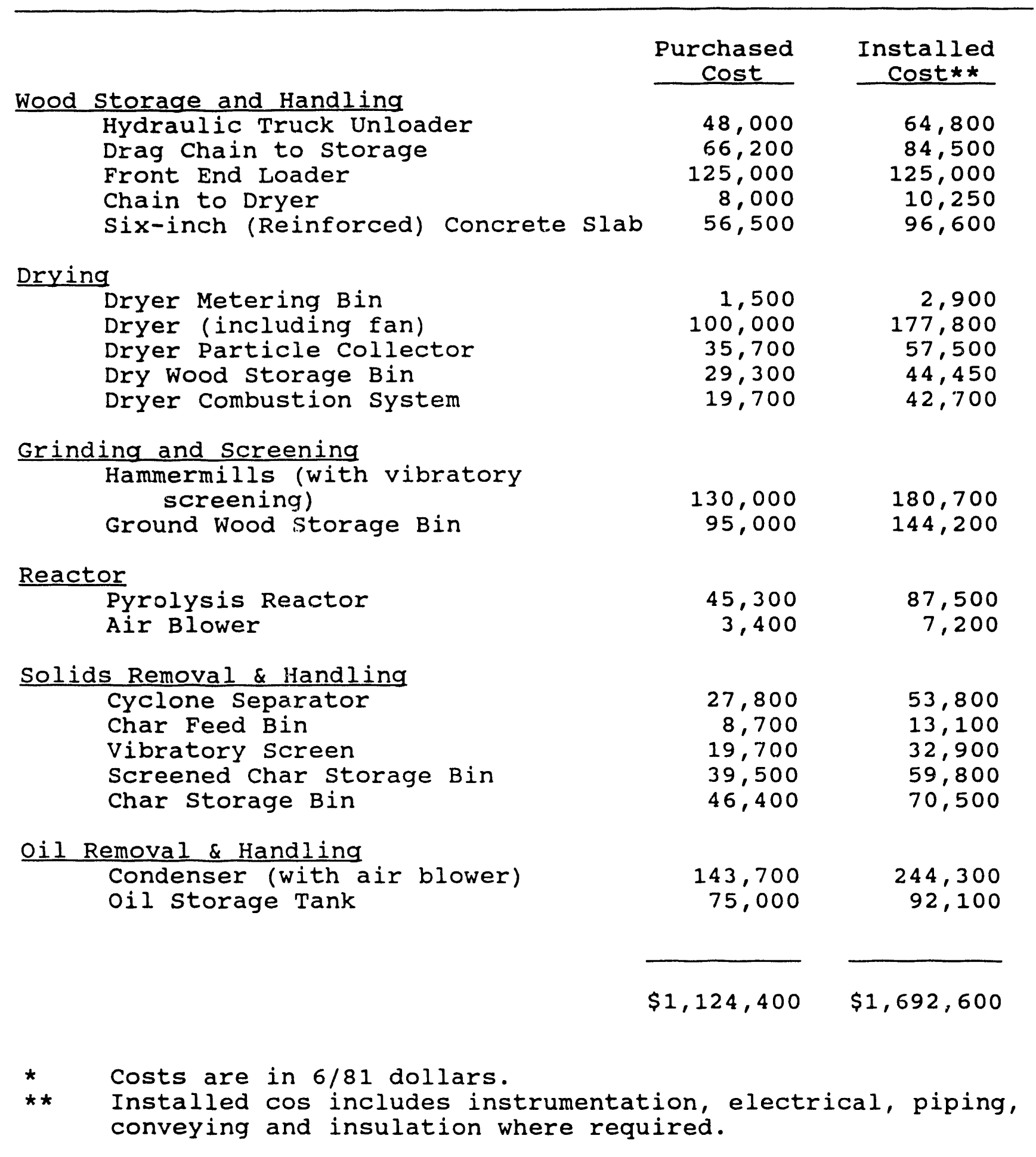


a report prepared (1980) by the Technology Applications Laboratory, GTRI, Georgia Tech, for the U. S. Department of Energy. Data from the section concerning the drying of wood fuels were used to estimate the cost of drying equipment.

(1) Wood Receiving, Handling and storage

(a) Hydraulic Truck Unloader

A 250 dry ton per day plant will require 500 tons per day of wet wood with an average moisture content of 50 \& on a wet basis. Truck trailers can haul 20 to 25 tons of wood chips or residues, such as sawdust, at 50\% moisture content on wet basis, and vary in length from 40 to 45 feet. On an average, the number of trucks, $(20$ tons of wet feedstock per truck), required to supply the feedstock for a 24 hour period would be 1.04 trucks per hour.

Information about back-on, hydraulic truck dumpers was obtained by phone conversations and a meeting with a representative of the Peerless Division of Lear Siegler, Inc. A back-on hydraulic truck dumper which can handle a 40-foot trailer with $c a b$ and an average size ramp was quoted. (Quote is used in this context as a verbal quote.) The calculated, installed cost was $\$ 64,800$. The unit has a capacity of 50 tons and a cycle time of 3.5 minutes. The quoted price does not include a receiving hopper or a hopper discharge drag chain.

(b) Drag Chain

The drag chain will be used to move the feedstock from the truck unloader and distribute it on the wood storage area. From Figure $\mathrm{J}-2$, the two acre wood storage paved area (discussed later) will require 570 feet of conveying equipment. The feedstock requirement for seven days' operation would be 3,500 wet tons and would require 175 trailer loads of feedstock at 20 tons per load. operating the unloading facility on a 
总
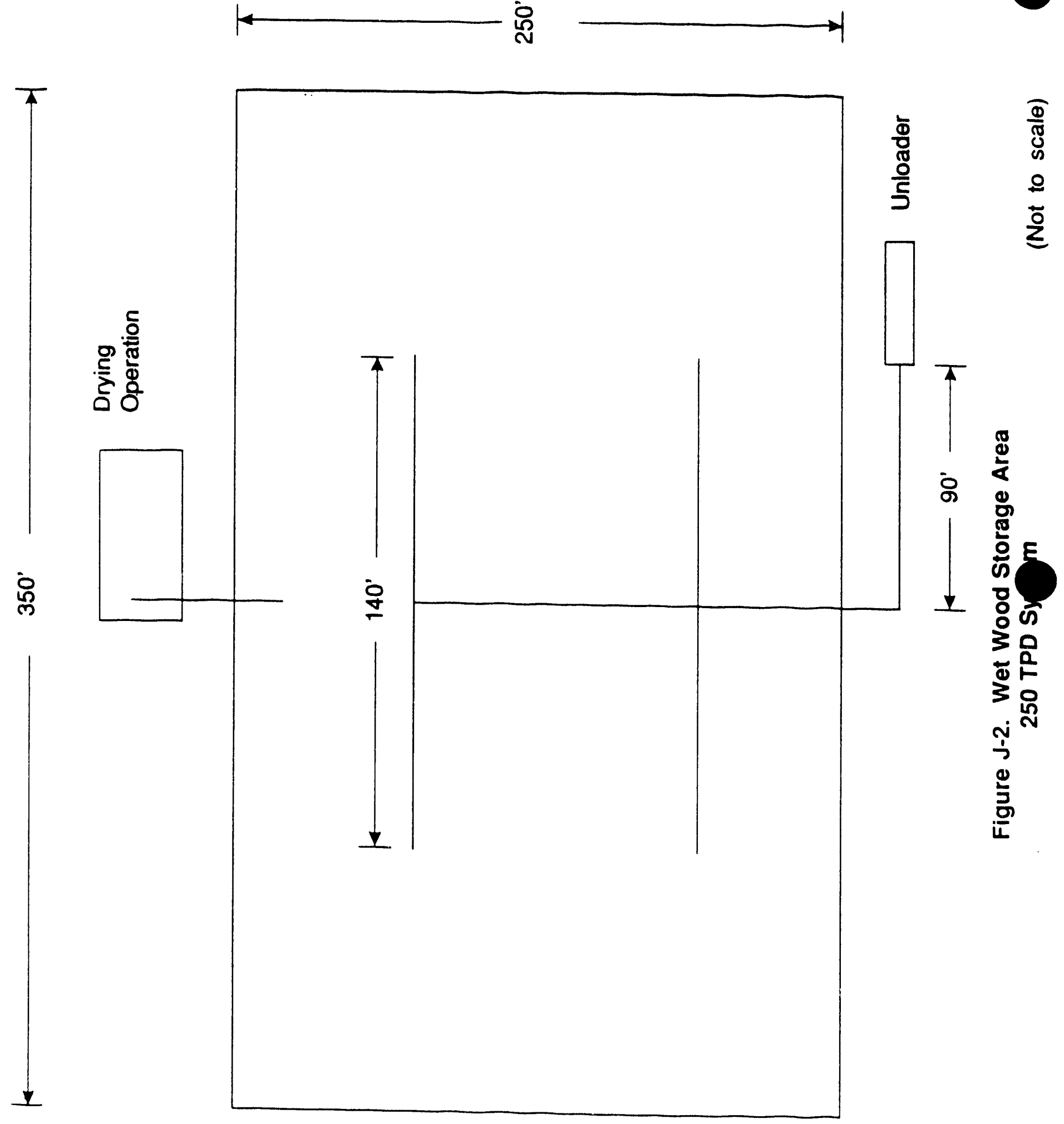

$\leftarrow$

$\stackrel{\circ}{i} \longrightarrow$

$J-8$ 
restricted schedule of two shifts per day during the week and one shift on saturday, an average of two trucks per hour would be unloaded. Therefore, the minimum capacity of the belt conveyor must be 40 tons per hour. From P\&T, Figure 13-92, p. 601, a belt conveyor with a speed of 150 feet per minute and a belt width of 14 inches has a capacity of 50 tons per hour and the purchased cost was $\$ 52,000$ in $1 / 79$ dollars. From Popper, Table IV, p.99, the field installation factor is 1.17 and includes field labor, electrical work and painting. The foundation was not included in this price since the six-inch concrete slab is the base. The total installed cost was $\$ 84,500$ in 6,81 dollars.

(c) Front End Loader

A vehicle will be needed to move the wood chips on the storage pile and maintain a supply of feed to the drag chain to the dryer metering bin. With the drag chain distribution system from the truck unloader to the wood storage pile, a front end loader assigned full time will be sufficient.

A quote of $\$ 125,000$ was received from Yancey Brothers, dealers for Caterpillar Tractor Company in Atlanta, for a Caterpillar 950, which is a rubber-tired, front-end loader with a three cubic yard bucket.

(d) Drag Chain to Dryer

A drag chain will be required to move feed material from the storage pile to the dryer metering bin. This drag chain is similar to the drag chain from the truck unloader to the wood storage pile. It will be 30 feet in length, with a capacity of 50 tons per hour, a belt width of 14 inches and a belt speed of 150 feet per minute. A belt conveyor with the above specifications, from P\&T, Figure 13-92, p. 601, had a purchased cost of $\$ 6,300$ in $1 / 79$ dollars; from Popper, 
Table IV, p. 99, the field installation factor is 1.17 and includes field labor, electrical work and painting. The foundation was not included in the price since the six-inch concrete slab is considered the base. The total installed cost was $\$ 10,250$ in $6 / 81$ dollars.

(e) Concrete Slab - Wet Wood Storage

The plant will require a 30-day supply of wet feedstock in open storage. The wood storage pile will be approximately 25 feet high. The bulk density of the wood material in storage was assumed to be 251 bs per ft. ${ }^{3}$ The required area for a 30-day supply of wood material would be $48,000 \mathrm{ft}^{2}$ or approximately 1.1 acres. since many plants in the southeast have additional storage space to take advantage of lower prices that may be available on the spot market, additional storage capacity was included in this analysis. The total wood storage area will consist of two acres of concrete slab with two additicnal acres of bare ground. P\&T, Table 2, p. 876, gives the prices for various building and construction costs. The price for an installed, flat slab of concrete, including excavation, back filling and forming ( $5.3 \mathrm{ft}^{2}$ of forms per cubic yard of concrete) and $100 \mathrm{lbs}$. of reinforcing steel bar per yard of concrete, was $\$ 47$ per yard in $1 / 79$ dollars. Two acres of concrete slab $\left(87,120 \mathrm{ft}^{2}\right)$ with a thickness of six inches will require 1,613 yards of concrete. The total installed cost was $\$ 96,600$ in $6 / 81$ dollars.

Three concrete companies in Atlanta were contacted for quotes on delivered concrete. The average price was $\$ 35$ per yard for 1,613 yards of concrete. The quoted, purchased price would be $\$ 56,500$ with the possibility of a quantity discount. The installation cost based on the above total installed cost was $\$ 40,100$. 
(2) Drying

(a) Dryer Metering Bin

The dryer metering bin receives wood material from the wood storage pile via a drag chain and provides surge capacity for the dryer to ensure a steady drying operation. The dryer metering bin has a holdup time of 15 minutes or a capacity of $416 \mathrm{ft}^{3}$. A cost range in dollars per $\mathrm{ft}^{3}$ for storage facilities used in the wood industry reported $\$ 3$ per $\mathrm{ft}^{3}$ (1/79 dollars) as the most conservative cost ${ }^{4}$. The purchased cost in $6 / 81$ dollars was $\$ 1,500$ with a total installed cost of $\$ 2,900$.

(b) Dryer (including fan)

The purchased cost of the dryer including fan was $\$ 100,000$ with a total installed cost of $\$ 177,800$. In our review of the economics since the Thirteenth Biomass Thermochemical Conversion Contractors' Meeting, more recent information on dryer costs for wood chips and residues has come to our attention. Cost information in 6/80 dollars was reported on wood dryers in a study on economic and technical design for wood fuel systems ${ }^{5}$. Vendor prices of $\$ 95,000$ for dryer only and $\$ 110,000$ for dryer and oil burner were reported for dryers with a capacity of 12 tons per hour of wet wood. These prices were scaled-up to 20.8 wet tons per hour to meet the requirements for a $250 \mathrm{dt} / \mathrm{d}$ plant. The total installed costs for each of these two dryers were $\$ 180,000$ and $\$ 208,200$ in $6 / 81$ dollars. The cost of the $\$ 208,200$ dryer included a burner which was a separate item in our equipment list. The above total installed costs compare favorably with our total installed dryer cost of $\$ 177,800$. The difference in installed cost is relatively small and would result in a negligible change in the resulting economic indicators. Thus, the originally used installed cost was not changed. 
(c) Dryer Particulate collector

The dryer particulate collector will be a

multiclone collector. From the material balance, the stream entering the multiclone has a mass flow rate 555,948 lbs per hour. The design temperature of the stream is $180^{\circ} \mathrm{F}$ and the volume flow rate at the design temperature is 141,019 ACFM. From P\&T, page 599, Figure 13-88, Cost of Dry Mechanical Dust Collectors, the purchased cost of the particulate collector described above was $\$ 28,000$ ( $1 / 79$ dollars) which was taken from the curve - Dry Mechanical Dust Collectors, multiple cyclones. The purchased cost of the unit was $\$ 35,700$ in $6 / 81$ dollars. The total installed cost of the particulate collector was $\$ 57,500$ in $6 / 81$ dollars.

(d) Dry Wood Storage Bin

The dry wood storage bin provides hold-up capacity between the dryer and the hammermill grinder. The dried wood will have a moisture content of $10 \%$ on a wet basis. The mass flow rate, from the material balance, is 23,148 Ibs of dried wood per hour. The bulk density of the dried wood is 15 lbs per $\mathrm{ft}^{3}$ A bin for eight hours of hold-up capacity has a size of $12,345 \mathrm{ft}^{3}$ The cost of prefabricated storage bins or silos with mechanical self-unloaders has been reported in the range of $\$ 2-3$ per $\mathrm{ft}^{3}$ (1/79 dollars) depending on size, manufacturer, and bin auxiliaries." For the bin required for this project, a cost of $\$ 2$ per $\mathrm{ft}^{3}$ in $1 / 79$ dollars was selected. The purchased cost was $\$ 29,300$ in $6 / 81$ dollars with a total installed cost of $\$ 44,450$.

(e) Dryer Combustion system

This equipment includes three associated items grouped together. The items are the combustion chamber, pilot burner system and metal ductwork. The mass flow

$$
\mathrm{J}-12
$$


rate of gases leaving the stack is 537,430 lbs per hour. The volume flow rate at the design temperature of $400{ }^{\circ} \mathrm{F}$ is 170,637 ACFM. Unit cost data from Popper, pages 99 and 116, for refractory stack was used as a basis for estimating the cost of the combustion chamber requirements. The estimated purchased cost was $\$ 19,700$ in $6 / 81$ dollars with a total installed cost of $\$ 24,500$ in 6/81 dollars. The pilot burner system was a complete system with all accessories. The quoted cost of the system provided by North American Manufacturing Company was $\$ 5,200$. An estimated length of 150 feet of duct work was included in the design. From P\&T, page 883, Figure $\mathrm{B}-2$, cost of ductwork was estimated at $\$ 50$ per lineal foot in $1 / 79$ dollars, or $\$ 7,500$. The price is for shopfabricated ductwork including hangers and supports. The installed cost was $\$ 10,000$ in 6/81 dollars. The total installed cost for the three items was $\$ 42,700$ including $\$ 3,000$ for instrumentation.

(3) Size Reduction and Storage

(a) Hammermill/Grinder (including vibratory screening circuit)

The dried feedstock must be reduced in size before pyrolysis. The hammermill is designed to have the capability to process $100 \%$ wood chips. The ground particle sizes will be smaller than 10 mesh with the bulk of the particles between 10 and 60 mesh. The capacity of the hammermill is based on processing 277.8 tons per day of dried feedstock with a $10 \%$ moisture content. If the size of the received feedstock is smaller than wood chips, the capacity of the hammermill will be greater.

From P\&T, page 594, Figure 13-79, Dry Grinding Mills, the cost of a grinding mill with a capacity of 12 tons per hour was $\$ 135,000$ in $1 / 79$ dollars. The cost 
was taken from the curve, close circuit with Air classifier. The price also include installation, screen or classifier, motors, drives and an average allowance for foundations and erection. The total installed cost of the equipment was $\$ 180,700$ in $6 / 81$ dollars.

To obtain a vendor price for comparison, crigler Enterprises, Inc. and Williams Patent Crusher and Pulverizer company, Inc. were contacted to provide a combined quote on a complete grinding system. A system to reduce chips to 10 mesh or smaller material would require two grinding mills. The first is a nominal 12 ton per hour mill which would produce about $50 \%$ oversize material and $50 \%$ acceptable feed material. The acceptable feed material would be transported to the storage bin after screening. The $50 \%$ oversize material from the first mill would be processed in the second mill. All oversize from the second mill is recycled back to the second mill. The $12 \mathrm{TPH}$ mill uses a $500 \mathrm{HP}$ motor and the quoted price was $\$ 69,675$ (10/81 dollars). The total quoted price of the system was $\$ 102,825$ in $10 / 81$ dollars, which does not include the screening equipment. The installed cost of screening equipment for use with the two hammermills was estimated to be $\$ 71,525$. This cost estimate was based on a unit factor of $\$ 3,000$ per $\mathrm{ft},{ }^{2}$ which was obtained from the cost of the screening equipment in the entrained pyrolysis research study. This combined cost of $\$ 173,525$ compares favorably with the estimated total installed cost of $\$ 180,700(6 / 81$ dollars) which was used in the economic analysis.

(b) Ground wood storage Bin

The ground wood storage bin provides hold-up capacity between the hammermill and the entrained pyrolysis reactor. The mass flow rate from the material balance was 22,163 lbs per hour. The density of the

$$
\text { J }-14
$$


dried, ground srood is 13 lbs per $\mathrm{ft} .{ }^{3}$ A hold-up capaciti of three days requires a ground wood storage bin with a size of $122,749 \mathrm{ft}^{3}$ Popper, page 96-99, gives an expression for determining the cost of storage bins and silos:

$$
\text { Purchased Cost }=\text { Unit Factor }(\text { Size }) \text { exponent }
$$

The size is $122,749 \mathrm{ft}^{3}$ and the exponent is 0.9. A range for the value of the unit factor is $\$ 2-3$ per $\mathrm{ft}^{3}(1 / 79$ dollars) taken from reference 4 , and a value of $\$ 2.50$ per $f t^{3}$ was selected. The purchased cost of the ground wood storage bin was $\$ 95,000$ in $6 / 81$ dollars. The total installed cost of the ground wood storage bin was $\$ 144,200$ in $6 / 81$ dollars.

(4) Entrained Pyrolysis Reactor system

(a) Pyrolysis Reactor

For the 250 dry ton per day plant, the entrainedflow reactor will. consist of a cluster of five vertical tubes, forty-two inches in diameter and twenty feet high. The material of construction will be 304 stainless steel and the walls will be relatively thin because the pyrolysis operation will take place at pressures near atmospheric. The design basis was the experimental work by Boley and Landers, 6 which resulted in a throughput rate of about 450 pounds per hour per square foot (values higher than these are believed to be possible with the same reactor, but this possibility awaits the outcome of further research). Since one of the key parameters is residence time, the throughput could always be increased by increasing the reactor height. Five, 42-inch diameter tubes were used instead of one larger tube because this was believed to be a more realistic configuration. This comment is based on 
a consideration of the mixing of the wood particles with the entraining gases. Even though uniform mixing will be more easily attained in the smaller diameter cubes, muiti-injection of wood particles will probably be desirable. It should be noted that the cost of the five reactor tubes would je about twice that of a single reactor tube, so the choice of five tubes is conservative. The 1,000 dry ton per day plant will use four of the 250 dry ton per day plant pyrolysis reactors. All of the fabrication of the pyrolysis reactors can be done in a jub shop, so that only the final structural erection will take place on site. The five tubes, type 304 stainless steel, each with a 42inch diameter, 20 feet in length and $1 / 2$ inch wall thickness have a total weight of 22,640 lbs. The following companies were contacted to determine the cost of the tubes: Industrial piping supply corporation, Southwest Stainless of Georgia, Incorporated, and Hub, Incorporated. Each company based their estimate on the weight of the metal with a range of $\$ 1.65$ to $\$ 1.75$ per pound for type 304 ss pipe. A cost of $\$ 1.70$ per pound was selected. The additional cost for fitting, penetrations, and auxiliaries was estimated by the above vendors to be $\$ 0.30$ per pound. The quoted, purchased cost of the reactor was $\$ 45,300$ in $6 / 81$ dollars. The total, installed cost of the reactor was $\$ 87,500$ in $6 / 81$ dollars.

(b) Air Blower

A portion of the char is recycled to the reactor for combustion. The air added to the reactor is the stoichiometric amount of air required to burn the char. From the material balance, the mass flow rate of the air entering the reactor is $9,630 \mathrm{lbs}$ per hour. The volume flow rate of the stream is 2,022 ACFM at ambient temperature. Popper, pages 96-99, gives data in 6/68

$$
\text { J-1 } 6
$$


dollars for determining the cost of blowers and fans. The estimated, purcisased price $(6 / 81)$, based on Popper, was $\$ 3,400$. The total, installed cost was $\$ 7,200$.

(5) Solids Removal and Handling

The solid particulates in the pyrolyzer offgas stream will be removed by a bank of cyclone separators. These solid particulates will consist of char (which contains ash) and ash from the char combustion in the pyrolyzer. The particles will be collected at an elevated temperature so that they must be cooled under an inert atmosphere. After cooling, the ash from the char combustion will be separated from the newly formed char by screening (industry has used this technique with larger sized particles). This ash removal is not necessary but produces a higher value char for use as a feed material for the briquetting industry.

\section{(a) Cyclone separator}

The cyclone separator removes the char and ash in the gas stream exiting the pyrolysis reactor. The mass flow rate of the gas stream is 29,368 lbs per hour, with a volume flow rate of 13,683 ACFM at $1,022^{\circ} \mathrm{F}$. From P\&T, page 599, Figure 13-88, Cost of Dry Mechanical Dust Collectors, the purchased cost of the solids separators described above is $\$ 6,000$ in $1 / 79$ dollars. The price is taken from the curve: Dry Dynamic scrubbers - Cyclone. The above cost is for a unit made of mild steel or carbon steel. A correction factor of 3.3 for type 316 SS metal, and a temperature correction factor of 1.1 (P\&T, Table 6, page 574, page 461, and page 178, Table 16) wert used. The purchased cost of the cyclone separator was $\$ 27,800$ in $6 / 81$ dollars. The total installed cost for the cyclone separator is $\$ 53,800$ in $6 / 81$ dollars. 
(b) Char Feed Bin

The char with ash collected by the cyclone separator is transported to the char feed bin for temporary storage prior to screening. The mass flow rate from the material balance is 3,422 lbs per hour. The density of the char mixture is 11.25 lbs per $\mathrm{ft} .^{3}$ The hold-up capacity is eight hours, and the requjired size of the char feed bin is $2,433 \mathrm{ft}^{3}$ The purchased cost of the char feed bin was based on data from reference 4 and uses the same unit cost ( $\$ 3$ per $\mathrm{ft}^{3}$ 1/79 dollars) as the dryer metering bin. The purchased cost in $6 / 81$ dollars was $\$ 8,700$, the total installed cost was $\$ 13,100$ in $6 / 81$ dollars.

(c) Vibratory Screening circuit (Ash Removal)

All the solids (char and ash) collected by the cyclone separator are screened before being conveyed to either the screened char storage bin or the product char storage bin. The mass flow rate from the material balance is 3,422 lbs per hour. A $50 \%$ recycle of oversize material is assumed. Based on conversations with representatives of Sweco, Inc. and previous operating data on similar feed materials, a screening rate of $200 \mathrm{lbs}$ per hour $-\mathrm{ft}^{2}$ was selected. The total required screening area is $25.67 \mathrm{ft}^{2}$ The purchased cost was determined by scaling up current bid information and recent prices from Sweco, Incorporated, and sprout waldron. From the expression in Popper, p.96, and the current unit price of $\$ 3,000$ per $\mathrm{ft}^{2}{ }^{2}$ the purchased cost of the vibratory screening circuit was $\$ 19,700$. The total installed cost was $\$ 32,900$ in 6/81 dollars.

(d) Screen Char Storage Bin

The screened char storage bin provides hold-up capacity for char, which has been screened to remove a portion of the ash and which will be used as fuel in the 
reactor. The mass flow rate from the material balance is 890 lbs per hour. The density of the char is 11.25 lbs per ft. 3 The hold-up capacity is one week, and the required capacj.ty of the char feed bin is 13,294 ft. ${ }^{3}$ The purchased cost of the screened char storage bin was based on data from reference 4. A unit factor of $\$ 2.50$ per $\mathrm{ft}^{3}$ in $1 / 79$ dollars was selected and the purchased cost was $\$ 39,500$ in $6 / 81$ dollars. The total, installed cost was $\$ 59,800$ in $6 / 81$ dollars.

\section{(e) Product Char storage Bin}

The char storage bin provides hold-up capacity for product prior to char shipment to customers. The mass flow rate from the material balance is 1,309 lbs per hour. The density of the char is 11.25 lbs per ft. ${ }^{3}$ The hold-up capacity of the product char storage bin is $19,549 \mathrm{ft}^{3}$ The purchased cost of the product char storage bin was based on reference 4. A unit factor $\$ 2.00$ per $\mathrm{ft}^{3}$ in $1 / 79$ dollars was selected and the purchased cost was $\$ 46,400$ in $6 / 81$ dollars. The total, installed cost was $\$ 70,500$ in $6 / 81$ dollars.

\section{(6) Oil Removal and Handling}

The bulk of the oil resoval will take place in an aircooled condenser. The entering hot mixture of pyrolysis oil vapors, noncondensable gases, and water vapor will be cooled to $185^{\circ} \mathrm{F}$ using ambient air as the cooling medium. This temperature is high enough that only a small amount of water vapor will be condensed along with the pyrolysis vapors. In the leaving stream will be an aerosol of oil, a very small amount of oil vapors, noncondensable gases, and water vapor. The aerosol will be removed in a demister. The combustible gases will serve to fuel the dryer along with the necessary amount of char. Ambient air will be used as the cooling medium in the condenser and will exit at $350^{\circ} \mathrm{F}$. This preheated air will provide part of the air needed for 
combustion in the dryer. The condenser configuration will be cross-flow with the condensation taking place inside vertical tubes. There will be several tube passes and the outside of the tubes will be finned because of the relatively low heat transfer coefficient of the air side. Fans will be used to force the air across the tube banks.

(a) Pyrolytic Oil Condenser (including blower) From the material balance, the mass flow rate on the process side of the condenser is 29,367 lbs per hour. The design temperature of the pyrolysis gas stream entering the condenser is $1,000^{\circ} \mathrm{F}$. The cooling load, to reduce the temperature of the process stream to $185^{\circ} \mathrm{F}$ and condense the oil and a portion of the water vapor, is 12,633,000 Btu per hour. Reference 7, "Design of Air-Cooled Exchangers," was used to determine the size of the condenser. The material of construction will be 316 SS. From P\&T, page 671, Figure 14-18, "Cost of Air-cooled Heat Exchangers," the purchased cost of the condenser was $\$ 143,700$ in $6 / 81$ dollars. The purchased cost was based on a unit cost of $\$ 32$ per $\mathrm{ft}^{2}$ (1/79 dollars) of heat transfer area. The correction factor for tube length is 1.06, and the correction factor for 316 ss material of construction versus mild steel is 3.00. The purchased cost included fans, motors, casing and structures. The total installed cost was $\$ 244,300$ in $6 / 81$ dollars.

(b) Pyrolytic Oil storage Tank

The pyrolytic oil storage tank provides hold-up capacity for oil prior to shipment. The mass flow rate from the material balance is 9,259 lbs per hour of the pyrolytic oil. The hold-up capacity is one week and the required capacity of the pyrolytic oil storage tank is 168,000 gallons. The material of construction will be 304 SS. From P\&T, 2nd ed., page 480, Figure 13-59, 
Floating Roof storage Tanks, the total installed cost of the storage tank was $\$ 92,100$ in 6/81 dollars. From P\&T, page 109, 2nd ed., the purchased cost was calculated to be $\$ 75,000$ in $6 / 81$ dollars. A second estimate was made using Popper, page 117, Vertical storage Tanks. The erected, total installed cost for a 304 ss storage tank, including f'Jundation, was $\$ 85,000$ in 6/81 dollars which compares favorably with the above cost of $\$ 92,100$.

\section{F. EQUIPMENT COSTS - 1,000 DRY TON PER DAY PLANT}

The discussion for each item of equipment covers the essentials that are important for the 1,000 dt/d plant, and consequently will be somewhat briefer than the $250 \mathrm{dt} / \mathrm{d}$ plant discussion. It is recommended that the reader refer to the equipment costs section for the $250 \mathrm{dt} / \mathrm{d}$ plant for more detail.

(1) Wood Receiving, Handling and storage

(a) Hydraulic Truck Inloader

The hydraulic truck unloader selected for the 250 $\mathrm{dt} / \mathrm{d}$ plant is also adequate for the $1,000 \mathrm{dt} / \mathrm{d}$ plant. on a restricted delivery and unloading schedule of two shifts per day operation and one shift on Saturday ( 88 operating hours), approximately eight trucks per hour would be required to deliver the required feedstock for a week's operation. Since the cycle time of the unloader is 3.5 minutes, the unloader can handle the required number of trucks. Therefore, the purchased and installed costs for the hydraulic truck unloader are the same for each plant.

\section{(b) Drag Chain}

The drag chain serves the same purpose as for the $250 \mathrm{dt} / \mathrm{d}$ plant. The wood storage area (9.0 acres) would require 1,220 ft of conveyor (see Figure 3 ). The delivery and unloading schedule requires that the minimum capacity of the belt be 160 tons per hour. From 
TABLE J-3. Equipment Costs*

$1,000 \mathrm{dt} / \mathrm{d}, 40 \%$ oil Yield

\begin{tabular}{|c|c|c|c|}
\hline & & $\begin{array}{c}\text { Purchased } \\
\text { Cost }\end{array}$ & $\begin{array}{c}\text { Installed } \\
\text { Cost } \star\end{array}$ \\
\hline \multicolumn{2}{|c|}{$\begin{array}{l}\text { Wood Storage and Handling } \\
\text { Hydraulic Truck Unloader } \\
\text { Drag Chain to Storage } \\
\text { Front End Loader } \\
\text { Drag Chain to Dryer } \\
\text { Six-inch (Reinforced) Concrete slab }\end{array}$} & $\begin{array}{r}48,000 \\
206,500 \\
125,000 \\
50,900 \\
254,300\end{array}$ & $\begin{array}{r}64,800 \\
263,300 \\
125,000 \\
64,950 \\
434,800\end{array}$ \\
\hline \multicolumn{2}{|c|}{$\begin{array}{l}\text { Drying } \\
\text { Dryer Metering Bin } \\
\text { Dryer (including fan) } \\
\text { Dryer Particle Collector } \\
\text { Dry Wood Storage Bin } \\
\text { Dryer Combustion System }\end{array}$} & $\begin{array}{r}3,950 \\
293,000 \\
133,800 \\
88,000 \\
78,800\end{array}$ & $\begin{array}{r}7,600 \\
647,500 \\
215,700 \\
133,600 \\
170,800\end{array}$ \\
\hline \multicolumn{2}{|c|}{$\begin{array}{l}\text { Grinding and Screening } \\
\text { Hammermills } \\
\text { Vibratory Screening } \\
\text { Ground Wood storage Bin }\end{array}$} & $\begin{array}{l}411,300 \\
119,800 \\
331,100\end{array}$ & $\begin{array}{l}534,700 \\
172,300 \\
433,300\end{array}$ \\
\hline \multicolumn{2}{|c|}{$\begin{array}{l}\frac{\text { Reactor }}{\text { Pyrolysis Reactor }} \\
\text { Air Blower } \\
\text { Solids Removal \& Handling }\end{array}$} & $\begin{array}{r}181,200 \\
8,900\end{array}$ & $\begin{array}{r}350,050 \\
18,500\end{array}$ \\
\hline Sol & $\begin{array}{l}\text { S Removal \& Handling } \\
\text { Cyclone Separator } \\
\text { Char Feed Bin } \\
\text { Vibratory Screen } \\
\text { Screened Char storage Bin } \\
\text { Char storage Bin }\end{array}$ & $\begin{array}{r}83,300 \\
34,300 \\
43,800 \\
92,700 \\
102,200\end{array}$ & $\begin{array}{r}159,800 \\
52,150 \\
75,700 \\
140,700 \\
155,100\end{array}$ \\
\hline \multirow{2}{*}{\multicolumn{2}{|c|}{$\begin{array}{l}\text { Oil Removal \& Handling } \\
\text { Condenser (with air blower) } \\
\text { Oil Storage Tank }\end{array}$}} & $\begin{array}{l}305,500 \\
255,200\end{array}$ & $\begin{array}{l}519,350 \\
276,500\end{array}$ \\
\hline & & $\$ 3,221,550$ & $\$ 5,016,200$ \\
\hline $\begin{array}{l}* \\
\star *\end{array}$ & $\begin{array}{l}\text { Costs are in } 6 / 81 \text { dollars. } \\
\text { Installed cost includes instrument } \\
\text { conveying and insulation where re }\end{array}$ & $\begin{array}{l}\text { ion, el } \\
\text { red. }\end{array}$ & :al, \\
\hline
\end{tabular}



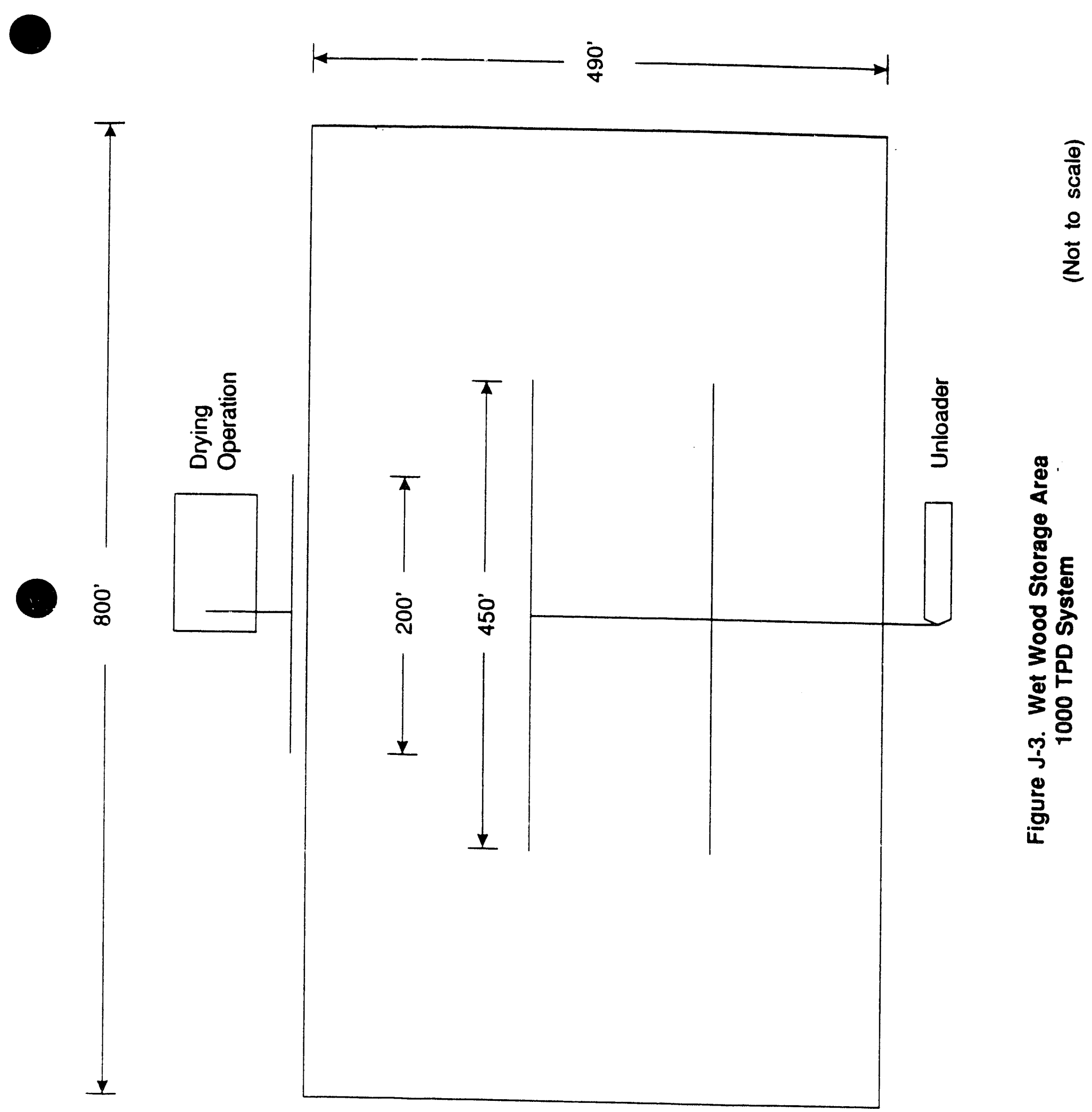

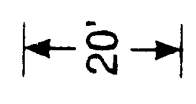

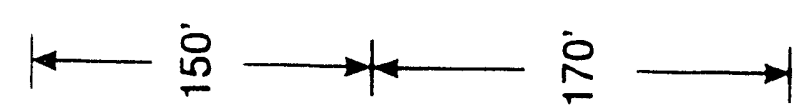


P\&T, Figure 13-92, page 601, a belt conveyor with a speed of $300 \mathrm{ft}$ per minute and a belt width of 18 inches has a capacity of 160 tons per hour. The purchased cost in 6/81 dollars was $\$ 206,500$. From Popper, Table IV, page 99, the field installation factor is 1.17 and includes field labor, electrical work and painting. The foundation was not included in this price, as the sixinch concrete slab is considered the base. The total, instailed cost was $\$ 263,300$ in $6 / 81$ dollars.

(c) Front End Loader

The capacity of the front end loader selected for the $250 \mathrm{dt} / \mathrm{d}$ plant is adequate for the $1,000 \mathrm{dt} / \mathrm{d}$ plant, and therefore the quoted price of $\$ 125,000$ from Yancey Brothers, the Atlanta dealers for Caterpillar Tractor Company, for a Caterpillar 950 front-end loader with a three cubic yard bucket was used in the economic analysis for the $1,000 \mathrm{dt} / \mathrm{d}$ plant.

(d) Drag Chain to Dryer

This drag chain is similar to the drag chain from the truck unloader to the wood storage pile. It has a total length of 220 feet with a capacity of 106 tons per hour. The belt width is 16 inches and the belt speed is 250 feet per minute. From P\&T, Figure 13-92, page 601, a bilt conveyor with the above specifications had a purchased cost of $\$ 40,000$ in $1 / 79$ dollars and $\$ 50,900$ in $6 / 81$ dollars. From Popper, Table IV, page 99, the field installation factor is 1.17 and iricludes field labor, electrical work and painting. The foundation is not included in the price, but the sixinch concrete $\mathrm{slab}$ is considered the base. The total, installed cost was $\$ 64,950$ in $6 / 81$ dollars. 
(e) Concrete slab - Wet Wood storage

The plant would require a 30-day wood supply which covers 4.5 acres approximately 25 feet high. The wood storage area was selected to be nine acres of concrete slab with nine additional acres of bare ground. The same procedure was used to determine the purchased and installed costs as for the $250 \mathrm{dt} / \mathrm{d}$ plant. The purchased and installed costs for 9 acres of concrete were $\$ 254,300$ and $\$ 434,800$ in $6 / 81$ dollars, respectively.

(2) Drying

(a) Dryer Metering Bin

The dryer metering bin with a hod-up time of 15 minutes will have a capacity of $1,664 \mathrm{ft}^{3}$ (1/79 dollars) or storage facilities ${ }^{4}$, the purchased price was $\$ 3,950$ in $6 / 81$ dollars with a total, installed cost of $\$ 7,600$ in $6 / 81$ dollars.

(b) Dryer (including fan)

The purchased cost of the dryer was $\$ 293,000$ with a total, installed cost of $\$ 647,500$. Vendor prices in $6 / 81$ dollars ${ }^{5}$ were scaled up to 83.3 wet tons per hr to meet the requirements for a $1,000 \mathrm{dt} / \mathrm{d}$ plant in the same manner as for the $250 \mathrm{dt} / \mathrm{d}$ plant. The total installed costs of the two dryers were $\$ 363,000$ and $\$ 313,000$. Both of these prices were lower than our total, installed costs and therefore, the originally used installed cost was conservative. Thus, it was not changed.

(c) Dryer Particulate Collector The dryer varticulate collector will be a multiclone type collector. From the material balance, the stream entering the multiclone has a mass flow rato $\mathrm{J}-25$ 
of $2,223,793$ lbs per hour. The design temperature of the stream is $180^{\circ} \mathrm{F}$. The volume flow rate at the design temperature is 564,075 ACFM. From P\&T, page 599, Figure 13-88, Cost of Dry Mechanical Dust Collectors, the purchased cost of the dust collector described above was $\$ 105,000$ in $1 / 70$ dollars, which was taken from the curve: Dry Mechanical Dust Collectors, Multiple Cyclones. The purchased cost of the unit was $\$ 133,800$ in 6/81 dollars. The total, installed cost of the particulate collector was $\$ 215,700$ in $6 / 81$ dollars.

(d) Dry Wood Storage Bin

The dry wood bin provides hold-up capacity between the dryer and the hammermill grinder. The dried wood will have a moisture content of $10 \%$ on a wet basis. The mass flow rate, from the material balance, is 92,593 lbs dry wood per hour. The bulk density of the dry wood is 15 lbs per ft. ${ }^{3}$ A bin with eight hours hold-up capacity has a size of $49,383 \mathrm{ft}^{3}$ The cost of prefabricated storage bins or silos with mechanical self-unloaders has been reported, depending on size, manufacturer and bin auxiliaries." A cost of $\$ 1.50 / \mathrm{ft}^{3}$ in $1 / 79$ dollars was selected resulting in a purchased cost of $\$ 88,000$ in $6 / 81$ dollars with a total installed cost of $\$ 133,600$.

\section{(e) Dryer Combustion system}

This equipment includes three associated items grouped together. The items are the combustion chamber, the pilot burner system, and metal ductwork. The approach used to obtain an estimate for the 1,000 $d t / d$ plant was to scale up by assuming the costs would be linear, which was felt to be conservative. The purchased cost in $6 / 81$ dollars was $\$ 78,000$ with a total installed cost of $\$ 170,800$. 
(3) Size Reduction and storage

(a) Hammermill/Grinder

The dried feedstock must be reduced in size before pyrolysis. The hammermill is designed to have the capability to process 100 \% wood chips. The particle sizes will be smaller that 10 mesh with the bulk of the particles between 10 and 60 mesh. The capacity of the hammermill is based on processing 1,110 tons per day of dried feedstock with a $10 \%$ moisture content.

crigler Enterprises, Incorporated, and williams Patent Crusher and Pulverizer Company, Incorporated were contacted to provide a combined quote on a complete grinding system. A system to reduce chips to 10 mesh or smaller material would require two grinding mills. The first is a nominal 12 ton per hour mill which would produce about $50 \%$ oversize material and $50 \%$ acceptable feed material which is transported to the storage bin. The oversize material from the first mill would be processed in a second, six ton per hour mill. All oversize from the second mill is recycled in the second mill. The $12 \mathrm{TPH}$ mill uses a $500 \mathrm{HP}$ motor, and the six TPH mill, a 250 HP motor. The quoted price of the $12 \mathrm{TPH}$ mill was $\$ 69,675$ and the six TPH mill $\$ 33,150$ in $10 / 81$ dollars. It was recommended that four mills of each size be used to meet the requirements of 46.25 tons per hour. The total purchased cost for the eight mills is $\$ 411,300$ in $10 / 81$ dollars. The total, installed cost using an installation factor of 1.30 was $\$ 534,700$. Using $P \& T$ in the same manner for the 1,000 $\mathrm{dt} / \mathrm{d}$ plant as was used for the $250 \mathrm{dt} / \mathrm{d}$ plant, the total installed cost was $\$ 294,500$ in $6 / 81$ dollars. The installed cost, based on the quoted purchased price, was larger than was used in the economic analysis. 
(b) Vibrating screening circuit

The capacity of the vibratory screening circuit was based on screening all of the material from the first hammermill which produces a stream of approximately 50,8 oversize material that is passed through the second hammermill. The output from the second mill is screened and the oversize material is recycled through the second hammermill. Based on conversations with Sweco, Inc., and previous operating data on similar feed materials a screening rate of 230 lbs per hour-ft $\mathrm{f}^{2}$ was selected, giving a total required screening area of $578 \mathrm{ft}^{2}$ A purchased cost of $\$ 119,800$ in $6 / 81$ dollars was obtained using a unit cost factor of $\$ 3,000$ per $f t,{ }^{2}$ which was obtained from the cost of screening equipment for the entrained pyrolysis research study, and the scale-up expression in Popper, page 96, with an exponent factor of 0.58 from Popper, page 98-99. The total, installed cost was $\$ 172,300$ in $6 / 81$ dollars.

(c) Ground Wood storage Bin

The same procedure was used to determine the purchased and installed costs for this item for the $1,000 \mathrm{dt} / \mathrm{d}$ plant as for the $250 \mathrm{dt} / \mathrm{d}$ plant. The mass flow rate from the material balance is 88,652 lbs per hour and a bin size of $490,996 \mathrm{ft}^{3}$ is required for a hold-up capacity of three days. The purchased cost was determined to be $\$ 331,100$ in $6 / 81$ dollars with a total, installed cost of $\$ 433,300$ in $6 / 81$ dollars.

(4) Entrained Pyrolysis Reactor

\section{(a) Pyrolysis Reactor}

The 1,000 dry ton per day plant will use four of the 250 dry ton per day plant pyrolysis reactors. All of the fabrication for the pyrolysis reactors can be done in a job shop, so that only the final structural 
erection will take place on site. The quoted prices and procedures used for the $250 \mathrm{dt} / \mathrm{d}$ plant were used in determining costs for the $1,000 \mathrm{dt} / \mathrm{d}$ plant. The purchased cost of the reactor in 6/81 dollars was $\$ 181,200$ with a total, installed cost of $\$ 350,050$.

(b) Air Blower

The mass flow rate of the air entering the reactor is 38,953 lbs per hour, and the volume flow rate is 8,037 ACFM at ambient temperature. A purchased cost in $6 / 81$ dollars of $\$ 8,900$ and a total, installed cost of $\$ 18,500$ was obtained using the same method as for the $250 \mathrm{dt} / \mathrm{d}$ plant.

(5) Solids Removal and Handling

The same methods and data were used to obtain purchased costs and total, installed costs for each of the items in this grouping for the $1,000 \mathrm{dt} / \mathrm{d}$ plant as for the $250 \mathrm{dt} / \mathrm{d}$ plant. The costs are given in Table 3 and in Table 10, $B$.

(6) Oil Removal and Handling

(a) Pyrolytic oil condenser (including blower)

The mass flow rate on the process side of the condenser is $117,479 \mathrm{lb}$ per $\mathrm{hr}$, and the design temperature of the pyrolysis gas entering the condenser is $1,000^{\circ} \mathrm{F}$. The cooling load to reduce the temperature of the process stream to $185^{\circ} \mathrm{F}$ and condense the oil and a portion of the water vapor is $50,531,000$ Btu per hour. The same procedure was used to determine the purchased and total, installed costs as for the $250 \mathrm{dt} / \mathrm{d}$ plant. The purchased cost of the condenser in 6.81 dollars was $\$ 305,500$. The purchased cost was based on a unit cost of $\$ 20$ per $\mathrm{ft}^{2}(1 / 79$ dollars) of heat transfer area. The correction factor for tube length is 0.85 , and the correction factor for 316 ss material of construction versus mild steel is 
3.00. The purchased cost includes fans, motors, casing and structures. The total, installed cost was $\$ 519,350$ in $6 / 81$ dollars.

(b) Pyrolytic oil storage Tank

The purchased cost of $\$ 225,200$ with a total, installed cost of $\$ 276,500$ in $6 / 81$ dollars was obtained using the same procedure as for the $250 \mathrm{dt} / \mathrm{d}$ plant.

\section{G. TOTAL CAPITAL INVESTMENT, MANUFACTURING COSTS AND PROFITABILITY ANALYSIS}

The total capital investments for the 250 dry ton per day plant and 1,000 dry ton per day plants are presented in Table J-4. The manufacturing costs are given in Table J-5, and the sales revenues are presented in Table $\mathrm{J}-6$. Table $\mathrm{J}-7$ and Table $\mathrm{J}-8$ present the percent rate of return on investment for the $250 \mathrm{dt} / \mathrm{d}$ plant and 1,000 dt/d plant, respectively. The payout period and discounted cash flow rate of return are shown in Table J-9.

\section{(1) Operating Labor - 250 dry tons per day}

The operating requirements were estimated as a function of the plant capacity and the principal processing steps as determined from the flow sheet. There are 4 processing steps: wood storage and handling, wood treatment, reactor section, and products removal and storage. The total plant production is 127 tons of products per day. From P\&T, p.198, Figures 5-8, "operaring Labor Requirements for Chemical Process Industries," a continuous processing plant, operating under average conditions will require 32 employee-hours per day per processing step. The number of men required per shift if calculated below:

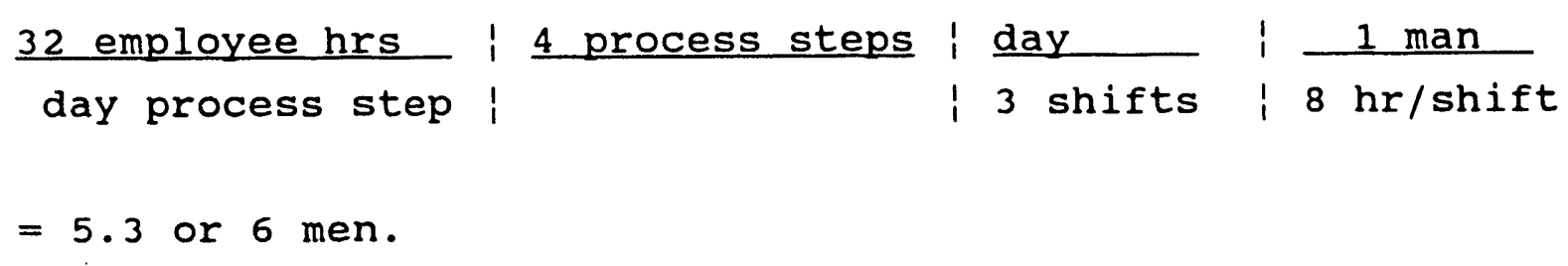




\section{TABLE J-4. Total Capital Investment}

40 \% Oil Yield

\section{Direct Costs}

Installed equipment cost* Building and Services (10 $\%$ of purchased equipment cost) $* *$

Yard Improvements ( $6 \%$ of purchased equipment cost)

Service Facilities ( 24 of purchased equipment cost)

Land - 8 acres e $\$ 5,000 /$ acre for $250 \mathrm{dt} / \mathrm{d} ; 36$ acres $\$ 5,000 /$ acre for $1,000 \mathrm{dt} / \mathrm{d}$

Total Direct Plant Costs

\section{Indirect Costs}

Engineering and Supervision (30\% of purchased equipment cost)

Construction Expense (10\% of total direct plant cost)

rotal Direct and Indirect costs

Contractors Fee (5\% of direct plant costs)

Contingency (10\% of direct and indirect costs)

\section{Fixed Capital Investment}

Working Capital ( 3 months total labor expenses t 2 months all

other operating expenses +1

month feedstock supply)

Start-up Costs ( $8 \%$ of fixed capital investment)

TOTAL CAPITAL INVESTMENT

* Tables 2 and 3 .

** Total purchased

less cost of equipment cost equals total purchased cost $1,000 \mathrm{dt} / \mathrm{d}$ concrete slab. For $250 \mathrm{dt} / \mathrm{d}, \$ 1,067,900 \%$ for $1,000 \mathrm{dt} / \mathrm{d}, \$ 2,967,250$. The percentage factors used to calculate costs were taken form P\&T.

$$
\begin{array}{rr}
250 \mathrm{dt} / \mathrm{d} & 1,000 \mathrm{dt} / \mathrm{d} \\
\$ 1,692,600 & \$ 5,016,200 \\
106,800 & 296,700 \\
64,100 & 178,000 \\
256,300 & 712,100 \\
40,000 & 180,000 \\
\hline 2,159,800 & 6,383,000
\end{array}
$$

$$
\begin{array}{rr}
320,40 & 890,200 \\
216,000 & 638,300 \\
\hline 2,696,200 & 7,911,500 \\
108,000 & 319,200
\end{array}
$$

$$
\begin{array}{rr}
269,200 & 791,200 \\
\hline 3,073,800 & 9,021,900 \\
493,900 & 1,516,000
\end{array}
$$

$245,900 \quad 721,800$

$\$ 3,813,600 \quad \$ 11,259,700$ 
Raw Material ( $\$ 22 /$ dry ton)

operating Labor (see following discussion)

operating supervision and clerical

( $15 \%$ of operating Labor)

Utilities (See following discussion)

Maintenance and Repairs

( $7 \%$ of Fixed Capital Investment)

operating supplies

(15\% of operating Labor)

Laboratory Charges

(15\% of operating Labor)

DIRECT PRODUCTION COST

Fixed Charges (Depreciation, Taxes, Insurance, Rent; $10 \%$ of Total

Product cost)

Plant overhead costs (50\% of operating Labor, Supervision and clerical, and Maintenance + Repairs)

TOTAL PRODUCT COST

$\begin{array}{rr}\frac{250 \mathrm{dt} / \mathrm{d}}{\$ 1,925,000} & \frac{1,000 \mathrm{dt} / \mathrm{d}}{\$ 7,700,000} \\ 436,000 & 871,900 \\ 65,400 & 130,800 \\ 210,200 & 823,200 \\ 215,200 & 631,500 \\ 32,300 & 94,700 \\ 65,400 & 130,800\end{array}$

$\$ 2,949,500 \$ 10,382,900$

$367,500 \quad 1,244,400$

$\underline{358,300}$

817,100

$\$ 3,675,300 \quad \$ 12,444,400$

* The percentage factors used to calculate costs were taken from $P \& T$. 
An operating, labor wage rate of $\$ 8.65$ per hour was used to determine the operating labor costs based on 350 days per year operation.

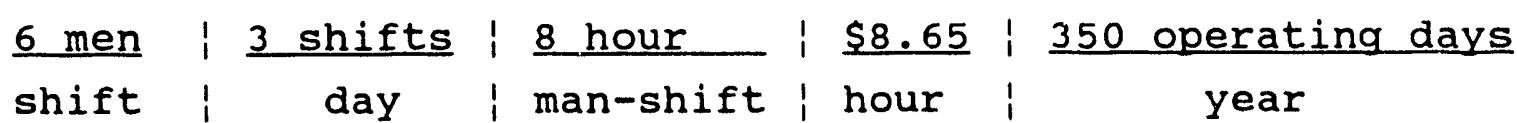

$=\$ 435,960$.

(2) Operating Labor - 1,000 dry tons per day

The same approach was used for the $1,000 \mathrm{dt} / \mathrm{d}$ plant as for the $250 \mathrm{dt} / \mathrm{d}$ plant. The total plant production is 507.3 tons of products per day. This requires 70 employee-hours per day per processing step. The number of men required per shift is calculated below:

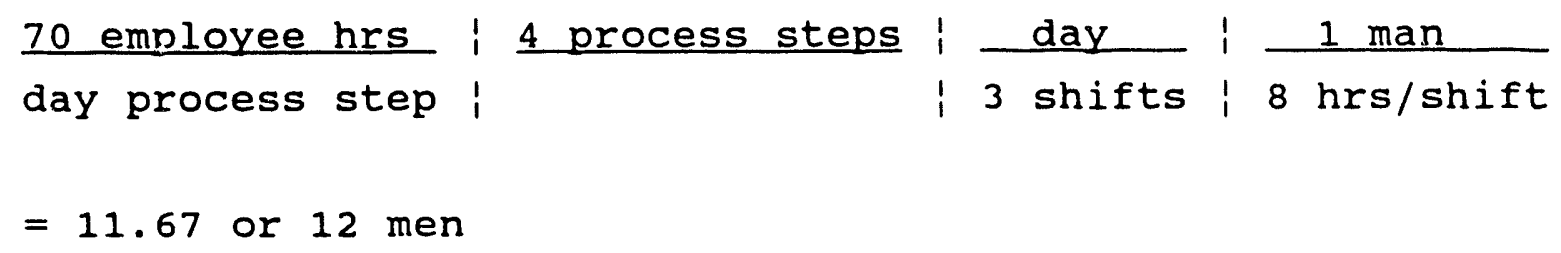

An operating labor wage rate of $\$ 8.65$ per hour was used to determine the operating labor costs based on 350 days per year operation.

$$
\begin{aligned}
& \begin{array}{l}
12 \text { men } \\
\text { shift }
\end{array} \frac{3 \text { shifts }}{\text { day }}: \frac{8 \text { hour }}{\text { man-shift }}: \text { hour } \\
& =\$ 871,900
\end{aligned}
$$

(3) Utilities Cost - 250 dry ton per day

The cost for utilities, which normally include steam, electricity, process and cooling water, natural gas, fuel oil, etc., varies depending on the amount of consumption, plant location, and source. The entrained-flow pyrolysis oil production plant does not require process steam, cooling water, or process 
water. The heat for drying is supplied by burning the pyrolysis gases and a portion of the char produced. Thus, there is no need for fuel oil or natural gas. The major utility cost is the cost of electric power. An estimate was made of the power requirements of each of the items in the process using electric power. The total calculated power requirement is 959 H.P. Although a portion of this power is on intermittent service, the total power

requirement was used to provide a conservative estimate. On a continuous basis the plant would require $17,163 \mathrm{kwh}$ per day. The yearly cost of electric power would be:

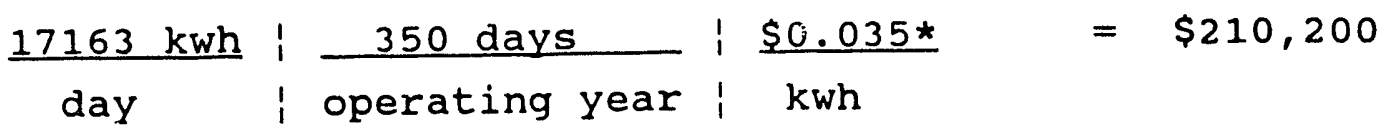

(4) Utilities cost - 1,000 dry ton per day

The utilities cost for the $1,000 \mathrm{dt} / \mathrm{d}$ plant was estimated in the same way as for the $250 \mathrm{dt} / \mathrm{d}$ plant. An estimate was made of the power requirements of each of the items in the process using electric power. The tocal power requirement was $3,755 \mathrm{H} . \mathrm{P}$. Although portion of this power is on intermittent service, the total power requirement was used to provide a conservative estimate. On a continuous basis the plant would require 67,200 kwh per day. The yearly cost of electric power is:

$\frac{67,200 \mathrm{kil} \text { owatt-hours }}{\text { day }} \quad \frac{350 \text { days }}{\text { Operating year }} \frac{\$ 0.35 *}{\mathrm{kwh}}=\$ 823,200$

\section{(5) Sales Revenue}

The pyrolytic oil sales revenue was calculated using an energy equivalent basis, with fuel oil at a market price of $\$ 0.93$ per gallon (Wall street Journal, week of October 12, 1981). The selling price of the fuel oil was $\$ 0.127$ per $1 \mathrm{~b}$. The energy equivalent selling price of pyrolysis oil was $\$ 0.073$ per $1 \mathrm{~b}$, or $\$ 0.675$ per galion. The char revenue was based on the market price of "loose" char, in bulk, which would be used to make charcoal 
briquets. The market price of the char was $\$ 80$ per ton, as is basis.

* Wan, E.I., Simmons, J.A., Price, J.D., "Biomass-Based Methanol Processes," presented at the 12th Biomass Thermoconversion Contractors' Meeting, Washington, D.C., March 18-19, 1981, prepared for the U.S. Department of Energy, Contract No. ET-78-C-01-3002; page 28-31. 


\section{TABLE J-6. Sales Revenue}

$40 \%$ Oil Yield

$250 \mathrm{dt} / \mathrm{d}$

$1,000 \mathrm{dt} / \mathrm{d}$

oil Production, 1b/yr

Char, tons/yr

oil Revenue*

Char Revenue**

TOTAL REVENUE
$\$ 77,776,000 \quad \$ 311,111,000$

5,498

21,992

$5,673,000$

$22,692,000$

$\underline{440,000}$

$1,760,000$

$\$ 6,113,000$

$\$ 24,452,000$

* Oil revenue based on an energy equivalent basis with fuel oil at a market price of $\$ 0.93 / \mathrm{gal}$ (Wall street Journal, week of october 12,1981 ). selling price of fuel oil/lb $=\$ 0.127 / 1 \mathrm{~b}$ Selling price of pyrolytic oil/gal $=\$ 0.675 / \mathrm{gaj}$ selling price of pyrolytic oil/lb $=\$ 0.073 / 1 \mathrm{~b}$

** Char revenue based on market price of $\$ 80 /$ ton for briquet charcoal. 


\begin{tabular}{lrr}
\hline & Years $1-5$ & Years $6-10$ \\
Sales Revenue & $\$ 6,112,800$ & $\$ 6,112,800$ \\
Manufacturing Cost & $3,675,300$ & $3,675,300$ \\
Gross Profit & $2,437,500$ & $2,437,500$ \\
Depreciation & 641,700 & 7,100 \\
Taxable Income & $1,795,800$ & $2,430,400$ \\
Income Tax (46\%) & 826,100 & $1,118,000$ \\
Net Annual Profit & 969,700 & $1,312,400$
\end{tabular}

Depreciation*

Fixed Capital Investment

$\$ 3,073,800$

start-up costs (depreciated; not expensed)

$\underline{245,900}$

$3,319,700$

Land (not depreciable)

$\underline{40,000}$

$3,279,700$

Buildings and Services (15 yr. depreciation)

106,800

Fixed Capital depreciable over 5 yr. period

$\$ 3,172,900$

Annual Depreciation (5 yr. period)

$=\frac{\$ 3,172,900}{5 \text { yrs. }}$

Annual Depreciation (5 yr. period)

$=\$ 634,600$

Annual Depreciation (Buildings and Services only)

$=$

$\$ 106,800$ 15 yrs.

Annual Depreciation (Buildings and Services only)

Total Annual Depreciation for Years 1-5

$=$

$\$ 634,600$

7, 100

Total Annual Depreciation for Years 1-5

$=$

$\$ 641,700$

Cont'd 
TABLE J-7. Rate of Return (continued)

$250 \mathrm{dt} / \mathrm{d} 40 \%$ oil Yield

\section{Cash Flow}

Cash flow = net profit + depreciation

Cash flow $(1-5$ yrs $)=\$ 969,700+\$ 641,700$

Cash flow $(1-5$ yrs $)=\$ 1,611,400$

Engineering Return on Investment**

Engineering return on investment ( $1-5$ yrs)

$=$ Cash Flow $\times 100$ Total Capital Investment

Engineering return on investment ( $1-5$ yrs)

$=\$ 1,611,400 \times 100$ $\$ 3,813,600$

Engineering return on investment $(1-5$ yrs $)=42.3 \%$

* Internal Revenue Service - Public Law Number 9734, published in Federal Register, August 13, 1981. Law provides for depreciation of plant equipment over a 5 year period and for buildings and services over a 15 year period. Private communication - Mr. Breland Collier, Atlanta District office of IRS.

** Linsley, J., "Return on investment: discounted and undiscounted," Chem. Eng. 86 (11), 201 (May 21,1979). Engineering return on investment is defined as the annual cash flow divided by the total plant investment. Annual cash flow is defined as the net, after tax profit plus depreciation. 


\section{TABLE J-8. Rate of Return \\ $1000 \mathrm{dt} / \mathrm{d} 40 \%$ 0il Yield}

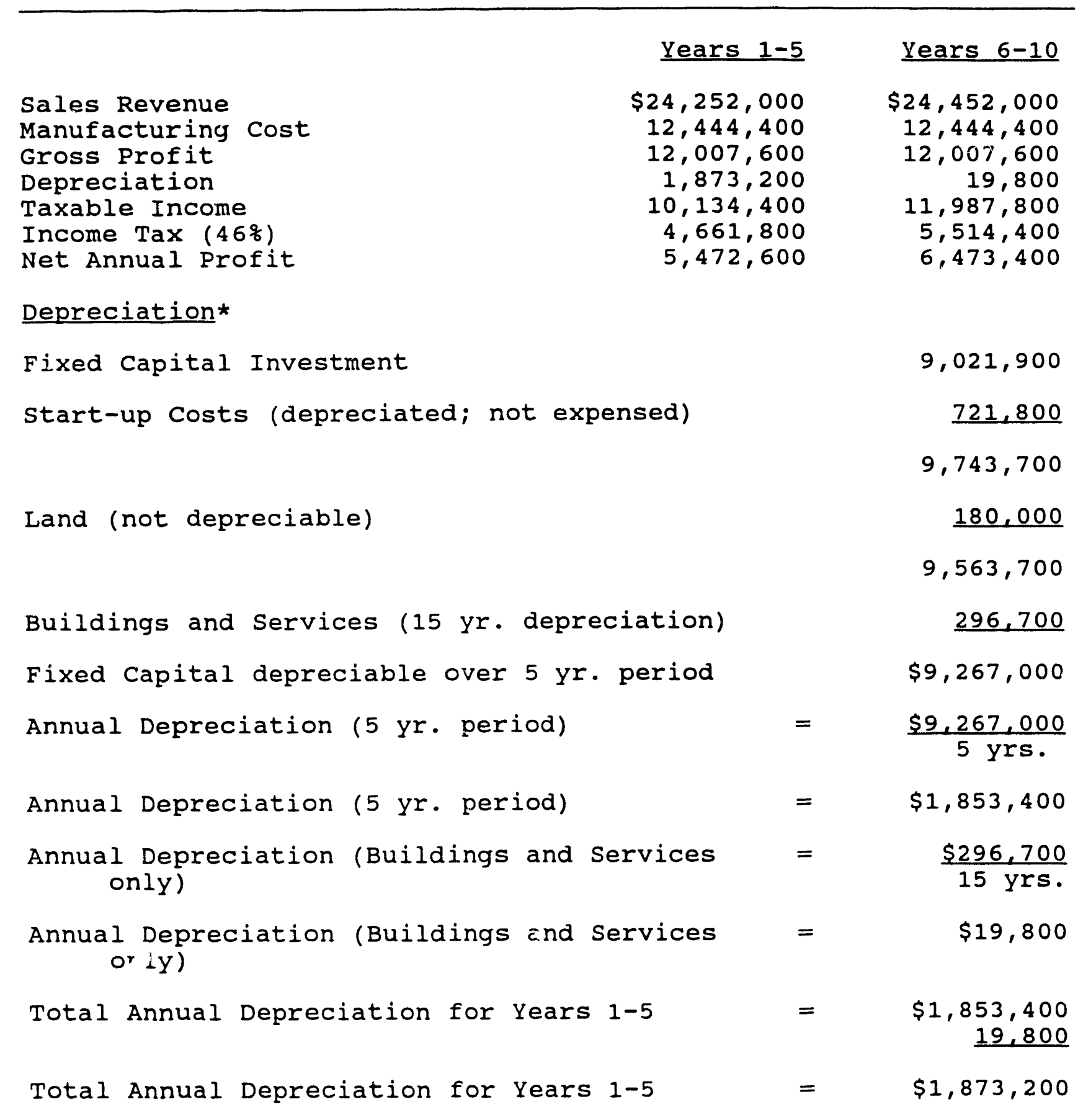

Cont'd 
TABLE J-8. Rate of Return (continued)

$1000 \mathrm{dt} / \mathrm{d} 40 \%$ Oil Yield

\section{Cash Flow}

Cash flow = net profit + depreciation

Cash flow $(1-5$ yrs $)=\$ 5,472,600+\$ 1,873,200$

Cash flow $(1-5$ yrs $)=\$ 7,345,800$

Engineering Return on Investment**

Engineering return on

investment $(1-5$ yrs $)$

$$
=\frac{\text { Cash Flow } \times 100}{\text { Total Capital Investment }}
$$

Engineering return on

investment $(1-5$ yrs $)$

Engineering return on investment $(1-5$ yrs $)=65.2$ \%

* Internal Revenue Service - Public Law Number 9734, published in Federal Register, August 13, 1981. Law provides for depreciation of plant equipment over a 5 year period and for buildings and services over a 15 year period. Private communication - Mr. Breland Collier, Atlanta District office of IRS.

* Linsley, J., "Return on investment: discounted and undiscounted," Chem. Eng. 86 (11), 201 (May 21,1979). Engineering return on investment is defined as the annual cash flow divided by the total plant investment. Annual cash flow is defined as the net, after tax profit plus depreciation. 
TABLE J-9. Payout Period And Discounted Cash Flow Rate of Return

\begin{tabular}{|c|c|c|}
\hline & $250 \mathrm{dt} / \mathrm{d}$ & $1000 \mathrm{dt} / \mathrm{d}$ \\
\hline Payout Period" & 2.04 years & 1.3 years \\
\hline $\begin{array}{l}\text { Discounted Cash Flow Rate } \\
\text { of Return }\end{array}$ & $33 \%$ & $60 \%$ \\
\hline
\end{tabular}

$\begin{aligned} & \text { Payout Period } \\ & \text { (No Interest Charge) }\end{aligned}=$

(No Interest Charge)
Depreciable Fixed - Capital Investment Average Profit + Average Depreciation per year per year
Depreciable Fixed-Capital Investment

Average Annual Profit

Average Annual Depreciation
$250 \mathrm{dt} / \mathrm{d}$

$\$ 3,279,700$

$1000 \mathrm{dt} / \mathrm{d}$

$\$ 9,563,700$

969,700

641,700
$5,472,600$

$1,873,200$

** Discounted Cash Flow Rate of Return $=i$

Annual Cash Flow To Project After Taxes
Annual Cash Flow

Working Capital

Salvage Value

Total Capital Investment

$$
\frac{1}{1+i}+\frac{1}{(1+i)}+\cdot \cdot \frac{1}{(1+i)}^{5}
$$

* $\quad \frac{1}{(1+i)}=\begin{aligned} & \text { Total Capital } \\ & \text { Investment }\end{aligned}$

$250 \mathrm{dt} / \mathrm{d}$

$1000 \mathrm{dt} / \mathrm{d}$

$\$ 1,611,400$

493,900

$\$ 7,345,800$

$1,516,000$

$\$ 3,813,600$

$\$ 11,259,700$ 


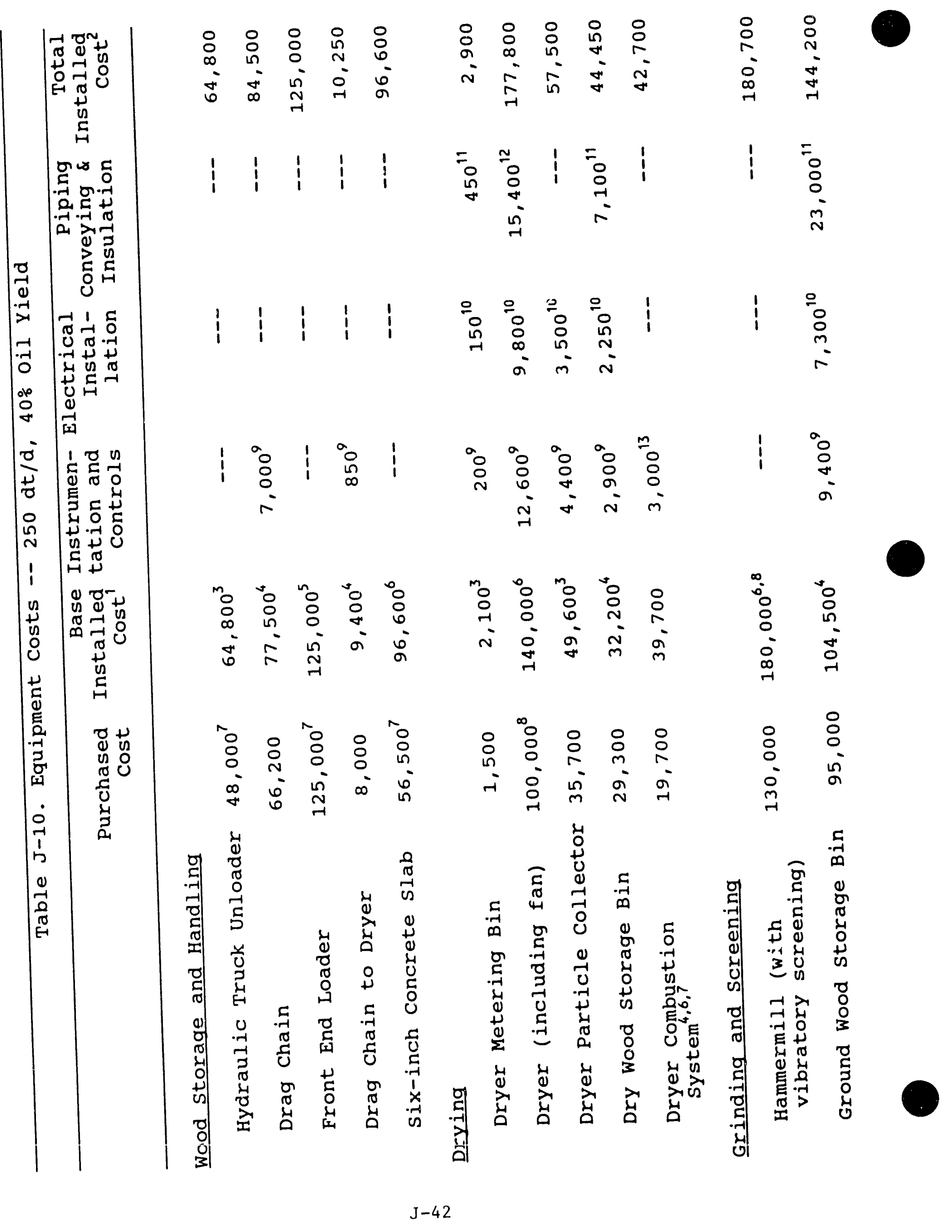




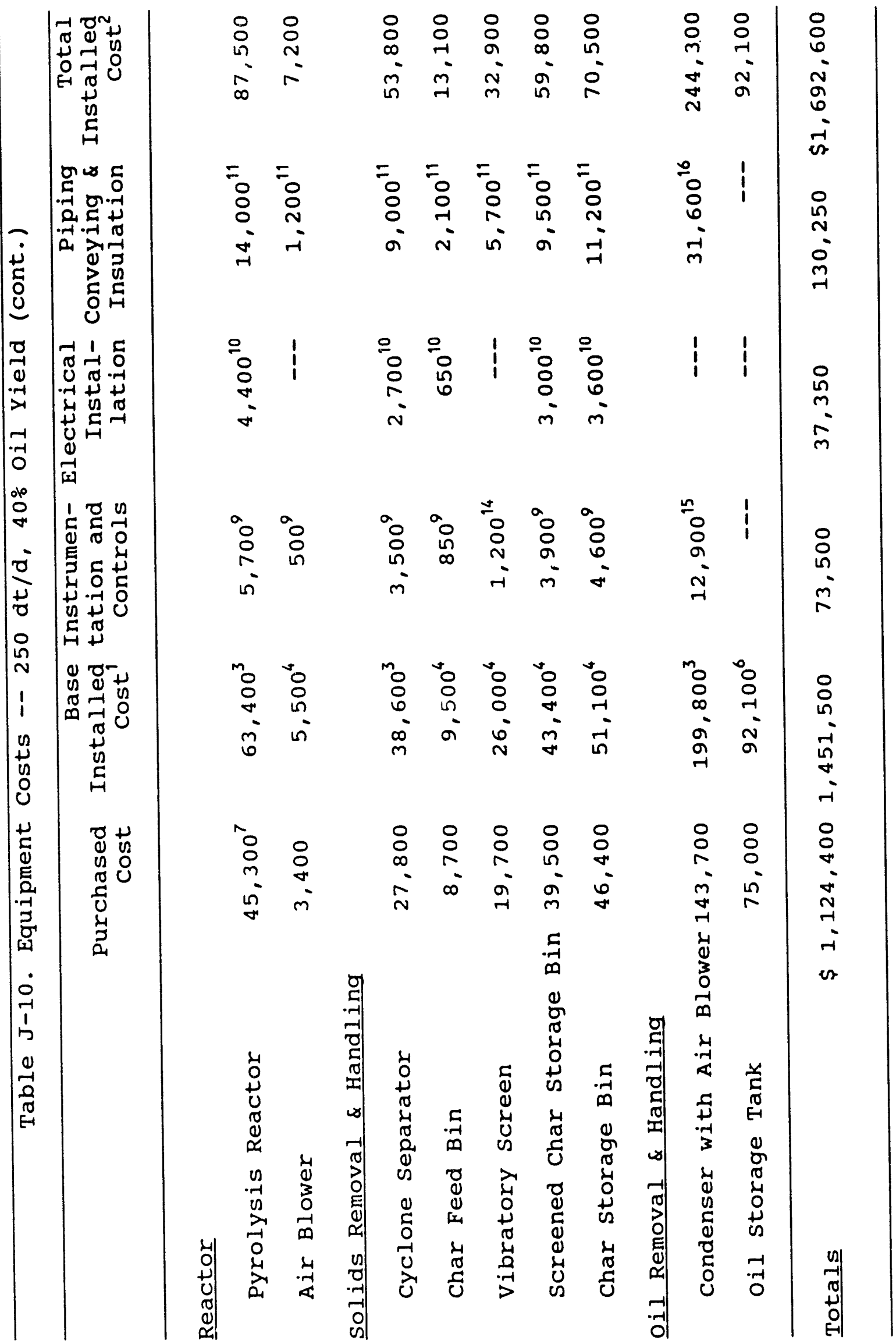




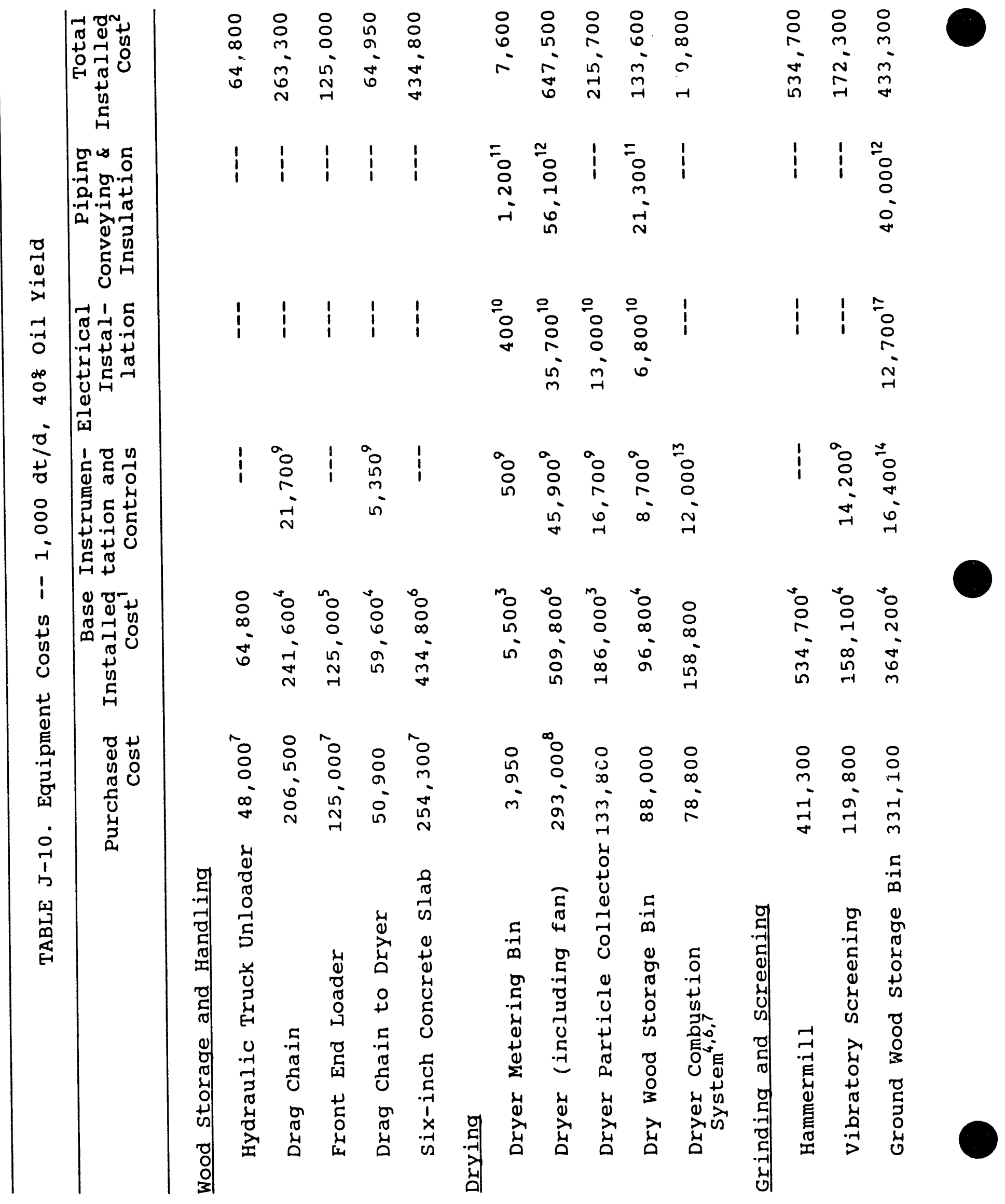




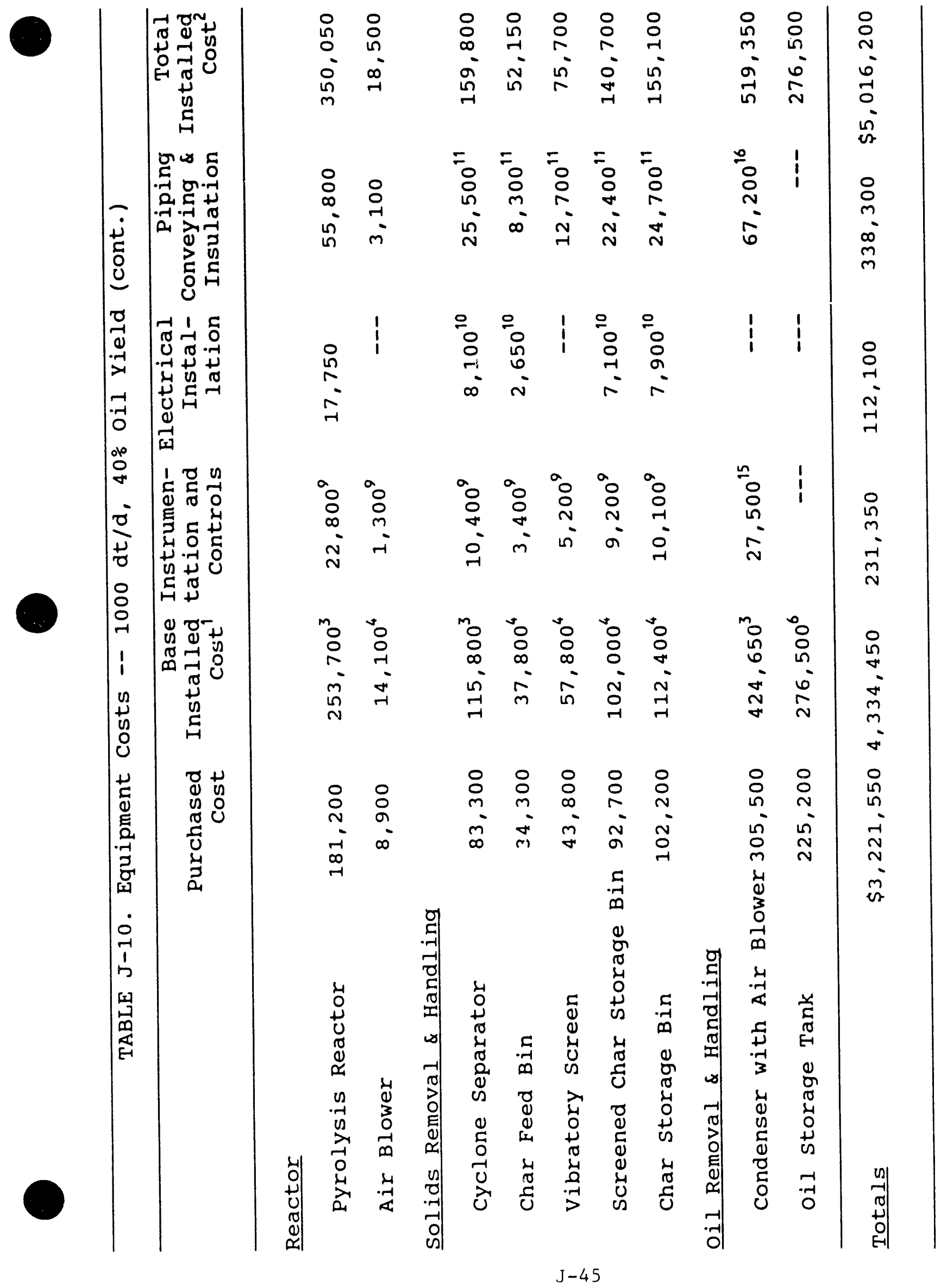




\section{Table 10, Footnotes}

1. Base installed costs include costs for labor, foundations, supports, platforms, construction expenses, etc. which are directly related to the erection of purchased equipment.

2. Total installed cost includes instrumentation, electrical, piping, conveying, and insulation where required.

3. Average installation cost, Peters and Timmerhaus, pages 168169 .

4. Field installation factor, Popper, pages 96-99, includes equipment foundations (concrete and steel), insulation, paint, also includes piping, instrumentation and electrical work.

5. No installation necessary.

6. Installed cost estimated directly.

7. Purchased cost obtained from quote.

8. Purchased cost determined using the average installation cost from Peters and Timmerhaus, pages 168-169.

9. 98 of installed cost, P\&T pages 163-191.

10. $7 \%$ of installed cost, P\&T pages 163-191.

11. $22 \%$ of installed cost, P\&T pages 163-191.

12. 118 of installed cost, P\&T pages 163-191.

13. Burner system complete; $9 \%$ of remaining installed cost.

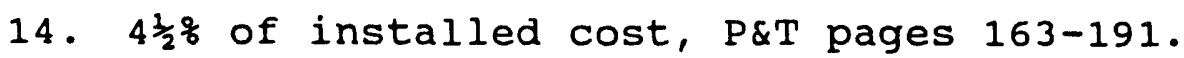

15. $9 \%$ of purchased cost, P\&T pages 163-191.

16. $22 \%$ of purchased cost, P\&T pages 163-191.

17. $3 \frac{1}{2} \%$ of installed cost, P\&T pages 163-191.

(1000 dry tons/day plant only) 
1. Knight, J. A., C. W. Gorton, R. J. Kovac, L. W. Elston and D. $R$. Hurst, "Oil Production via Entrained-Flow Pyrolysis of Biomass," In the Proceedings of the 13th Biomass Thermochemical Conversion Contractor's Meeting, Arlington, Virginia, October 27-29, 1981. CONF-8110115/PNL-SA-10093. Available from the National Technical Information Service, U.S. Department of Commerce, 5285 Port Royal Road, Springfield, VA 22161.

2. Peters, M. S. and K. D. Timmerhaus, "Plant Design and Economics for Chemical Engineers," Third Edition, McGraw-Hill Book Company, New York 1981; (Second Edition, 1968).

3. Popper, H., editor, "Modern Cost-Engineering Techniques," McGraw-Hill Book Company, New York, 1970.

4. Clifton, D. and W. S. Bulpitt, "A Feasibility Study for Wood Energy Utilization in Georgia." Prepared for the Georgia Forestry Commission under sponsorship of the Coastal plains Regional Commission, August, 1979. Project Number a-2140, GTRI, Georgia Institute of Technology.

5. McGowan, T. F., et al, "Wood Fuel Processing - Economic and Technical Design Manual for Wood Systems." Prepared for Georgia Office of Energy Resources, June, 1980. Project Number A-2400, GTRI, Georgia Institute of Technology.

6. Boley, C. C. and W. S. Landers, "Entrainment Drying and Carbonization of Wood Waste," U. S. Bureau of Mines, Rep. 7282 (1969).

7. Brown, R., "Design of Air-Cooled Exchangers - A Procedure for Preliminary Estimates", Chem. Eng.' pp. 108-111, March 27,
1978 . 


\section{DISTRIBUTION}

No. of

Copies

\section{OFFSITE}

12 DOE/Office of Scientific and Technical Information

R. Annan

Office of Solar Energy Conversion

U.S. Department of Energy

Forrestal Building (CE-13)

1000 Independence Avenue

Washington, D.C. 20585

J. Allsup

Office of Alternative Fuels

U.S. Department of Energy

Forrestal Building (CE-33)

1000 Independence Avenue

Washington, D.C. 20585

W. Ayres

Pyrotech, Inc.

8016 Stateline

Suite 101

Leawood, KS 66208

S. Babu

Institute of Gas Technology

IIT Center

3424 South State Street

Chicago, IL 60616

P. Badger

Southeastern Regional Biomass Energy Program

Tennessee Valley Authority

CEB 4W 436A-M

Muscle Shoals, AL 35660

N. Banns

Onsite*0fsite, Inc.

2500 East Foothill Blvd.

Suite 201

Pasadena, CA 91107
No. of

Copies
K. Birkinshaw

Cal ifornia Energy Commission

1516 - 9th Street, MS-43

Sacramento, CA 95814

H. Clark

American Society of Mechanical

Engineers

1825 K Street N.W. Suite 216

Washington, D.C. 20006-1202

R. Costello

Biofuels Systems Division

U.S. Department of Energy

Forrestal Building (CE-331)

1000 Independence Avenue

Washington, D.C. 20585

J. Diebold

Solar Energy Research Inst.

1617 Cole Blvd.

Golden, CO 80401

K. Durai-Swamy

Manufacturing and Technology

Conversion International, Inc.

13080 Park Street

Santa Fe Springs, CA 90670

V. Flanigan

223 Engineering Research Lab. University of Missouri-Rolla

Rolla, MO 65401

G. Fleischman

Bureau of Energy

Idaho Department of Water Resources

1301 N. Orchard St.

Boise, ID 83706 
No. of

Copies

P. Fox

Pacific Northwest and Alaska

Regional Biomass Energy Program

Bonneville Power

Administration

P.0. Box 3621

Portland, OR 97208

S. Friedrich

Waste Material Management Division

U.S. Department of Energy

Forrestal Building (CE-222)

1000 Independence Avenue

Washington, D.C. 20585

B. Goodman

Solar Energy Research Institute

1617 Cole Blvd.

Golden, CO 80401

S. Gronich

Solar Thermal \& Biomass Power

Division

U.S. Department of Energy

Forrestal Building (CE-132)

1000 Independence Avenue

Washington, D.C. 20585

\author{
J. Hamrick \\ Aerospace Research Corporation \\ 5454 Jae Valley Rd., S.E. \\ Roanoke, VA 24014 \\ W. Densmore Hunter \\ Manager, Energy Technology \\ Department \\ Weyerhaeuser Company \\ WTC-1B-30 \\ Tacoma, WA 98477 \\ J. Kadyszewski \\ Winrock International \\ 611 Kent St. Suite 600 \\ Arlington, VA 22209-2134
}

No. of

Copies

J. Kerstetter

Washington State Energy Office

State of Washington

809 Legion Way S.E., ER-11

0lympia, WA 98504-1211

D. Kirchgessner

Global Warming Control Branch

U.S. Environmental Protection Agency

Research Triangle Park, NC 27711

D. Klass

Institute of Gas Technology

IIT Center

3424 South State Street

Chicago, IL 60616

F. Kuzel

Council of Great Lakes

Governors

310 South Michigan Ave.

Chicago, IL 60604

E. Larson

Center for Energy and Environmental Studies

Engineering Quadrangle

Princeton University

Princeton, NJ 08544-5263

M. Mansour

Manufacturing \& Technology Conversion International, Inc.

P.0. Box 21

Columbia, MD 21044

P. Mathusa

Program Director

New York State Energy Research and Development Authority

2 Rockefeller Plaza

Albany, NY 12223 
No. of

Copies

T. Miles

Consulting Engineer

5475 S.W. Arrowwood Lane

Portland, OR 97225

T. Milne

Solar Energy Research

Institute

1617 Cole Blvd.

Golden, C0 80401

R. Moorer

Biofuels Systems Division

U.S. Department of Energy

Forrestal Building (CE-331)

1000 Independence Avenue

Washington, D.C. $20 \leqslant 85$

R. O'Connell

CONEG Policy Research Center, Inc.

400 N. Capital Street, NW

Washington, DC 20001

D. O'Neil

Georgia Tech Research Institute

Georgia Institute of

Tecinology

Atlanta, GA 30332-0420

R. Overend

Solar Energy Research

Institute

1617 Cole Blvd.

Golden, C0 80401

M. Paisley

Battelle-Columbus Division

505 King Avenue

Columbus, $\mathrm{OH} 43201$

J. Roethell

Office of Critical Materials

U.S. Department of Agriculture

342 Aerospace Building

Washington, DC 20250-2200
No. of

Copies

PNL -7788

UC -245

P. Salmon-Cox

Office of Industrial Programs

Department of Energy

1000 Independence Avenue, SW

Washington, D.C. 20585

R. San Martin

Deputy Assistant Secretary

Office of Utility Technology

Forrestal Building

1000 Independence Avenue, SW

Washington D.C. 20585

M. Scheve

Solar Thermal \& Biomass Power Division

U.S. Department of Energy

Forrestal Building (CE-132)

1000 Independence Avenue

Washington, DC 20585

C. Scouten

Senior Research Scientist

Amoco 0 il Company

Amoco Research Center

Post Office Box 3011

Naperville, Illinois 60566

G. Simons

California Energy Commission

1516 - 9th Street, MS-43

Sacramento, CA 9581

S. Sobczinnski

Division of Improved Energy

Productivity

U.S. Department of Energy

Forrestal Building CE-231

1000 Independence Avenue

Washington, DC 20585

D. Stevens

Cascade Research, Inc.

2952 George Washington Way

Richland, WA 99352 
No. of

Copies

C. Sullivan

Electric Power Research Institute

P. 0. Box 10412

Palo Alto, CA 94303

D. Swanson

Western Regional Biomass

Energy Program

Western Area Power

Administration

P.0. Box 3402

Golden, C0 80401

E. Taylor

Corporate Manager,

Energy \& Environmental Affairs Louisiana-Pacific Corporation

P.0. Box 158

Samoa, CA 95564

C. Wallace

Solar Energy Research Institute

409 12th St. S.W. , Suite 710

Washington, DC 20024

D. Walter

Waste Material Management

Division

U.S. Department of Energy

Forrestal Building (CE-222)

1000 Independence Avenue

Washington, D.C. 20585

E. Wan

Science Applications

International Corporation

1710 Goodridge Drive

McLean, VA 22102

D. White

Department of Chemical

Engineering

University of Arizona

Geology Building

Tucson, AZ 85721
No. of

Copies

R. Williams

Center for Energy and

Environmental Studies

Princeton University

Princeton, NJ 08544

\section{FOREIGN}

D. Asplund

Valtion Teknillinen

Tutkimuseskus

Statens Tekniska

Forskningscentral

Technical Research Centre of Finl and

P.0. Box 221

SF-40101 Jyväskylä 10

FINLAND

T. Bridgwater

The University of Aston in Birmingham

Dept. of Chemical Engineering

Gosta Green

Birmingham

ENGLAND B4 7ET

J. Fredriksson

Department of Thermal Engineering

The Royal Institute of Technology

S-100 44 Stockholm, SWEDEN

E. Rensfelt

Department of Fuel Technology Studsvik Energiteknik $A B$ S-611 82 Nykoping, SWEDEN 
No. of

Copies

ONSITE

DOE Field Office, Richland

E. Norman A5-10

18 Pacific Northwest Laboratory

D. Elliott K2-40

M. Gerber P8-38

G. Schiefelbein (10) P8-38

Publishing Coordination

Technical Refort Files 

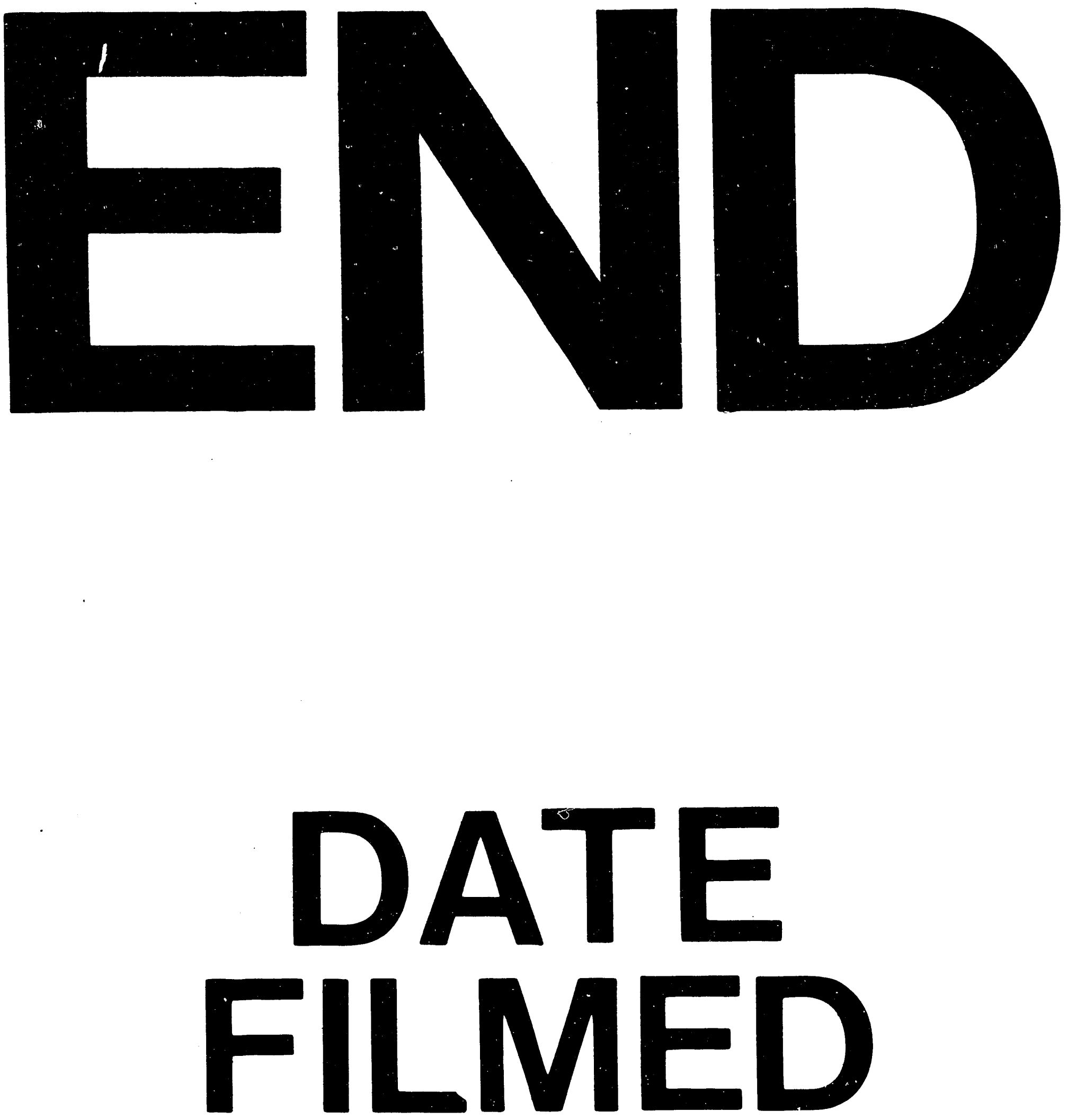

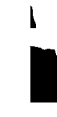

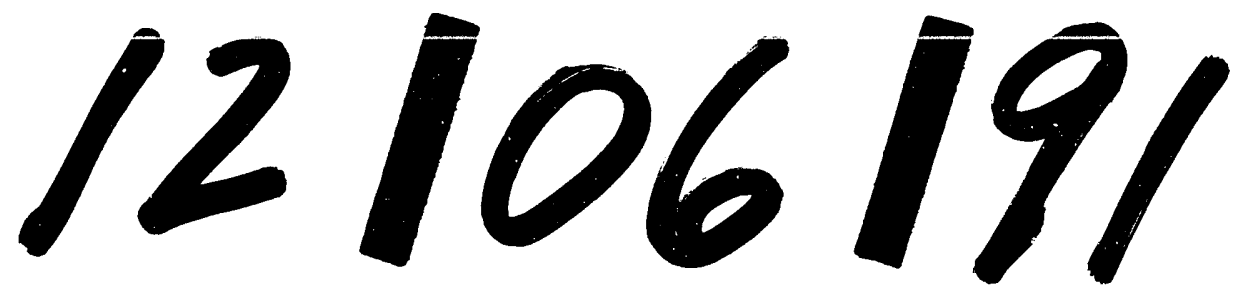


